RENAN TREVISOLI DORIA

OPERAÇÃO E MODELAGEM DE TRANSISTORES MOS SEM JUNÇÕES

São Paulo

2013 
RENAN TREVISOLI DORIA

\title{
OPERAÇÃO E MODELAGEM DE TRANSISTORES MOS SEM JUNÇÕES
}

\author{
Tese apresentada à Escola Politécnica \\ da Universidade de São Paulo como \\ parte dos requisitos necessários para a \\ obtenção do título de Doutor em \\ Ciências.
}

Área de Concentração: Microeletrônica Orientador: Prof. Dr. Marcelo Antonio Pavanello 
Este exemplar foi revisado e corrigido em relação à versão original, sob responsabilidade única do autor e com a anuência de seu orientador.

São Paulo, 11 de abril de 2013.

Assinatura do autor

Assinatura do orientador

FICHA CATALOGRÁFICA

Doria, Renan Trevisoli

Operação e modelagem de transistores MOS sem junções /

R.T. Doria. -- versão corr. -- São Paulo, 2013.

$196 \mathrm{p}$.

Tese (Doutorado) - Escola Politécnica da Universidade de São Paulo. Departamento de Engenharia de Sistemas Eletrônicos.

1. Transistores 2. Silício 3. Dispositivos eletrônicos 4. Medidas elétricas I. Universidade de São Paulo. Escola Politécnica. Departamento de Engenharia de Sistemas Eletrônicos II. t. 


\section{DEDICATÓRIA}

Gostaria de dedicar este trabalho aos meus pais Sonali e Francisco, a quem devo o que sou e aonde cheguei, e ao meu irmão Rodrigo por todo 0 incentivo, pela dedicação e pelo carinho. 


\section{AGRADECIMENTOS}

Ao meu orientador Prof. Dr. Marcelo Antonio Pavanello pela confiança no meu trabalho, e por toda a contribuição e pelo incentivo ao longo do mesmo.

À Fundação de Amparo à Pesquisa do Estado de São Paulo (FAPESP) pelo suporte financeiro durante os três anos do doutorado.

Aos meus pais Sonali e Francisco por todo o incentivo, carinho e dedicação não apenas ao longo desses três anos de doutorado, mas por toda a minha vida.

Ao meu irmão Rodrigo pelo incentivo, pela dedicação e por todas as contribuições na parte técnica, especialmente pelas revisões e discussões do trabalho.

Ao Prof. Dr. Jean-Pierre Colinge por ter permitido que eu fizesse um estágio no Tyndall National Institute em Cork, Irlanda, tendo acesso aos dispositivos de última geração fabricados no CEA-LETI.

À Dra. Isabelle Ferain e ao Dr. Samaresh Das pela ajuda e pelas contribuições ao longo do estágio no Tyndall National Institute.

Ao Prof. Dr. João Antonio Martino por ter permitido que eu fizesse parte do grupo SOI-CMOS e por todos os conselhos advindos do exame de qualificação.

Ao Prof. Dr. Marco Isaías Alayo Chávez pelos conselhos advindos do exame de qualificação.

À Prof. Dra. Michelly de Souza pela amizade e por toda a contribuição ao longo do doutorado. 
A todos os amigos do grupo SOI-CMOS pela convivência e pela amizade ao longo desses três anos.

Ao Centro Universitário da FEI por permitir que eu utilizasse os seus laboratórios durante o meu doutorado e aos alunos do grupo de Dispositivos Eletrônicos Integrados pela convivência.

Aos meus avós Anna e Adão que sempre acreditaram em mim e que sempre estiveram ao meu lado.

A todos aqueles que contribuíram para o desenvolvimento deste trabalho, mas que foram involuntariamente esquecidos. 


\section{RESUMO}

Neste trabalho é apresentado um estudo dos transistores MOS sem junções (Junctionless Nanowire Transistors - JNTs), cujo foco é a modelagem de suas características elétricas e a análise do funcionamento dos mesmos quanto à tensão de limiar, ponto invariante com a temperatura e operação em aplicações analógicas. Os JNTs possuem uma concentração de dopantes constante da fonte ao dreno. Eles foram desenvolvidos a fim de se evitar as implantações iônicas de fonte e dreno, que requerem condições rigorosamente controladas para se evitar a difusão de dopantes para o interior do canal em dispositivos de tamanho extremamente reduzido (sub-20 nm). Dessa forma, esses dispositivos permitem um maior escalamento, com um processo de fabricação simplificado. Os trabalhos recentes de modelagem desses transistores consideram dispositivos de canal longo, de forma geral o comprimento utilizado é de $1 \mu \mathrm{m}$, de porta dupla ou cilíndricos. Pouco tem sido feito relacionado à modelagem de JNTs porta tripla e a influência da temperatura no funcionamento dos mesmos. Assim, este trabalho tem como objetivo a modelagem do funcionamento dos dispositivos MOS sem junções de porta tripla quanto à tensão de limiar, potencial de superfície, carga de condução e corrente de dreno. Os modelos são derivados da solução da equação de Poisson com as condições de contorno adequadas, apresentando grande concordância com simulações numéricas tridimensionais e com resultados experimentais para dispositivos com comprimento de canal de até $30 \mathrm{~nm}$. No caso do modelo da tensão de limiar, o maior erro obtido entre modelo e simulação foi de $33 \mathrm{mV}$, que representa uma percentagem menor que $5 \%$. Também foi apresentado um método de extração da tensão de limiar baseado na igualdade das componentes de deriva e difusão da corrente de dreno. Este método foi igualmente validado com resultados simulados, apresentando um erro máximo de $3 \mathrm{mV}$ (menor que $0,5 \%$ ) e aplicado à dispositivos experimentais. A influência da temperatura na tensão de limiar também foi analisada tanto pelo modelo proposto como por simulações e resultados experimentais, mostrando que a dependência da concentração de 
dopantes ionizados com a temperatura devido à ionização incompleta dos portadores tem grande influência na tensão de limiar. No caso da modelagem da corrente de dreno e do potencial de superfície, foi acrescentada uma correção de efeitos de canal curto. O erro médio foi menor que $12 \%$ para as curvas de corrente e suas derivadas, quando comparadas às dos dispositivos experimentais de comprimento de canal de $30 \mathrm{~nm}$. Também foi realizado um estudo do funcionamento dos JNTs, mostrando que o ponto invariante com a temperatura, onde a corrente de dreno se mantém constante independentemente da temperatura, pode ou não existir nesses dispositivos, dependendo da resistência série e de sua dependência com a temperatura. Por fim, a operação em aplicações analógicas dos dispositivos sem junções é analisada para dispositivos de diferentes dimensões.

Palavras-chave: Transistor MOS sem junções, Junctionless, múltiplas portas, modelagem, tensão de limiar, método de extração, temperatura 


\section{ABSTRACT}

In this work, a study of the Junctionless Nanowire Transistors (JNTs) is presented, focusing their modeling and analyzing their operation. The JNTs are heavily doped devices with a doping concentration constant from source to drain, without presenting doping gradients. They have been developed in order to avoid drain and source ion implantation, which requires rigorous controlled conditions to avoid dopants diffusion into the channel in extremely reduced devices (sub-20 nm). Therefore, these devices provide a higher scalability with a simplified fabrication process. Recent works on junctionless nanowire transistors modeling have considered long-channel (a length of $1 \mu \mathrm{m}$ is commonly used) double-gate or cylindrical devices. Few works have presented the modeling of triple-gate JNTs and the temperature influence on the device operation. The goal of this work is the modeling of the threshold voltage, surface potential, conduction charge and drain current in triple-gate junctionless nanowire transistors. The models are derived from the solution of the Poisson equation with the appropriate boundary conditions and exhibit a great concordance with three-dimensional numerical simulations and experimental data even for devices with channel length of $30 \mathrm{~nm}$. In the case of the threshold voltage, the higher error obtained between model and simulation was $33 \mathrm{mV}$, which represents an error lower than $5 \%$. A method for the threshold voltage extraction based on the equality of the drift and diffusion components of the drain current has also been presented. This method was also validated using simulated results, with a maximum error of $3 \mathrm{mV}$ (lower than $0.5 \%$ ), and applied to experimental devices. The influence of the temperature on the threshold voltage has also been analyzed through the proposed model, the numerical simulations and the experimental data. It has been shown that the dependence of the ionized dopant concentration with the temperature due to the incomplete carrier ionization has a great influence on the threshold voltage. In the case of the surface potential and drain current modeling, a correction for the short channel effects has been proposed. The mean error has been lower than $12 \%$ for the drain current curves and their derivatives when compared to 
the ones of experimental devices with a channel length of $30 \mathrm{~nm}$. An analysis on the operation of the JNTs has been also performed, showing that the zero temperature coefficient point, in which the current is the same independent of the temperature, can or not exist depending on the series resistance and its dependence on the temperature. Finally, the operation of junctionless nanowire transistors in analog applications has been analyzed for devices of different dimensions.

Keywords: Junctionless Nanowire Transistors, Multiple-Gate, Modeling, Threshold Voltage, Extraction Method, Temperature 


\section{LISTA DE FIGURAS}

Figura 2.1 - Perfil longitudinal de um dispositivo SOI nMOS modo inversão... 38

Figura 2.2 - Perfil longitudinal do dispositivo SOI pMOS modo acumulação. .. 40

Figura 2.3 - Modos de funcionamento do dispositivo SOI modo acumulação: (A) sublimiar, (B) piçamento do corpo, (C) pinçamento da camada de acumulação, (D) corpo em triodo, (E) corpo e camada de acumulação em triodo e (F) pinçamento do corpo e da camada de acumulação ${ }^{27}$. . 41

Figura 2.4 - Estrutura dos Dispositivos de Porta Tripla. ............................... 42

Figura 2.5 - Estrutura multi-fins ou multi-dedos ............................................. 43

Figura 2.6 - Corte longitudinal dos dispositivos nMOS JNT e porta tripla modo inversão.

Figura 2.7 - Comparação das curvas do logaritmo da corrente de dreno versus a tensão entre porta e fonte para os dispositivos modo inversão (A), modo acumulação (B) e JNT (C) ${ }^{44}$

Figura 2.8 - Diagrama de faixa de energia ao longo do dispositivo sem junções nMOS no centro do canal para $V_{G S}$ abaixo (A) e acima do limiar (B), na superfície para $\mathrm{V}_{\mathrm{GS}}<\mathrm{V}_{\mathrm{TH}}(\mathrm{C}), \quad \mathrm{V}_{\mathrm{TH}}<\mathrm{V}_{\mathrm{GS}}<\mathrm{V}_{\mathrm{FB}}(\mathrm{D}), \mathrm{V}_{\mathrm{GS}}>\mathrm{V}_{\mathrm{FB}}(\mathrm{E}) \mathrm{e}$ para alto $V_{D S}(F)$

Figura 2.9 - Corte longitudinal de um dispositivo nMOS sem junções considerando que as tensões $V_{G S}$ e $V_{D S}$ são aplicadas à porta e ao dreno do dispositivo, respectivamente.

Figura 2.10 - Tensão de limiar em função da altura e da largura do fin para dispositivos sem junções com $N_{D}=5 \times 10^{19} \mathrm{~cm}^{-3}$ e tox $=0,5 \mathrm{~nm}^{44}$

Figura 2.11 - Concentração intrínseca de portadores e largura de faixa proibida em função da temperatura para o silício.

Figura 2.12 - Percentagem de impurezas ionizadas e potencial de Fermi em função da temperatura 56

Figura 2.13 - Curva das componentes da mobilidade independente de campo elétrico versus temperatura. 60

Figura 2.14 - Mobilidade independente de campo elétrico para diversas concentrações de dopantes em função da temperatura. 60 
Figura 2.15 - Densidades de estado 1D (A) e 2D (B) na banda de condução de dispositivos porta tripla em inversão forte ${ }^{3}$. 64

Figura 2.16 - Amplificador de tensão formado por um único transistor MOS. . 66

Figura 2.17 - Obtenção da tensão Early a partir da curva $I_{D} \times V_{D S}$. 67

Figura 3.1 - Potencial (A) e campo elétrico (B) em função das direções $x$ e $z$ comparando-se os mesmos no centro e nas superfícies do dispositivo. 72 Figura 3.2 - Seção transversal de um dispositivo sem junções enfatizando as

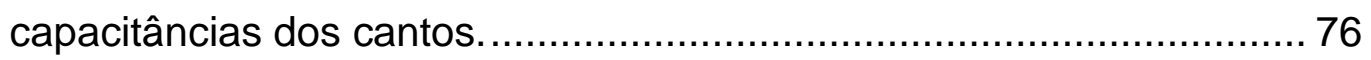

Figura 3.3 - Tensão de limiar simulada e modelada em função da concentração de dopantes (A) e da espessura do óxido de porta (B) analisando a inclusão do termo $f$ no cálculo da capacitância de porta por unidade de comprimento. 78

Figura 3.4 - Seção transversal de um dispositivo MOS sem junções com o óxido de canto arredondado. 79

Figura 3.5 - Tensão de limiar em função do raio do óxido de canto normalizado pela espessura do óxido de porta. 79

Figura 3.6 - Seção transversal de um dispositivo MOS sem junções com os cantos superiores do fin e do óxido arredondados. 80

Figura 3.7 - Tensão de limiar em função do raio dos cantos superiores do silício 80

Figura 3.8 - Corrente de dreno versus tensão de porta para dispositivos de diferentes larguras apontando a tensão de limiar. 81

Figura 3.9 - Tensão de limiar simulada e modelada em função da largura do fin (A), da altura do mesmo (B), da espessura do óxido de porta (C) e da concentração de dopantes (D) 82

Figura 3.10 - Tensão de limiar simulada e modelada em função da largura do fin em escala logarítmica. 82

Figura 3.11 - Tensão de limiar simulada e modelada em função da altura do fin em escala logarítmica.

Figura 3.12 - Comparação entre dados experimentais e o modelo proposto em função da largura efetiva do fin para dispositivos nMOS. 84

Figura 3.13 - Tensão de limiar em função da largura efetiva do fin comparando o modelo proposto com os dados experimentais para dispositivos pMOS. 
Figura 3.14 - Tensão de limiar em função da temperatura para dispositivos nMOS simulados de diferentes dimensões. 85

Figura 3.15 - Variação da tensão de limiar com a temperatura em função da concentração de dopantes para resultados modelados e experimentais de dispositivos nMOS. 86

Figura 3.16 - Variação da tensão de limiar com a temperatura em função da largura do fin comparando 0 modelo proposto com resultados experimentais de dispositivos pMOS. 86

Figura 3.17 - Componentes da variação da tensão de limiar com a temperatura $\left(\theta_{1}\right.$ e $\left.\theta_{2}\right)$ em função da concentração de dopantes. 87

Figura 3.18 - Taxa de ionização das impurezas em função da temperatura para diversas concentrações de dopantes. 88

Figura 3.19 - Diferença entre a tensão de limiar calculada utilizando o modelo de ionização incompleta $\left(\mathrm{V}_{\mathrm{TH}, \text { com ii) }}\right.$ e sem considera-lo $\left(\mathrm{V}_{\mathrm{TH} \text {,sem ii }}\right)$ em função da temperatura. 88

Figura 3.20 - Corrente de dreno em função da tensão de porta analisando-se a influência da polarização de substrato. 89

Figura 3.21 - Tensão de limiar em função da tensão aplicada ao substrato para os dispositivos simulados. 90

Figura 3.22 - Tensão de limiar modelada e simulada em função da tensão aplicada ao substrato para dispositivos de diferentes dimensões. 91

Figura 3.23 - Vista esquemática de um JNT com seção transversal circular (A) e o corte transversal desse dispositivo (B) 91

Figura 3.24 - Tensão de limiar em função da espessura do óxido de porta $(A)$ e da concentração de dopantes (B) para dispositivos cilíndricos com diversas espessuras de silício. 93

Figura 3.25 - Tensão de limiar em função da temperatura para dispositivos com diferentes espessuras $t_{\mathrm{Si}}$ 94

Figura 3.26 - Variação da tensão de limiar com a temperatura para JNTs cilíndricos em função da espessura tsi 94

Figura 3.27 - Variação da tensão de limiar com T em função da área da seção transversal $(A)$ e do perímetro de porta $(B)$, comparando dispositivos porta tripla com $\mathrm{H}_{\text {Fin }}=10 \mathrm{~nm}$ e cilíndricos. 95 
Figura 3.28 - Variação da tensão de limiar com T em função da área da seção transversal $(A)$ e do perímetro de porta (B) comparando dispositivos porta tripla com $\mathrm{W}_{\text {Fin }}=10 \mathrm{~nm}$ e cilíndricos........................................ 96

Figura 4.1 - Componentes de deriva e difusão da corrente de dreno (eixo da esquerda) e razão da transcondutância pela corrente (eixo da direita) em função da tensão de porta para duas temperaturas. 100

Figura 4.2 - Comparação entre a tensão de limiar extraída com os métodos de $\mathrm{g}_{\mathrm{m}} / \mathrm{l}_{\mathrm{D}}$, DD e CC e a igualdade entre as componentes da corrente de dreno obtida por simulação numérica tridimensional em função da largura do dispositivo. 102

Figura 4.3 - Comparação entre a tensão de limiar extraída com os métodos de $\mathrm{g}_{\mathrm{m}} / \mathrm{I}_{\mathrm{D}}$, DD e CC e a igualdade entre as componentes da corrente de dreno obtida por simulação numérica tridimensional em função da altura do dispositivo. 102

Figura 4.4 - Comparação entre a tensão de limiar extraída com os métodos de $g_{m} / I_{D}$, DD e CC e a igualdade entre as componentes da corrente de dreno obtida por simulação numérica tridimensional em função da temperatura. 103

Figura 4.5 - Comparação entre a tensão de limiar extraída com os métodos de $\mathrm{g}_{\mathrm{m}} / \mathrm{L}_{\mathrm{D}}$, DD e CC e a igualdade entre as componentes da corrente de dreno obtida por simulação numérica tridimensional em função do

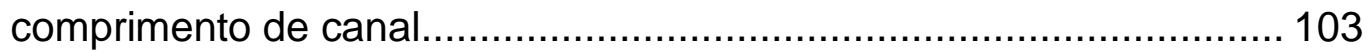

Figura 4.6 - Comparação entre o modelo de tensão de limiar descrito pela equação (4.14) e a igualdade entre as componentes da corrente de dreno obtida por simulação numérica tridimensional em função da largura do dispositivo. 105

Figura 4.7 - Comparação entre o modelo de tensão de limiar descrito pela equação (4.14) e a igualdade entre as componentes da corrente de dreno obtida por simulação numérica tridimensional em função da altura do dispositivo. 105

Figura 4.8 - Corrente de dreno em escalas logarítmica (A) e linear (B) em função da tensão de porta de dispositivos experimentais para diferentes temperaturas indicando as tensões de limiar extraídas pelo método de $\mathrm{g}_{\mathrm{m}} / \mathrm{I}_{\mathrm{D}}$ e pelo método da segunda derivada (DD). 106 
Figura 4.9 - Tensão de limiar de dispositivos experimentais extraídas usando os métodos da segunda derivada (DD) e de $\mathrm{g}_{\mathrm{m}} / \mathrm{L}_{\mathrm{D}}$ em função da temperatura comparando com o modelo de tensão de limiar da equação (4.14). 108

Figura 5.1 - Corrente em escalas linear (A) e logarítmica (B) em função da tensão de porta mostrando as contribuições das componentes $I_{1}$ e $I_{2}$ na corrente de dreno. 115

Figura 5.2 - Corrente de dreno e transcondutância modeladas e simuladas em função da tensão de porta. 116

Figura 5.3 - Razão entre transcondutância e corrente de dreno em função da corrente de dreno comparando o modelo com resultados simulados.. 116

Figura 5.4 - Corrente e condutância de dreno modeladas e simuladas em função da tensão de dreno para diversos $V_{G T}\left(V_{G T}=V_{G S}-V_{T H}\right) \ldots \ldots . .117$

Figura 5.5 - Corrente de dreno e transcondutância em função da tensão de porta para diversas tensões de dreno mostrando a aplicação do modelo a dispositivos pMOS 118

Figura 5.6 - Corrente de dreno em escalas linear e logarítmica em função da tensão de porta comparando o modelo com resultados experimentais para $\mathrm{V}_{\mathrm{DS}}=50 \mathrm{mV}$.

Figura 5.7 - Corrente de dreno e transcondutância em função da tensão de porta comparando os resultados do modelo com resultados experimentais para diversas temperaturas e $\mathrm{V}_{\mathrm{DS}}=1 \mathrm{~V}$......................119

Figura 5.8 - Corrente de dreno em escalas linear e logarítmica e transcondutância em função da tensão $V_{G S}$ apresentando resultados modelados e simulados para um JNT de $\mathrm{L}=40 \mathrm{~nm}$......................... 122

Figura 5.9 - Corrente de dreno e condutância de saída em função da tensão aplicada ao dreno mostrando resultados modelados e simulados para

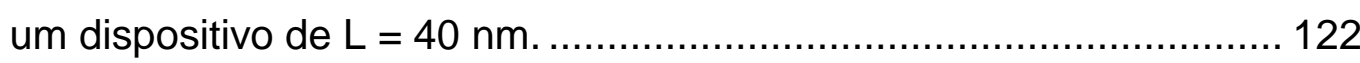

Figura 5.10 - Ponto do potencial mínimo no canal normalizado pelo comprimento de canal em função da tensão de porta.

Figura 5.11 - Potencial mínimo no canal em função da tensão de porta para dispositivos de diferentes comprimentos de canal considerando uma baixa polarização de dreno. 124 
Figura 5.12 - Inclinação de sublimiar em função do comprimento de canal para dispositivos de diferentes dimensões comparando o modelo analítico com os resultados simulados. 125

Figura 5.13 - Potencial $\phi_{\min , \text { vth }}$ (Threshold Voltage Roll-off) em função do comprimento de canal obtido pelas simulações e pelo modelo analítico para dispositivos de diferentes dimensões.

Figura 5.14 - Redução da barreira induzida pelo dreno (DIBL) em função do comprimento de canal para dispositivos de diferentes dimensões. ..... 128

Figura 6.1 - Potencial efetivo de superfície extraído na fonte e no dreno de um dispositivo sem junções em função da tensão de porta comparando o modelo com as simulações numéricas.

Figura 6.2 - Densidade de carga de condução por unidade de comprimento obtida por simulações numéricas e pelo modelo proposto em função da tensão de porta

Figura 6.3 - Capacitância de porta em função da tensão aplicada à mesma obtida pelas simulações numéricas e pelo modelo analítico para dispositivos de diferentes concentrações de dopantes.

Figura 6.4 - Curva do logaritmo da diferença entre a tensão $V_{G 3}$ e a tensão de limiar em função da tensão de porta.

Figura 6.5 - Corrente de dreno em escalas linear e logarítmica em função da tensão de porta mostrando resultados simulados e obtidos com o modelo analítico desenvolvido com base nos potenciais de superfície.

Figura 6.6 - Transcondutância em função da tensão aplicada à porta comparando-se as simulações numéricas com o modelo analítico desenvolvido com base nos potenciais de superfície.

Figura 6.7 - Corrente de dreno em função da tensão $V_{D S}$ apresentando resultados simulados e obtidos com o modelo analítico desenvolvido com base nos potenciais de superfície. 140

Figura 6.8 - Condutância de saída em função da tensão de dreno obtidas através da derivada das curvas da Figura 6.7.

Figura 6.9 - Corrente de dreno em função da tensão de dreno para diversas sobretensões de porta mostrando a continuidade do modelo em torno da tensão $V_{D S}=0 \mathrm{~V}$ 
Figura 6.10 - Corrente de dreno em função da tensão de porta para dispositivos de diferentes larguras e alturas comparando simulações numéricas com o modelo analítico desenvolvido em função dos potenciais de superfície.

Figura 6.11 - Corrente de dreno em função da tensão de porta para dispositivos de diferentes espessuras de óxido de porta e concentrações de dopantes comparando simulações numéricas com o modelo analítico desenvolvido em função dos potenciais de superfície. 142

Figura 6.12 - Corrente de dreno e transcondutância em função da tensão de porta mostrando resultados modelados e simulados para um dispositivo com $\mathrm{L}=20 \mathrm{~nm}$. 144

Figura 6.13 - Corrente de dreno e condutância de saída em função da tensão de dreno obtidas pelo modelo analítico e por simulações para um dispositivo com $\mathrm{L}=20 \mathrm{~nm}$. 145

Figura 6.14 - Razão $\mathrm{gm}_{\mathrm{m}} / \mathrm{I}_{\mathrm{D}}$ em função da corrente de dreno obtida pelo modelo analítico e por simulações para dispositivos de diferentes comprimentos de canal.

Figura 6.15 - Corrente de dreno e transcondutância em função da tensão de porta comparando o modelo analítico com resultados experimentais para dispositivos com $\mathrm{L}=30 \mathrm{~nm}$.

Figura 6.16 - Corrente de dreno e condutância de saída em função da tensão de dreno apresentando dados modelados e experimentais para dispositivos com $\mathrm{L}=30 \mathrm{~nm}$. 149

Figura 6.17 - Corrente de dreno em função da tensão de porta exibindo resultados modelados e simulados para diversas polarizações de substrato. 150

Figura 7.1 - Curvas características experimentais $I_{D} \times V_{G S}$ para dispositivos nMOS e pMOS com L $=30 \mathrm{~nm}, 50 \mathrm{~nm}, 100 \mathrm{~nm}$ e $10 \mu \mathrm{m}$ variando-se a temperatura e a concentração de dopantes. 152

Figura 7.2 - Tensão de limiar em função da temperatura extraída das curvas da Figura 7.1 para dispositivos com comprimento de canal de $50 \mathrm{~nm} . \ldots 154$

Figura 7.3 - Transcondutância máxima em função da temperatura para os dispositivos longos $(\mathrm{L}=10 \mu \mathrm{m})$. 156 
Figura 7.4 - Transcondutância máxima em função da temperatura para dispositivos simulados considerando mobilidade de baixo campo constante.

Figura 7.5 - Resistência série extraída dos dispositivos em função da temperatura. 158

Figura 7.6 - Taxa de ionização incompleta dos portadores em função da temperatura para boro e fósforo considerando diferentes concentrações de dopantes. 159

Figura 7.7 - Razão entre a transcondutância máxima e $g_{m, \max }$ para $L f d=1 \mathrm{~nm}$ em função do comprimento das regiões de fonte e dreno 159

Figura 8.1 - Corrente de dreno e transcondutância em função de $V_{G T}$ para dispositivos de diferentes concentrações de dopantes do tipo $n(A)$ e do tipo $p(B)$. 161

Figura 8.2 - Razão entre a transcondutância e a corrente de dreno em função da corrente de dreno para dispositivos nMOS e pMOS de diferentes concentrações de dopantes. 163

Figura 8.3 - Condutância de saída e transcondutância em função da razão $\left|g_{m} / I_{D}\right|$ comparando os dispositivos de diferentes concentrações de dopantes. 163

Figura 8.4 - Ganho de tensão de malha aberta e tensão Early em função da razão $\left|g_{m} / l_{D}\right|$ para JNTs de diferentes concentrações de dopantes. .... 164

Figura 8.5 - Ganho de tensão de malha aberta em função de $g_{m} / l_{D}$ para dispositivos de diferentes dimensões. 164

Figura 8.6 - Razão entre a transcondutância e a corrente de dreno em função da corrente de dreno para dispositivos nMOS e pMOS em diferentes temperaturas. 165

Figura 8.7 - Ganho de tensão de malha aberta e tensão Early em função da razão $\left|g_{\mathrm{m}} / \mathrm{I}_{\mathrm{D}}\right|$ para dispositivos nMOS e pMOS em diferentes temperaturas... 166

Figura 8.8 - Condutância de saída e transcondutância em função da razão $\left|g_{m} / I_{D}\right|$ comparando os dispositivos nMOS e pMOS em diferentes temperaturas 166 


\section{LISTA DE TABELAS}

Tabela 2.1 - Parâmetros utilizados para o cálculo da ionização incompleta para o caso de silício dopado com boro, arsênio ou fósforo ${ }^{58,59}$ 55

Tabela 4.1 - Variações da tensão de limiar com a temperatura extraídas da Figura 4.9 comparadas aos modelos de tensão de limiar da equação (3.14) e da equação (4.14). 108

Tabela 5.1 - Erro máximo absoluto entre os dados simulados e modelados da Figura 5.2 e da Figura 5.4 117

Tabela 6.1 - Parâmetros extraídos utilizando o algoritmo Levenberg-Marquardt 128 147

Tabela 7.1 - Diferença entre o ponto de ZTC e a tensão de limiar em temperatura ambiente para os dispositivos de diferentes concentrações de dopantes da Figura 7.1. 153 


\section{LISTA DE SÍMBOLOS}

a

A

$A_{V}$

$A_{1}$

$\mathrm{A}_{2}$

$\mathrm{A}_{3}$

$\mathrm{A}_{4}$

$\mathrm{A}_{5}$

$A_{7}$

$\mathrm{A}_{8}$

$\mathrm{A}_{9}$

$b_{A}$

$b_{D}$

C

Parâmetro utilizado no cálculo da modulação do comprimento de canal $\left[\mathrm{V} / \mathrm{cm}^{2}\right]$

Área da seção transversal de um dispositivo $\left[\mathrm{cm}^{2}\right]$

Ganho de tensão de malha aberta [V/V ou dB]

Parâmetro utilizado na modelagem da corrente de dreno relacionado à tensão efetiva entre dreno e fonte

Parâmetro utilizado na modelagem da corrente de dreno relacionado à tensão efetiva de transição $\mathrm{V}_{\mathrm{A}}$

Parâmetro utilizado na modelagem da corrente de dreno relacionado à tensão efetiva de transição $\mathrm{V}_{\mathrm{A}}$

Parâmetro utilizado na modelagem da corrente de dreno relacionado à região de sublimiar

Parâmetro utilizado na modelagem do potencial de superfície relacionado à transição entre condução pelo corpo e pela camada de acumulação

A $\quad$ Parâmetro utilizado na modelagem do potencial de superfície relacionado à região de sublimiar

Parâmetro utilizado na modelagem do potencial de superfície no cálculo do parâmetro $A_{5}$

Parâmetro utilizado na modelagem do potencial de superfície no cálculo do parâmetro $A_{5}$

Parâmetro utilizado na modelagem do potencial de superfície no cálculo do parâmetro $A_{5}$

Parâmetro utilizado no cálculo da ionização incompleta das impurezas aceitadoras

Parâmetro utilizado no cálculo da ionização incompleta das impurezas doadoras

Parâmetro que depende da impureza utilizado no cálculo de $E_{A}$ ou $E_{D}$ 
$\mathrm{C}_{\text {cantos }} \quad$ Capacitância dos cantos do óxido de porta por unidade de comprimento $[\mathrm{F} / \mathrm{cm}]$

Cox Capacitância do óxido de porta por unidade de comprimento $[\mathrm{F} / \mathrm{cm}]$

Cox' Capacitância do óxido de porta por unidade de área $\left[\mathrm{F} / \mathrm{cm}^{2}\right]$

$\mathrm{C}_{\mathrm{qu}} \quad$ Capacitância de um quadrado unitário $[\mathrm{F}]$

$\mathrm{C}_{\mathrm{G}} \quad$ Capacitância de porta por unidade de comprimento [F/cm]

$\mathrm{C}_{\mathrm{L}} \quad$ Carga capacitiva $[\mathrm{F}]$

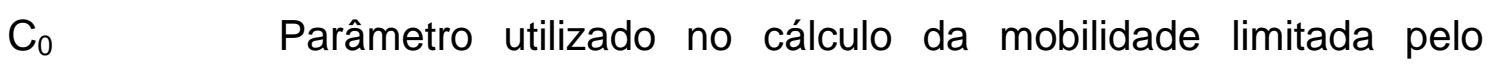
espalhamento por impurezas neutras $\left[\mathrm{cm}^{2} / \mathrm{V} . \mathrm{s}\right]$

d Parâmetro que depende da impureza utilizado no cálculo de $b_{A}$ ou $b_{D}$

E Mínimo clássico da banda de condução [eV]

$E_{\text {eff }} \quad$ Campo elétrico efetivo [V/cm]

$E_{j} \quad$ Nível de energia da função de onda de um determinado elétron [eV]

$\mathrm{E}_{\mathrm{A}} \quad$ Energia de ativação das impurezas aceitadoras [eV]

$E_{\text {dop }, 0} \quad$ Energia que depende da impureza utilizada no cálculo de $E_{A}$ ou $\mathrm{E}_{\mathrm{D}}[\mathrm{eV}]$

$\mathrm{E}_{\mathrm{D}} \quad$ Energia de ativação das impurezas doadoras [eV]

$\mathrm{E}_{\mathrm{Fn}} \quad$ Nível de Fermi para elétrons [eV]

$\mathrm{E}_{\mathrm{Fp}} \quad$ Nível de Fermi para lacunas [eV]

$\mathrm{E}_{\mathrm{G}} \quad$ Altura da banda proibida [eV]

$\mathrm{E}_{\mathrm{ni}} \quad$ Energia utilizada no cálculo da mobilidade limitada pelo espalhamento por impurezas neutras $[\mathrm{eV}]$

ES Campo elétrico de superfície $[\mathrm{V} / \mathrm{cm}]$

$E_{\text {Sat }} \quad$ Campo elétrico de saturação $[\mathrm{V} / \mathrm{cm}]$

$f \quad$ Fator de correção utilizado no cálculo da capacitância de porta

g Parâmetro que depende da impureza utilizado no cálculo de $\mathrm{g}_{\mathrm{A}}$ ou gD

gA Parâmetro utilizado no cálculo da ionização incompleta das impurezas aceitadoras

$g_{d} \quad$ Condutância de dreno ou de saída [S] 
Parâmetro utilizado no cálculo da ionização incompleta das impurezas doadoras

$g_{m} \quad$ Transcondutância [S]

$g_{m, \max } \quad$ Transcondutância máxima [S]

h Constante de Planck [6,626 x 10 $\left.0^{-34} \mathrm{J.s}\right]$

$\hbar \quad$ Constante de Planck normalizada $\left[1,055 \times 10^{-34} \mathrm{~J} . \mathrm{s}\right]$

$\mathrm{H}_{\text {Fin }} \quad$ Altura do fin $[\mathrm{nm}]$

lacc $\quad$ Corrente que flui pela camada de acumulação [A]

$\mathrm{I}_{\mathrm{b}} \quad$ Corrente de corpo em um dispositivo SOI modo acumulação [A]

$I_{D} \quad$ Corrente de dreno $[A]$

IDer $\quad$ Componente de deriva da corrente de dreno [A]

$\mathrm{I}_{\text {Dif }} \quad$ Componente de difusão da corrente de dreno [A]

IDsat $\quad$ Corrente de saturação $[A]$

$I_{p} \quad$ Corrente de polarização de um amplificador $[A]$

$\mathrm{I}_{1} \quad$ Corrente de dreno quando há condução tanto pelo corpo do dispositivo como por uma camada de acumulação $[A]$

$\mathrm{I}_{2} \quad$ Corrente de dreno quando há apenas condução pelo corpo do dispositivo $[A]$

k Constante de Boltzmann $\left[1,38 \times 10^{-23} \mathrm{~J} / \mathrm{K}\right]$

$\mathrm{L} \quad$ Comprimento do canal [cm]

$L_{\text {eff }} \quad$ Comprimento efetivo de canal [cm]

Lfd Comprimento de fonte e dreno [cm]

$\mathrm{m}_{0} \quad$ Massa do elétron $\left[9,11 \times 10^{-31} \mathrm{~kg}\right]$

$\mathrm{m}^{*} \quad$ Massa de confinamento do portador na direção transversal [kg]

$m_{d e}{ }^{*} \quad$ Massa efetiva das densidades de estados para elétrons

$\mathrm{m}_{\mathrm{dh}}{ }^{*} \quad$ Massa efetiva das densidades de estados para lacunas

$m_{e}^{*} \quad$ Massa efetiva dos elétrons

$m_{\mathrm{x}}{ }^{*}, \mathrm{~m}_{\mathrm{y}}{ }^{*}, \mathrm{~m}_{\mathrm{z}}{ }^{*}$ Massas efetivas correspondentes aos diferentes vales $\mathrm{e}$ relacionadas com a orientação cristalográfica

n Fator de corpo do transistor

$\mathrm{n}_{1} \quad$ Densidade de estados obtida a partir da energia de ativação $E_{D}$ $\left[\mathrm{cm}^{-3}\right]$

$\mathrm{n}_{\mathrm{i}} \quad$ Concentração intrínseca do silício $\left[\mathrm{cm}^{-3}\right]$

$\mathrm{N}_{\mathrm{A}} \quad$ Concentração de impurezas aceitadoras [ $\mathrm{cm}^{-3}$ ] 
$\mathrm{N}_{\mathrm{A}}^{-} \quad$ Concentração de impurezas aceitadoras ionizadas [ $\left[\mathrm{cm}^{-3}\right]$

$\mathrm{N}_{\mathrm{b}} \quad$ Parâmetro que depende da impureza utilizado no cálculo de $\mathrm{b}_{\mathrm{A}}$ ou $b_{D}\left[\mathrm{~cm}^{-3}\right]$

$\mathrm{N}_{\mathrm{C}} \quad$ Densidade de estados da banda de condução $\left[\mathrm{cm}^{-3}\right]$

$\mathrm{N}_{\mathrm{D}} \quad$ Concentração de impurezas doadoras $\left[\mathrm{cm}^{-3}\right]$

$\mathrm{N}_{\mathrm{D}}{ }^{+} \quad$ Concentração de impurezas doadoras ionizadas [ $\mathrm{cm}^{-3}$ ]

$\mathrm{N}_{\mathrm{it}} \quad$ Densidade de armadilhas de interface por unidade de área $\left[\mathrm{F} / \mathrm{cm}^{2}\right]$

$\mathrm{N}_{\text {ref }} \quad$ Densidade de portadores que depende da impureza utilizada no cálculo de $\mathrm{E}_{\mathrm{A}}$ ou $\mathrm{E}_{\mathrm{D}}\left[\mathrm{cm}^{-3}\right]$

$N_{\text {Ref }} \quad$ Densidade de portadores utilizada no cálculo da mobilidade limitada pelo espalhamento por impurezas ionizadas $\left[\mathrm{cm}^{-3}\right]$

$\mathrm{N}_{\mathrm{V}} \quad$ Densidade de estados da banda de valência $\left[\mathrm{cm}^{-3}\right]$

$p_{1} \quad$ Densidade de estados obtida a partir da energia de ativação $E_{A}$ $\left[\mathrm{cm}^{-3}\right]$

P Perímetro da porta do dispositivo [nm]

q Carga elementar do elétron $\left[1,6 \times 10^{-19} \mathrm{C}\right]$

Q Densidade de carga controlada pela porta por unidade de comprimento [C/cm]

$Q_{c} \quad$ Densidade de carga de condução por unidade de comprimento $[\mathrm{C} / \mathrm{cm}]$

$\mathrm{Q}_{\mathrm{C}, \mathrm{D}} \quad$ Densidade de carga de condução por unidade de comprimento no lado do dreno do dispositivo $[\mathrm{C} / \mathrm{cm}]$

$\mathrm{Q}_{\mathrm{c}, \mathrm{F}} \quad$ Densidade de carga de condução por unidade de comprimento no lado da fonte do dispositivo $[\mathrm{C} / \mathrm{cm}]$

$\mathrm{Q}_{\text {depl }} \quad$ Densidade de carga de depleção por unidade de comprimento $[\mathrm{C} / \mathrm{cm}]$

Qox $\quad$ Densidade de cargas fixa no óxido por unidade de área $\left[\mathrm{C} / \mathrm{cm}^{2}\right]$

$Q_{\text {sat }} \quad$ Densidade de cargas por unidade de comprimento na condição de saturação $[\mathrm{C} / \mathrm{cm}]$

$Q_{\mathrm{Si}} \quad$ Densidade de carga fixa no silício por unidade de comprimento $[\mathrm{C} / \mathrm{cm}]$ 
Q $\quad$ Densidade de carga de condução quando há condução tanto pelo corpo como por uma camada de acumulação nas superfícies por unidade de comprimento $[\mathrm{C} / \mathrm{cm}]$

$\mathrm{Q}_{2}$ Densidade de carga de condução quando há apenas condução pelo corpo por unidade de comprimento $[\mathrm{C} / \mathrm{cm}]$

$r$ Eixo na direção radial de um dispositivo de seção transversal circular

$r_{\text {int }} \quad$ Raio dos cantos superiores do nanofio de silício [nm]

$r_{\text {ox }}$ Raio do óxido de canto [nm]

$\mathrm{R}_{\mathrm{S}}$ Resistência série $[\Omega]$ Inclinação de sublimiar [mV/década] Inclinação de sublimiar considerando efeitos de canal curto [mV/década]

$t_{\text {Box }} \quad$ Espessura do óxido enterrado [nm]

tox Espessura do óxido de porta [nm]

Espessura efetiva do óxido de porta devido aos efeitos quânticos [nm]

Espessura da camada de silício [nm]

Temperatura absoluta $[\mathrm{K}]$

Potencial na fonte utilizado na correção de efeitos de canal curto [V]

V

Velocidade dos portadores $[\mathrm{cm} / \mathrm{s}]$

Amplitude da parcela alternada da tensão de dreno [V] Amplitude da parcela alternada da tensão de porta [V]

Velocidade de saturação [cm/s]

Potencial no dreno utilizado na correção de efeitos de canal curto [V]

$V_{\mathrm{A}} \quad$ Tensão no ponto $\mathrm{A}$ usada na modelagem da corrente de dreno [V]

$V_{B} \quad$ Tensão no ponto $B$ usada na modelagem da corrente de dreno [V]

$V_{B S} \quad$ Tensão aplicada entre o substrato e a fonte [V]

$V_{D S}$ Tensão aplicada entre o dreno e a fonte [V] 


\begin{tabular}{|c|c|}
\hline$V_{\text {DSe }}$ & Tensão efetiva entre o dreno e a fonte [V] \\
\hline $\mathrm{V}_{\text {Dsat }}$ & Tensão de saturação [V] \\
\hline$V_{E A}$ & Tensão Early [V] \\
\hline$V_{F B}$ & Tensão de faixa plana [V] \\
\hline $\mathrm{V}_{\mathrm{FBs}}$ & Tensão de faixa plana do substrato [V] \\
\hline$V_{\mathrm{G} 1}$ & Tensão de porta utilizada no cálculo da corrente de sublimiar [V] \\
\hline $\mathrm{V}_{\mathrm{G} 2}$ & $\begin{array}{l}\text { Tensão de porta utilizada no cálculo do potencial de superfície } \\
\text { [V] }\end{array}$ \\
\hline $\mathrm{V}_{\mathrm{G} 3}$ & $\begin{array}{l}\text { Tensão de porta utilizada no cálculo do potencial de superfície } \\
\text { na região de sublimiar [V] }\end{array}$ \\
\hline$V_{G S}$ & Tensão aplicada entre a porta e a fonte [V] \\
\hline $\mathrm{V}_{\mathrm{GT}}$ & Sobretensão de porta [V] \\
\hline $\mathrm{V}_{\mathrm{S}}$ & Tensão na fonte [V] \\
\hline $\mathrm{V}_{\mathrm{TH}}$ & Tensão de limiar [V] \\
\hline $\mathrm{V}_{\mathrm{TH}, \mathrm{com} \text { ii }}$ & $\begin{array}{l}\text { Tensão de limiar considerando o modelo de ionização } \\
\text { incompleta dos portadores [V] }\end{array}$ \\
\hline $\mathrm{V}_{\mathrm{TH}, \mathrm{sem} \mathrm{ii}}$ & $\begin{array}{l}\text { Tensão de limiar desprezando o modelo de ionização incompleta } \\
\text { dos portadores [V] }\end{array}$ \\
\hline $\mathrm{V}_{\mathrm{Y}}$ & Tensão em uma posição $y$ do canal [V] \\
\hline $\mathrm{W}_{\text {masc }}$ & Largura de máscara $[\mathrm{nm}]$ \\
\hline $\mathrm{W}_{\mathrm{ox}}$ & Largura efetiva de porta [nm] \\
\hline $\mathrm{W}_{\text {Fin }}$ & Largura do fin $[\mathrm{nm}]$ \\
\hline $\mathrm{x}$ & Eixo na direção da largura de um dispositivo \\
\hline$x_{\text {depl }}$ & Espessura da região de depleção [nm] \\
\hline$x_{d \max }$ & Espessura máxima da camada de depleção [nm] \\
\hline$y$ & Eixo na direção do comprimento de um dispositivo \\
\hline$y_{\min }$ & Ponto de mínimo potencial no canal [nm] \\
\hline z & Eixo na direção da altura de um dispositivo \\
\hline$\alpha$ & $\begin{array}{l}\text { Parâmetro utilizado no cálculo da mobilidade limitada pelo } \\
\text { espalhamento de rede }\end{array}$ \\
\hline$\alpha_{a}$ & $\begin{array}{l}\text { Parâmetro utilizado no cálculo da mobilidade limitada pelo } \\
\text { espalhamento por impurezas ionizadas }\end{array}$ \\
\hline$\alpha_{E g}$ & Parâmetro utilizado no cálculo da largura de faixa proibida $[\mathrm{eV} / \mathrm{K}]$ \\
\hline
\end{tabular}




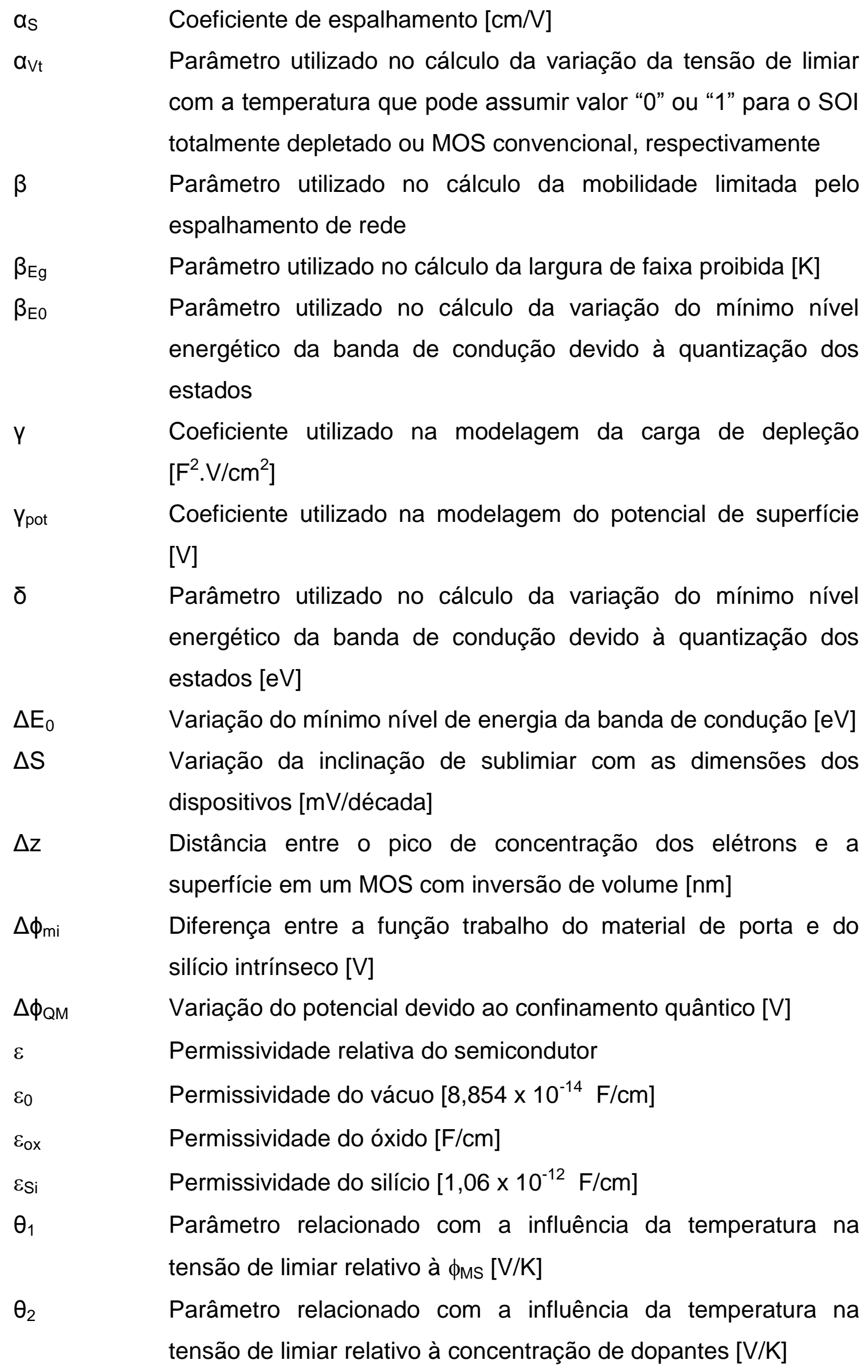
com a temperatura que pode assumir valor "0" ou "1" para o SOI totalmente depletado ou MOS convencional, respectivamente $\beta \quad$ Parâmetro utilizado no cálculo da mobilidade limitada pelo espalhamento de rede

$\beta_{\mathrm{Eg}} \quad$ Parâmetro utilizado no cálculo da largura de faixa proibida [K]

$\beta_{\mathrm{EO}} \quad$ Parâmetro utilizado no cálculo da variação do mínimo nível energético da banda de condução devido à quantização dos estados

y Coeficiente utilizado na modelagem da carga de depleção $\left[\mathrm{F}^{2} \cdot \mathrm{V} / \mathrm{cm}^{2}\right]$

Ypot Coeficiente utilizado na modelagem do potencial de superfície [V]

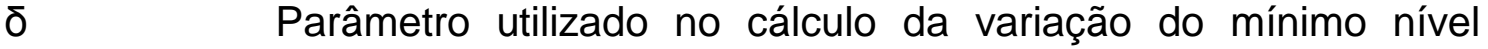
energético da banda de condução devido à quantização dos estados [eV]

$\Delta \mathrm{E}_{0} \quad$ Variação do mínimo nível de energia da banda de condução [eV] $\Delta S \quad$ Variação da inclinação de sublimiar com as dimensões dos dispositivos [mV/década]

$\Delta z \quad$ Distância entre o pico de concentração dos elétrons e a superfície em um MOS com inversão de volume [nm]

$\Delta \phi_{\mathrm{mi}} \quad$ Diferença entre a função trabalho do material de porta e do silício intrínseco [V]

$\Delta \phi_{\mathrm{QM}} \quad$ Variação do potencial devido ao confinamento quântico [V]

$\varepsilon$ Permissividade relativa do semicondutor Permissividade do vácuo $\left[8,854 \times 10^{-14} \mathrm{~F} / \mathrm{cm}\right]$

$\varepsilon_{0 x} \quad$ Permissividade do óxido $[\mathrm{F} / \mathrm{cm}]$

$\varepsilon_{\mathrm{Si}} \quad$ Permissividade do silício $\left[1,06 \times 10^{-12} \mathrm{~F} / \mathrm{cm}\right]$

$\theta_{1} \quad$ Parâmetro relacionado com a influência da temperatura na tensão de limiar relativo à $\phi_{\mathrm{MS}}[\mathrm{V} / \mathrm{K}]$

$\theta_{2} \quad$ Parâmetro relacionado com a influência da temperatura na tensão de limiar relativo à concentração de dopantes [V/K] 
$\Phi_{\mathrm{F}}$

$\Phi_{\mathrm{MS}}$
Comprimento característico [nm]

Comprimento característico relacionado à largura [nm]

Comprimento característico relacionado à altura [nm]

Mobilidade independente de campo elétrico $\left[\mathrm{cm}^{2} / \mathrm{V} . \mathrm{s}\right]$

Parâmetro utilizado no cálculo da mobilidade limitada pelo espalhamento de rede $\left[\mathrm{cm}^{2} / \mathrm{V} . \mathrm{s}\right]$

Parâmetro utilizado no cálculo da mobilidade limitada pelo espalhamento de rede $\left[\mathrm{cm}^{2} / \mathrm{V} . \mathrm{s}\right]$

Mobilidade devida ao espalhamento portador-portador $\left[\mathrm{cm}^{2} / \mathrm{V} . \mathrm{s}\right]$

Mobilidade efetiva $\left[\mathrm{cm}^{2} / \mathrm{V} . \mathrm{s}\right]$

Mobilidade mínima utilizada no cálculo da mobilidade limitada pelo espalhamento por impurezas ionizadas $\left[\mathrm{cm}^{2} / \mathrm{V} . \mathrm{s}\right]$

Mobilidade devida ao espalhamento por impurezas neutras $\left[\mathrm{cm}^{2} / \mathrm{V} . \mathrm{s}\right]$

Mobilidade devida ao espalhamento de rede $\left[\mathrm{cm}^{2} / \mathrm{V} . \mathrm{s}\right]$

Mobilidade devida aos espalhamentos por impurezas ionizadas e de rede $\left[\mathrm{cm}^{2} / \mathrm{V} . \mathrm{s}\right]$

Potencial [V]

Potencial mínimo no canal utilizado na correção de efeitos de canal curto [V]

Potencial mínimo no canal no sublimiar [V]

Potencial mínimo no canal na condição de limiar [V]

Potencial de superfície efetivo [V]

Potencial efetivo de superfície no regime de acumulação [V]

Potencial efetivo de superfície no regime de depleção parcial [V]

Potencial de superfície considerando efeitos de canal curto [V]

Potencial térmico [V]

Potencial de Fermi [V]

Diferença da função trabalho entre o material de porta e o silício [V]

Função de onda de um elétron 


\section{LISTA DE ABREVIATURAS}

CEA Commissariat à l'Energie Atomique et aux Energies Alternatives - Comissão de Energia Atômica e Energias Alternativas

CC Constant Current - Corrente Constante

CYNTHIA Cylindrical Thin-Pillar Transistor-Transistor Cilíndrico Vertical

$\mathrm{DD}$

Double Derivative - Segunda Derivada

DELTA Fully Depleted Lean-Channel Transistor - Transistor de canal vertical totalmente depletado

DIBL Drain Induced Barrier Lowering - Redução da Barreira Induzida pelo Dreno

EOT Effective Oxide Thickness - Espessura Efetiva do Óxido

FD Fully Depleted - Totalmente Depletado

GAA Gate-All-Around - Porta Circundante

JNT Junctionless Nanowire Transistor - Transistor de Nanofio sem Junções

LETI Laboratoire d'Électronique des Technologies de I'Information Laboratório de Eletrônica da Tecnologia da Informação

MOS Metal-Oxide-Semiconductor-Metal-Óxido-Semicondutor

NFD Near Fully Depleted - Quase Totalmente Depletado

PD Partially Depleted - Parcialmente Depletado

PhuMob Philips Unified Mobility Model - Modelo de Mobilidade Unificado de Baixo Campo

SOI Silicon-on-Insulator - Silício-sobre-isolante

TCAD Technology Computer Aided Design - Projeto Tecnológico Assistido por computador

ZTC Zero Temperature Coefficient - Ponto Invariante com a Temperatura

1DEG One Dimensional Electron Gas - Nuvem de elétrons unidimensional

2DEG Two Dimensional Electron Gas - Nuvem de elétrons bidimensional 


\section{SUMÁRIO}

1 INTRODUÇÃO .................................................................. 33

2 CONCEITOS FUNDAMENTAIS................................................

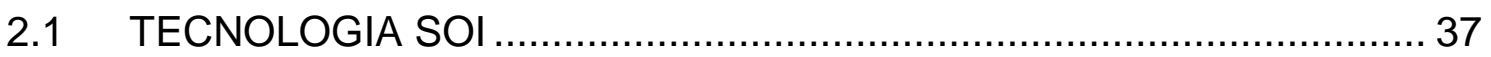

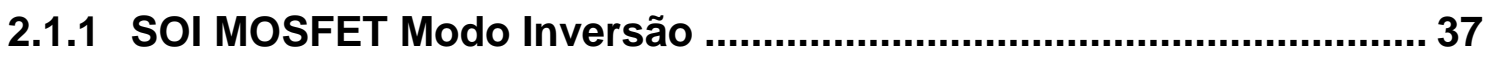

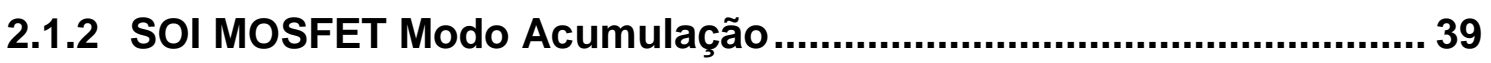

2.2 DISPOSITIVOS DE MÚLTIPLAS PORTAS …...................................... 41

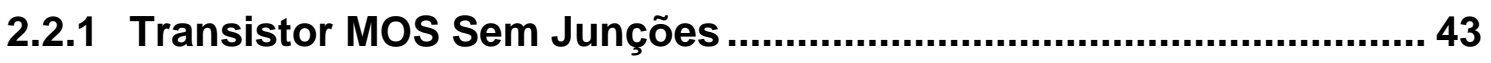

2.2.2 Funcionamento dos Transistores MOS Sem Junções ...................... 45

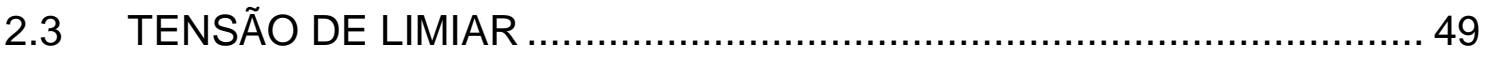

2.4 EFEITOS DA REDUÇÃO DA TEMPERATURA..................................51

2.4.1 Propriedades Físicas................................................................ 51

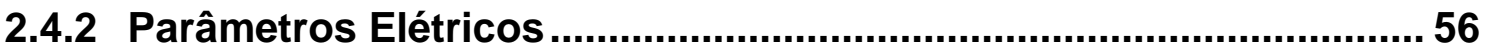

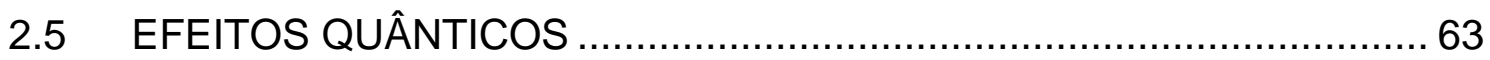

2.6 OPERAÇÃO DOS TRANSISTORES MOS EM APLICAÇÕES

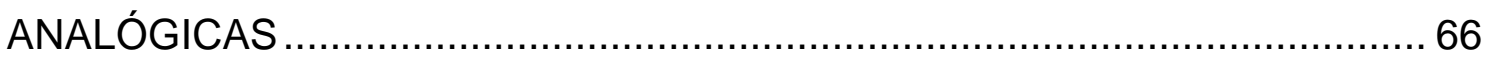

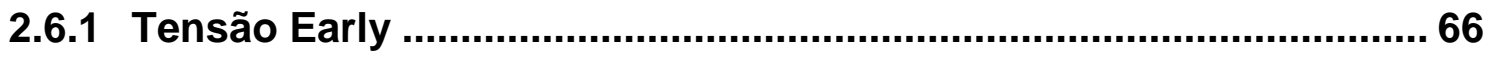

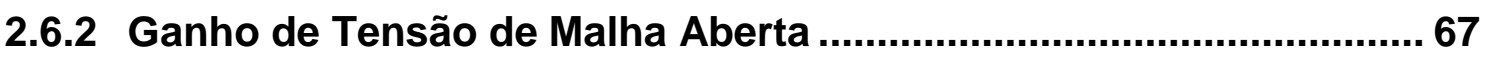

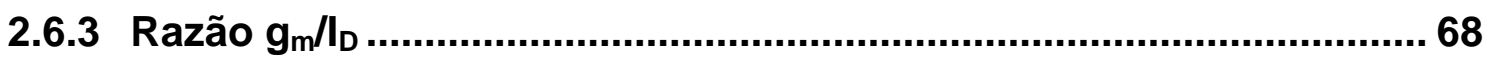

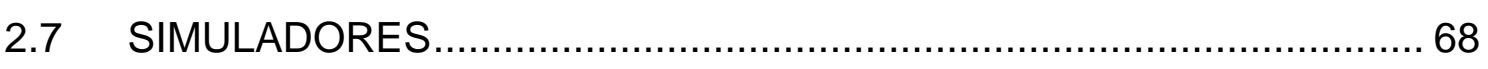

3 MODELO ANALÍTICO PARA TENSÃO DE LIMIAR .............. 71

3.1 DISPOSITIVOS PORTA TRIPLA ....................................................... 71

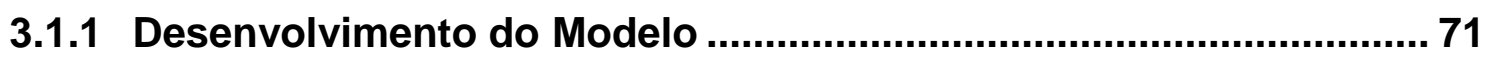

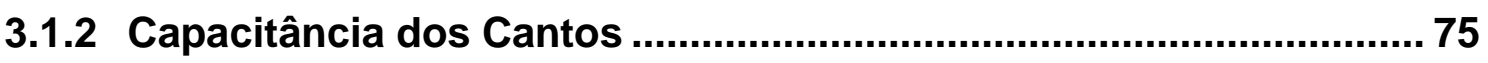

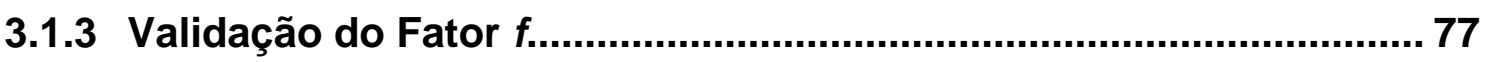


3.1.4 Validação do Modelo de Tensão de Limiar...................................... 80

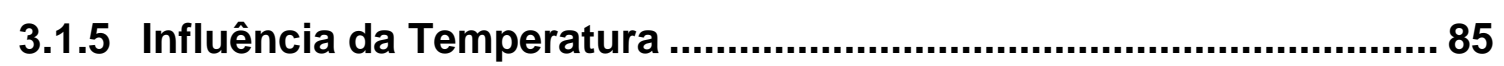

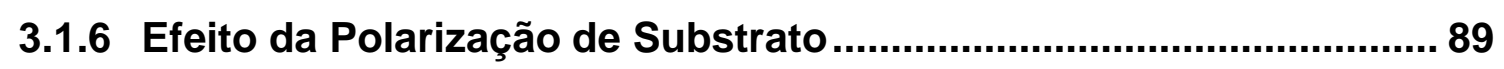

3.2 DISPOSITIVO DE SEÇÃO TRANSVERSAL CIRCULAR ...................... 91

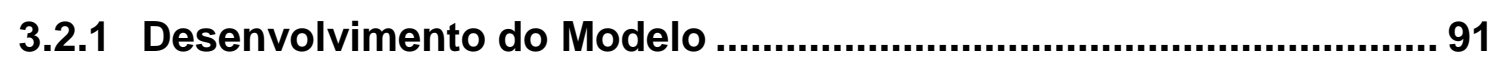

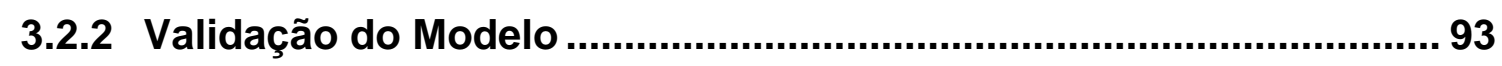

3.3 COMPARAÇÃO ENTRE DISPOSITIVOS CILÍNDRICOS E PORTA

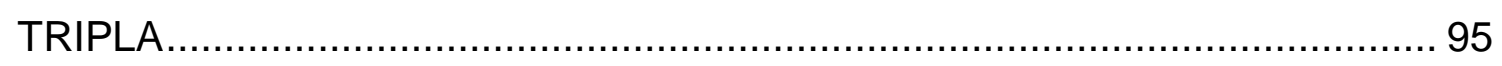

4 MÉTODO DE EXTRAÇÃO DA TENSÃO DE LIMIAR ............. 97

4.1 DESENVOLVIMENTO DO MÉTODO …................................................. 97

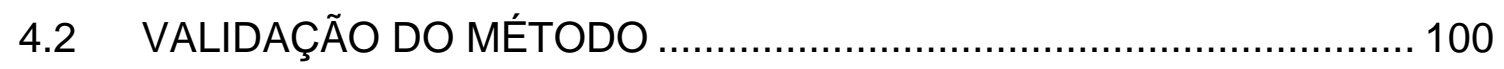

4.3 MODELO ANALÍTICO DE TENSÃO DE LIMIAR BASEADO NAS COMPONENTES DA CORRENTE DE DRENO …........................................ 103

4.4 APLICAÇÃO DO MÉTODO A DISPOSITIVOS EXPERIMENTAIS...... 106

5 MODELAGEM DA CORRENTE DE DRENO ....................... 109

5.1 CONDUÇÃO PELO CORPO E PELA CAMAdA DE ACUMULAÇÃO

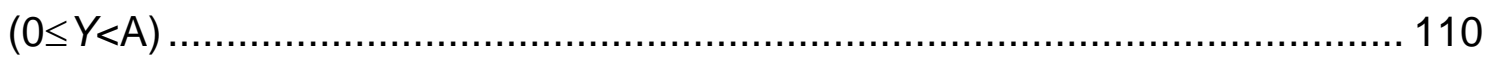

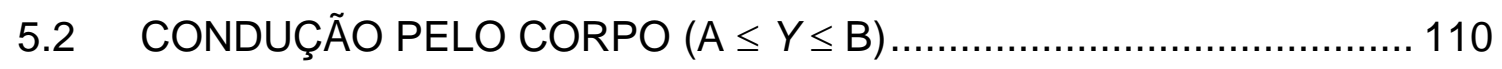

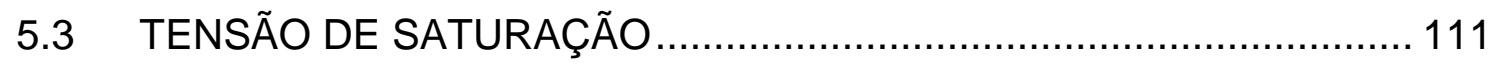

5.4 TENSÃO EFETIVA ENTRE FONTE E DRENO................................. 112

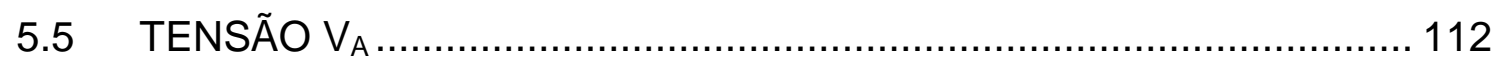

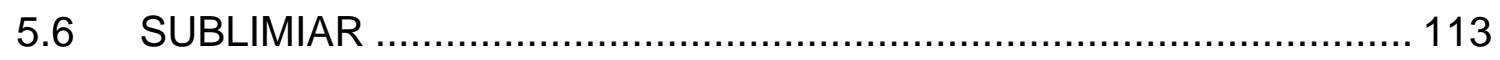

5.7 MODULAÇÃO DO COMPRIMENTO DE CANAL …........................... 113

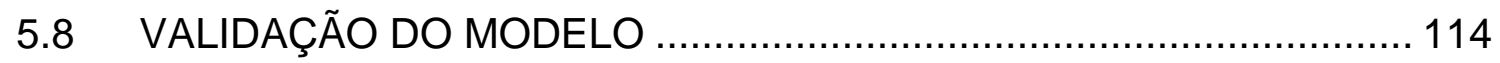

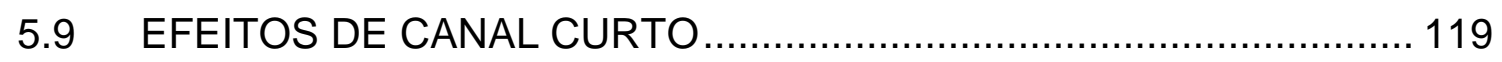

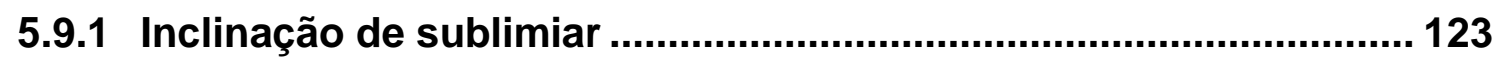

5.9.2 Redução da Tensão de Limiar e da Barreira Induzida pelo Dreno 125 


\section{MODELO DE POTENCIAL DE SUPERFÍCIE E DENSIDADE}

DE CARGAS 130

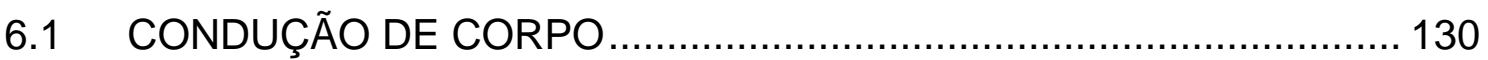

6.2 CONDUÇÃO PELA CAMADA DE ACUMULAÇÃO ............................ 131

6.3 TRANSIÇÃO CONTÍNUA ENTRE OS REGIMES DE CONDUÇÃO.... 132

6.4 EXPRESSÃO ANALÍTICA PARA CORRENTE DE DRENO.................134

6.5 PARÂMETRO A

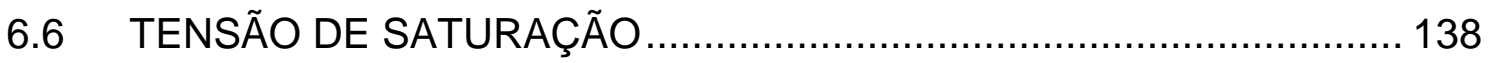

6.7 COMPARAÇÃO COM SIMULAÇÕES NUMÉRICAS ........................... 138

6.8 DISPOSITIVO DE CANAL CURTO …………............................... 143

6.9 DETERMINAÇÃO DOS PARÂMETROS DE AJUSTE........................ 145

6.10 COMPARAÇÃO COM RESULTADOS EXPERIMENTAIS .................. 147

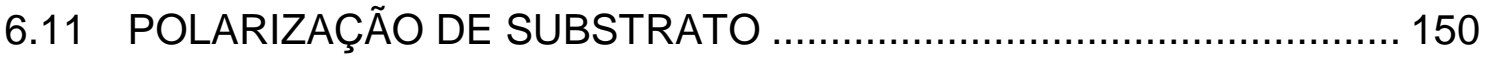

7 PONTO INVARIANTE COM A TEMPERATURA................. 151

7.1 CURVAS CARACTERÍSTICAS DOS DISPOSITIVOS ........................ 151

7.2 DEPENDÊNCIA DA TENSÃO DE LIMIAR E DA TRANSCONDUTÂNCIA MÁXIMA COM A TEMPERATURA …....................................................... 154

7.3 INFLUÊNCIA DA RESISTÊNCIA SÉRIE ......................................... 157

8 OPERAÇÃO EM APLICAÇÕES ANALÓGICAS .................. 161

8.1 CURVAS CARACTERÍSTICAS DOS DISPOSITIVOS ........................ 161

8.2 PARÂMETROS DE INTERESSE EM APLICAÇÕES ANALÓGICAS .. 162

8.3 INFLUÊNCIA DA TEMPERATURA …................................................ 165

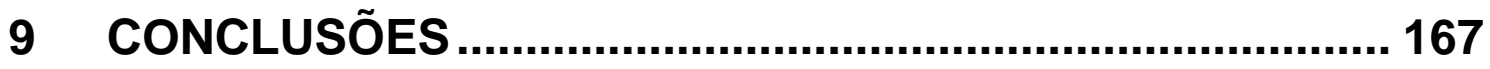

REFERÊNCIAS BIBLIOGRAFICAS ........................................ 171

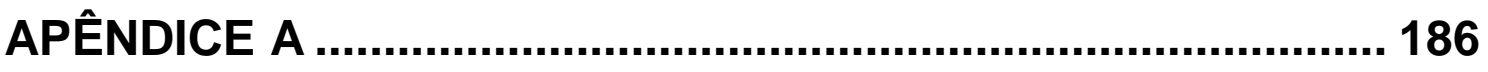

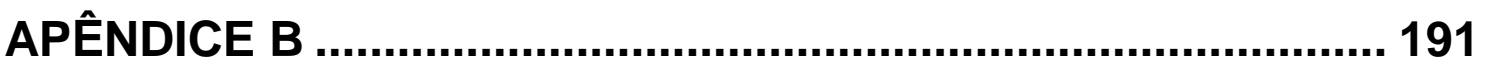


APÊNDICE C 


\section{INTRODUÇÃO}

A miniaturização dos transistores Metal-Óxido-Semicondutor (MetalOxide-Semiconductor - MOS) planares reduz o controle da porta sobre as cargas no canal, de forma que as regiões de depleção nas junções fonte/canal e dreno/canal passam a controlar uma parcela significativa destas cargas ${ }^{1}$. A solução ou redução dos efeitos decorrentes da perda parcial de controle, chamados de efeitos de canal curto, tornam complexa a fabricação de circuitos integrados em altíssima escala de integração com bilhões de transistores. Uma forma de minimizar os efeitos advindos das reduções das dimensões é o uso da tecnologia Silício-sobre-Isolante (Silicon-On-Insulator - SOI) que isola a região ativa da lâmina do substrato através de uma camada de óxido enterrado 1. Uma outra forma é a da adição de mais de um eletrodo de porta.

Como forma de aumentar o controle da porta sobre as cargas no canal, os dispositivos com mais de uma porta foram desenvolvidos a partir do final da década de $80^{2}$. Por ter mais de um eletrodo, estes dispositivos aumentam $\mathrm{O}$ controle eletrostático e diminuem a ocorrência de efeitos de canal curto ${ }^{3}$. Além disso, há a formação de múltiplos canais de inversão nesses dispositivos, aumentando a corrente de dreno quando comparados aos dispositivos MOS planares de largura similar ${ }^{3}$. No entanto, para comprimentos de canal extremamente reduzidos (tecnologias sub-20 nm), a fabricação de dispositivos modo inversão se torna muito complexa, devido às rigorosas condições necessárias para ativação dos dopantes das regiões de fonte e dreno, de forma a se evitar a difusão lateral destes dopantes para o canal, uma vez que a concentração de dopantes deve variar diversas ordens de grandeza em alguns nanômetros ${ }^{4}$.

Para continuar a miniaturização dos dispositivos sem a necessidade de complexos processos de fabricação, foi proposta uma nova estrutura de múltiplas portas em que o perfil de concentração de dopantes é constante da fonte ao dreno, sem gradientes de concentração, chamada de Junctionless Nanowire Transistor - JNT (Transistor de Nanofio sem Junções) ${ }^{5,6,7}$. Esta estrutura possui altas concentrações de dopantes a fim de se obter uma 
corrente de corpo considerável. A alta concentração de dopantes também ajuda a evitar os efeitos decorrentes da distribuição aleatória dos mesmos, que pode causar flutuações nas características elétricas do dispositivo. De acordo com Colinge et al. ${ }^{4}$, a variação da tensão de limiar devido à aleatoriedade dos dopantes em um JNT é similar à de um dispositivo porta-tripla modo inversão não dopado. A espessura da camada de silício na qual o dispositivo é fabricado deve ser da ordem de poucas dezenas de nanômetros para que o mesmo funcione adequadamente, permitindo a depleção completa da camada de silício na condição de sublimiar ${ }^{4}$.

Na literatura atual, são encontrados principalmente estudos referentes à operação desses dispositivos em circuitos digitais ${ }^{4,5,8,9,10}$ e alguns poucos relativos a seu emprego em aplicações analógicas ${ }^{11,12}$. No que diz respeito à modelagem, o foco tem sido dispositivos de porta dupla ou cilíndricos ${ }^{7,13,14,15,16}$.

A variação da temperatura de operação do dispositivo altera suas principais características elétricas, tais como inclinação de sublimiar, mobilidade dos portadores e concentração de dopantes ${ }^{17}$. Estudos reportam que os dispositivos MOS sem junções apresentam características peculiares como a ausência do ponto invariante com a temperatura (Zero Temperature Coefficient - ZTC) e uma grande dependência da tensão de limiar com a temperatura, quando comparados aos dispositivos modo inversão ${ }^{10}$.

Neste trabalho será realizado um estudo dos dispositivos MOS sem junções fabricados na tecnologia SOI, onde será feita a modelagem de suas características elétricas, bem como a análise da influência da temperatura em seu funcionamento. No Capítulo 2, são apresentados os conceitos fundamentais necessários para o desenvolvimento do trabalho. Neste capítulo, é feita uma breve introdução da tecnologia SOI onde serão apresentados os dispositivos modo inversão e modo acumulação. Também serão apresentados os dispositivos de múltiplas portas, com ênfase nos transistores MOS sem junções, detalhando seu funcionamento e suas similaridades com os dispositivos SOI modo acumulação. Serão abordados ainda os efeitos da variação da temperatura nas propriedades físicas e nos parâmetros elétricos dos dispositivos, os efeitos quânticos advindos da redução das dimensões, os principais parâmetros de análise analógica e o simulador numérico utilizado neste trabalho. 
No Capítulo 3, é proposto um modelo de tensão de limiar para os dispositivos sem junções de porta tripla. São apresentadas a dedução do modelo a partir da equação de Poisson e a inclusão de um fator no cálculo da capacitância de porta, a fim de se contabilizar a influência do óxido nos cantos. Tanto o fator como o modelo proposto são validados através de simulações numéricas tridimensionais para dispositivos com diferentes características (dimensões e concentração de dopantes). O modelo é também validado com resultados experimentais. Com base no modelo, nas simulações e nos resultados experimentais, é feita uma análise da influência da variação da temperatura na tensão de limiar. A dedução do modelo também é estendida para dispositivos cilíndricos, também sendo validada através de resultados simulados. Por fim, é realizada uma comparação entre a dependência da tensão de limiar com a temperatura dos dispositivos porta tripla e cilíndrico.

No Capítulo 4, é proposto um método de extração da tensão de limiar. 0 método desenvolvido se baseia na igualdade das componentes de deriva e difusão da corrente de dreno. A partir dessa igualdade, é determinado um ponto na curva da razão da transcondutância pela corrente de dreno em função da tensão de porta que representa a condição de limiar. O método proposto foi comparado com resultados simulados e também foi aplicado aos dispositivos experimentais. A partir do método, também é possível se obter uma expressão analítica para a tensão de limiar.

No Capítulo 5, é realizada a modelagem da corrente de dreno desses dispositivos. Para o desenvolvimento do modelo, o canal foi dividido em duas partes relacionadas com a forma de condução do dispositivo e, portanto, a corrente é obtida a partir de duas integrais. Este modelo também é deduzido a partir da solução da equação de Poisson. A partir da equação de carga e da velocidade de saturação dos portadores, um cálculo da tensão de saturação foi desenvolvido. A tensão efetiva entre fonte e dreno e a tensão de transição entre as formas de condução dos transistores MOS sem junções também são apresentadas neste Capítulo. Também é proposta uma correção para os efeitos de canal curto, obtida através da solução da equação tridimensional de Laplace. O modelo é validado com resultados de simulações numéricas e experimentais para diversas condições de polarização, sendo que as análises também contemplam as derivadas da corrente de dreno. Através da correção 
dos efeitos de canal curto, é possível desenvolver expressões analíticas para o cálculo da dependência da inclinação de sublimiar e da redução da barreira induzida pelo dreno no comprimento de canal dos dispositivos.

No Capítulo 6, a solução da equação de Poisson é utilizada de forma a se obter um modelo analítico para o potencial de superfície nos JNTs. Como os dispositivos estudados são do tipo porta-tripla, o campo elétrico induzido pela porta é bidimensional, de forma que o potencial de superfície não é uniforme. Assim, a solução proposta para o potencial é interpretada como seu valor efetivo. Funções de suavização foram utilizadas como forma de se obter a continuidade do potencial e de sua derivada nas diferentes regiões de operação do dispositivo. A partir do potencial, pode-se obter a carga de condução e consequentemente a corrente de dreno. As correções de efeitos de canal curto são acrescentadas ao modelo, assim como no Capítulo 5, e os efeitos quânticos também são adicionados. Por fim, o modelo é comparado aos resultados simulados e à dispositivos experimentais de canal curto.

$\mathrm{Na}$ sequência do trabalho, a análise do ponto invariante com a temperatura é apresentada no Capítulo 7. Nesta análise, foram utilizados resultados experimentais de dispositivos de diferentes comprimentos de canal. Ao contrário do publicado anteriormente na literatura ${ }^{10}$, é mostrado que os JNTs podem ou não apresentar o ponto invariante com a temperatura, dependendo da resistência série dos dispositivos e da dependência da mesma com a temperatura. A análise é realizada com base na transcondutância máxima, na tensão de limiar e na resistência série extraída dos dispositivos. Também são usadas simulações numéricas nas explicações do funcionamento do dispositivo.

No Capítulo 8, é realizada uma análise da operação em aplicações analógicas dos JNTs, onde parâmetros como ganho de tensão de malha aberta, condutância de saída, transcondutância e razão entre a transcondutância e a corrente de dreno são analisados. São estudados dispositivos de diferentes dimensões e concentração de dopantes.

Por fim, no Capítulo 9 são apresentadas as conclusões obtidas ao longo do trabalho e as propostas de continuidade do mesmo. Grande parte dos resultados obtidos neste trabalho foi publicada em artigos de periódicos ou em anais de congressos conforme descrito no Apêndice A. 


\section{CONCEITOS FUNDAMENTAIS}

Neste capítulo, serão apresentados os transistores MOS fabricados na tecnologia silício-sobre-isolante (Silicon-On-Insulator - SOI), onde será detalhado o modo de funcionamento dos dispositivos, especialmente dos transistores modo acumulação. Também serão abordados os dispositivos de múltiplas portas, especialmente os sem junções, que é o foco deste trabalho. Na sequência, será apresentada a influência da variação da temperatura nos parâmetros elétricos dos transistores e, então, os efeitos quânticos advindos da redução nas dimensões dos dispositivos. Por fim, os parâmetros de um transistor MOS operando como amplificador unitário são apresentados.

\subsection{TECNOLOGIA SOI}

A tecnologia SOI surgiu como uma alternativa à tecnologia convencional (bulk), melhorando as características elétricas dos dispositivos através do isolamento da região ativa da lâmina em relação ao substrato por uma camada de óxido espesso. A presença da camada de dielétrico proporciona a redução das capacitâncias parasitárias e elimina o efeito tiristor parasitário ${ }^{1}$. Os dispositivos SOI podem ser classificados através do modo de funcionamento como modo inversão (ou enriquecimento) ou modo acumulação, que serão detalhados a seguir.

\subsubsection{SOI MOSFET Modo Inversão}

O modo inversão é o modo de funcionamento mais comum para transistores de canal tipo $\mathrm{N}^{1}$, sendo que as características dos dispositivos dependem fortemente da espessura da camada de silício ( $t_{s_{\mathrm{si}}}$ ), da concentração 
de dopantes $\left(\mathrm{N}_{\mathrm{A}}\right)$ e da temperatura $(\mathrm{T})$. Esses três parâmetros definem o tipo do dispositivo, que pode ser totalmente depletado (Fully Depleted - FD), parcialmente depletado (Partially Depleted - PD) ou quase totalmente depletado (Near Fully Depleted - NFD). O perfil transversal de um dispositivo SOI nMOS é apresentado na Figura 2.1, onde são apresentadas as espessuras da camada de silício, do dielétrico de porta ( $\left.t_{o x}\right)$ e do óxido enterrado ( $\left.t_{\text {Box }}\right)$.

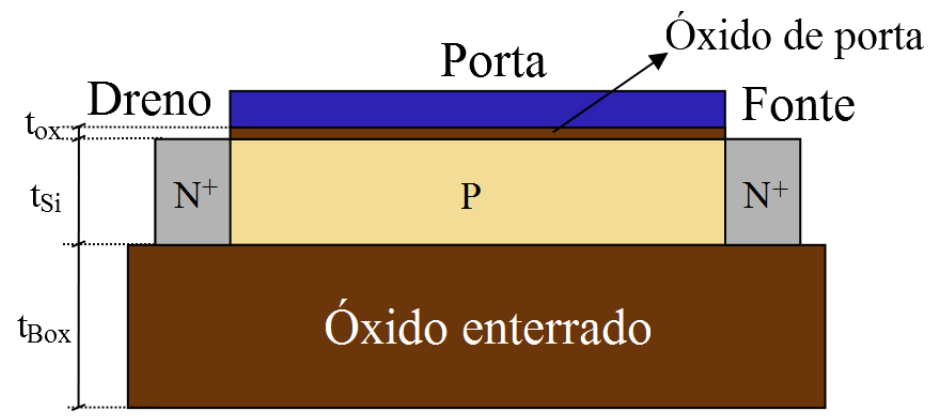

Figura 2.1 - Perfil longitudinal de um dispositivo SOI nMOS modo inversão.

No dispositivo nMOS convencional, a espessura máxima da camada depleção $\mathrm{x}_{\mathrm{dmax}}$ é descrita por ${ }^{18}$ :

$$
x_{\text {dmax }}=\sqrt{\frac{2 \varepsilon_{S i} 2 \Phi_{F}}{q N_{A}}}
$$

onde $\varepsilon_{S i}$ é a permissividade do silício, $q$ é a carga do elétron, $N_{A}$ é a concentração de dopantes aceitadores e $\Phi_{\mathrm{F}}$ é o potencial de Fermi, dado por:

$$
\Phi_{\mathrm{F}}=\frac{\mathrm{kT}}{\mathrm{q}} \ln \left(\frac{\mathrm{N}_{\mathrm{A}}}{\mathrm{n}_{\mathrm{i}}}\right)
$$

onde $k$ é a constante de Boltzmann e $\mathrm{n}_{\mathrm{i}}$ é a concentração intrínseca do silício.

Se a espessura da camada de silício for maior que duas vezes $x_{d m a x}$, não haverá interação entre as regiões de depleção das interfaces região ativa/óxido de porta e região ativa/óxido enterrado. Dessa forma, haverá uma região neutra na camada de silício tipo $P$ entre as regiões de depleção. Esses são os dispositivos parcialmente depletados, também chamados de SOI de camada espessa. A região neutra pode ou não ter contato elétrico. Caso haja contato e 
este esteja aterrado, o dispositivo se comportará como um dispositivo MOS convencional, com a vantagem da redução das capacitâncias de junção. Caso não haja contato da região neutra, o dispositivo apresentará efeitos de corpo flutuante, tais como a elevação abrupta da corrente (Efeito kink) e o efeito bipolar parasitário ${ }^{19}$.

Se a espessura $t_{\mathrm{Si}}$ for menor que $\mathrm{X}_{\mathrm{dmax}}$, haverá uma interação entre as regiões de depleção induzidas pela porta e pelo substrato. O dispositivo estará totalmente depletado para tensão entre porta e fonte $\left(\mathrm{V}_{\mathrm{GS}}\right)$ acima da tensão de limiar $\left(\mathrm{V}_{\mathrm{TH}}\right)$, no caso de um dispositivo nMOS. Esses transistores, também chamados de SOI de camada fina, são os que apresentam as melhores características elétricas quando comparados aos dispositivos MOS convencionais. Entre as vantagens do SOI FD, tem-se a redução do campo elétrico horizontal ${ }^{20}$, a maior mobilidade dos portadores na região de canal ${ }^{21}$, a diminuição dos efeitos de canal curto ${ }^{22}$, menor variação da tensão de limiar com a temperatura ${ }^{23}$, menor inclinação de sublimiar ${ }^{24,25}$, entre outras. As vantagens desse dispositivo estão relacionadas com o menor fator de corpo que, por sua vez, está relacionado às menores capacitâncias parasitárias no SOI FD em relação ao MOS convencional ${ }^{26}$.

Se a espessura da camada de silício for menor que duas vezes $x_{d m a x} e$ maior que $x_{d \max }$, o dispositivo pode se comportar como um totalmente depletado ou um parcialmente depletado, dependendo da tensão aplicada ao substrato ${ }^{1}$. Neste caso, os dispositivos são chamados de quase totalmente depletados.

\subsubsection{SOI MOSFET Modo Acumulação}

O transistor SOI modo acumulação possui dopantes de mesmo tipo tanto na fonte/dreno como no canal. A Figura 2.2 mostra o perfil transversal de um dispositivo modo acumulação canal $P$. Este dispositivo não possui um similar nas tecnologias MOS convencional e SOI de camada espessa, sendo portanto um dispositivo da tecnologia SOI de camada fina. 


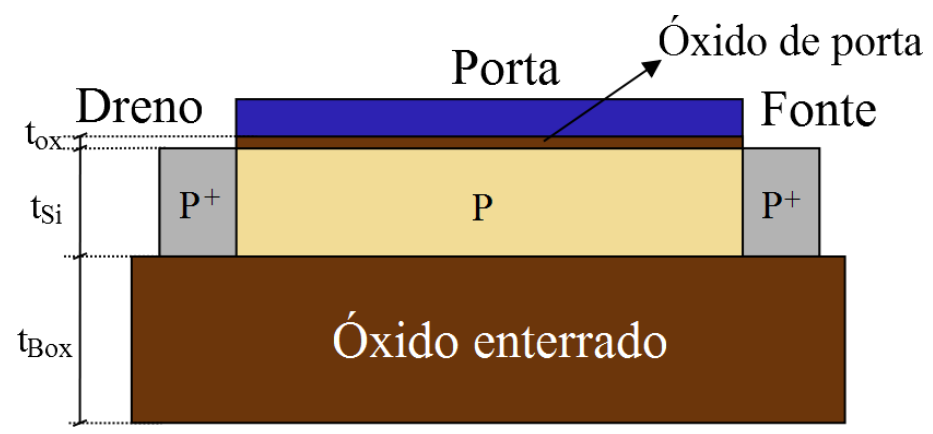

Figura 2.2 - Perfil longitudinal do dispositivo SOI pMOS modo acumulação.

Quando não é aplicada tensão na porta, a diferença entre as funções trabalho do material de porta (geralmente silício policristalino $\mathrm{N}^{+}$) e do silício $\left(\Phi_{\mathrm{MS}}\right)$ e a presença de cargas positivas na interface óxido de porta/silício fazem com que a camada de silício esteja totalmente depletada. Neste caso, não há passagem de corrente entre fonte e dreno. Ao se aplicar uma tensão negativa na porta (considerando um dispositivo pMOS), ocorre a redução da região de depleção, que permite a passagem de corrente entre fonte e dreno. Nesses dispositivos, há dois caminhos para a condução de corrente: o corpo do dispositivo $\left(\mathrm{l}_{\mathrm{b}}\right)$ e uma camada de acumulação $\left(\mathrm{l}_{\mathrm{acc}}\right)$ formada na superfície do silício ${ }^{27,28}$. Devido à presença de mais de uma componente da corrente, o dispositivo apresenta mais de uma tensão de limiar ${ }^{1}$.

Na Figura 2.3 são apresentadas as situações possíveis de condução do dispositivo SOI modo acumulação. No item (A), a camada de silício está totalmente depletada, ou seja, a tensão aplicada entre porta e fonte é menor que a tensão de limiar, logo não há corrente de condução.

Se a tensão aplicada à porta for maior que $\mathrm{V}_{\mathrm{TH}}$, haverá uma redução na camada de depleção, permitindo a passagem de corrente pelo corpo. Caso $V_{G S}$ seja menor que a tensão de faixa plana $\left(\mathrm{V}_{\mathrm{FB}}\right)$, ela não será suficiente para induzir a formação de uma camada de acumulação na superfície. Neste caso, as condições possíveis são as apresentadas nos itens (B) e (D) onde pode ou não ocorrer o pinçamento do corpo, dependendo da tensão aplicada entre dreno e fonte $\left(V_{D S}\right)$.

Caso $V_{G s}$ seja maior que $V_{F B}$, haverá a formação de uma camada de acumulação próxima a fonte que pode ou não se estender até o dreno. Neste caso, as condições possíveis de condução, dependendo de $V_{D S}$, são apresentadas nos itens $(C),(E)$ e $(F)$. Nos itens $(C)$ e $(E)$, não há pinçamento 
do corpo, sendo que em (C) há o pinçamento da camada de acumulação, enquanto em (E) a acumulação ocorre desde a fonte até o dreno. No item $(F)$, ocorre o pinçamento dos dois canais de condução (corpo e camada de acumulação). As equações de corrente para cada uma das regiões de operação são apresentadas por Colinge ${ }^{27}$.

(A)

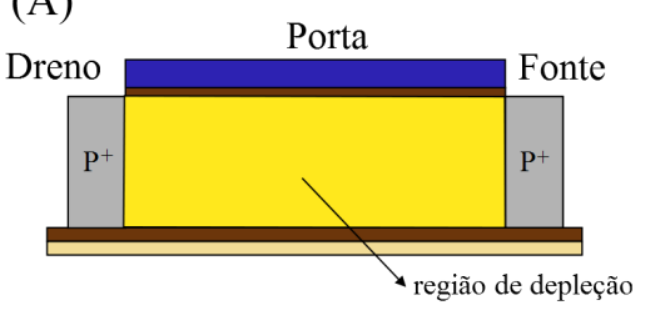

(B)

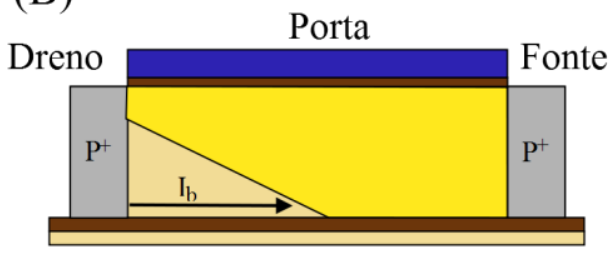

(C)

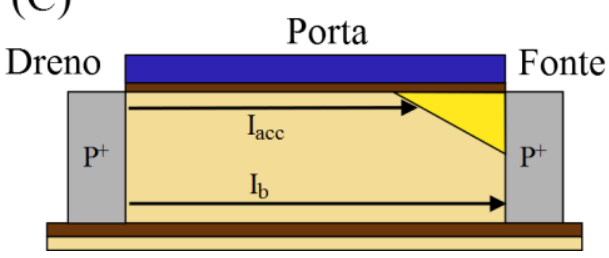

(D)

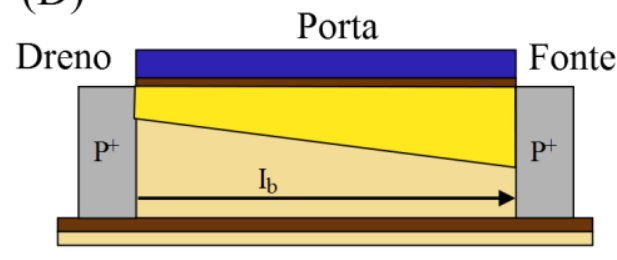

(E)

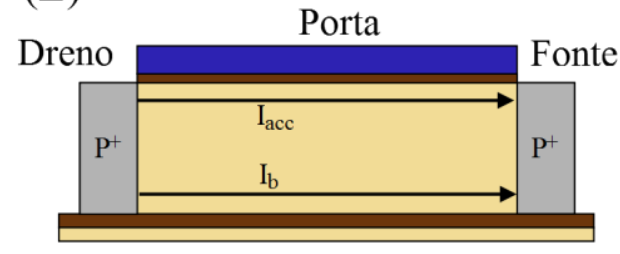

(F)

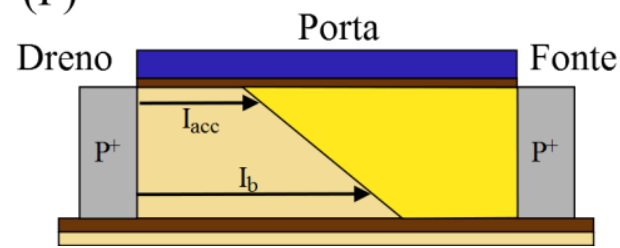

Figura 2.3 - Modos de funcionamento do dispositivo SOI modo acumulação: (A) sublimiar, (B) piçamento do corpo, (C) pinçamento da camada de acumulação, (D) corpo em triodo, (E) corpo e camada de acumulação em triodo e (F) pinçamento do corpo e da camada de acumulação ${ }^{27}$.

\subsection{DISPOSITIVOS DE MÚLTIPLAS PORTAS}

Os dispositivos de múltiplas portas foram desenvolvidos com o objetivo de se minimizar os efeitos de canal curto, permitindo um maior escalamento dos transistores ${ }^{3}$. Há diversos dispositivos de múltiplas portas, como XMOS ${ }^{29}$, DELTA $^{2}$ (Fully Depleted Lean-Channel - Transistor de canal vertical totalmente depletado), FinFET ${ }^{30,31}$, Gate-All-Around (GAA - dispositivo de porta circundante) ${ }^{32}$, porta tripla ${ }^{3}, \pi$-gate ${ }^{33}$, o $\Omega$-gate ${ }^{34}$ e CYNTHIA ${ }^{35}$ (Cylindrical Thin-Pillar Transistor - Transistor cilíndrico vertical). A presença de mais de 
uma porta aumenta o controle eletrostático das cargas na região de canal, reduzindo a influência do campo elétrico do dreno no canal e, portanto, reduzindo os efeitos de canal curto.

A Figura 2.4 mostra um dispositivo de porta tripla, que é constituído de uma fina camada de silício ( fin) envolta por óxido e material de porta sobre uma camada de óxido enterrado. Nesta figura estão indicados o comprimento de canal (L), a largura do fin $\left(\mathrm{W}_{\mathrm{Fin}}\right)$, a altura do fin $\left(\mathrm{H}_{\text {Fin }}\right)$, as espessuras do óxido de porta e do óxido enterrado.

Nos dispositivos de múltiplas portas, ocorre a formação de múltiplos canais de inversão, fazendo com que estes dispositivos conduzam uma maior quantidade de corrente por unidade de área de silício, quando comparados à um dispositivo planar. A corrente do dispositivo é, de forma geral, proporcional à quantidade de portas do dispositivo ${ }^{3}$. Assim, um dispositivo porta tripla teria 0 triplo de corrente de um dispositivo planar de dimensões similares. No entanto, a mobilidade nos canais de inversão formados no topo e nas laterais não é a mesma, pois a mobilidade depende da orientação cristalográfica ${ }^{36}$. Assim, temse que, usualmente, a superfície do topo da lâmina apresenta orientação $<100>$ enquanto as laterais apresentam orientação <110>, sendo que a mobilidade na primeira orientação é maior que na segunda, fazendo com que a corrente nas laterais seja menor que no topo para a mesma condição de polarização $^{37}$.

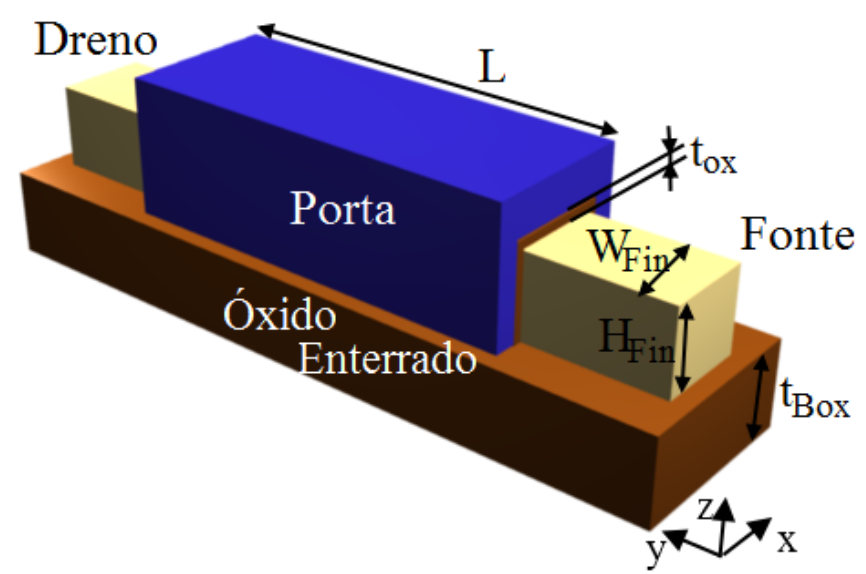

Figura 2.4 - Estrutura dos Dispositivos de Porta Tripla.

Para se aumentar a corrente de dreno $\left(I_{D}\right)$ nos dispositivos de múltiplas portas, utiliza-se a estrutura multi-fins ou multi-dedos ${ }^{3}$, onde um dispositivo é composto de diversos fins em paralelo, conforme apresentado pelo perfil 
transversal do dispositivo na Figura 2.5. Para que a estrutura multi-dedos seja vantajosa, a corrente nesta estrutura normalizada pelo período da mesma (distância entre dois nanofios consecutivos) deve ser maior que a corrente de um dispositivo planar de mesmas dimensões ${ }^{3}$.

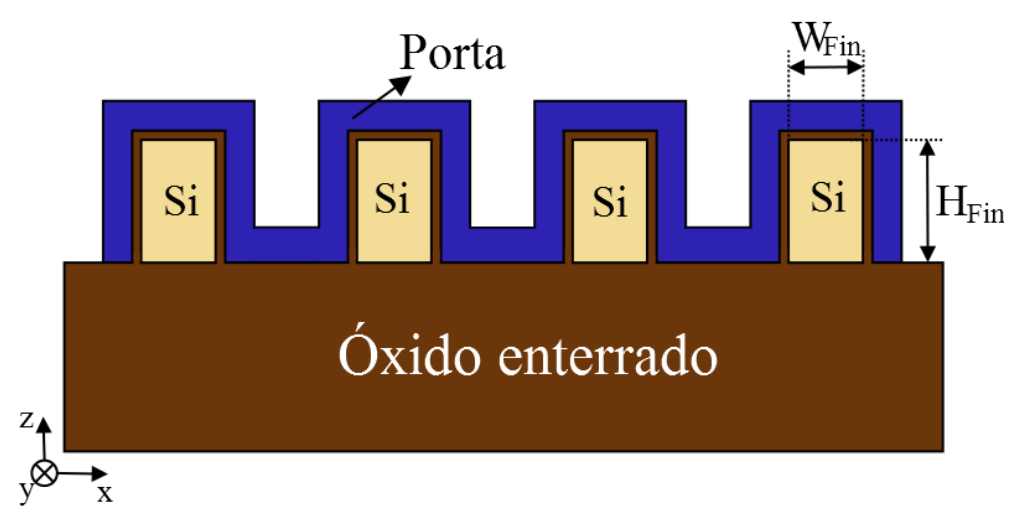

Figura 2.5 - Estrutura multi-fins ou multi-dedos

Como mencionado, a porta envolve a fina camada de silício. Dessa forma, os cantos superiores do canal sofrem influência tanto do campo elétrico lateral como do campo elétrico vertical, apresentando uma maior resultante de campo elétrico. Em um dispositivo modo inversão, a quantidade de portadores minoritários atraídos nos cantos será maior que nas partes planas da interface óxido/silício. Isso pode resultar em tensões de limiar diferentes entre as superfícies planas e os cantos ${ }^{38,39}$.

Se os dispositivos apresentarem largura $\mathrm{W}_{\text {Fin }}$ ou altura $\mathrm{H}_{\text {Fin }}$ (ou ambos) bem reduzidas (menores que $10 \mathrm{~nm}$ ), os portadores ficarão confinados quanticamente ${ }^{3}$. Um dos efeitos decorrente do confinamento é a inversão de volume ${ }^{40}$. Para modelar esses efeitos, deve-se resolver a equação de Schrödinger juntamente com a equação de Poisson ${ }^{41}$. Os efeitos de confinamento quântico serão tratados mais detalhadamente no item 2.5.

\subsubsection{Transistor MOS Sem Junções}

A crescente miniaturização dos dispositivos para comprimentos menores que $20 \mathrm{~nm}$ faz com que o processo de fabricação das junções de fonte e dreno com o canal seja complexo. Devido ao comprimento reduzido de canal, as junções de fonte e dreno devem ser abruptas, de forma que a concentração de 
dopantes varie diversas ordens de grandeza em poucos nanômetros. Recentemente, uma estrutura de múltiplas portas foi proposta de forma a evitar esse problema: o dispositivo MOS sem Junções (Junctionless Nanowire Transistor - JNT) ${ }^{5}$.

A Figura 2.6 apresenta o corte longitudinal para os dispositivos nMOS sem junções e porta tripla modo inversão. Pode-se ver que o JNT apresenta perfil constante de concentração de dopantes desde a fonte até o dreno e que o tipo de dopantes no canal varia, sendo silício tipo N para o JNT e silício tipo P para o modo inversão. No dispositivo sem junções nMOS, o material de porta usualmente é o silício policristalino tipo $\mathrm{P}$ ou um Midgap (material que apresenta função trabalho próxima à do silício intrínseco) e o canal possui uma concentração de dopantes doadores $\left(\mathrm{N}_{\mathrm{D}}\right)$ alta $\left(\sim 10^{19} \mathrm{~cm}^{-3}\right)^{4}$. Em todas as simulações numéricas utilizadas neste trabalho, o silício policristalino é utilizado como material de porta. Já o dispositivo modo inversão apresenta baixa concentração de dopantes aceitadores no canal $\left(\sim 10^{15} \mathrm{~cm}^{-3}\right)$ e usualmente um material Midgap na porta ${ }^{42}$. Esses valores de concentração de dopantes e o material de porta são definidos de forma a ser obter uma tensão de limiar adequada ( 0,4-0,6V). A concentração de dopantes no JNT deve ser suficientemente alta de forma a permitir uma corrente de corpo considerável e também deve permitir a depleção total da camada de silício na condição de sublimiar. $\mathrm{O}$ valor alto de $\mathrm{N}_{\mathrm{D}}$ também diminui o efeito da variação aleatória dos dopantes relacionado à natureza discreta da distribuição dos dopantes ${ }^{4}$. No entanto, como a concentração de dopantes é menor que aquela das regiões de fonte e dreno dos dispositivos modo inversão, há uma maior influência da resistência série nos JNTs ${ }^{43}$.

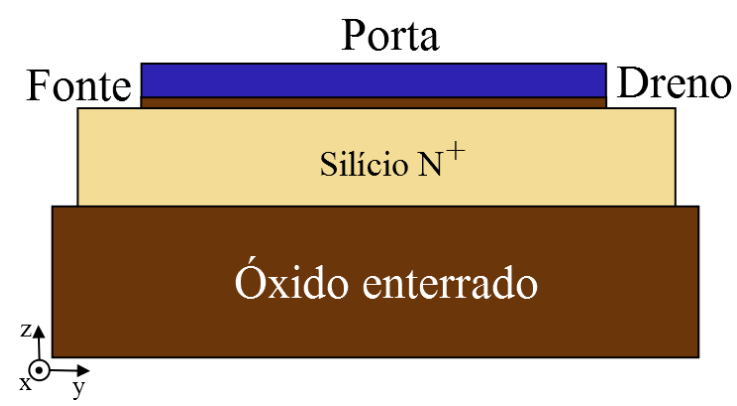

(A)

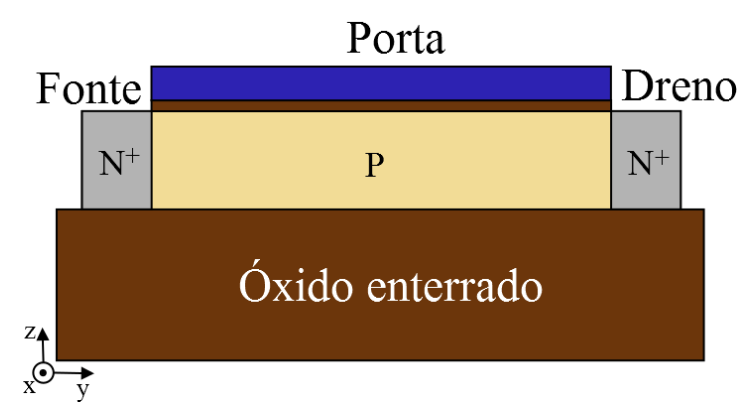

(B)

Figura 2.6 - Corte longitudinal dos dispositivos nMOS JNT e porta tripla modo inversão. 
O modo de funcionamento do JNT é similar ao do dispositivo SOI modo acumulação, no entanto, ele não pode ser considerado modo acumulação pois a maior parte da condução ocorre no corpo e não pela camada superficial de acumulação ${ }^{44}$. A diferença entre a função trabalho do material de porta e da camada de silício é grande ( 0,5-1V) fazendo com que toda a camada de silício esteja depletada quando a porta não é polarizada. Dessa forma, não haverá portadores livres que possibilitem a formação de um canal de condução. Se uma tensão positiva for aplicada à porta do JNT, a camada de depleção terá sua profundidade reduzida, havendo portanto uma região que não está depletada. Assim, haverá condução entre fonte e dreno por meio dessa região não depletada. Se a tensão na porta for suficientemente positiva de modo que toda a camada de silício deixe a depleção, tem-se início a acumulação de elétrons na superfície (no caso do nMOS).

A Figura 2.7 apresenta as curvas do logaritmo da corrente de dreno (ID) versus a tensão entre porta e fonte para os dispositivos modo inversão $(A)$, modo acumulação (B) e JNT (C). Pode-se notar que no JNT a diferença entre a tensão de faixa plana e a tensão de limiar é maior que no dispositivo modo acumulação. Assim, a maior parte da condução do JNT ocorre no regime de depleção parcial onde há apenas a componente da corrente de corpo.

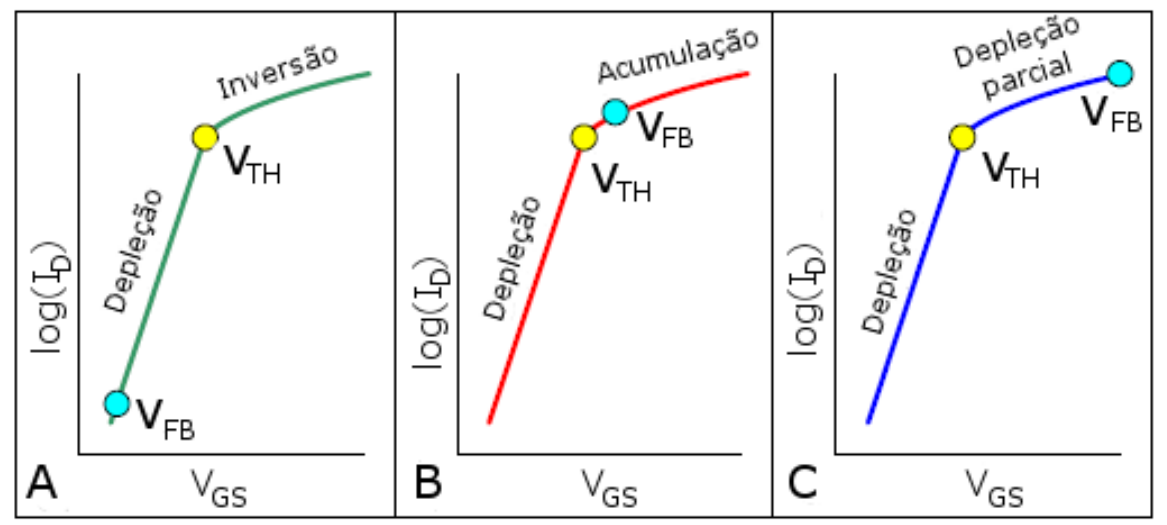

Figura 2.7 - Comparação das curvas do logaritmo da corrente de dreno versus a tensão entre porta e fonte para os dispositivos modo inversão (A), modo acumulação (B) e JNT (C) ${ }^{44}$.

\subsubsection{Funcionamento dos Transistores MOS Sem Junções}

Neste tópico, será detalhado o funcionamento do dispositivo MOS sem junções, juntamente com algumas considerações que serão utilizadas na 
modelagem desse dispositivo nos próximos capítulos. A Figura 2.8 apresenta os diagramas de banda de energia na direção do comprimento de canal para um nMOS JNT para diversas condições.

Na Figura 2.8 (A), tem-se o diagrama no centro do dispositivo para uma baixa tensão entre dreno e fonte $\left(V_{D S}\right)$ (dispositivo operando em triodo) e uma tensão $V_{G S}$ menor que a tensão de limiar. Na Figura 2.8 (C) tem-se o diagrama na superfície do dispositivo na mesma condição de polarização. Pode-se notar nessas figuras que a tensão aplicada à porta juntamente com a diferença de função trabalho entre o material de porta e o silício gera uma barreira de potencial no canal, de forma que os elétrons presentes na fonte só podem se mover em direção ao dreno por meio de difusão. O potencial na condição de sublimiar é menor (mais negativo) na superfície do dispositivo em relação ao centro do mesmo.

Na Figura 2.8 (B), é apresentado o diagrama no centro do dispositivo, para uma tensão de porta maior que a tensão de limiar. Neste caso, pode-se observar que o potencial no começo do canal (nas proximidades da fonte) é o mesmo potencial da fonte, justamente por causa da ausência de junção. Assim, uma forma de se definir a tensão de limiar nestes dispositivos consiste na menor tensão de porta (para um nMOS) que faz com que o potencial no centro do dispositivo nas proximidades da fonte seja o mesmo da fonte. Considerando que a fonte esteja aterrada, este potencial é zero. Esta definição de tensão de limiar será usada no Capítulo 3 na modelagem da tensão de limiar.

Pode-se observar ainda na Figura 2.8 (B) que não há mais nenhuma barreira de potencial entre fonte e dreno, sendo que os elétrons (no nMOS) fluem da fonte para o dreno através da deriva. Assim, diferentes formas de condução dominam $I_{D}$ nas regiões de sublimiar e acima do limiar, sendo que na primeira a condução ocorre por difusão enquanto na segunda ocorre por deriva. Dessa forma, pode-se considerar que a transição entre sublimiar e acima do limiar ocorre quando as componentes de deriva ( $\left.I_{\text {Der }}\right)$ e difusão ( $\left.I_{\text {Dif }}\right)$ da corrente de dreno possuem a mesma magnitude. Esta transição que representa o limiar será analisada no Capítulo 4, onde é discutido um método de extração da tensão de limiar nestes dispositivos. 
Baixo VDS

Potencial no centro do dispositivo Potencial na superficie do dispositivo

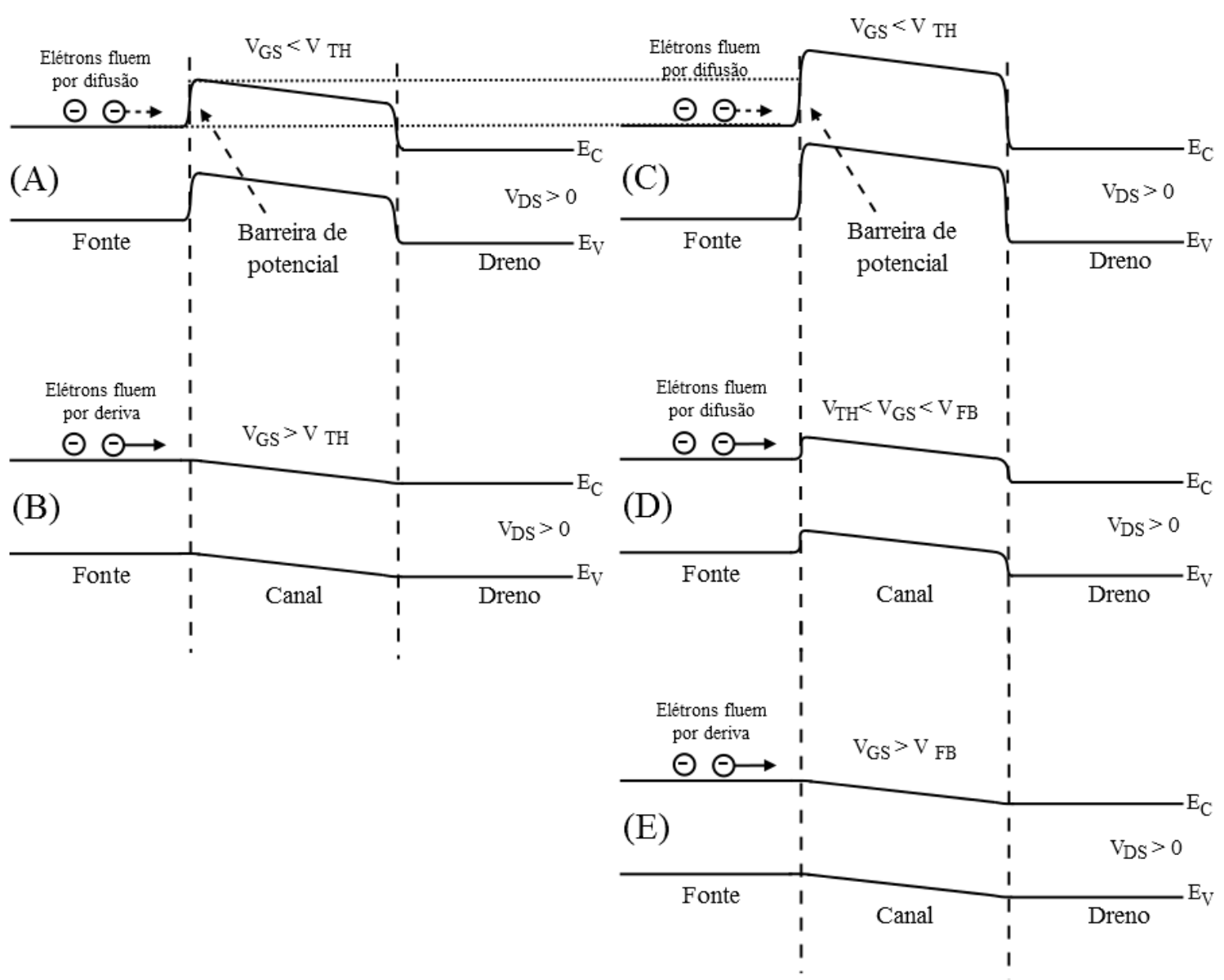

Alto VDS

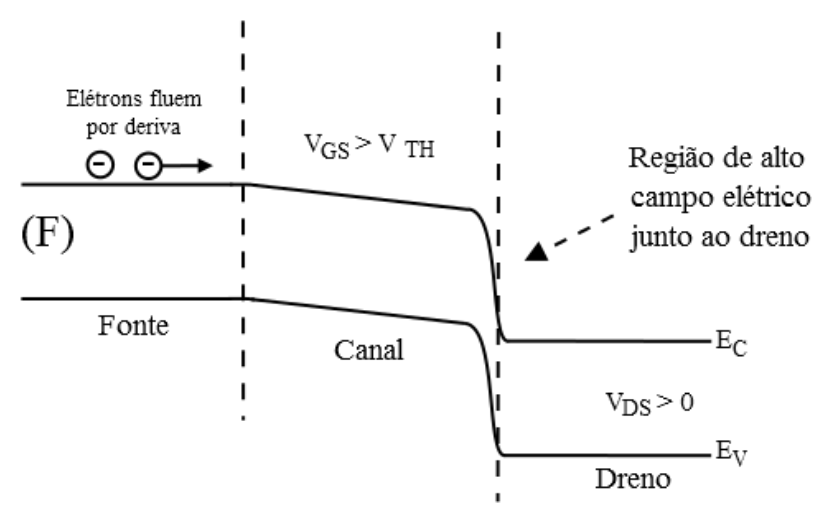

Figura 2.8 - Diagrama de faixa de energia ao longo do dispositivo sem junções nMOS no centro do canal para $\mathrm{V}_{\mathrm{GS}}$ abaixo $(\mathrm{A})$ e acima do limiar (B), na superfície para $\mathrm{V}_{\mathrm{GS}}<\mathrm{V}_{\mathrm{TH}}(\mathrm{C})$, $V_{T H}<V_{G S}<V_{F B}(D), V_{G S}>V_{F B}(E)$ e para alto $V_{D S}(F)$.

Na Figura 2.8 (D), é mostrado o diagrama na superfície do dispositivo, considerando que a tensão de porta esteja entre as tensões de limiar e a 
tensão de faixa plana. Neste caso, pode-se observar que ainda existe uma barreira de potencial na superfície de modo que não há condução na mesma. Assim, a condução de corrente no JNT começa no centro do dispositivo e vai em direção das interfaces ao se aumentar a tensão de porta. A Figura 2.8 (E) considera que a tensão aplicada à porta é maior que a tensão de faixa plana. Neste caso, o potencial de superfície passa a ser o mesmo que o potencial no centro do dispositivo. Ao se aumentar a tensão de porta acima da faixa plana, ocorre a formação de uma camada de acumulação na superfície e o potencial na mesma passa a ter uma dependência logarítmica com a tensão de porta ${ }^{45}$.

A Figura $2.8(F)$ apresenta o diagrama de faixa de energia no centro do dispositivo para uma tensão de porta acima do limiar, considerando que uma tensão alta é aplicada ao dreno (dispositivo em saturação). Esta tensão gera uma região de depleção nas proximidades do dreno. Portanto, para alto $\mathrm{V}_{\mathrm{DS}}$, há uma região com ausência de cargas móveis e alto campo elétrico lateral assim como nos dispositivos MOS convencionais. Dessa forma, haverá uma tensão de saturação ( $\left.V_{\text {Dsat }}\right)$ a partir da qual a corrente de dreno se mantém praticamente constante, exceto pela modulação do comprimento de canal. Para o cálculo desta tensão de saturação pode-se utilizar a velocidade de saturação $\left(\mathrm{v}_{\mathrm{sat}}\right)$ dos portadores, conforme será apresentado no Capítulo 5.

Na Figura 2.9, é apresentado o corte longitudinal de um dispositivo MOS sem junções, considerando que certas tensões $V_{G s}$ e $V_{D S}$ são aplicadas à porta e ao dreno, respectivamente. Na região entre $0 \leq y \leq A$, haverá condução tanto pelo corpo do dispositivo como por uma camada de acumulação formada na superfície. Já na região entre $A<y \leq B$, haverá apenas condução pelo corpo. $O$ ponto A representa o limite da camada de acumulação que é obtido quando a tensão no canal $V_{Y}$ for $V_{Y}=V_{G S}-V_{D S}-\Phi_{M S}$. Assim, quanto maior for a tensão de dreno, menor será $V_{Y}$ e, portanto, mais perto da fonte estará o ponto $A$. Se $V_{Y}$ obtido pela expressão for menor que $0\left(V_{G S}-V_{D S}-\Phi_{M S}<0\right)$, haverá depleção no canal inteiro. Se for maior que a tensão aplicada ao dreno, indica que ocorre a formação de uma camada acumulação no canal inteiro. Na figura, $\mathrm{Q}_{1}$ é a soma das densidades de carga fixa e da camada de acumulação por unidade de comprimento na região entre 0 e $A$. Já $Q_{2}$ é a densidade de carga fixa na região entre $A$ e $B$. Pode-se ainda notar que caso o ponto $B$ seja menor que $L$, haverá um pinçamento no centro do canal. $A$ tensão no ponto $B$ é a 
tensão efetiva entre fonte e dreno que está limitada à tensão de saturação. Qualquer incremento na tensão de dreno acima da tensão de saturação aumenta a queda de tensão na região de depleção entre canal e dreno, mas não afeta o potencial no canal.

Pode-se ressaltar ainda que, como as regiões de fonte e dreno apresentam a mesma concentração de dopantes do canal, que é menor que a concentração utilizada nas formações de fonte e dreno de dispositivos modo inversão, é esperada uma maior resistência série $\left(R_{S}\right)$ nesses dispositivos ${ }^{46}$.

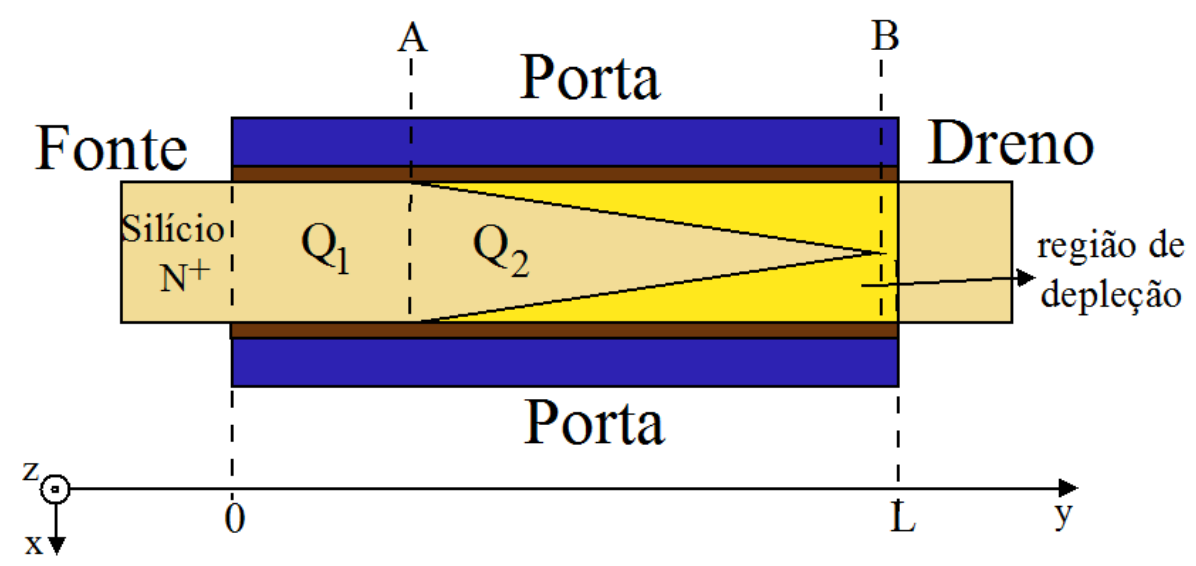

Figura 2.9 - Corte longitudinal de um dispositivo nMOS sem junções considerando que as tensões $\mathrm{V}_{\mathrm{GS}} \mathrm{e} \mathrm{V}_{\mathrm{DS}}$ são aplicadas à porta e ao dreno do dispositivo, respectivamente.

\subsection{TENSÃO DE LIMIAR}

A tensão de limiar em um dispositivo MOS convencional pode ser definida como a tensão aplicada à porta que forma um canal de inversão com uma concentração de portadores minoritários igual à de portadores majoritários no substrato ${ }^{18}$. Essa condição ocorre para um potencial de superfície de aproximadamente $2 \Phi_{\mathrm{F}}{ }^{18}$. Para um dispositivo MOS convencional e para o SOI parcialmente depletado, a tensão de limiar é dada por ${ }^{47}$ :

$$
V_{T H}=\Phi_{M S}-\frac{Q_{o x}{ }^{\prime}}{C_{o x}{ }^{\prime}}+2 \Phi_{F}+\frac{q N_{A} x_{d m a x}}{C_{o x}{ }^{\prime}}+\frac{2 q N_{i t} \Phi_{F}}{C_{o x}{ }^{\prime}}
$$


onde $\mathrm{Q}_{\mathrm{ox}}$ 'é a densidade de cargas fixas no óxido por unidade de área, $\mathrm{N}_{\mathrm{it}}$ é a densidade de armadilhas de interface por unidade de área e $\mathrm{C}_{0 x}$ ' é a capacitância do óxido de porta por unidade de área descrita por $\mathrm{C}_{\mathrm{ox}}{ }^{\prime}=\varepsilon_{\mathrm{ox}} / \mathrm{t}_{\mathrm{ox}}$, sendo $\varepsilon_{o x}$ é a permissividade do óxido de porta.

Em dispositivos com concentração de dopantes intrínseca, a definição clássica da tensão de limiar relacionada com o potencial de Fermi passa a não ter mais um significado físico ${ }^{48}$. Neste caso, outras definições de $\mathrm{V}_{\mathrm{TH}}$ devem ser utilizadas como a igualdade entre as componentes de deriva e de difusão da corrente ${ }^{49,50}$ ou a relação entre capacitâncias ${ }^{3,51}$.

A tensão de limiar em um dispositivo porta dupla com concentração de dopantes intrínseca baseado na relação de capacitâncias pode ser descrita por 51 :

$$
\mathrm{V}_{\mathrm{TH}}=\Delta \phi_{\mathrm{mi}}+\frac{\mathrm{kT}}{\mathrm{q}} \ln \left(\frac{2 \mathrm{C}_{\mathrm{ox}}{ }^{\prime} \mathrm{kT}}{\mathrm{q}^{2} \mathrm{n}_{\mathrm{i}} \mathrm{W}_{\mathrm{Fin}}}\right)+\frac{\pi^{2} \hbar^{2}}{2 \mathrm{qm}^{*} \mathrm{~W}_{\mathrm{Fin}}{ }^{2}}
$$

onde $\Delta \phi_{\mathrm{mi}}$ é a diferença de função trabalho entre o material de porta e o silício intrínseco, $\mathrm{m}^{*}$ é a massa de confinamento do portador na direção transversal e $\hbar$ é a constante de Planck normalizada.

De forma geral, o objetivo da tensão de limiar é definir uma certa tensão de porta a partir da qual se considera que o dispositivo esteja conduzindo. Nos dispositivos MOS sem junções, a tensão de limiar é a tensão de porta a partir da qual haverá a redução da camada de depleção, possibilitando a condução de corrente pelo corpo. O conceito de tensão de limiar em JNTs é revisto no Capítulo 3.

A tensão de limiar nos dispositivos sem junções apresenta uma grande dependência com as características físicas dos dispositivos (concentração de dopantes e dimensões), conforme demonstrado por Colinge et al. ${ }^{4}$ e por Kranti et al. ${ }^{44}$. A Figura 2.10, adaptada de Kranti et al. ${ }^{44}$, apresenta a tensão de limiar em JNTs em função da altura e da largura do fin, através da qual se pode notar que $\mathrm{V}_{\mathrm{TH}}$ varia entre $0 \mathrm{~V}$ e $0,7 \mathrm{~V}$ ao se variar $\mathrm{H}_{\text {Fin }}$ e/ou $\mathrm{W}_{\text {Fin }}$ entre $4 \mathrm{~nm}$ e $10 \mathrm{~nm}$. 


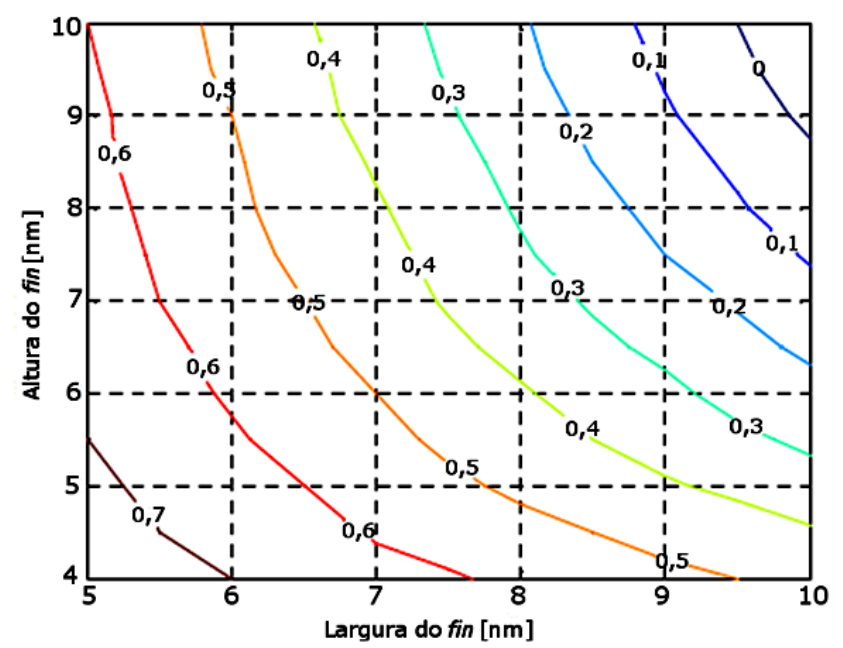

Figura 2.10 - Tensão de limiar em função da altura e da largura do fin para dispositivos sem junções com $\mathrm{N}_{\mathrm{D}}=5 \times 10^{19} \mathrm{~cm}^{-3}$ e $\mathrm{t}_{\mathrm{ox}}=0,5 \mathrm{~nm}^{44}$.

Embora esta variação possa representar um problema, uma vez que pequenas variações nas características dos dispositivos podem ocasionar mudanças significativas na tensão de limiar, o projeto de circuitos analógicos e digitais pode ser mais vantajoso devido à flexibilidade de $\mathrm{V}_{\mathrm{TH}}$. Por exemplo, uma associação série assimétrica com dispositivos de diferentes larguras, e consequentemente diferentes tensões de limiar, pode ser utilizada como forma de melhorar o desempenho destes dispositivos em aplicações analógicas ${ }^{52}$.

\subsection{EFEITOS DA REDUÇÃO DA TEMPERATURA}

A redução da temperatura causa diversos efeitos nas propriedades físicas dos semicondutores e nos parâmetros elétricos dos dispositivos, conforme apresentados a seguir.

\subsubsection{Propriedades Físicas}

A concentração intrínseca de portadores em um material semicondutor depende apenas do material e da temperatura. Ela representa a quantidade de portadores livres gerados por excitação térmica. Na temperatura de zero absoluto $(0 \mathrm{~K})$, não há energia térmica suficiente para a geração de pares elétron-lacuna, não havendo portanto portadores livres. Ao se aumentar a 
temperatura, elétrons ganham energia suficiente para que ocorra a geração de pares elétron-lacuna, aumentando a concentração intrínseca de portadores, que é descrita por ${ }^{17}$ :

$$
n_{i}=\sqrt{N_{C} \cdot N_{V}} \cdot \exp \left(\frac{-E_{G}}{2 k T}\right)
$$

onde $N_{C}$ e $N_{V}$ são as densidades de estados nas bandas de condução e de valência, respectivamente, e $E_{G}$ é a altura da banda proibida do semicondutor.

As densidades de estados $\mathrm{N}_{C}$ e $\mathrm{N}_{V}$ são dadas por ${ }^{53}$ :

$$
\begin{aligned}
& \mathrm{N}_{\mathrm{C}}=2\left(\frac{2 \pi \mathrm{m}_{\mathrm{de}}{ }^{*} \mathrm{~m}_{0} \mathrm{kT}}{\mathrm{h}^{2}}\right)^{3 / 2} \\
& \mathrm{~N}_{\mathrm{v}}=2\left(\frac{2 \pi \mathrm{m}_{\mathrm{dh}}{ }^{*} \mathrm{~m}_{0} \mathrm{kT}}{\mathrm{h}^{2}}\right)^{3 / 2}
\end{aligned}
$$

onde $m_{d e}{ }^{*} e m_{d h}{ }^{*}$ são as massas efetivas das densidades de estados para elétrons e lacunas ${ }^{53}$, respectivamente, $m_{0}$ é a massa do elétron e $\mathrm{h}$ é a constante de Planck.

A largura da faixa proibida pode ser descrita por ${ }^{54}$ :

$$
E_{G}=E_{G}(0)-\frac{\alpha_{E g} T^{2}}{\beta_{E g}+T}
$$

onde $\alpha_{E g}$ e $\beta_{E g}$ são parâmetros do material, definidos como $\alpha_{E g}=4,73 \times 10^{-4}$ $\mathrm{eV} / \mathrm{K}$ e $\beta_{\mathrm{Eg}}=636 \mathrm{~K}$ e $\mathrm{E}_{\mathrm{G}}(0)$ é a altura da banda proibida em $0 \mathrm{~K}$ definido como $1,17 \mathrm{eV}^{54}$. Esses valores são válidos para o silício.

A Figura 2.11 apresenta a variação da concentração intrínseca de portadores e da altura da banda proibida em função da temperatura no intervalo de $50 \mathrm{~K}$ a $400 \mathrm{~K}$. Os valores apresentados na figura foram obtidos através das equações (2.5) e (2.8). Pode-se perceber que com a redução de $T$, $n_{i}$ diminui diversas ordens de grandeza, enquanto $E_{G}$ tem um leve incremento. 


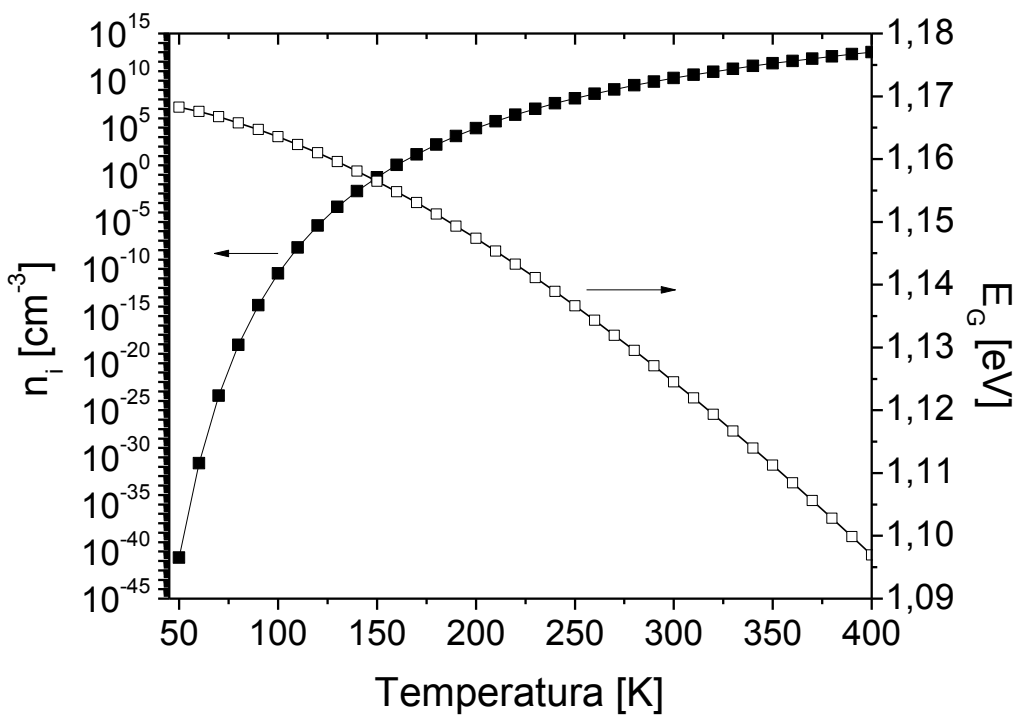

Figura 2.11 - Concentração intrínseca de portadores e largura de faixa proibida em função da temperatura para o silício.

Em um semicondutor dopado, a redução da temperatura faz com que a energia térmica disponível não seja capaz de ionizar todas as impurezas ${ }^{53}$. Dessa forma, apenas uma fração da concentração de dopantes, $N_{A}$ ou $N_{D}$, dependendo do tipo do semicondutor, será ionizada.

Um modelo para a concentração de impurezas aceitadoras ionizadas $\left(\mathrm{N}_{\mathrm{A}}{ }^{-}\right)$é dado por ${ }^{53}$.

$$
\mathrm{N}_{\mathrm{A}}^{-}=\frac{\mathrm{N}_{\mathrm{A}}}{1+\mathrm{g}_{\mathrm{A}} \exp \left(\frac{\mathrm{E}_{\mathrm{A}}-\mathrm{E}_{\mathrm{Fp}}}{\mathrm{kT}}\right)}
$$

Para impurezas doadoras ionizadas $\left(\mathrm{N}_{\mathrm{D}}{ }^{+}\right)$é descrito por:

$$
\mathrm{N}_{\mathrm{D}}^{+}=\frac{\mathrm{N}_{\mathrm{D}}}{1+g_{\mathrm{D}} \exp \left(\frac{\mathrm{E}_{\mathrm{Fn}}-\mathrm{E}_{\mathrm{D}}}{\mathrm{kT}}\right)}
$$

onde $E_{A}$ e $E_{D}$ são as energias de ativação das impurezas aceitadoras e doadoras, respectivamente, $E_{f n}$ e $E_{f p}$ são os níveis de Fermi para os elétrons e para as lacunas ${ }^{55}$ e $_{\mathrm{A}}$ e $\mathrm{g}_{\mathrm{D}}$ valem respectivamente 4 e $2^{53}$. 
Ao se aumentar a concentração de dopantes no semicondutor, este modelo prevê uma diminuição na percentagem de impurezas ionizadas. Esta redução é válida até uma concentração de dopantes de aproximadamente $10^{18}$ $\mathrm{cm}^{-3}{ }^{56}$, chamada de transição de Mott (Mott transition) ${ }^{57}$, a partir da qual o semicondutor se comporta como um metal. Para concentrações de dopantes maiores, a percentagem de impurezas ionizadas aumenta até atingir a ionização completa das impurezas para concentrações acima de $10^{20} \mathrm{~cm}^{-3}$. A fim de se prever adequadamente a ionização incompleta das impurezas, podese utilizar as equações (2.9) e (2.10) conforme descrito por Altermatt et al. ${ }^{58,59}$ onde $g_{A}, g_{D}, E_{A}$ e $E_{D}$ são considerados em função da concentração de dopantes sendo descritos pelas equações:

$$
\begin{aligned}
& g_{D}=\frac{b_{D}}{g+\left(1-b_{D}\right) N_{D} / n_{1}} \\
& g_{A}=\frac{b_{A}}{g+\left(1-b_{A}\right) N_{A} / p_{1}}
\end{aligned}
$$

onde $b_{D}=\left[1+\left(N_{D} / N_{b}\right)^{d}\right]^{-1}, b_{A}=\left[1+\left(N_{A} / N_{b}\right)^{d}\right]^{-1}$ e $d, N_{b}$ e $g$ são parâmetros que dependem da impureza. Os parâmetros $n_{1}$ e $p_{1}$ são descritos por ${ }^{60}$ :

$$
\begin{aligned}
& \mathrm{n}_{1}=\mathrm{N}_{\mathrm{C}} e^{-\mathrm{E}_{\mathrm{D}} / k T} \\
& \mathrm{p}_{1}=\mathrm{N}_{\mathrm{V}} e^{-\mathrm{E}_{\mathrm{A}} / \mathrm{kT}}
\end{aligned}
$$

As energias de ativação são dadas por:

$$
\begin{gathered}
E_{D}=\frac{E_{\text {dop }, 0}}{1+\left(\frac{N_{D}}{N_{\text {ref }}}\right)^{c}} \\
E_{A}=\frac{E_{\text {dop }, 0}}{1+\left(\frac{N_{A}}{N_{\text {ref }}}\right)^{c}}
\end{gathered}
$$

onde $\mathrm{E}_{\mathrm{dop}, 0}, \mathrm{~N}_{\text {ref }}$ e c são parâmetros que dependem da impureza. 
Os parâmetros $\mathrm{E}_{\mathrm{dop}, 0}, \mathrm{~N}_{\text {ref }}, c, \mathrm{~N}_{\mathrm{b}}, d$ e $g$ para silício dopado com boro, arsênio ou fósforo são apresentados na Tabela $2.1^{58,59}$.

Tabela 2.1 - Parâmetros utilizados para o cálculo da ionização incompleta para o caso de silício dopado com boro, arsênio ou fósforo 58,59

\begin{tabular}{|l|l|l|l|}
\hline Parâmetro & Boro & Arsênio & Fósforo \\
\hline $\mathrm{E}_{\text {dop }, 0}[\mathrm{meV}]$ & 44,39 & 53,70 & 45,50 \\
\hline $\mathrm{N}_{\text {ref }}\left[\mathrm{cm}^{-3}\right]$ & $1,3 \times 10^{18}$ & $3,0 \times 10^{18}$ & $2,2 \times 10^{18}$ \\
\hline$c$ & 1,4 & 1,5 & 2,0 \\
\hline $\mathrm{N}_{\mathrm{b}}\left[\mathrm{cm}^{-3}\right]$ & $4,5 \times 10^{18}$ & $9,0 \times 10^{18}$ & $6,0 \times 10^{18}$ \\
\hline$d$ & 2,4 & 1,8 & 2,3 \\
\hline$g$ & $1 / 4$ & $1 / 2$ & $1 / 2$ \\
\hline
\end{tabular}

Para baixos valores de dopagens, as funções $g_{D}$ e $g_{A}$ tendem ao inverso de $g$, valendo 2 e 4, respectivamente, assim como apresentado anteriormente. Para concentrações de dopantes altas $\left(\sim 10^{20} \mathrm{~cm}^{-3}\right), g_{D}$ e $g_{A}$ tendem a zero. $O$ modelo proposto por Altermatt et al. considera que a energia de ativação diminui em função da concentração de dopantes ${ }^{60}$. O modelo também considera que a ionização incompleta é parcialmente compensada por uma fração de portadores que permanecem ligados a clusters (aglomerados) de dopantes acima da transição de Mott ${ }^{58}$.

O potencial de Fermi $\Phi_{\mathrm{F}}$ também apresenta dependência com a temperatura, tanto diretamente através do termo $\mathrm{kT} / \mathrm{q}$ como indiretamente através da concentração intrínseca e da concentração de dopantes. A Figura 2.12 apresenta a percentagem de impurezas ionizadas em função da temperatura, bem como a variação do potencial de Fermi, calculadas pelas equações (2.10) e (2.2). Na figura, são apresentadas as curvas para duas concentrações de dopantes: $10^{15} \mathrm{~cm}^{-3}$ (comumente utilizada em dispositivos modo inversão como FinFETs e de porta tripla) e $10^{19} \mathrm{~cm}^{-3}$ (utilizada nos JNTs).

Pode-se perceber que, para altas concentrações de dopantes, a percentagem de impurezas ionizadas se mantém acima de $90 \%$ para todo o intervalo de temperatura apresentado. Já para a dopagem menor, praticamente não há impureza ionizada para temperaturas abaixo de $50 \mathrm{~K}$. O potencial de 
Fermi sofre uma maior influência da variação da temperatura para concentrações de dopantes mais baixas, sendo que o potencial aumenta com a redução da temperatura devido à redução da concentração intrínseca de portadores.

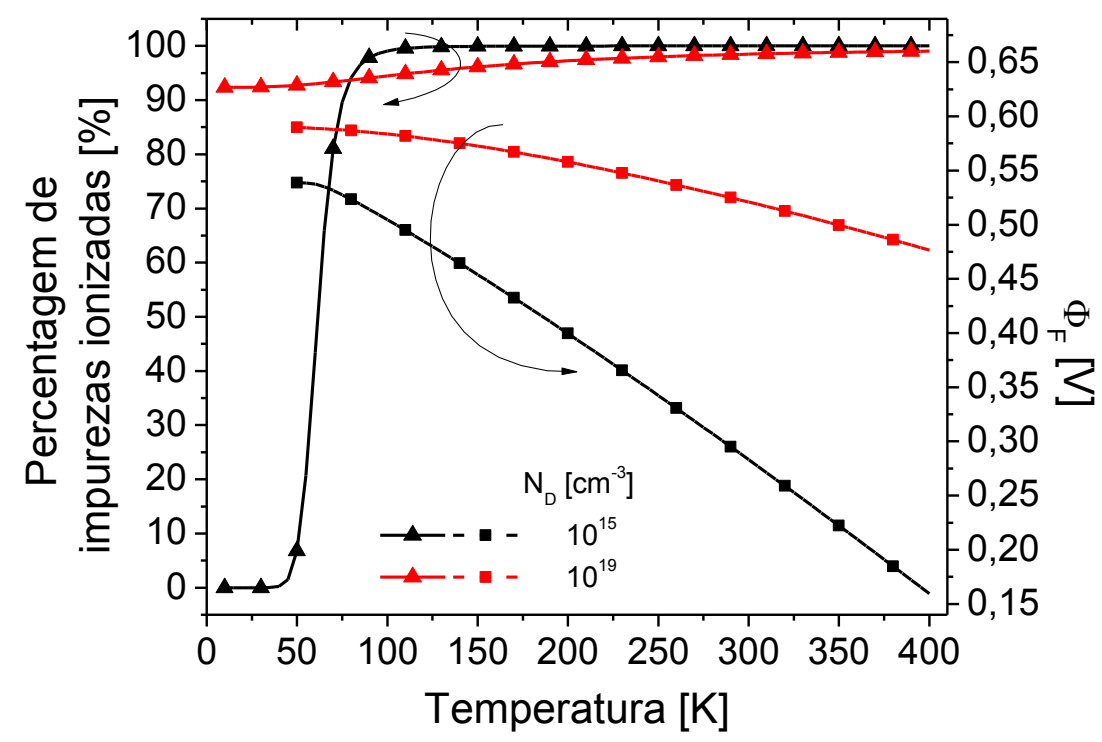

Figura 2.12 - Percentagem de impurezas ionizadas e potencial de Fermi em função da temperatura.

\subsubsection{Parâmetros Elétricos}

Nesta seção serão apresentados os efeitos da redução da temperatura nos principais parâmetros elétricos dos dispositivos.

- Tensão de limiar

A redução da temperatura aumenta o potencial de Fermi conforme visto na Figura 2.12. $O$ aumento de $\Phi_{F}$ juntamente com o aumento da influência das armadilhas de interface faz com que $\mathrm{V}_{\mathrm{TH}}$ seja maior para temperaturas mais baixas. Diferenciando a equação (2.3) em relação à temperatura, pode-se obter que ${ }^{1}$ :

$$
\frac{d V_{T H}}{d T}=\frac{d \Phi_{F}}{d T}\left[1+\alpha_{V_{T}} \frac{q}{C_{o x}}\left(\frac{\varepsilon_{S i} N_{A}}{k T \ln \left(N_{A} / n_{i}\right)}\right)^{1 / 2}+\frac{2 q N_{i t}}{C_{o x}}\right]
$$

onde $\alpha_{V_{t}}=1$. 
Para o dispositivo SOI totalmente depletado, a dependência da tensão de limiar com a temperatura também poderá ser descrita pela equação (2.17), mas com $\alpha_{V_{t}}=0{ }^{1}$. Se a influência das armadilhas de interface for a mesma nos dispositivos SOI FD e MOS convencional, a variação de $\mathrm{V}_{\mathrm{TH}}$ com $\mathrm{T}$ será menor nos transistores $\mathrm{SOI}$ totalmente depletados.

Diferenciando a equação (2.4) em relação a $\mathrm{T}$, pode-se obter a dependência entre $V_{T H}$ e $T$ para dispositivos porta dupla com concentração intrínseca ${ }^{61}$ :

$$
\frac{d V_{T H}}{d T}=-\frac{1}{2} \frac{d E_{G}}{d T}+\frac{k}{q}\left(1+\ln \left(\frac{2 C_{o x}{ }^{\prime} k T}{q^{2} n_{i} W_{\text {Fin }}}\right)-\frac{T}{n_{i}} \frac{d n_{i}}{d T}\right)-\frac{\pi^{2} \hbar^{2}}{2 q W_{\text {Fin }}{ }^{2}\left(m^{*}\right)^{2}} \frac{d m^{*}}{d T}
$$

Apesar da equação (2.18) ser aparentemente complexa, a variação $\mathrm{dV}_{\mathrm{TH}} / \mathrm{dT}$ é aproximadamente linear e menor que a variação obtida para dispositivos SOI totalmente depletados ${ }^{61,62}$.

Já a tensão de limiar nos JNTs apresenta uma dependência com a temperatura maior que os dispositivos de múltiplas portas modo inversão. Essa variação $d V_{T H} / d T$ dos dispositivos sem junções é similar à variação do MOS convencional ${ }^{10,63}$. A análise detalhada da tensão de limiar em dispositivos MOS sem junções, bem como a sua dependência com a temperatura, são apresentadas no Capítulo 3.

- Mobilidade

O movimento dos portadores em um cristal semicondutor é limitado por diversos mecanismos de espalhamento que reduzem a sua mobilidade, como: por fônons ou de rede, por impurezas ionizadas, por impurezas neutras e espalhamento portador-portador. Nesta seção, serão apresentados esses espalhamentos, bem como a sua dependência com a temperatura.

- Espalhamento por fônons ou de rede (lattice scattering - $\mu_{\mathrm{ps}}$ ):

Este mecanismo de espalhamento está relacionado com a interação entre os portadores e as vibrações da rede cristalina. A redução da 
temperatura diminui a vibração da rede cristalina, aumentando a mobilidade. Um modelo para o cálculo deste espalhamento é proposto por Sah et al. ${ }^{64}$ :

$$
\mu_{\text {psephs }}=\frac{1}{\left(\frac{1}{\mu_{0 e a, 0 h a}\left(\frac{T}{300}\right)^{-a e,-a h}}+\frac{1}{\mu_{0 e b, 0 h b}\left(\frac{T}{300}\right)^{-\beta e,-\beta h}}\right)}
$$

onde os índices e e $h$ correspondem, respectivamente, aos elétrons e às lacunas, $\mu_{0 \mathrm{ea}}=4195 \mathrm{~cm}^{2} / \mathrm{Vs}, \mu_{0 \mathrm{eb}}=2153 \mathrm{~cm}^{2} / \mathrm{Vs}, \mu_{0 \mathrm{ha}}=2502 \mathrm{~cm}^{2} / \mathrm{Vs}$, $\mu_{0 h b}=591 \mathrm{~cm}^{2} / \mathrm{Vs}, \alpha_{e}=\alpha_{h}=1,5, \beta_{e}=3,13$ e $\beta_{h}=3,25$. Este modelo combina os fônons ópticos e acústicos através da regra de Mathiessen ${ }^{17}$.

- Espalhamento por impurezas ionizadas (ionized impurity scattering):

Este mecanismo de espalhamento está relacionado com a redução da mobilidade devido à alta concentração de dopantes. O modelo empírico de Caughey e Thomas ${ }^{65}$ considera os mecanismos de espalhamentos por fônons e por impurezas ionizadas em uma única equação, uma vez que esses dois mecanismos não são totalmente independentes:

$$
\mu_{\mathrm{psiie}}=\mu_{\mathrm{min}, \mathrm{e}}+\frac{\mu_{\mathrm{pse}}-\mu_{\mathrm{min}, \mathrm{e}}}{1+\left(\frac{\mathrm{N}_{\mathrm{A}}^{-}}{\mathrm{N}_{\text {Ref,e }}}\right)^{\mathrm{a}_{\mathrm{ae}}}}
$$

onde $\alpha_{a e}=0,72 \cdot\left(\frac{T}{300}\right)^{0,065} ; \mu_{\min , e}=197,7-45,5 \log (T)$ e $N_{\text {Ref,e }}=1,12 \cdot 10^{17} \cdot\left(\frac{T}{300}\right)^{3,2}$.

Para o caso das lacunas, os coeficientes são dados por: $\mu_{\min , \mathrm{h}}=110,9-25,6 \log (\mathrm{T}) ; \mathrm{N}_{\mathrm{Ref}, \mathrm{h}}=2,23 \cdot 10^{17} \cdot\left(\frac{\mathrm{T}}{300}\right)^{3,2}$ e $\alpha_{\mathrm{ah}}=\alpha_{\mathrm{ae}}$. 
- Espalhamentos por impurezas neutras (neutral-impurity scattering $-\mu_{\mathrm{ni}}$ ):

Como visto no item 2.4.1, a redução da temperatura faz com que não haja energia térmica suficiente para ionizar todos os portadores. Assim, este mecanismo está relacionado com as impurezas não ionizadas e pode ser descrito por ${ }^{66}$ :

$$
\mu_{n i}=C_{0} \cdot\left[\frac{2}{3} \sqrt{\frac{k T}{E_{n i, e}}}+\frac{1}{3} \sqrt{\frac{E_{n i, e}}{k T}}\right]
$$

onde $C_{0}=\left(\frac{2 \pi^{3} q^{3} m_{e}^{*}}{5 \varepsilon_{\mathrm{Si}} h^{3}\left(\mathrm{~N}_{\mathrm{A}}-\mathrm{N}_{\mathrm{A}}^{-}\right)}\right)$e $\mathrm{E}_{\mathrm{ni}, \mathrm{e}}=1,1136.10^{-19}\left(\frac{\mathrm{m}_{\mathrm{e}}^{*}}{\mathrm{~m}_{0}}\right)\left(\frac{\varepsilon_{0}}{\varepsilon}\right)$, sendo $\varepsilon_{0}$ a permissividade do vácuo, $\varepsilon$ a permissividade relativa do semicondutor e $\mathrm{m}_{\mathrm{e}}{ }^{*} \mathrm{a}$ massa efetiva dos elétrons. Para o caso do cálculo da mobilidade de lacunas, deve-se substituir a massa efetiva na equação (2.21) pelas das lacunas.

- Espalhamento portador-portador (carrier-to-carrier scattering - $\mu_{\mathrm{cc}}$ ):

Este mecanismo tem importância em dispositivos que apresentam alta densidade de portadores, como transistores submicrométricos ou dispositivos de potência. Para um semicondutor tipo $p$, este mecanismo é descrito por ${ }^{67}$ :

$$
\mu_{\mathrm{CC}}=\frac{2 \cdot 10^{17}}{\sqrt{\mathrm{N}_{\mathrm{A}}} \cdot \ln \left(1+8,28 \cdot 10^{8} \cdot \mathrm{T}^{2} \cdot \mathrm{N}_{\mathrm{A}}^{-1 / 3}\right)}
$$

Os mecanismos descritos até aqui não apresentam dependência com as tensões aplicadas, definindo a mobilidade independente de campo elétrico $\left(\mu_{0}\right)$ através da regra de Mathiessen ${ }^{17}$ :

$$
\mu_{0}=\left(\frac{1}{\frac{1}{\mu_{\mathrm{psii}}}+\frac{1}{\mu_{\mathrm{cc}}}+\frac{1}{\mu_{\mathrm{ni}}}}\right)
$$


A Figura 2.13 mostra as curvas das componentes que formam a mobilidade independente de campo em função da temperatura e para uma concentração de dopantes $N_{D}=10^{19} \mathrm{~cm}^{-3}$. Pode-se perceber que na faixa de temperatura de $200 \mathrm{~K}$ a $500 \mathrm{~K}$, a componente da mobilidade $\mu_{\mathrm{psii}}$ (que considera espalhamento de fônons juntamente com as impurezas ionizadas) é dominante. Para temperaturas menores que $200 \mathrm{~K}$, a componente da mobilidade relacionada com as impurezas neutras $\left(\mu_{\mathrm{ni}}\right)$ passa a influenciar a mobilidade de baixo campo. A Figura 2.14 apresenta a mobilidade independente de campo elétrico em função da temperatura para diversas concentrações de dopantes. Pode-se observar que para concentrações de dopantes mais altas, a dependência da mobilidade de baixo campo com a temperatura diminui.

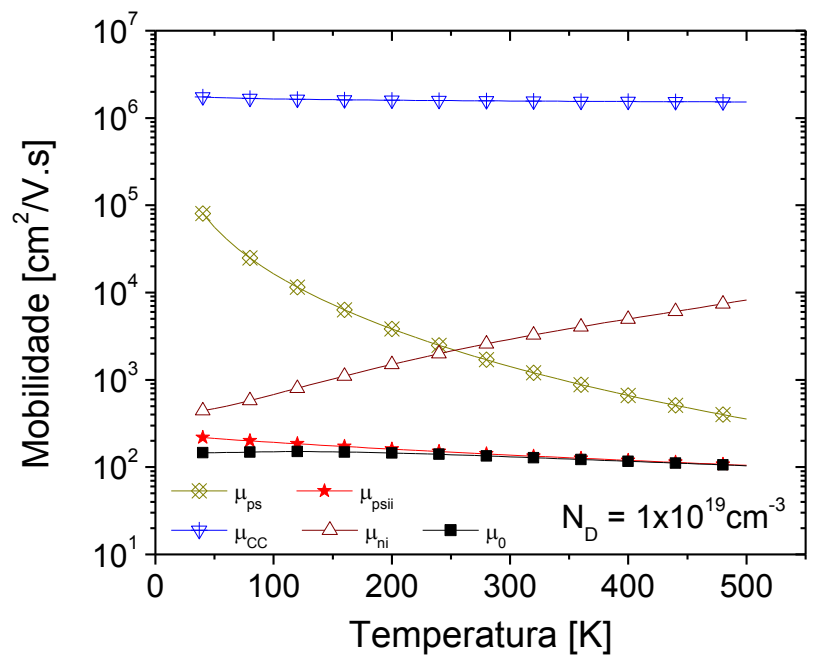

Figura 2.13 - Curva das componentes da mobilidade independente de campo elétrico versus temperatura.

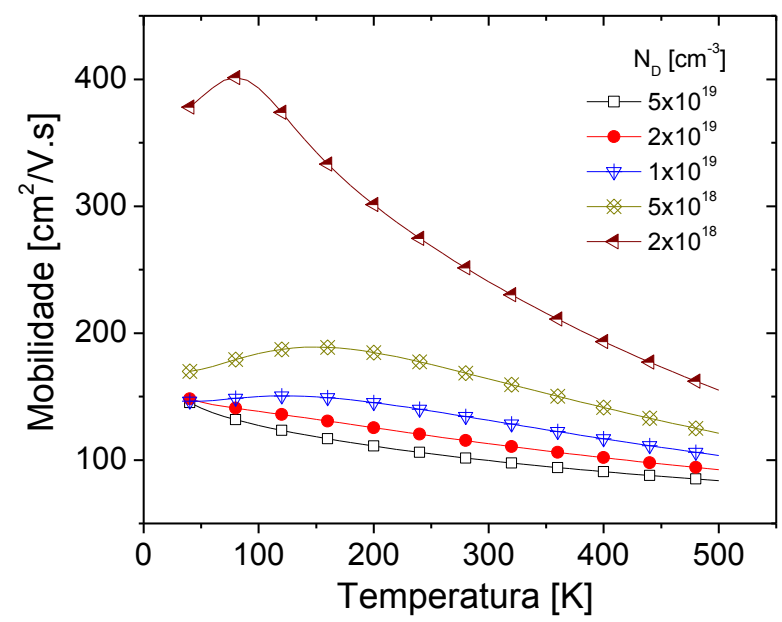

Figura 2.14 - Mobilidade independente de campo elétrico para diversas concentrações de dopantes em função da temperatura. 
A aplicação de tensão na porta do dispositivo modo inversão gera um campo elétrico vertical que atrai os portadores para a superfície silício/óxido de porta, sendo que a mobilidade dos portadores sofre uma diminuição devido à rugosidade de superfície ${ }^{47}$. A mobilidade efetiva ou degradada por campo elétrico ( $\mu_{\text {eff }}$ ) pode ser expressa por ${ }^{68}$ :

$$
\mu_{\text {eff }}=\frac{\mu_{0}}{1+\alpha_{s}\left|E_{\text {eff }}\right|}
$$

onde $\alpha_{S}$ é o coeficiente de espalhamento e $E_{\text {eff }}$ é o campo elétrico efetivo nas direções horizontal e vertical.

A dependência entre a mobilidade efetiva e a temperatura se dá através do potencial de Fermi. Este potencial aumenta com a redução de $T$, aumentando o campo elétrico efetivo e aumentando a degradação da mobilidade ${ }^{17}$.

Nos JNTs, a aplicação de tensão à porta apenas afetará a mobilidade quando $V_{G S}$ for maior que a tensão de faixa plana, portanto, apenas quando ocorrer a formação da camada de acumulação. Quando o dispositivo opera em condução pelo corpo, o campo elétrico induzido pela porta nas cargas fixas é baixo, de forma que a mobilidade não é afetada ${ }^{69}$.

- Inclinação de sublimiar

A inclinação de sublimiar (S) é definida como a variação de tensão de porta necessária para se aumentar a corrente de dreno em uma década ${ }^{47}$. Assim, S é dado por:

$$
\mathrm{S}=\frac{\partial \mathrm{V}_{\mathrm{GS}}}{\partial\left(\log \left(\mathrm{I}_{\mathrm{D}}\right)\right)}
$$

A componente predominante na região de sublimiar da corrente de dreno é a de difusão ${ }^{18}$. Assim, utilizando a equação da corrente de difusão, pode-se obter que ${ }^{70}$ : 


$$
\mathrm{S}=\mathrm{n} \frac{\mathrm{kT}}{\mathrm{q}} \ln (10)
$$

onde $n$ é o fator de corpo, cujo limite mínimo teórico é a unidade.

Como o fator de corpo está relacionado com o acoplamento capacitivo e o dispositivo SOI totalmente depletado apresenta um acoplamento melhor em relação ao MOS convencional, o fator $n$ é menor nos transistores SOI FD ${ }^{1}$. Já os dispositivos de múltiplas portas apresentam fator de corpo muito próximo da unidade (menores que do SOI FD) ${ }^{71}$. Assim, a inclinação de sublimiar desses dispositivos se aproxima do valor mínimo teórico. Pela equação (2.26), pode-se perceber que a inclinação de sublimiar é diretamente proporcional à temperatura. Assim, ao se reduzir a temperatura, a inclinação irá diminuir. Nos JNTs, o fator de corpo é muito próximo da unidade, de forma que S é próximo do limite mínimo teórico ${ }^{9}$.

- Efeitos de canal curto

A redução do comprimento de canal nos dispositivos modo inversão faz com que a influência das regiões de depleção de fonte e dreno se torne mais significativa em relação à depleção induzida pela porta ${ }^{72}$. Dessa forma, passa a haver uma disputa entre as regiões de depleção pelo controle das cargas na região de canal. Assim, a carga controlada pela porta em um dispositivo de canal curto será proporcionalmente menor que em um dispositivo de canal longo. Essa redução das cargas controladas pela porta causa uma redução na tensão de limiar e o aumento da inclinação de sublimiar ${ }^{68}$.

As junções PN de fonte e dreno com o corpo são polarizadas reversamente. À medida que a tensão reversa nas junções aumenta, a largura da região de depleção também aumenta. Dessa forma, a carga controlada pela porta é reduzida. Em um dispositivo de canal curto, o aumento da tensão aplicada ao dreno pode reduzir a barreira de potencial na fonte. Assim, ocorre a redução da tensão de limiar para altos valores de $V_{D S}{ }^{72}$. Esse efeito de redução da barreira de potencial junto à fonte recebe o nome de DIBL (Drain Induced Barrier Lowering). 
A diminuição da temperatura reduz os efeitos de canal curto ${ }^{73}$. Quando a temperatura é reduzida, ocorre uma diminuição da diferença de potencial entre dreno e canal para uma mesma corrente de dreno ${ }^{73}$. Isto resulta em um menor efeito do potencial do dreno no canal, reduzindo os efeitos de canal curto ${ }^{73}$.

Os dispositivos sem junções têm mostrado uma maior imunidade aos efeitos de canal curto devido à ausência de junções PN, apresentando uma tensão de limiar constante independentemente do comprimento de canal e menor DIBL, quando comparados aos dispositivos modo inversão ${ }^{9}$.

\subsection{EFEITOS QUÂNTICOS}

Em dispositivos de dimensões reduzidas $\left(\mathrm{H}_{\text {Fin }}\right.$ e/ou $\mathrm{W}_{\text {Fin }}$ menores que $10 \mathrm{~nm}^{3}$ ), os portadores não estão livres para se mover em qualquer direção. Se uma das dimensões for reduzida, os portadores poderão se mover nas outras duas dimensões (2DEG - Two Dimensional Electron Gas) e se ambas as dimensões forem reduzidas eles poderão se mover em apenas uma direção (1DEG - One Dimensional Electron Gas). De acordo com a mecânica quântica, um elétron em um determinado estado é descrito por uma função de onda $\Psi_{j}$. $A$ função de onda de um elétron e seu correspondente nível de energia $\left(E_{j}\right)$ podem ser obtidos pela solução da equação de Poisson juntamente com a equação de Schrödinger, usando a aproximação da massa efetiva ${ }^{3}$ :

$$
\left(-\frac{\hbar^{2}}{2 m^{*}} \nabla^{2}-\mathrm{q} \phi\right) \Psi_{j}=E_{j} \Psi_{j}
$$

onde $\phi$ é o potencial.

A equação (2.27) é anisotrópica e é descrita por ${ }^{3}$ :

$$
\left(-\frac{\hbar^{2}}{2}\left(\frac{\partial}{\partial x}\left(\frac{1}{\mathrm{~m}_{\mathrm{x}}^{*}} \frac{\partial}{\partial x}\right)+\frac{\partial}{\partial y}\left(\frac{1}{\mathrm{~m}_{\mathrm{y}}^{*}} \frac{\partial}{\partial y}\right)+\frac{\partial}{\partial z}\left(\frac{1}{\mathrm{~m}_{\mathrm{z}}^{*}} \frac{\partial}{\partial z}\right)\right)-\mathrm{q} \phi\right) \Psi_{\mathrm{j}}=\mathrm{E}_{\mathrm{j}} \Psi_{\mathrm{j}}
$$

sendo $m_{x}{ }^{*}, m_{y}{ }^{*}$ e $m_{z}{ }^{*}$ as massa efetivas correspondente aos diferentes vales nas direções $x, y$ e $z$, estando relacionadas com a orientação cristalográfica ${ }^{74}$. 
Na teoria clássica, o espectro dos estados energéticos que podem ser ocupados por elétrons é considerado contínuo acima da energia de condução. No entanto, devido ao confinamento quântico, os estados energéticos passam a ser quantizados. A equação (2.27) pode ser utilizada, em um caso particular, para se obter os níveis de energia da sub-banda de condução, desprezando-se a variação do potencial no silício. Neste caso, a solução é dada por ${ }^{47}$ :

$$
\mathrm{E}_{\mathrm{j}}=\frac{\hbar^{2} \pi^{2}}{2 \mathrm{~m}^{*}}\left(\frac{\mathrm{j}^{2}}{\mathrm{~W}_{\text {Fin }}{ }^{2}}+\frac{\mathrm{j}^{2}}{\mathrm{H}_{\text {Fin }}{ }^{2}}\right) \quad(j=1,2,3, \ldots)
$$

A energia da menor sub-banda será obtida considerando $j=1$ :

$$
E_{j=1}=E_{c o}+\frac{\hbar^{2} \pi^{2}}{2 m^{*}}\left(\frac{1}{{W_{\text {Fin }}{ }^{2}}^{2}}+\frac{1}{{\mathrm{H}_{\text {Fin }}}^{2}}\right)
$$

onde $\mathrm{E}_{\mathrm{co}}$ é o mínimo clássico da banda de condução.

A quantização dos estados de energia altera a função de densidade de estados do semicondutor. A Figura 2.15 apresenta as densidades de estados em dispositivos porta tripla ${ }^{3}$.

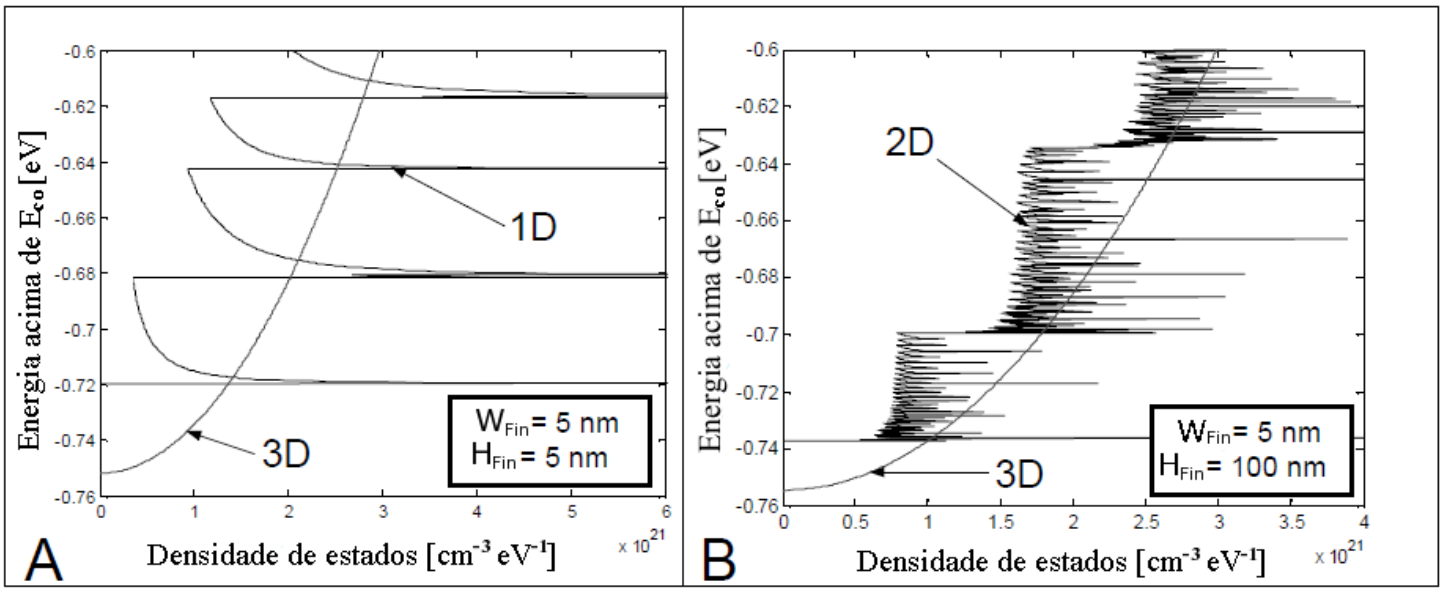

Figura 2.15 - Densidades de estado 1D (A) e 2D (B) na banda de condução de dispositivos porta tripla em inversão forte ${ }^{3}$.

No item (A), é apresentada a densidade de estados 1D (tanto $\mathrm{H}_{\text {Fin }}$ como $W_{\text {Fin }}$ são reduzidos) em comparação com a densidade de estados 3D. Pode-se 
perceber que a densidade unidimensional é formada por uma sucessão de picos, sendo que cada um deles representa uma sub-banda ${ }^{75,76}$. No item (B), tem-se a densidade de estados 2D onde é possível notar que a mesma forma degraus, sendo que cada um deles é formado por diversos picos ${ }^{77}$. Já a densidade de estados 3D apresenta uma distribuição contínua.

A alteração na densidade de estados causa mudanças na concentração dos portadores ${ }^{3,78}$. Assim, o pico de concentração dos portadores não se concentra na superfície, mas há alguns angstroms da mesma, ao contrário da teoria clássica que prevê a concentração máxima na superfície ${ }^{79}$. Este efeito é chamado de inversão de volume e foi descoberto em 1987 por Balestra et al. ${ }^{3,40}$. Uma forma de se considerar esse efeito é através de um aumento na espessura efetiva do óxido de porta ${ }^{80}$ :

$$
\mathrm{t}_{\mathrm{ox}}^{\mathrm{eff}}=\mathrm{t}_{\mathrm{ox}}+\Delta \mathrm{z} \varepsilon_{\mathrm{ox}} / \varepsilon_{\mathrm{Si}}
$$

onde $\Delta z$ representa a distância entre o pico de concentração dos elétrons e a superfície.

Com a inversão de volume, os portadores passam a sofrer menos influência da rugosidade de superfície, resultando em um aumento da mobilidade ${ }^{81,82}$.

A equação (2.30) apresenta o nível mínimo energético desprezando-se o efeito da variação do potencial na camada de silício na solução da equação de Schrödinger. Como forma de se considerar a dependência do potencial na quantização dos estados de energia, o modelo proposto por Hareland et al. ${ }^{83}$ pode ser somado ao potencial de superfície. De acordo com Hareland et al. ${ }^{83}$, a variação do nível mínimo energético da banda de condução $\left(\Delta \mathrm{E}_{0}\right)$ em uma camada de acumulação pode ser descrita por:

$$
\Delta \mathrm{E}_{0}=\beta_{\mathrm{E} 0}\left(\frac{\varepsilon_{\mathrm{Si}}}{4 \mathrm{qkT}}\right)^{1 / 3}\left(\mathrm{E}_{\mathrm{S}}\right)^{0,63}+\delta
$$

onde $\beta_{E 0}=8,45 \times 10^{-8} /\left(1+N_{D} / 2 \times 10^{19}\right), \delta=0 \mathrm{meV}$ para $N_{D}$ maior ou igual à $10^{19}$ $\mathrm{cm}^{-3}$ e ES é o campo elétrico de superfície. 


\subsection{OPERAÇÃO DOS TRANSISTORES MOS EM APLICAÇÕES ANALÓGICAS}

Para a análise da operação dos dispositivos, será considerado o amplificador formado por um único dispositivo MOS, conforme apresentado na Figura 2.16. A fonte de corrente constante $\left(I_{p}\right)$ é responsável pelo ponto de polarização. Neste circuito, a parcela alternada da tensão de porta $\left(v_{g s}\right)$ é amplificada na tensão de saída $\left(\mathrm{V}_{\mathrm{ds}}\right)$, onde uma carga capacitiva $\left(\mathrm{C}_{\mathrm{L}}\right)$ é considerada. A partir desse circuito, pode-se analisar parâmetros importantes da operação dos dispositivos, como tensão Early $\left(\mathrm{V}_{E A}\right)$, ganho de tensão de malha aberta $\left(A_{V}\right)$ e a razão entre a transcondutância e a corrente de dreno $\left(g_{m} / I_{D}\right)$.

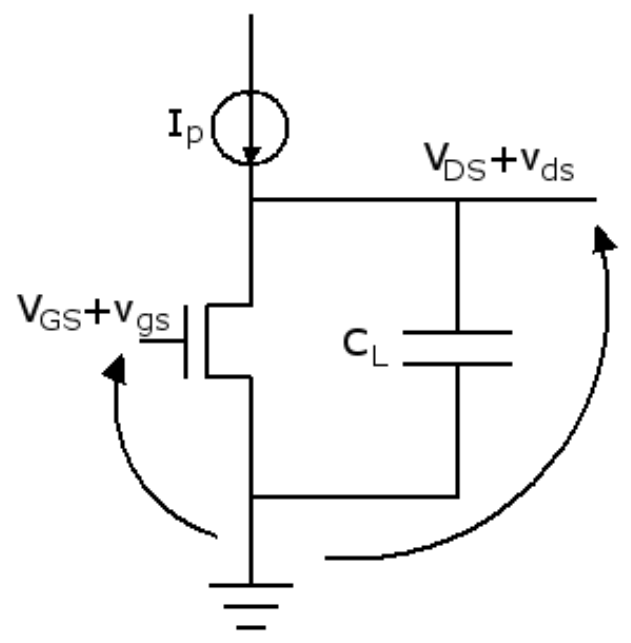

Figura 2.16 - Amplificador de tensão formado por um único transistor MOS.

\subsubsection{Tensão Early}

Quando os dispositivos MOS operam em saturação, ocorre o pinçamento (pinch-off) do canal próximo ao dreno. Ao se aumentar a tensão $V_{D S}$, a região de depleção da junção canal/dreno aumenta, deslocando o ponto de pinch-off para o interior do canal. Assim, ocorre a diminuição do comprimento efetivo de canal, aumentando a corrente de dreno. Então, a região de saturação da curva $I_{D} \times V_{D S}$ adquire certa inclinação. $O$ cruzamento entre o eixo de $V_{D S}$ e o prolongamento da curva $I_{D} \times V_{D S}$ na região de saturação é definido como a tensão Early ${ }^{84}$, conforme mostrado na Figura 2.17. 


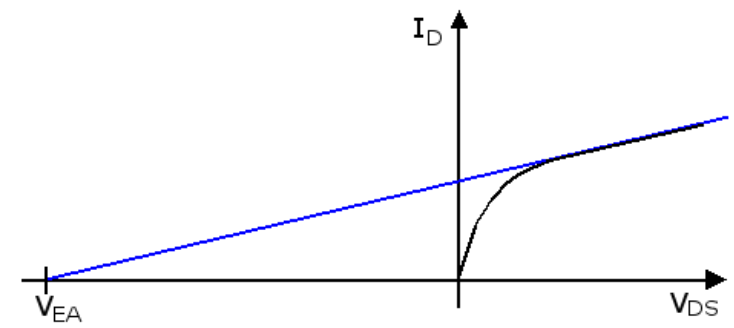

Figura 2.17 - Obtenção da tensão Early a partir da curva $I_{D} \times V_{D S}$.

A tensão Early é obtida de forma aproximada pela razão $I_{D} / g_{d}$ quando 0 dispositivo opera em saturação ${ }^{47}$, onde $g_{d}$ é a condutância de dreno dada por $g_{d}=\partial I_{D} / \partial V_{D S}$.

Em dispositivos de múltiplas portas, o maior controle das cargas no canal em relação a um dispositivo porta simples faz com que a influência do potencial de dreno na corrente de dreno seja menor, reduzindo a condutância de dreno e aumentando a tensão Early ${ }^{85}$. Ao se reduzir $W_{\text {Fin }}, V_{E A}$ aumenta, devido ao maior acoplamento das portas laterais, que diminui a penetração do campo elétrico do dreno ${ }^{86}$. Os JNTs tem apresentado tensão Early maior que os dispositivos modo inversão para baixo $\mathrm{V}_{\mathrm{GS}}$, o que está associado à menor condutância de dreno quando esses dispositivos operam próximo ao limiar ${ }^{11,87}$.

Em dispositivos porta tripla, a condutância de saída degrada com a redução da temperatura devido à modulação do comprimento do canal, reduzindo a tensão Early ${ }^{88}$. Nos dispositivos sem junções, o aumento da tensão Early com a temperatura tem sido relacionado à fraca dependência da mobilidade com a temperatura nesses dispositivos ${ }^{11,89}$.

\subsubsection{Ganho de Tensão de Malha Aberta}

O ganho de tensão em baixas frequências $\left(A_{v}\right)$ para o amplificador da Figura 2.16 é descrito por ${ }^{90}$ :

$$
\left|A_{v}\right|=\frac{v_{d s}}{v_{g s}}=\frac{g_{m}}{g_{d}} \cong \frac{g_{m}}{I_{D}}\left|V_{E A}\right|
$$


Pela equação (2.33), pode-se notar que o ganho $A_{V}$ está diretamente relacionado à tensão Early. Assim, a maior tensão Early obtida nos dispositivos de múltiplas portas resulta em um ganho de tensão maior ${ }^{85,86}$. No caso dos dispositivos sem junções, o ganho de tensão é maior que o dos dispositivos modo inversão para baixo $V_{G S}$. A razão $g_{m} / I_{D}$ também representa um importante parâmetro e será detalhada a seguir.

\subsubsection{Razão $\mathrm{g}_{\mathrm{m}} / \mathrm{l}_{\mathrm{D}}$}

A razão $g_{m} / I_{D}$ representa a eficácia de um dispositivo em converter corrente elétrica em transcondutância ${ }^{90}$. Esta razão relaciona a amplificação de um dispositivo $\left(g_{m}\right)$ com a potência dissipada por ele $\left(\mathrm{I}_{\mathrm{D}}\right)^{90}$. O valor máximo da razão ocorre quando o dispositivo está operando em inversão fraca e é dado por $^{91}$ :

$$
\frac{g_{m}}{I_{D}}=\frac{q}{n k T}
$$

Como nos dispositivos de múltiplas portas o fator de corpo é muito próximo da unidade ${ }^{71}$, a razão $\mathrm{g}_{\mathrm{m}} / \mathrm{l}_{\mathrm{D}}$ tenderá ao inverso do potencial térmico. $\mathrm{Na}$ inversão forte, ocorre uma redução no valor da razão $g_{m} / l_{D}{ }^{92}$. Como o ganho de tensão de malha aberta está relacionado com a razão, o ganho $A_{V}$ será maior quando o dispositivo opera em inversão fraca ${ }^{90}$.

Os dispositivos MOS sem junções operando em inversão forte apresentam uma mesma razão $g_{m} / I_{D}$ independentemente da temperatura, 0 que está relacionado à menor degradação da mobilidade em relação aos dispositivos MOS modo inversão ${ }^{11,93}$.

\subsection{SIMULADORES}

As simulações numéricas tridimensionais foram realizadas utilizando-se as ferramentas TCAD (Technology Computer Aided Design - Projeto 
Tecnológico Assistido por computador) da Synopsys: Sentaurus Structure Editor ${ }^{94}$ e Sentaurus Device ${ }^{95}$. A primeira ferramenta é utilizada para gerar a estrutura do dispositivo e a segunda realiza a simulação numérica. $O$ Apêndice $B$ apresenta um arquivo utilizado para gerar um dispositivo de $W_{\text {Fin }}=10 \mathrm{~nm}$ e $\mathrm{H}_{\text {Fin }}=10 \mathrm{~nm}$ no Sentaurus Structure Editor.

O programa Sentaurus Device utiliza o método dos elementos finitos para o cálculo das equações de Poisson e da continuidade, juntamente com outros modelos analíticos para os diversos efeitos que ocorrem nos dispositivos como ionização incompleta das impurezas, degradação da mobilidade por campo elétrico, entre outros. Assim, é usado um arquivo texto de entrada definindo todos os modelos que devem ser utilizados. Os modelos aplicados nas simulações foram:

- PhuMob (Philips Unified Mobility Mode): Modelo de mobilidade de baixo campo proposto por Klaassen ${ }^{96,97}$, que unifica a descrição das mobilidades dos portadores majoritários e minoritários. Possui dependência com a temperatura e com os mecanismos de espalhamento portador-portador e por impurezas.

- Lombardi: Modelo de degradação de mobilidade nas interfaces devido ao campo elétrico ${ }^{98}$. Considera os espalhamentos por fônons acústicos e por rugosidade de superfície e possui dependência com a concentração de dopantes e com a temperatura.

- Canali: Modelo que considera a saturação da velocidade dos portadores em altos campos elétricos ${ }^{99}$. Este modelo possui dependência com a temperatura.

- Incompletelonization: Considera a ionização incompleta dos portadores em baixa temperatura. O modelo padrão do simulador não é válido para dispositivos com concentração de dopantes elevadas, como é o caso do JNT. Assim, para implementar no simulador o modelo descrito no item 2.4.1, foi utilizada a interface do modelo físico do Sentaurus Device (Physical Model Interface), através da qual é possível ter acesso direto à alguns modelos do simulador. O modelo deve ser implementado na linguagem de programação $\mathrm{C}++$ e compilado através de um script do 
próprio simulador. No Apêndice $C$ é apresentado o arquivo utilizado para implementar o modelo.

- Shockley-Read-Hall Recombination: Modelo de geração e recombinação dos portadores ${ }^{100,101}$. Foram utilizados os parâmetros "DopingDependence" e "TempDependence" no modelo a fim de se considerar a dependência com a temperatura e com a concentração de dopantes.

- BandGapNarrowing: Considera o estreitamento da largura de faixa proibida para altas concentrações de dopantes ${ }^{102,103}$.

- Density Gradient Quantization Model: Modelo que considera os efeitos quânticos devido à redução das dimensões dos dispositivos no cálculo da concentração de portadores ${ }^{104,105}$.

No Apêndice $D$ é apresentado um exemplo de um arquivo de simulação do Sentaurus Device. 


\section{MODELO ANALÍTICO PARA TENSÃO DE LIMIAR}

Nesta seção será apresentado o modelo proposto para a tensão de limiar nos dispositivos sem junções ${ }^{106}$, válido tanto em dispositivos porta tripla como em dispositivos cilíndricos ${ }^{107}$. A validação do modelo através de simulações tridimensionais e medidas experimentais também será apresentada, bem como a análise da influência da temperatura em $\mathrm{V}_{\mathrm{TH}}{ }^{108}$.

\subsection{DISPOSITIVOS PORTA TRIPLA}

\subsubsection{Desenvolvimento do Modelo}

Para o desenvolvimento do modelo, foi utilizada a equação de Poisson bidimensional, dada por:

$$
\frac{d^{2} \phi}{d x^{2}}+\frac{d^{2} \phi}{d z^{2}}=-\frac{q N_{D}}{\varepsilon_{S i}}
$$

onde $x$ e $z$ representam as direções da largura e da altura do fin, conforme mostrado na Figura 2.4 .

Pode-se observar na equação (3.1) que a densidade de portadores móveis foi desprezada. Essa consideração foi feita baseada no fato de que a condição de limiar é dada pela profundidade da região de depleção, e não pela formação de canal de acumulação ou inversão.

Se for considerada uma estrutura Gate-All-Around (GAA) ${ }^{32}$ com seção transversal quadrada, sendo que o dispositivo é composto de uma camada de silício com óxido de porta e material de porta em seus quatro lados, a fim de simplificar os cálculos, pode-se considerar que a variação de potencial é a mesma nas direções $x$ e $z(d \phi / d x=d \phi / d z)$.

Como forma de analisar se esta mesma consideração é válida para dispositivos porta tripla, foram realizadas simulações tridimensionais de um 
dispositivo sem junções longo $(\mathrm{L}=1 \mu \mathrm{m})$ com altura e largura de $10 \mathrm{~nm}$, espessura da camada de óxido de porta de $2 \mathrm{~nm}$ e $\mathrm{N}_{\mathrm{D}}$ de $10^{19} \mathrm{~cm}^{-3}$. O potencial e o campo elétrico foram extraídos ao longo das direções $x(\operatorname{com} z=-1 \mathrm{~nm}$ ) e $z(\operatorname{com} x=0)$, sendo que o ponto $(x=0$ e $z=-1 \mathrm{~nm})$ representa o ponto de mínimo potencial na seção transversal do dispositivo. O potencial e o campo elétrico são apresentados na Figura 3.1 considerando $\mathrm{V}_{\mathrm{GS}}=\mathrm{V}_{\mathrm{TH}}$ e $\mathrm{V}_{\mathrm{DS}}=0$. Pode-se notar que a variação entre o potencial no centro do dispositivo e em qualquer uma das três superfícies é praticamente a mesma (há apenas um aumento de $10 \mathrm{mV}$ para a superfície do topo). Da mesma forma, pode-se perceber que a variação do campo elétrico entre o centro e as superfícies também é aproximadamente a mesma (há apenas uma diminuição de $1 \times 10^{4}$ V/cm para a superfície do topo). Assim, pode-se considerar que a aproximação é válida para dispositivos porta tripla.

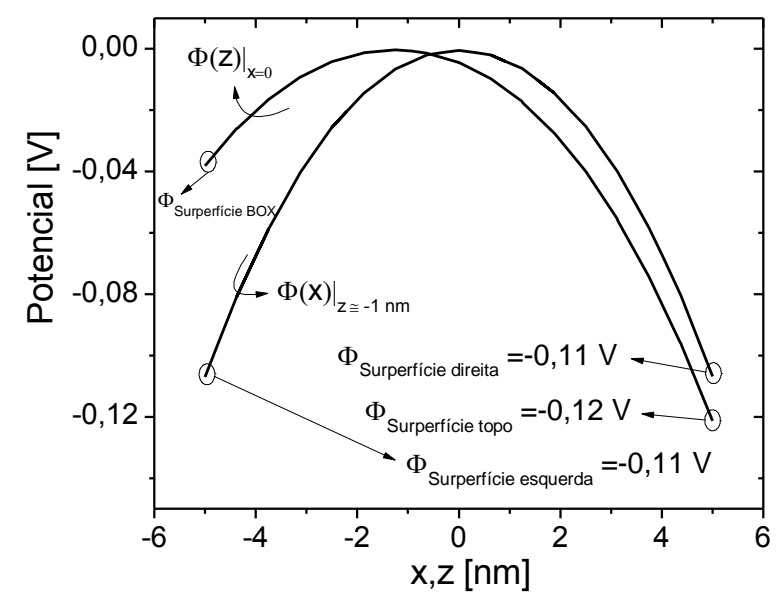

(A)

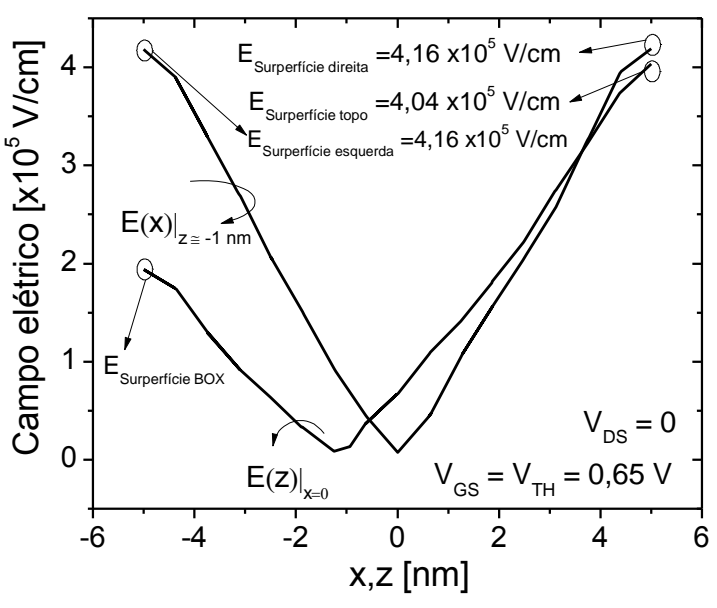

(B)

Figura 3.1 - Potencial (A) e campo elétrico (B) em função das direções $x$ e $z$ comparando-se os mesmos no centro e nas superfícies do dispositivo.

O ponto $x=0$ e $z=-5 \mathrm{~nm}$ na Figura 3.1 representa o potencial e 0 campo elétrico na interface entre a camada de silício e o óxido enterrado. Pode-se notar que há uma influência do substrato no potencial e no campo elétrico, no entanto esta influência não afeta a modelagem da tensão de limiar conforme será visto neste Capítulo. A influência do substrato será discutida no item 3.1.6. Em todos os demais itens do Capítulo, a polarização de substrato é desprezada e o mesmo é considerado aterrado. 
Multiplicando ambos os lados da equação (3.1) por (dф/dx) e utilizando a relação $\frac{d}{d x}\left(\frac{d u}{d x}\right)^{2}=2 \frac{d u}{d x}\left(\frac{d^{2} u}{d x^{2}}\right)^{45}$, pode-se obter:

$$
2 d\left(\frac{d \phi}{d x}\right)^{2}=-\frac{q N_{D}}{\varepsilon_{S i}} 2 d \phi
$$

A condição de limiar no JNT pode ser definida como a tensão aplicada à porta tal que haja um ponto no centro da seção transversal do canal que não esteja depletado. Assim, a partir desse ponto passa a ocorrer a condução de corrente de corpo (bulk). Considerando que a fonte do dispositivo esteja aterrada e devido à ausência de junções, pode-se assumir que o potencial no centro da seção transversal do canal é zero quando este deixa o regime de depleção. O termo $(d \phi / d x)$ é a componente do campo elétrico na direção $x$ (largura do JNT), que é zero no centro do dispositivo (as componentes do campo elétrico de cada interface se anulam no centro). Ainda com o objetivo de simplificar o modelo, foi assumido um potencial constante $\phi_{s}$ nas superfícies laterais e na superior, que pode ser entendido como um potencial de superfície efetivo. Também foi considerado um campo elétrico constante $E_{S}$ em toda a superfície. Assim, a equação (3.2) pode ser integrada da seguinte forma:

$$
-\int_{0}^{E_{S}} d\left(\frac{d \phi}{d x}\right)^{2}=-\frac{q N_{D}}{\varepsilon_{S i}} \int_{0}^{\phi_{S}} d \phi
$$

resultando na relação entre campo elétrico e potencial de superfície no regime de depleção parcial:

$$
\mathrm{E}_{\mathrm{S}}=\sqrt{\frac{\mathrm{q} \mathrm{N}_{\mathrm{D}}}{\varepsilon_{\mathrm{Si}}} \phi_{\mathrm{S}}}
$$

A densidade de carga por unidade de comprimento $(\mathrm{Q})$ controlada pela porta é dada por:

$$
\mathrm{Q}=\varepsilon_{\mathrm{Si}}\left(2 \mathrm{H}_{\mathrm{Fin}}+\mathrm{W}_{\mathrm{Fin}}\right) \mathrm{E}_{\mathrm{S}}
$$


Substituindo (3.4) em (3.5), pode-se obter a carga de depleção por unidade de comprimento $\left(Q_{\text {depl }}\right)$ :

$$
Q_{\text {depl }}=\varepsilon_{\mathrm{Si}}\left(2 \mathrm{H}_{\mathrm{Fin}}+\mathrm{W}_{\mathrm{Fin}}\right) \sqrt{\frac{\mathrm{qN} \mathrm{N}_{\mathrm{D}}}{\varepsilon_{\mathrm{Si}}} \phi_{\mathrm{S}}}
$$

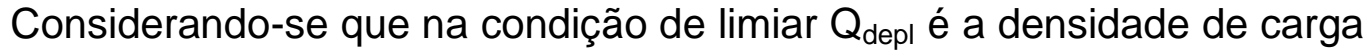
fixa por unidade de comprimento $\left(Q_{\mathrm{Si}}=\mathrm{q} . \mathrm{N}_{\mathrm{D}} \cdot \mathrm{H}_{\text {Fin. }} \mathrm{W}_{\mathrm{Fin}}\right)$, pode-se isolar $\mathrm{o}$ potencial de superfície na equação (3.6):

$$
\phi_{\mathrm{S}}=\frac{\mathrm{qN}}{\varepsilon_{\mathrm{Si}}}\left(\frac{\mathrm{W}_{\text {Fin }} \mathrm{H}_{\mathrm{Fin}}}{\mathrm{W}_{\mathrm{ox}}}\right)^{2}
$$

onde $\mathrm{W}_{\mathrm{ox}}$ é a largura efetiva da porta dada por $\mathrm{W}_{\mathrm{ox}}=2 \mathrm{H}_{\text {Fin }}+\mathrm{W}_{\text {Fin }}$.

Para o capacitor MOS, pode-se escrever a relação:

$$
\left(\mathrm{V}_{\mathrm{FB}}-\mathrm{V}_{\mathrm{GS}}-\phi_{\mathrm{S}}\right) \mathrm{C}_{\mathrm{ox}}=\mathrm{Q}
$$

onde $\mathrm{C}_{\mathrm{ox}}$ é a capacitância do óxido de porta por unidade de comprimento.

Substituindo $\phi_{s}$ por (3.7) e Q por $Q_{S i}$ (considerando que toda a camada de silício está depletada na condição de limiar) na equação (3.8), tem-se:

$$
\mathrm{V}_{\mathrm{TH}}=\mathrm{V}_{\mathrm{FB}}-\mathrm{qN}_{\mathrm{D}}\left[\frac{\mathrm{W}_{\mathrm{Fin}} \mathrm{H}_{\mathrm{Fin}}}{\mathrm{C}_{\mathrm{ox}}}+\frac{1}{\varepsilon_{\mathrm{Si}}}\left(\frac{\mathrm{W}_{\mathrm{Fin}} \mathrm{H}_{\mathrm{Fin}}}{\mathrm{W}_{\mathrm{ox}}}\right)^{2}\right]
$$

Para dispositivos com $\mathrm{W}_{\text {Fin }}$ e/ou $\mathrm{H}_{\text {Fin }}$ estreitos, pode haver confinamento quântico conforme mencionado no item 2.5. Assim, a solução da equação de Schrödinger (equação (2.29)) para o menor nível energético da banda de condução deve ser acrescentada à equação (3.9):

$$
V_{T H}=V_{F B}-q N_{D}\left[\frac{W_{\text {Fin }} H_{\text {Fin }}}{C_{o x}}+\frac{1}{\varepsilon_{\text {Si }}}\left(\frac{W_{\text {Fin }} H_{\text {Fin }}}{W_{\text {ox }}}\right)^{2}\right]+\frac{\pi^{2} \hbar^{2}}{2 \mathrm{qm}^{*}}\left[\frac{1}{W_{\text {Fin }}{ }^{2}}+\frac{1}{{H_{\text {Fin }}}^{2}}\right]
$$


Com o acréscimo da solução da equação de Schrödinger na equação (3.9), não é necessário considerar o aumento da espessura efetiva do óxido de porta conforme descrito pela equação (2.31).

A equação (3.10) foi deduzida para um dispositivo nMOS. Para um dispositivo pMOS, a tensão de limiar é calculada de forma análoga:

$$
\mathrm{V}_{\mathrm{TH}}=\mathrm{V}_{\mathrm{FB}}+\mathrm{qN}_{\mathrm{A}}\left[\frac{\mathrm{W}_{\text {Fin }} \mathrm{H}_{\text {Fin }}}{\mathrm{C}_{\text {ox }}}+\frac{1}{\varepsilon_{\mathrm{Si}}}\left(\frac{\mathrm{W}_{\text {Fin }} \mathrm{H}_{\text {Fin }}}{\mathrm{W}_{\mathrm{ox}}}\right)^{2}\right]-\frac{\pi^{2} \hbar^{2}}{2 \mathrm{qm}^{*}}\left[\frac{1}{\mathrm{~W}_{\text {Fin }}{ }^{2}}+\frac{1}{\mathrm{H}_{\text {Fin }}{ }^{2}}\right]
$$

$\mathrm{Na}$ equação (3.10), o termo $\mathrm{m}^{*}$ representa a massa efetiva dos elétrons enquanto na equação (3.11) $\mathrm{m}^{*}$ é a massa efetiva das lacunas.

A equação (3.10) pode ser reescrita da seguinte forma:

$$
\mathrm{V}_{\mathrm{TH}}=\mathrm{V}_{\mathrm{FB}}-\mathrm{qN}\left[\frac{\mathrm{A}}{\mathrm{C}_{\mathrm{ox}}}+\frac{1}{\varepsilon_{\mathrm{Si}}}\left(\frac{\mathrm{A}}{\mathrm{P}}\right)^{2}\right]+\frac{\Delta \mathrm{E}_{0}}{\mathrm{q}}
$$

onde $A$ é a área da seção transversal, $P$ é o perímetro da porta e $\Delta \mathrm{E}_{0}$ é a variação do mínimo nível de energia da banda de condução.

\subsubsection{Capacitância dos Cantos}

A capacitância de porta por unidade de comprimento é geralmente aproximada por $\mathrm{C}_{\mathrm{ox}}=\varepsilon_{\mathrm{ox}} \cdot \mathrm{W}_{\mathrm{ox}} / \mathrm{t}_{\mathrm{ox}}$. Essa aproximação despreza a capacitância dos cantos, e é válida quando $t_{0 x}$ é muito menor que $W_{\text {Fin }}$ e/ou $\mathrm{H}_{\text {Finn }}$, por exemplo, $\mathrm{W}_{\text {Fin }}=\mathrm{H}_{\text {Fin }}=60 \mathrm{~nm}$ e $\mathrm{t}_{\mathrm{ox}}=2 \mathrm{~nm}$ ( $\mathrm{t}_{\mathrm{ox}}$ é $3 \%$ de $\mathrm{W}_{\text {Fin }}$ ou $\mathrm{H}_{\text {Fin }}$ ). No entanto, para dispositivos com dimensões reduzidas como o MOS sem junções, a espessura do óxido de porta se torna comparável às dimensões do dispositivo, por exemplo, $\mathrm{W}_{\text {Fin }}=\mathrm{H}_{\text {Fin }}=10 \mathrm{~nm}$ e $\mathrm{t}_{\text {ox }}=2 \mathrm{~nm}$ ( $\mathrm{t}_{\text {ox }}$ é $20 \%$ de $\mathrm{W}_{\text {Fin }}$ ou $\mathrm{H}_{\text {Fin }}$ ). Nesta situação, a capacitância dos cantos não pode ser desprezada. A fim de se obter resultados mais precisos para $\mathrm{C}_{\text {ox }}$, foi acrescentado um fator de correção no cálculo da capacitância de porta: 


$$
\mathrm{C}_{\mathrm{ox}}=\varepsilon_{\mathrm{ox}}\left(\mathrm{W}_{\mathrm{ox}} / \mathrm{t}_{\mathrm{ox}}+f\right)
$$

onde fé constante e corresponde à capacitância dos cantos.

Na Figura 3.2, é apresentada a seção transversal de um dispositivo sem junções, enfatizando os cantos do dispositivo. Considerando o canto superior esquerdo (indicado por $A B C D$ ), a capacitância deve ser obtida entre os lados $A B$ e $A D$ em relação ao ponto $C$. Para o canto superior direito, a capacitância deve ser obtida entre os lados EF e FG em relação ao ponto H. Pela Figura 3.2, pode-se perceber que os dois cantos superiores podem ser considerados juntos como a metade de um quadrado de lado $2 \mathrm{t}_{\mathrm{ox}}$. Neste caso, a capacitância é calculada entre o centro do quadrado $(\mathrm{C}, \mathrm{H})$ e os lados $\mathrm{AD}$, AF e FG. Esta capacitância não depende das dimensões do quadrado, apresentando um valor fixo ${ }^{109}$. Pela equação (3.13), pode-se notar que $C_{o x}$ é dado pela soma de duas capacitâncias: a das portas superior e laterais $\left(\varepsilon_{0 x} \cdot W_{o x} / t_{o x}\right)$ e a capacitância dos cantos $\left(\mathrm{C}_{\text {cantos }}=\varepsilon_{\mathrm{ox}} \cdot f\right)$. A capacitância $\mathrm{C}_{\text {cantos }}$ pode ser calculada para um dispositivo porta tripla como a metade da capacitância de um quadrado unitário $\left(\mathrm{C}_{\mathrm{qu}}\right), \mathrm{C}_{\text {cantos }}=\mathrm{C}_{\mathrm{qu}} / 2$. Esta última é definida como a capacitância entre o centro de um quadrado e seus quatro lados e é obtida numericamente. Segundo Read ${ }^{109}, \mathrm{C}_{\mathrm{qu}}$ é dado por $0.367 \times 4 . \pi . \varepsilon_{\mathrm{ox}}$. Através das relações acima, tem-se que $f=\mathrm{C}_{\text {qu }} /\left(2 . \varepsilon_{\mathrm{ox}}\right)$. Logo, pode-se obter que $f=2,3059$.

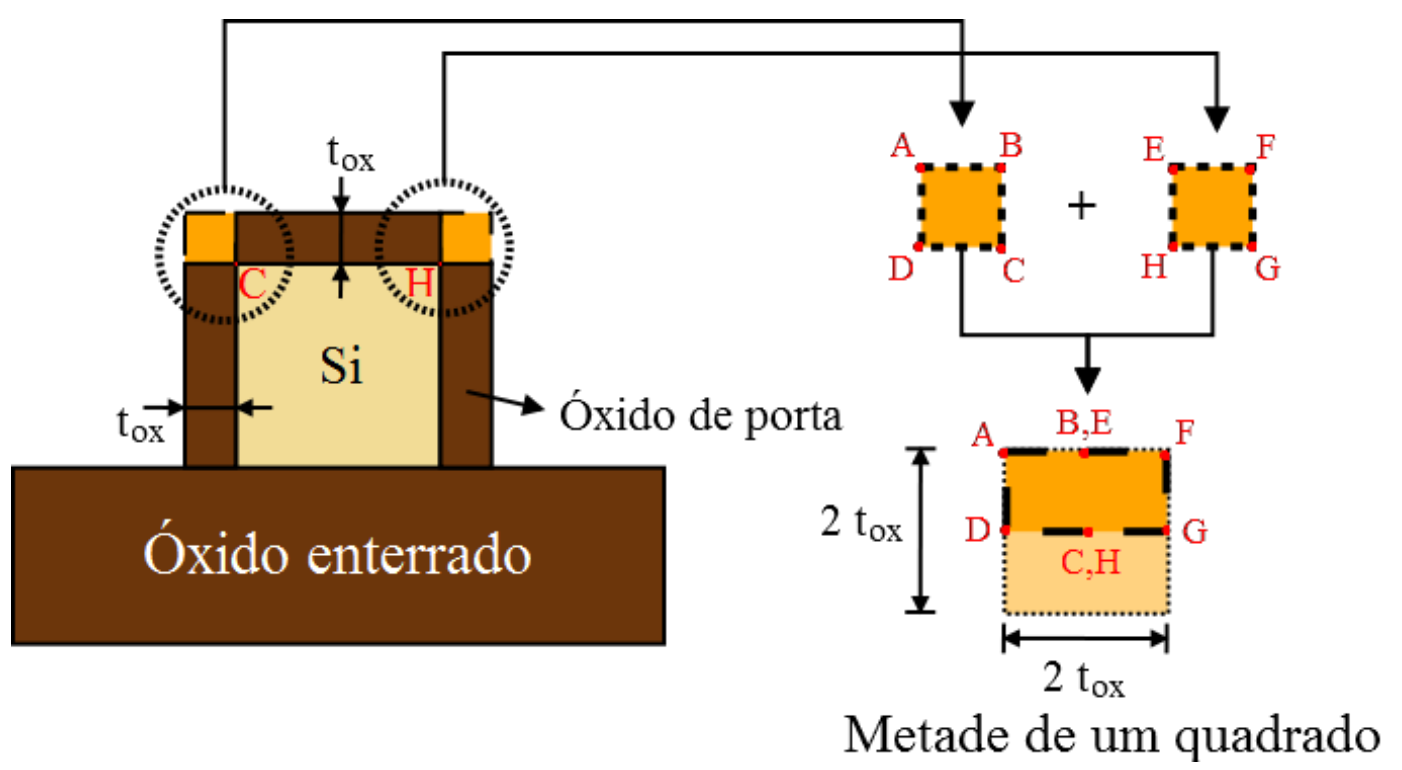

Figura 3.2 - Seção transversal de um dispositivo sem junções enfatizando as capacitâncias dos cantos. 
Em dispositivos reais, o canto é geralmente arredondado. A análise de dispositivos com cantos arredondados é apresentada no item 3.1.3 juntamente com a validação de fator $f$ a fim de se adicionar o efeito de canto no cálculo da capacitância de porta.

\subsubsection{Validação do Fator $f$}

Primeiramente, foram comparadas as tensões de limiar obtidas por simulações tridimensionais de dispositivos longos $(\mathrm{L}=1 \mu \mathrm{m})$ com $\mathrm{W}_{\text {Fin }}=\mathrm{H}_{\text {Fin }}=10 \mathrm{~nm}, \mathrm{t}_{\mathrm{ox}}$ variando entre $1 \mathrm{~nm}$ e $7 \mathrm{~nm}, N_{\mathrm{D}}$ variando entre $5 \times 10^{18} \mathrm{~cm}^{-3}$ e $4 \times 10^{19} \mathrm{~cm}^{-3}$ e silício policristalino $\mathrm{P}^{+}$na porta. A tensão de limiar foi primeiramente obtida pela equação (3.10), considerando-se ou desprezando-se o termo $f$. As simulações foram efetuadas conforme descrito no item 2.7. Para se obter $\mathrm{V}_{\mathrm{TH}}$ dos dispositivos simulados, foi utilizado o método da segunda derivada da curva $I_{D} \times V_{G S}{ }^{110}$ para uma tensão $V_{D S}$ de 50 $\mathrm{mV}$. Este é um método de base matemática que tem sido aplicado a dispositivos SOI modo acumulação ${ }^{111,112}$, sendo capaz de determinar o começo de cada mecanismo de condução (condução pelo corpo e início da camada acumulação), embora neste momento seja apenas importante a tensão de limiar. Este método foi utilizado em todas as extrações de tensão de limiar neste capítulo, sempre considerando $\mathrm{V}_{\mathrm{DS}}=50 \mathrm{mV}$.

A Figura 3.3 apresenta as tensões de limiar calculadas e simuladas em função da concentração de dopantes e da espessura do óxido de porta, analisando-se a influência do termo $f$ em $\mathrm{C}_{\text {ox }}$. Pela figura, pode-se perceber que $f$ corrige adequadamente o efeito de canto, sendo que o erro máximo entre os dados simulados e modelados é de $30 \mathrm{mV}$. Quando $f$ é desprezado, ao se aumentar $\mathrm{N}_{\mathrm{D}}$ e/ou $\mathrm{t}_{\mathrm{ox}}$, o erro entre $\mathrm{V}_{\mathrm{TH}}$ simulado e calculado aumenta. Por exemplo, para $t_{\mathrm{ox}}=7 \mathrm{~nm}$ e $\mathrm{N}_{\mathrm{D}}=1 \times 10^{19} \mathrm{~cm}^{-3}$, o erro é de $340 \mathrm{mV}$, enquanto que se $f$ for considerado, esse erro cai para menos de $10 \mathrm{mV}$. Assim, o fator $f$ será usado em todos os cálculos de $\mathrm{V}_{\mathrm{TH}}$ nesse trabalho para dispositivos porta tripla. 

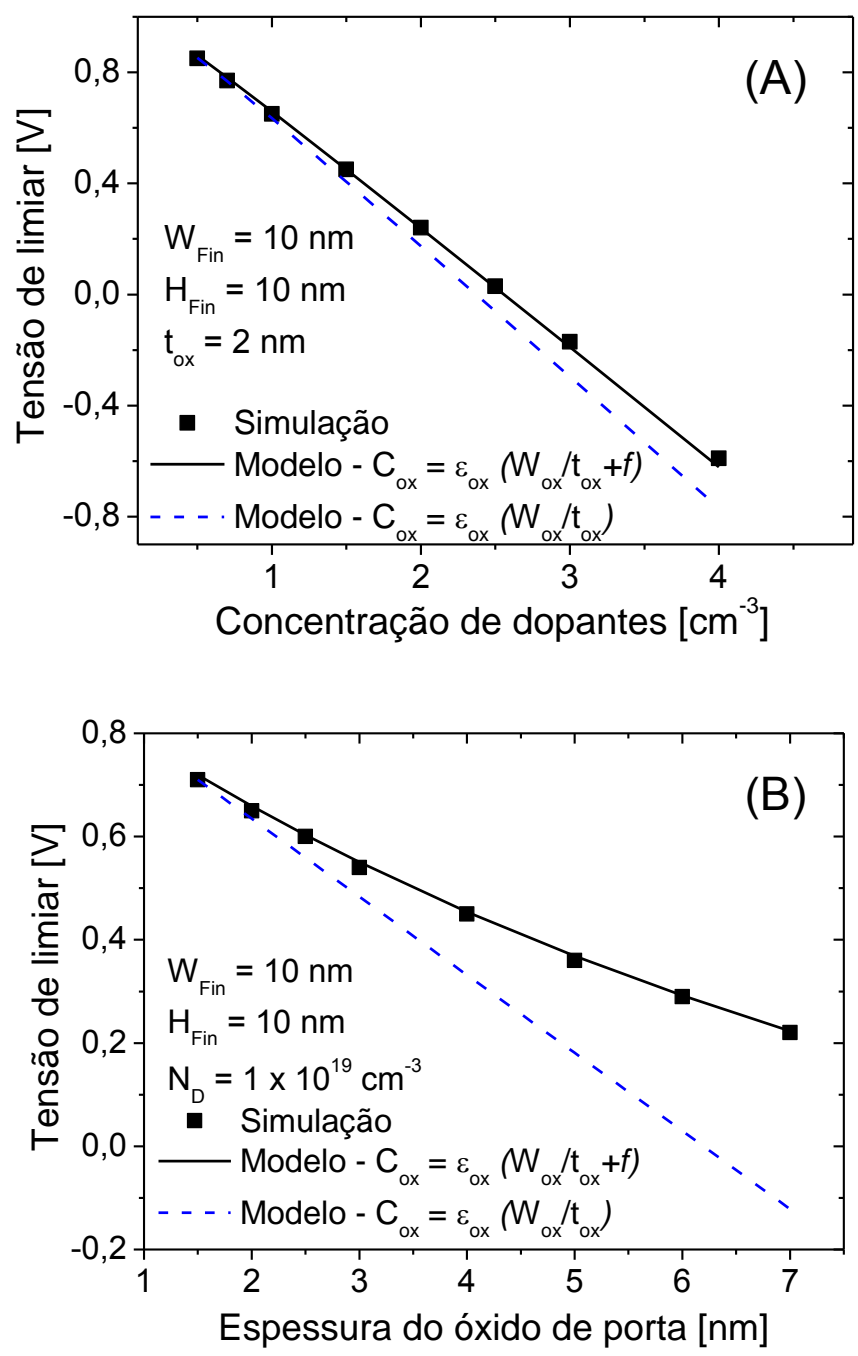

Figura 3.3 - Tensão de limiar simulada e modelada em função da concentração de dopantes (A) e da espessura do óxido de porta (B) analisando a inclusão do termo $f$ no cálculo da capacitância de porta por unidade de comprimento.

Conforme mencionado, em dispositivos reais os cantos são geralmente arredondados. Dessa forma, foram simulados dispositivos conforme apresentado na Figura 3.4, com o óxido de canto arredondado com um raio $r_{o x}$, que foi variado entre 0 (sem arredondamento) e $t_{\text {ox. }}$. A Figura 3.5 apresenta a tensão de limiar em função do raio do óxido de canto, normalizado pela espessura do óxido de porta, para dispositivos com diferentes concentrações de dopantes e tox. Pela figura, pode-se perceber que o arredondamento do canto não afeta a tensão de limiar em nenhum dos casos, não influenciando significativamente no funcionamento dos dispositivos, mostrando que o fator $f$ pode ser aplicado a esses dispositivos. 


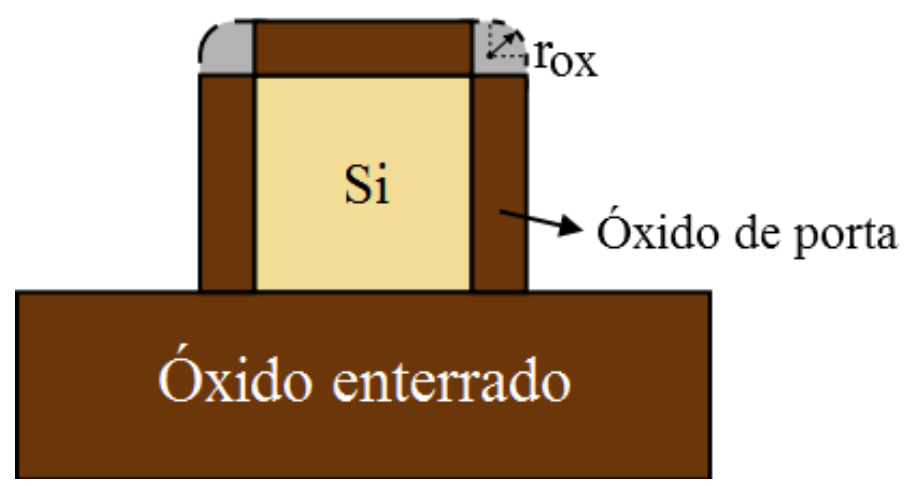

Figura 3.4 - Seção transversal de um dispositivo MOS sem junções com o óxido de canto arredondado.

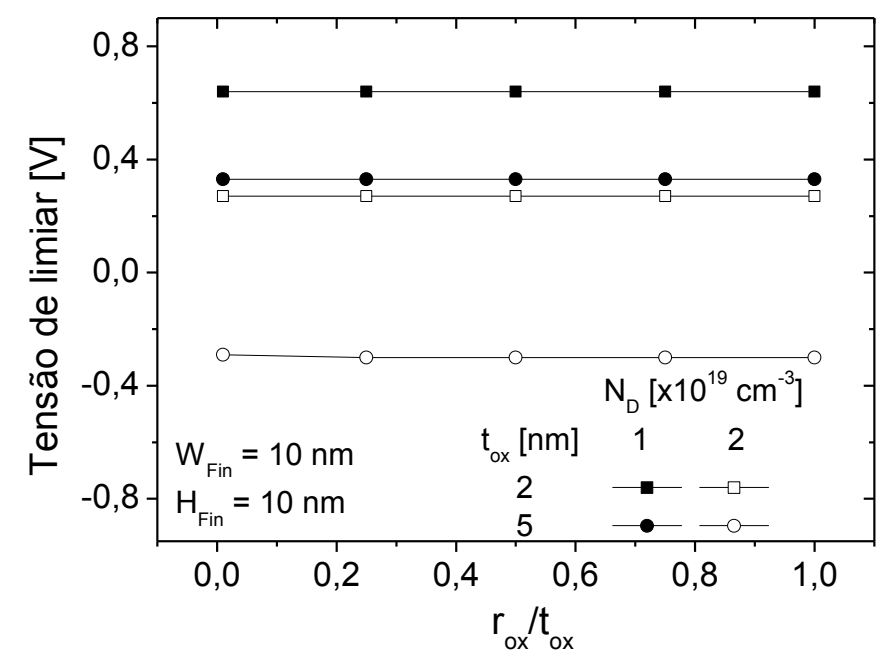

Figura 3.5 - Tensão de limiar em função do raio do óxido de canto normalizado pela espessura do óxido de porta.

$\mathrm{Na}$ sequência, foram realizadas simulações considerando $\mathrm{o}$ arredondamento do canto da camada de silício, com um raio $r_{\text {int. Neste caso, }}$ tanto os cantos superiores do silício como os cantos do óxido foram considerados arredondados conforme apresentado na Figura 3.6. $O$ raio $r_{\text {ox }}$ foi considerado como $r_{\text {ox }}=r_{\text {int }}+t_{\text {ox }}$. A Figura 3.7 apresenta a tensão de limiar obtida para essa estrutura em função do raio $r_{\text {int, }}$ para dispositivos com diferentes concentrações de dopantes e espessuras de óxido de porta. Podese observar que o canto interno arredondado pode afetar ligeiramente a tensão de limiar, especialmente para concentrações de dopantes mais altas e óxidos de porta mais espessos. No entanto, esta variação é menor que $30 \mathrm{mV}$ para $r_{\text {int }} \leq 3 \mathrm{~nm}$, que representa $30 \%$ da altura e da largura do fin. Assim, para dispositivos com os cantos superiores do silício ligeiramente arredondados, pode-se ainda utilizar o fator $f$ como forma de correção. Para dispositivos com 0 canto significativamente arredondado, $\mathrm{C}_{\mathrm{ox}}$ deve ser calculado como a 
associação paralela de capacitâncias cilíndricas e planares. Deve-se ressaltar ainda que, neste caso, a carga total no silício por unidade de comprimento sofrerá uma redução devido ao arredondamento, sendo que a redução da carga no silício provoca um aumento de $\mathrm{V}_{\mathrm{TH}}$.

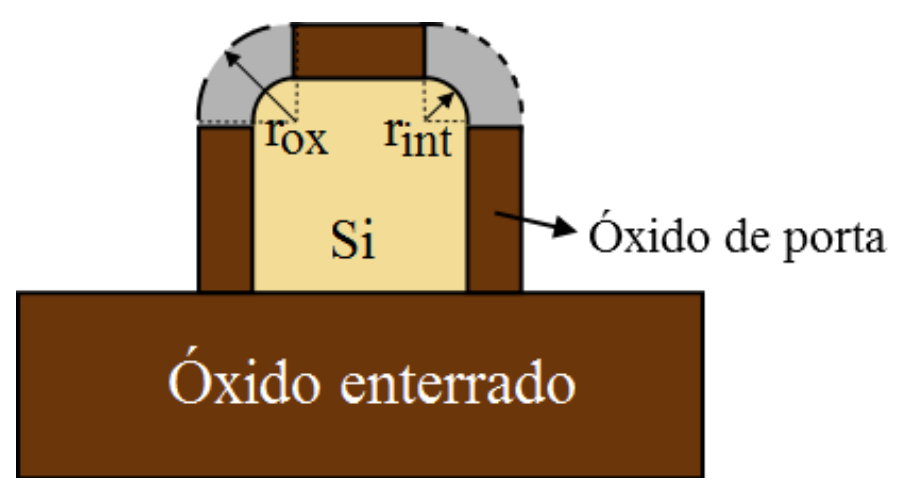

Figura 3.6 - Seção transversal de um dispositivo MOS sem junções com os cantos superiores do fin e do óxido arredondados.

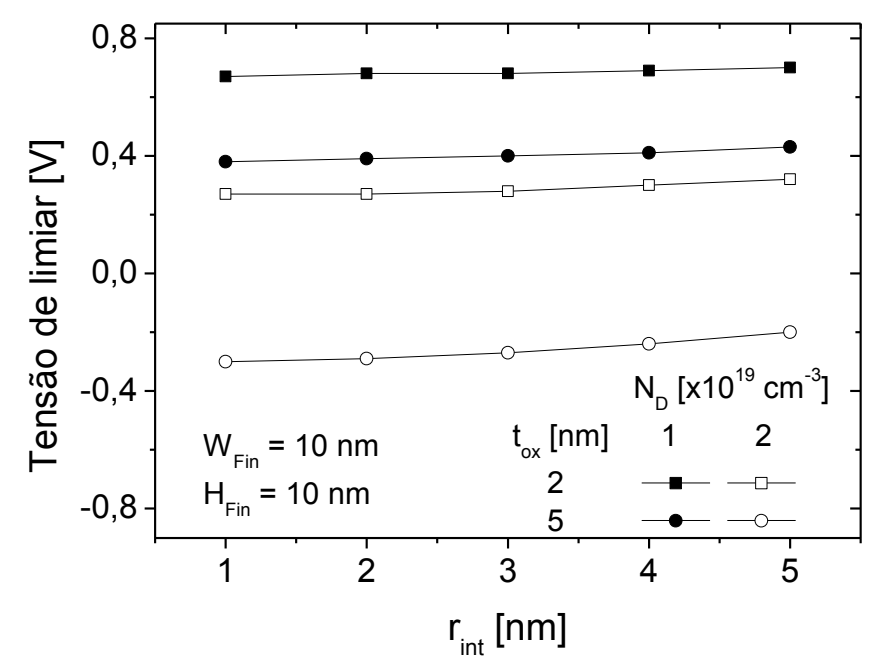

Figura 3.7 - Tensão de limiar em função do raio dos cantos superiores do silício.

\subsubsection{Validação do Modelo de Tensão de Limiar}

A fim de analisar se a dependência da tensão de limiar nas características dos dispositivos é corretamente prevista pelo modelo, simulações variando a largura do fin e a altura do mesmo entre $5 \mathrm{~nm}$ e $30 \mathrm{~nm}$, a espessura do óxido de porta entre $1 \mathrm{~nm}$ e $7 \mathrm{~nm}$ e a concentração de dopantes entre $0,5 \times 10^{19} \mathrm{~cm}^{-3}$ e $5 \times 10^{19} \mathrm{~cm}^{-3}$ foram realizadas. $O$ material de porta é o silício policristalino tipo P. A Figura 3.8 apresenta a corrente de dreno em função de tensão de porta para dispositivos de diversas larguras, 
apontando a tensão de limiar modelada. Pode-se notar que a definição de $\mathrm{V}_{\mathrm{TH}}$ como a depleção completa da camada de silício (item 2.2.2) é adequada para JNTs.

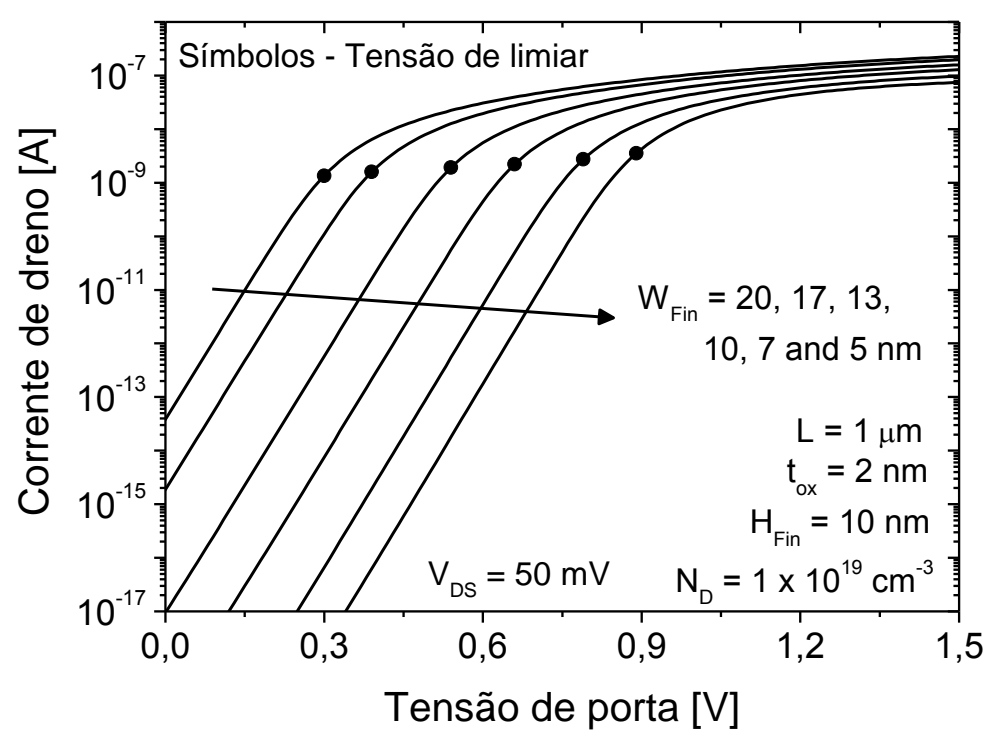

Figura 3.8 - Corrente de dreno versus tensão de porta para dispositivos de diferentes larguras apontando a tensão de limiar.

$\mathrm{Na}$ Figura 3.9 são apresentadas as tensões de limiar modeladas e simuladas em função da largura do fin (A), da altura do mesmo (B), da espessura do óxido de porta (C) e da concentração de dopantes (D). As tensões de limiar foram extraídas utilizando o método da segunda derivada da curva $I_{D} \times V_{G S}$ para $V_{D S}=50 m V^{110}$, conforme mencionado no item 3.1.3. Podese perceber que o modelo prevê adequadamente a dependência de $\mathrm{V}_{\mathrm{TH}}$ em função de $\mathrm{W}_{\text {Fin, }}, \mathrm{H}_{\mathrm{Fin}}, \mathrm{N}_{\mathrm{D}}$ e $\mathrm{t}_{\mathrm{ox}}$. $\mathrm{O}$ máximo erro apresentado na Figura 3.9 foi de $33 \mathrm{mV}$. Pode-se observar também que há uma redução na tensão de limiar ao se aumentar a largura, a altura ou a concentração de dopantes do dispositivo, devido à maior carga de depleção e ao maior valor absoluto do potencial de superfície na condição de limiar.

O modelo da equação (3.10) foi desenvolvido como forma de se calcular a tensão de limiar em um dispositivo porta-tripla. Para um dispositivo planar, a tensão de limiar pode ser calculada conforme proposto por Colinge et al. ${ }^{1}$. A fim de se analisar até quais dimensões de dispositivo o modelo proposto pode ser adequadamente utilizado, o valor da tensão de limiar é apresentado em função da largura do fin em escala logarítmica na Figura 3.10. Pode-se notar que o modelo proposto apresenta uma boa concordância com $V_{T H}$ simulado 
para dispositivos com largura de até $80 \mathrm{~nm}$, nas duas concentrações de dopantes analisadas. Para dispositivos mais largos, a influência do campo elétrico das portas laterais se torna desprezível, sendo que o dispositivo se comporta como um transistor planar.
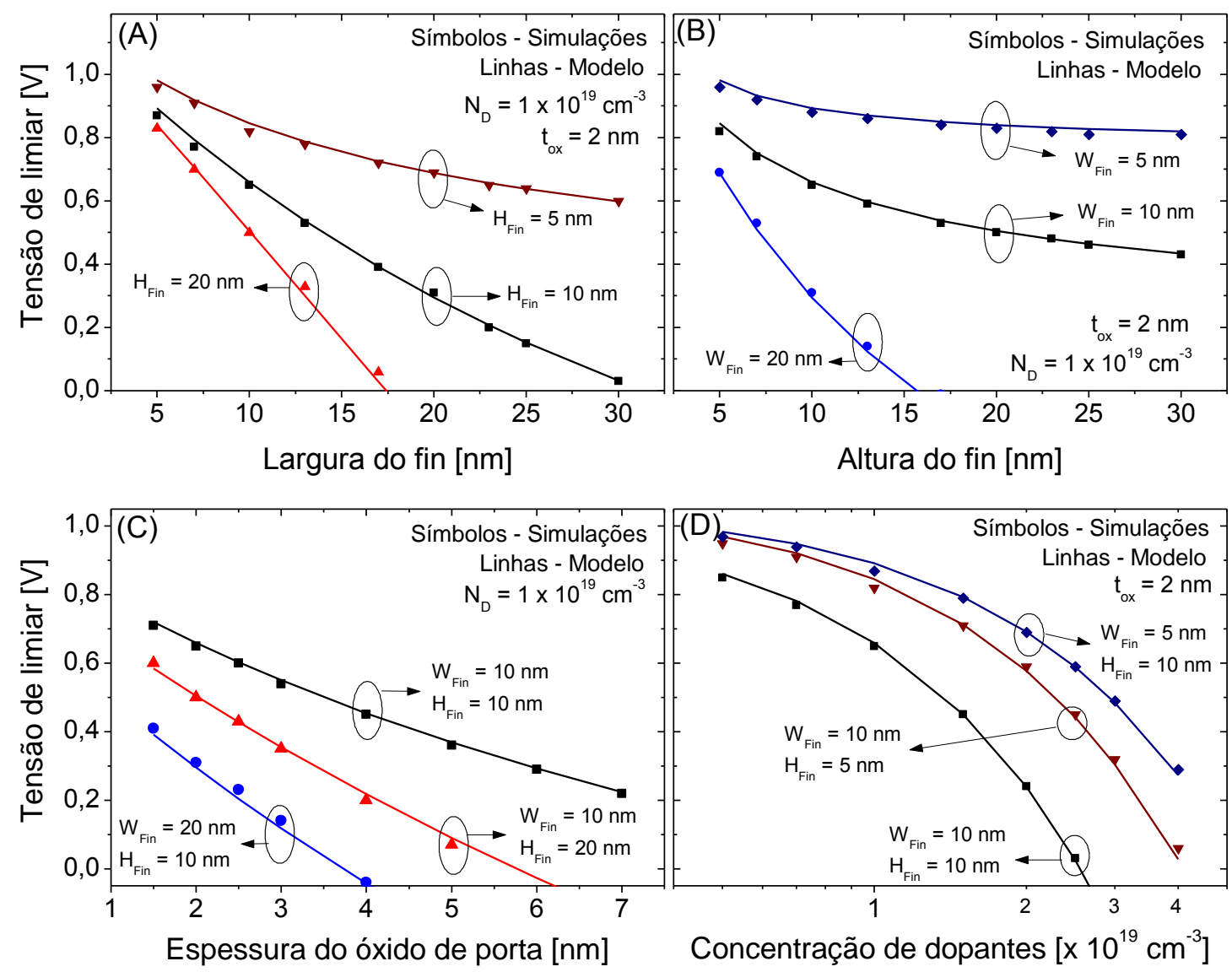

Figura 3.9 - Tensão de limiar simulada e modelada em função da largura do fin (A), da altura do mesmo (B), da espessura do óxido de porta (C) e da concentração de dopantes (D).

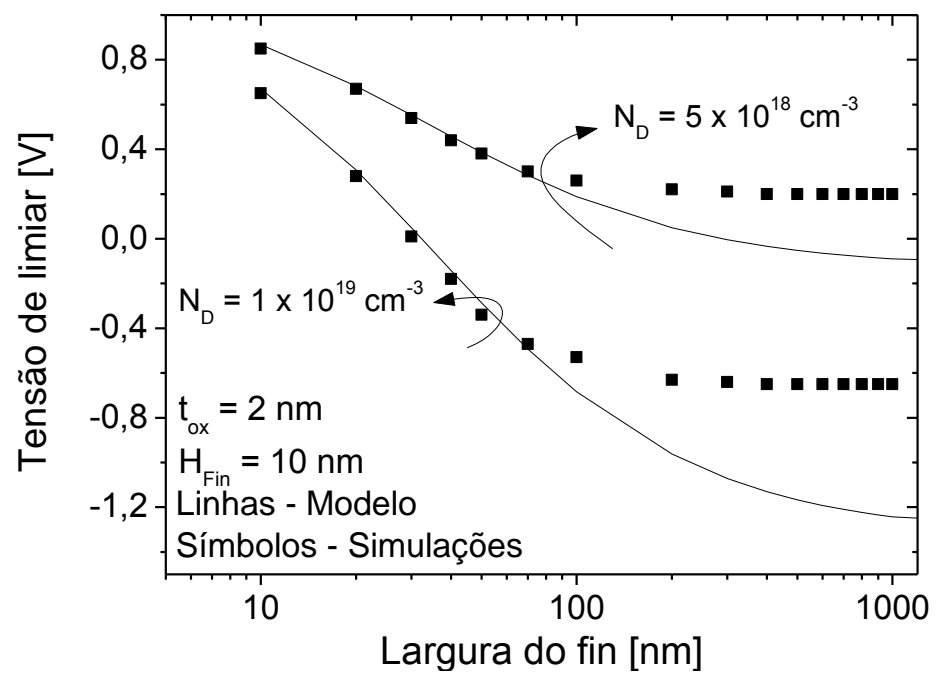

Figura 3.10 - Tensão de limiar simulada e modelada em função da largura do fin em escala logarítmica. 
Na Figura 3.11, a tensão de limiar é apresentada em função da altura do fin em escala logarítmica. Para a concentração de dopantes mais altas, o modelo proposto apresenta uma boa concordância com $0 \mathrm{~V}_{\mathrm{TH}}$ simulado até uma altura de aproximadamente $70 \mathrm{~nm}$. Já para a concentração mais baixa, o modelo resulta em valores de $\mathrm{V}_{\mathrm{TH}}$ similares aos simulados em toda a faixa de $\mathrm{H}_{\text {Fin. }}$.

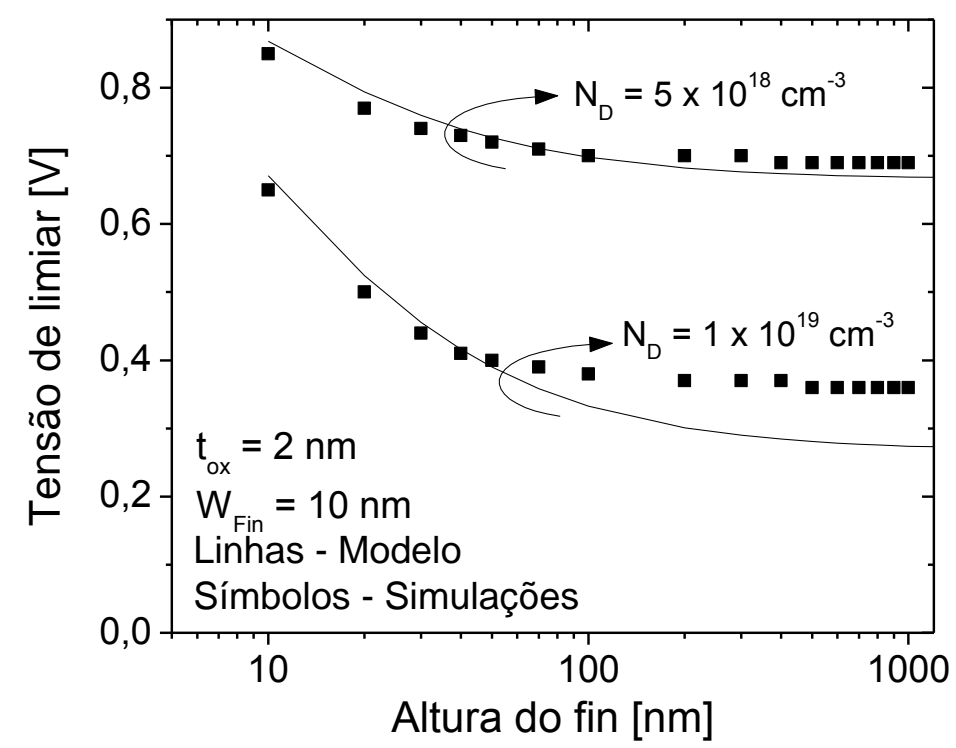

Figura 3.11 - Tensão de limiar simulada e modelada em função da altura do fin em escala logarítmica.

Depois da comparação com as simulações tridimensionais, $\mathrm{V}_{\mathrm{TH}}$ modelado foi comparado com resultados experimentais. Os dispositivos nMOS medidos foram fabricados no Tyndall National Institute, Cork, Irlanda, de acordo com Colinge et al. ${ }^{5}$. A altura do fin foi reduzida para aproximadamente $10 \mathrm{~nm}$ através de oxidação de sacrifício e remoção úmida. A largura de máscara $\left(W_{\text {masc }}\right)$ varia entre $23 \mathrm{~nm}$ e $50 \mathrm{~nm}$ e foi definida através de litografia por feixe de elétrons, sendo que é esperada uma redução de 5 10 nm na largura efetiva do dispositivo. O comprimento de canal é de $1 \mu \mathrm{m}$. Para cada $W_{\text {masc }}$, doze dispositivos diferentes foram medidos em regiões distintas da lâmina, que podem apresentar pequenas variações nas dimensões e/ou concentração de dopantes. Foi utilizado o Sistema de Caracterização de Semicondutores Keithley 4200 para a realização da medidas. Os dispositivos apresentam $N_{D}=$ $1 \times 10^{19} \mathrm{~cm}^{-3}$ e $t_{\mathrm{ox}}=10 \mathrm{~nm}$. O método de extração de $\mathrm{V}_{\mathrm{TH}}$ utilizado é o da segunda derivada ${ }^{110}$, de forma similar aos dispositivos simulados, onde a curva $I_{D} \times V_{G S}$ para $V_{D S}=50 \mathrm{mV}$ é usada. Na Figura 3.12, a comparação entre $V_{T H}$ 
medido e modelado é apresentada em função da largura efetiva do fin para dispositivos nMOS, considerando uma redução de $8 \mathrm{~nm}$ em $W_{\text {masc. }}$ O modelo apresenta boa concordância com os dispositivos experimentais.

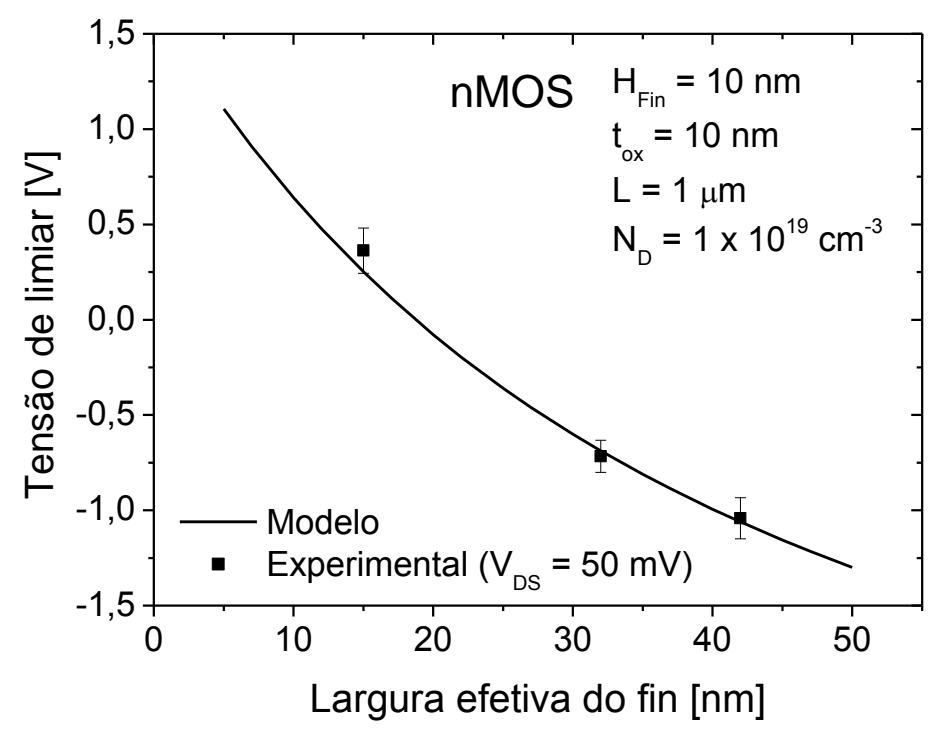

Figura 3.12 - Comparação entre dados experimentais e o modelo proposto em função da largura efetiva do fin para dispositivos nMOS.

Dispositivos pMOS fabricados de acordo com Colinge et al. ${ }^{5}$ no Tyndall National Institute, Cork, Irlanda, também foram medidos, sendo $\mathrm{V}_{\mathrm{TH}}$ apresentado na Figura 3.13. Neste caso, o material de porta é silício policristalino tipo $\mathrm{N}^{+}$, sendo a tensão de faixa plana próxima de $-1,1 \mathrm{~V}$. Para cada $\mathrm{W}_{\text {masc }}$, seis dispositivos diferentes foram medidos. Novamente, o modelo apresenta boa concordância com os resultados experimentais.

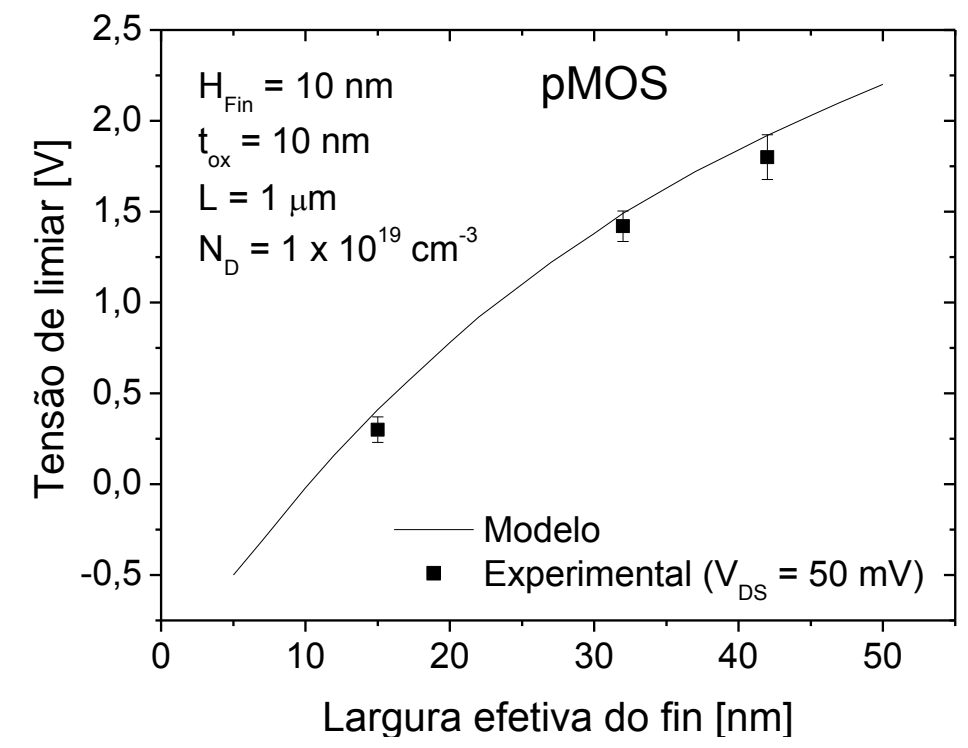

Figura 3.13 - Tensão de limiar em função da largura efetiva do fin comparando o modelo proposto com os dados experimentais para dispositivos pMOS. 


\subsubsection{Influência da Temperatura}

A tensão de limiar é apresentada na Figura 3.14 para dispositivos longos $(L=1 \mu \mathrm{m})$ de diferentes dimensões em função da temperatura, comparando os valores obtidos com o modelo proposto com resultados simulados. As tensões de limiar dos dispositivos simulados foram extraídas utilizando-se o método da segunda derivada da curva $I_{D} \times V_{G S}{ }^{110}$, com $V_{D S}=50 \mathrm{mV}$. Pode-se perceber que o modelo prevê adequadamente a dependência de $\mathrm{V}_{\mathrm{TH}}$ com a temperatura com erro máximo de $35 \mathrm{mV}$, sendo a variação $\mathrm{dV}_{\mathrm{TH}} / \mathrm{dT}$ aproximadamente linear. Com a redução da temperatura, ocorre um aumento na tensão de limiar, o que está relacionado ao aumento da tensão de faixa plana e à redução da concentração de dopantes ionizados. Na Figura 3.15, a variação da tensão de limiar com a temperatura é apresentada em função da concentração de dopantes para dispositivos nMOS com diferentes larguras de fin. Nesta figura também estão presentes dados experimentais dos mesmos dispositivos do item 3.1.4, mostrando que $\mathrm{dV}_{\mathrm{TH}} / \mathrm{dT}$ é corretamente descrito pelo modelo. Podese perceber que essa variação aumenta com a largura do fin e com a redução da concentração de dopantes. Estes dispositivos foram medidos em uma faixa de temperatura entre $100 \mathrm{~K}$ e $483 \mathrm{~K}$.

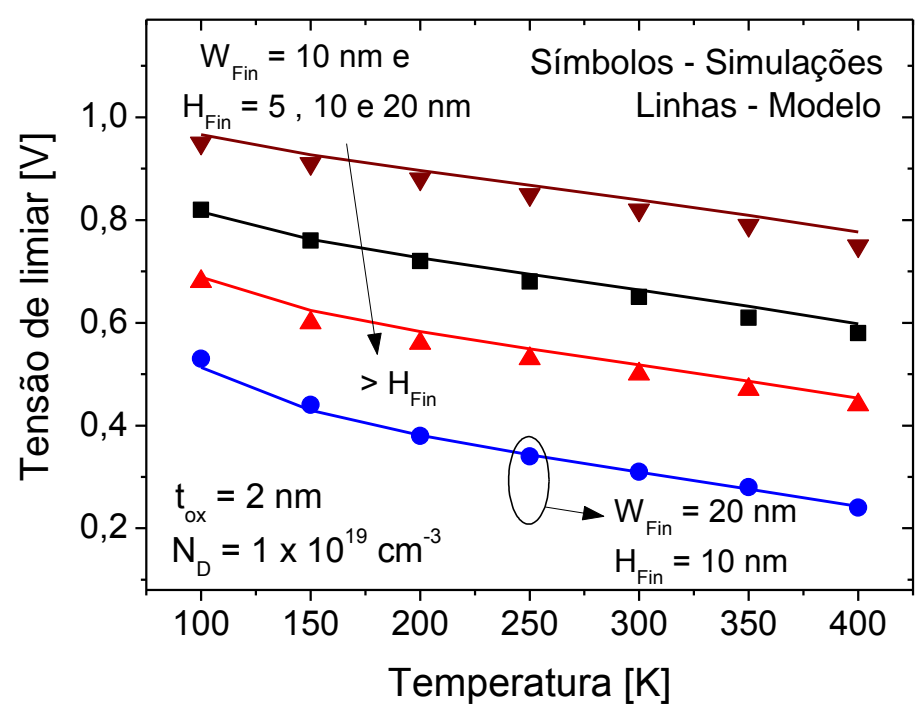

Figura 3.14 - Tensão de limiar em função da temperatura para dispositivos nMOS simulados de diferentes dimensões. 
A mesma dependência de $\mathrm{V}_{\mathrm{TH}}$ com a temperatura pode ser observada em dispositivos pMOS conforme apresentado na Figura 3.16. Ao se aumentar $\mathrm{W}_{\mathrm{Fin}}$, a variação $\mathrm{dV} \mathrm{V}_{\mathrm{TH}} / \mathrm{dT}$ aumenta. Estes dispositivos foram medidos em uma faixa de temperatura entre $223 \mathrm{~K}$ e $363 \mathrm{~K}$.

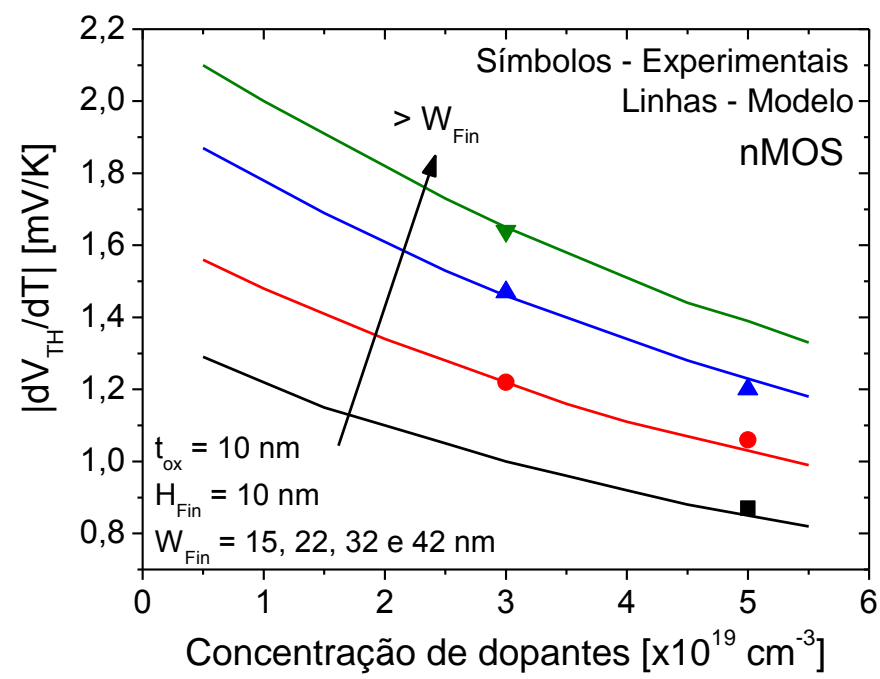

Figura 3.15 - Variação da tensão de limiar com a temperatura em função da concentração de dopantes para resultados modelados e experimentais de dispositivos nMOS.

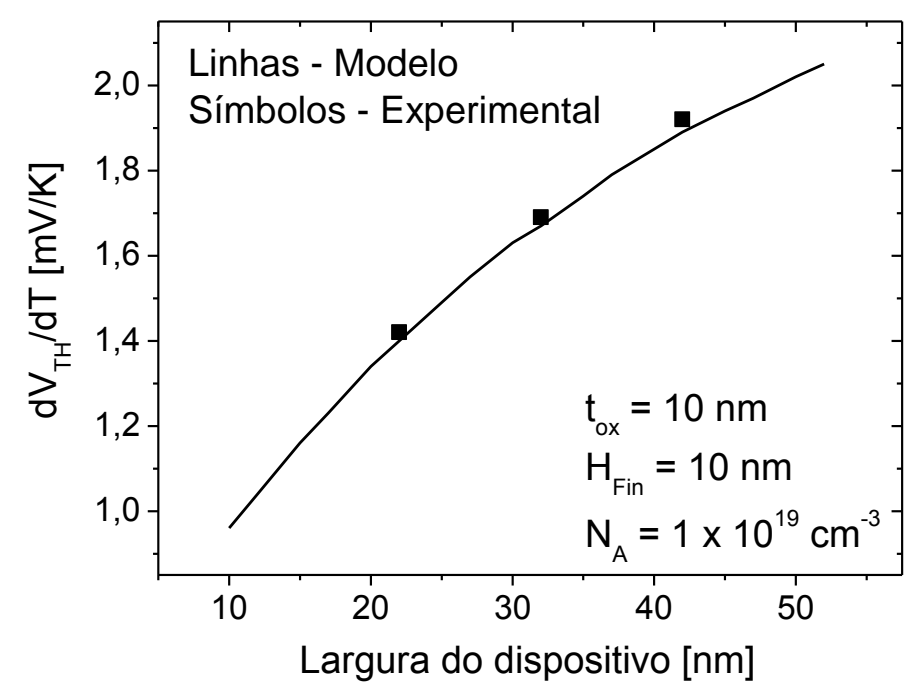

Figura 3.16 - Variação da tensão de limiar com a temperatura em função da largura do fin comparando o modelo proposto com resultados experimentais de dispositivos pMOS.

A fim de se analisar a influência da temperatura em $V_{T H}$, a equação (3.12) foi diferenciada em relação a T:

$$
\frac{\partial \mathrm{V}_{\mathrm{TH}}}{\partial \mathrm{T}}=\frac{\partial \mathrm{V}_{\mathrm{FB}}}{\partial \mathrm{T}}-\left(\frac{\mathrm{q}}{\varepsilon_{\mathrm{Si}}}\left(\frac{\mathrm{A}}{\mathrm{W}_{\mathrm{ox}}}\right)^{2}+\frac{\mathrm{qA}}{\mathrm{C}_{\mathrm{ox}}}\right) \frac{\partial \mathrm{N}_{\mathrm{D}}}{\partial \mathrm{T}}+\frac{1}{\mathrm{q}} \frac{\partial \Delta \mathrm{E}_{0}}{\partial \mathrm{T}}
$$


Como nos dispositivos nMOS o material de porta é o silício policristalino $\mathrm{P}^{+}$, o primeiro termo da equação (3.14) $\left(\theta_{1}=\partial \mathrm{V}_{\mathrm{FB}} / \partial \mathrm{T}\right)$ depende das variações do potencial de Fermi e da largura de faixa proibida com a temperatura. $O$ segundo termo $\left(\theta_{2}=-\left(\frac{\mathrm{q}}{\varepsilon_{\mathrm{si}}}\left(\frac{\mathrm{A}}{\mathrm{W}_{\mathrm{ox}}}\right)^{2}+\frac{\mathrm{qA}}{\mathrm{C}_{\mathrm{ox}}}\right) \frac{\partial \mathrm{N}_{\mathrm{D}}}{\partial \mathrm{T}}\right)$ está relacionado somente com a dependência de $N_{D}$ em T. O terceiro termo depende da massa efetiva, que possui uma pequena dependência com $T$, no entanto, esta dependência é menor que a dos outros dois termos. A fim de se analisar a influência de cada termo da equação (3.14) na dependência de $V_{T H} \operatorname{com} T$, os termos $\theta_{1}$ e $\theta_{2}$ são apresentados na Figura 3.17 em função da concentração de dopantes para diversas larguras de fin, similares às larguras dos dispositivos utilizados nos experimentos. Pode-se notar que o segundo termo $\left(\theta_{2}\right)$ domina a variação $\mathrm{dV}_{\mathrm{TH}} / \mathrm{dT}$. Apenas para dispositivos com concentrações de dopantes mais baixas, o termo $\theta_{1}$ poderia ter uma influência maior. Pode-se ainda perceber que $d N_{D} / d T$ é multiplicado por um termo relacionado às dimensões dos dispositivos, aumentando o efeito de $\mathrm{dN} \mathrm{N}_{\mathrm{D}} / \mathrm{dT}$ para dispositivos com dimensões maiores.

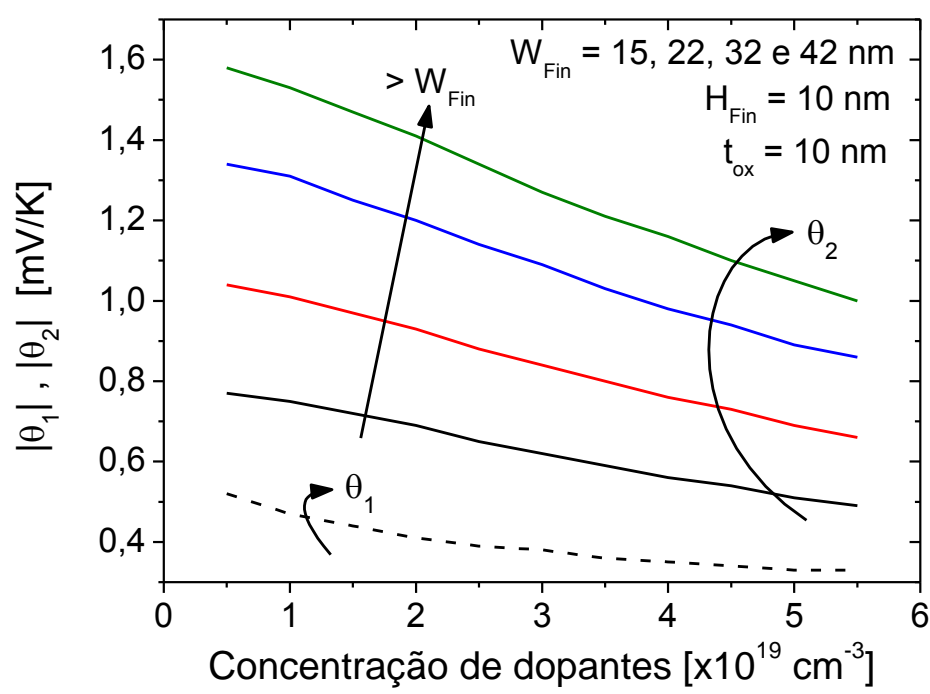

Figura 3.17 - Componentes da variação da tensão de limiar com a temperatura $\left(\theta_{1}\right.$ e $\left.\theta_{2}\right)$ em função da concentração de dopantes.

Apesar da concentração de dopantes nos JNTs ser maior que a transição de Mott ${ }^{57,60}$, o que significa que a taxa de impurezas ionizadas em relação às impurezas ativas tende à unidade em qualquer temperatura, $N_{D}$ tem uma importante influência em $d V_{T H} / d T$. A taxa de ionização calculada usando o 
modelo de Altermatt et al. ${ }^{59}$ é apresentada na Figura 3.18 em função da temperatura. Pode-se notar que a taxa de ionização é muito próxima da unidade conforme $N_{D}$ é aumentado. No entanto, esta pequena variação em $N_{D}$ pode deslocar a tensão de limiar como apresentado na Figura 3.19, que apresenta a diferença de $\mathrm{V}_{\mathrm{TH}}$ modelada com e sem o modelo de ionização

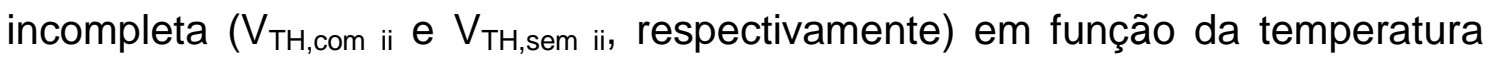
para um dispositivo com $\mathrm{W}_{\text {Fin }}=\mathrm{H}_{\text {Fin }}=\mathrm{t}_{\mathrm{ox}}=10 \mathrm{~nm}$. Para uma concentração de dopantes de $N_{D}=5 \times 10^{18} \mathrm{~cm}^{-3}$, esta variação de $V_{T H}$ pode chegar a $100 \mathrm{mV}$ em $100 \mathrm{~K}$.

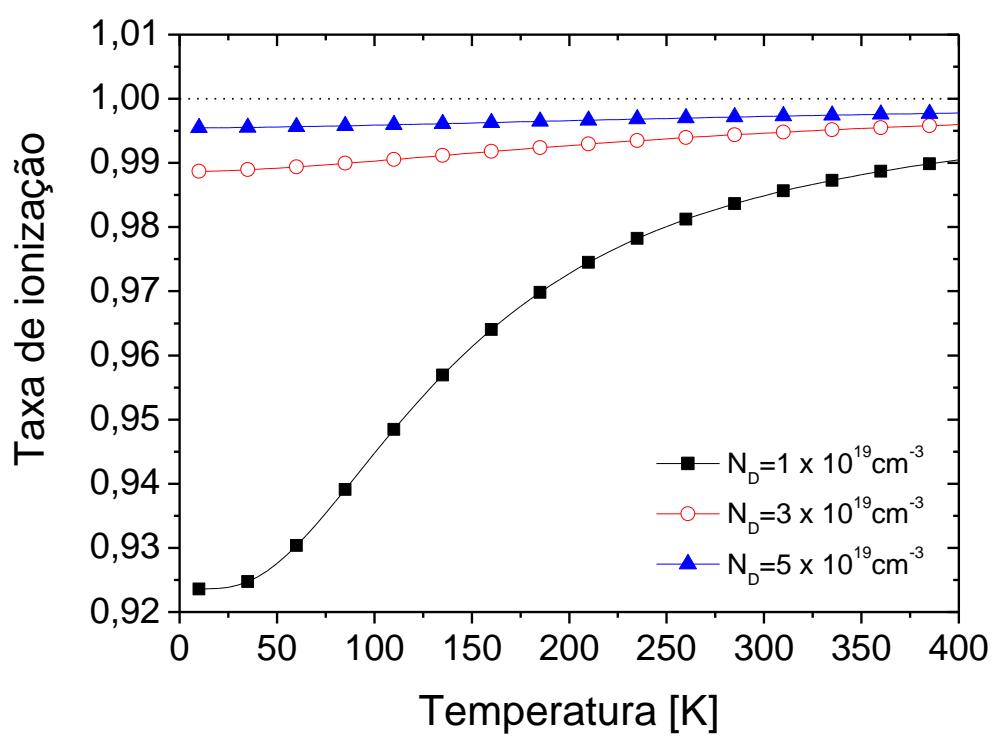

Figura 3.18 - Taxa de ionização das impurezas em função da temperatura para diversas concentrações de dopantes.

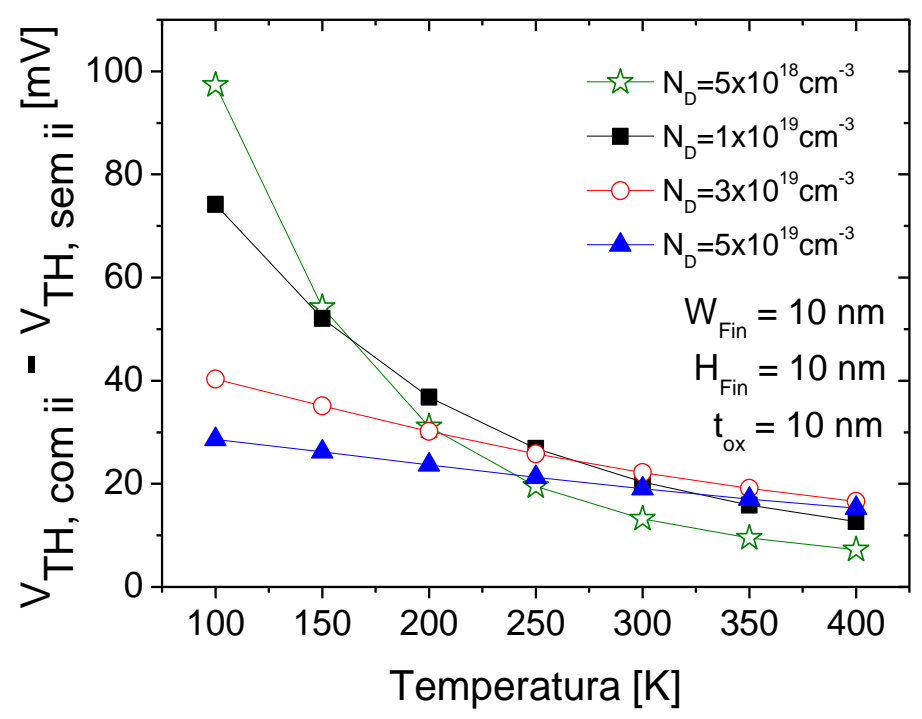

Figura 3.19 - Diferença entre a tensão de limiar calculada utilizando o modelo de ionização incompleta $\left(\mathrm{V}_{\mathrm{TH}, \text { com ii }}\right)$ e sem considera-lo $\left(\mathrm{V}_{\mathrm{TH} \text {,sem ii }}\right)$ em função da temperatura. 


\subsubsection{Efeito da Polarização de Substrato}

Por fim, foi analisada a influência da polarização de substrato na tensão de limiar. A Figura 3.20 mostra a variação da curva de corrente de dreno em função da tensão de porta para diversas polarizações de substrato $\left(\mathrm{V}_{\mathrm{BS}}\right)$.

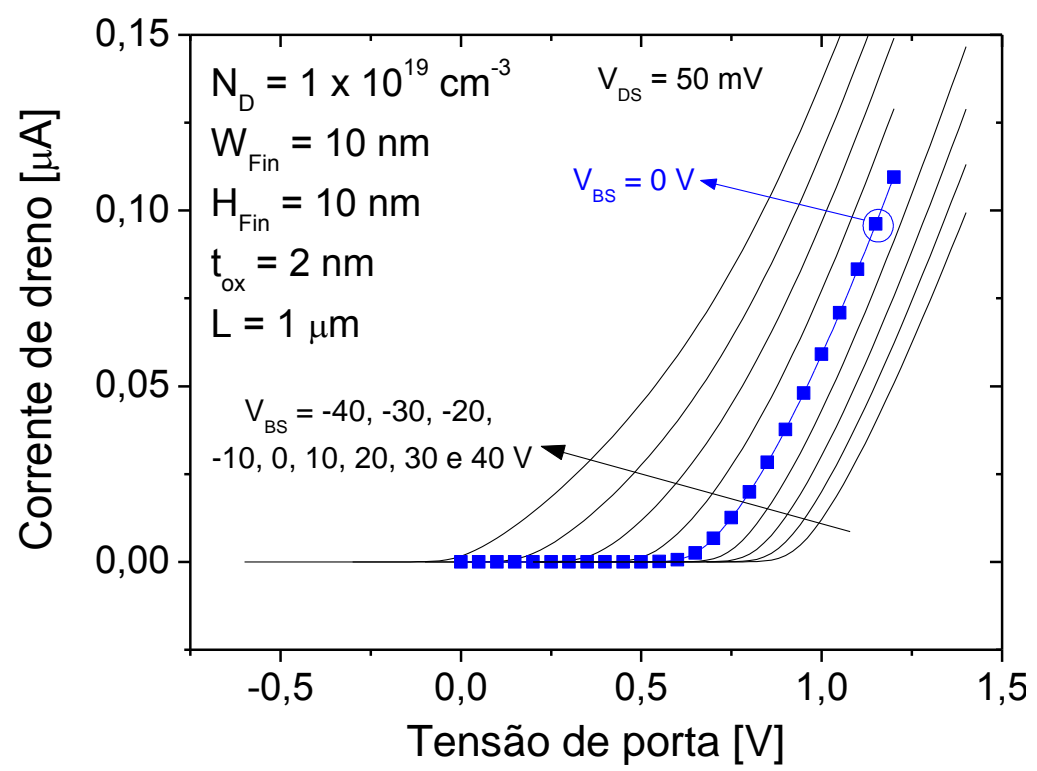

Figura 3.20 - Corrente de dreno em função da tensão de porta analisando-se a influência da polarização de substrato.

A Figura 3.21 mostra os valores de tensão de limiar extraídos da Figura 3.20 em função da tensão de substrato, utilizando-se o método da segunda derivada ${ }^{110}$. Para valores positivos de tensão de substrato (maiores que a tensão de faixa plana entre substrato e canal, que é $\mathrm{V}_{\mathrm{FBs}} \approx 0,8 \mathrm{~V}$ - calculada considerando-se que o silício abaixo do óxido enterrado é tipo $p$ com concentração de $\mathrm{N}_{\mathrm{A}}=10^{15} \mathrm{~cm}^{-3}$ ), há a formação de uma camada de acumulação na interface com o substrato. Para que o dispositivo não conduza nessa condição, é necessária uma tensão de porta menor, de forma a atrair mais cargas positivas a fim de se neutralizar as cargas negativas atraídas pela tensão de substrato. Nessa região da curva, a tensão de limiar varia linearmente com a tensão de substrato, conforme indicado pela linha tracejada. Isso ocorre porque o segundo termo que equação (3.9), que está relacionado à carga, é proporcional à mesma, que por sua vez varia de forma proporcional à tensão aplicada ao substrato. 


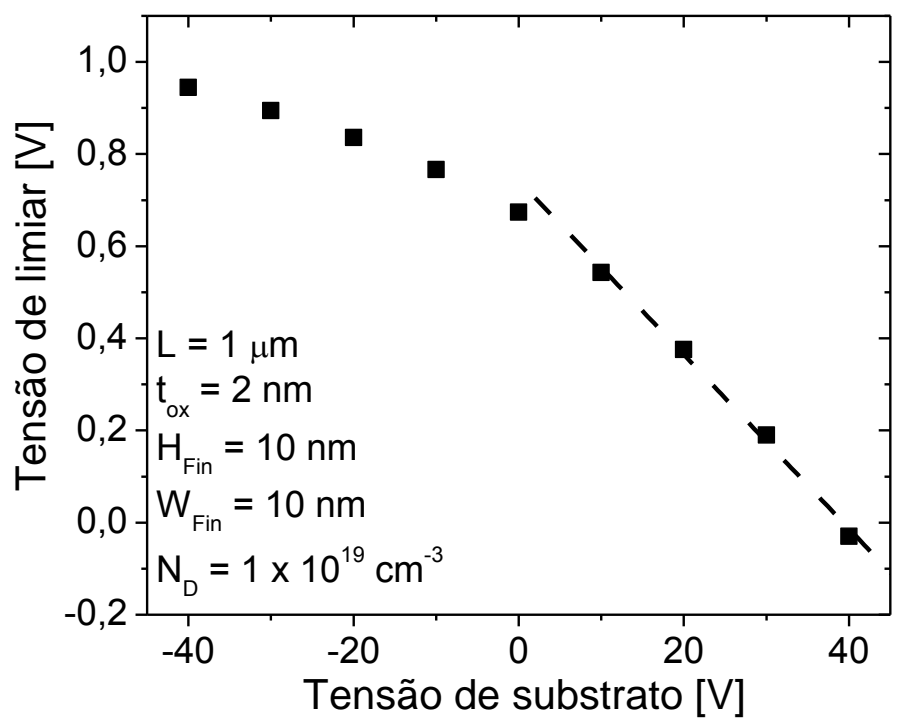

Figura 3.21 - Tensão de limiar em função da tensão aplicada ao substrato para os dispositivos simulados.

Uma forma de se considerar o efeito da acumulação na interface com o substrato na tensão de limiar é acrescentar a dependência da carga $Q_{S i}$ na tensão de substrato. Assim, para $\mathrm{V}_{\mathrm{BS}}>\mathrm{V}_{\mathrm{FBs}}$, $\mathrm{Q}_{\mathrm{Si}}$ passa a ser descrita por:

$$
Q_{\mathrm{Si}}=\mathrm{qN}_{\mathrm{D}} \mathrm{H}_{\mathrm{Fin}} \mathrm{W}_{\mathrm{Fin}}-\frac{\varepsilon_{\mathrm{ox}} \mathrm{W}_{\mathrm{Fin}}}{\mathrm{t}_{\mathrm{Box}}}\left(\mathrm{V}_{\mathrm{FBs}}-\mathrm{V}_{\mathrm{BS}}\right)
$$

Para tensões de substrato menores que a tensão de faixa plana, há a formação de uma camada de depleção nas proximidades da interface com o óxido enterrado. Neste caso, a variação da tensão de limiar com a tensão de substrato é diferente daquela em que a condição na interface do canal com o óxido enterrado é de acumulação. Com o intuito de considerar a camada de depleção na interface silício/óxido enterrado, a profundidade da região de depleção $\left(x_{\text {depl }}\right)$ pode ser calculada pela equação ${ }^{47}$ :

$$
\mathrm{x}_{\mathrm{depl}}=-\frac{\varepsilon_{\mathrm{Si}} \mathrm{t}_{\mathrm{Box}}}{\varepsilon_{\mathrm{ox}}} \sqrt{\left(\frac{\varepsilon_{\mathrm{Si}} \mathrm{t}_{\mathrm{Box}}}{\varepsilon_{\mathrm{ox}}}\right)^{2}+\frac{2 \varepsilon_{\mathrm{Si}}}{\mathrm{qN}_{\mathrm{D}}}\left(\mathrm{V}_{\mathrm{FBs}}-\mathrm{V}_{\mathrm{BS}}\right)}
$$

A altura efetiva do dispositivo que será utilizada no cálculo da tensão de limiar no termo relacionado à carga de depleção será considerada como $\left(\mathrm{H}_{\mathrm{Fin}}-\right.$

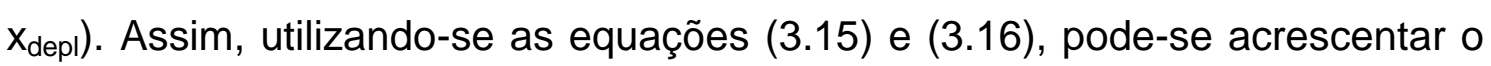
efeito da polarização do substrato na tensão de limiar. A Figura 3.22 mostra a 
comparação entre simulação e modelagem para dispositivos de diferentes características, mostrando que o efeito da polarização de substrato pode ser adicionado ao modelo de tensão de limiar de uma forma simples e efetiva. Para a extração de $\mathrm{V}_{\mathrm{TH}}$, foi utilizada a curva $\mathrm{I}_{\mathrm{D}} \times \mathrm{V}_{\mathrm{GS}}$ para $\mathrm{V}_{\mathrm{DS}}=50 \mathrm{mV}$.
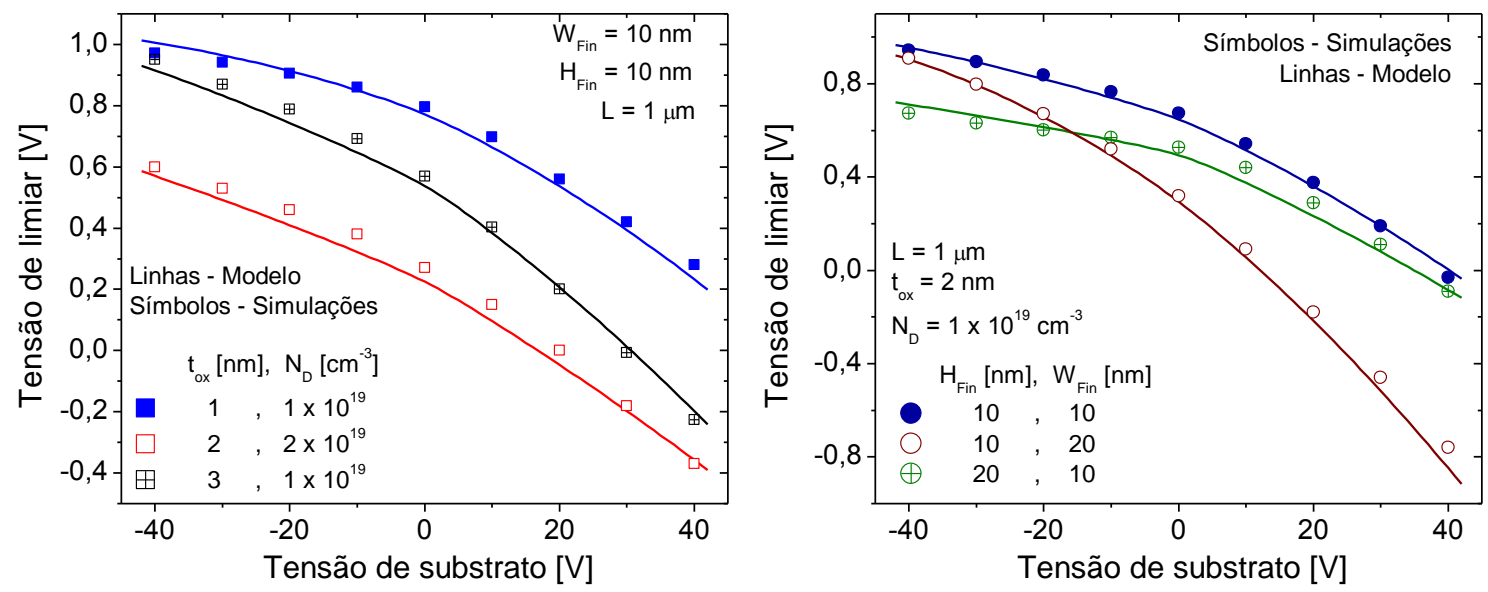

Figura 3.22 - Tensão de limiar modelada e simulada em função da tensão aplicada ao substrato para dispositivos de diferentes dimensões.

\subsection{DISPOSITIVO DE SEÇÃO TRANSVERSAL CIRCULAR}

\subsubsection{Desenvolvimento do Modelo}

A Figura 3.23 apresenta a vista esquemática e o corte transversal de um JNT com seção transversal circular.

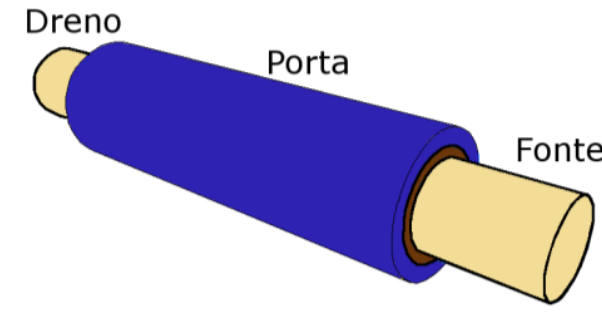

(A)

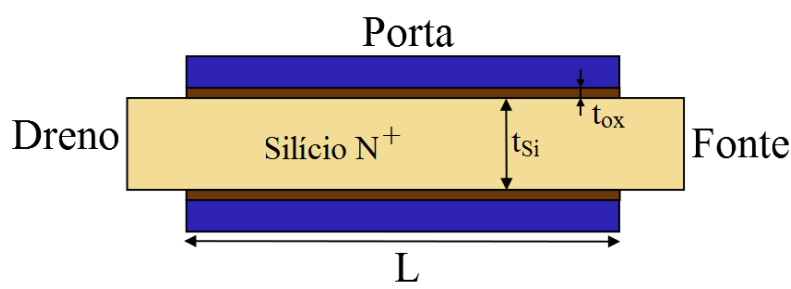

(B)

Figura 3.23 - Vista esquemática de um JNT com seção transversal circular (A) e o corte transversal desse dispositivo (B). 
Neste caso a equação de Poisson em coordenadas cilíndricas é descrita por:

$$
\frac{1}{r} \frac{d}{d r}\left(r \frac{d \phi}{d r}\right)=-\frac{q N_{D}}{\varepsilon_{S i}}
$$

onde ré a direção radial.

Usando as mesmas condições de contorno, tal como descrito no item 3.1.1 (potencial e campo elétrico nulos no centro), pode-se integrar a equação (3.17):

$$
\phi=-\frac{q N_{D}}{\varepsilon_{S i}} \frac{r^{2}}{4}
$$

Quando $r=t_{s i} / 2$, tem-se que $\phi$ é o potencial de superfície:

$$
\phi_{\mathrm{S}}=-\frac{\mathrm{q} \mathrm{N}_{\mathrm{D}}}{\varepsilon_{\mathrm{Si}}} \frac{\mathrm{t}_{\mathrm{Si}}{ }^{2}}{16}
$$

Usando a relação do capacitor MOS apresentada pela equação (3.8), sendo $Q=Q_{S i}=q \cdot N_{D} \cdot \pi \cdot t_{S i}{ }^{2} / 4$ na condição de limiar para o dispositivo cilíndrico, substituindo $\Phi_{S}$ pela equação (3.19) e isolando $V_{G S}$, pode-se obter:

$$
V_{G S}=V_{T H}=V_{F B}-\frac{q N_{D}}{\varepsilon_{S i}} \frac{t_{S i}{ }^{2}}{16}-\frac{q N_{D} \pi t_{S i}^{2}}{4 C_{o x}}
$$

Vale a pena ressaltar que no caso de um capacitor cilíndrico, a capacitância $\mathrm{C}_{\mathrm{ox}}$ é descrita por ${ }^{113}$ :

$$
C_{o x}=\frac{2 \pi \varepsilon_{o x}}{\ln \left(1+\frac{2 t_{o x}}{t_{s i}}\right)}
$$

Conforme mencionado no item 3.1.1, deve-se acrescentar um termo na equação (3.20) a fim de contabilizar o efeito de confinamento quântico ${ }^{78,114}$. Assim, a equação completa de $\mathrm{V}_{\mathrm{TH}}$ em dispositivos cilíndricos é descrita por: 


$$
V_{T H}=V_{F B}-\frac{q N_{D}}{\varepsilon_{S i}} \frac{t_{S i}^{2}}{16}-\frac{q N_{D} \pi t_{S i}^{2}}{4 C_{o x}}+\frac{0,765^{2} h^{2}}{2 m^{*} \mathrm{qt}_{\mathrm{Si}}^{2}}
$$

Pode-se observar que a equação (3.22) também pode ser reescrita da mesma forma que a equação (3.12). Portanto, a equação (3.12) pode ser considerada como uma equação genérica para $\mathrm{V}_{\mathrm{TH}}$ em JNTs.

\subsubsection{Validação do Modelo}

Para validar o modelo em dispositivos cilíndricos, foram utilizadas simulações tridimensionais de acordo com o item 2.7. Assim como no item 3.1.3, foi considerado um dispositivo com $L=1 \mu \mathrm{m}$ e silício policristalino $\mathrm{P}^{+}$na porta. A espessura $t_{\mathrm{Si}}$ varia entre $5 \mathrm{~nm}$ e $20 \mathrm{~nm}$, tox entre $1 \mathrm{~nm}$ e $7 \mathrm{~nm}, \mathrm{~N}_{\mathrm{D}}$ entre $5 \times 10^{18} \mathrm{~cm}^{-3}$ e $10^{20} \mathrm{~cm}^{-3}$ e a temperatura entre $100 \mathrm{~K}$ e $400 \mathrm{~K}$. O método da segunda derivada da curva $I_{D} \times V_{G S}$ para $V_{D S}=50 \mathrm{mV}$ foi utilizado para extrair $\mathrm{V}_{\mathrm{TH}}{ }^{110}$.

A Figura 3.24 apresenta a tensão de limiar em função da espessura do óxido de porta (A) e da concentração de dopantes (B) para diversos valores de $t_{\mathrm{s}}$, comparando o modelo analítico com as simulações. Pode-se observar que 0 modelo prevê corretamente a dependência de $\mathrm{V}_{T H}$ com $t_{\mathrm{ox}}$, $\mathrm{t}_{\mathrm{Si}}$ e $\mathrm{N}_{\mathrm{D}}$.
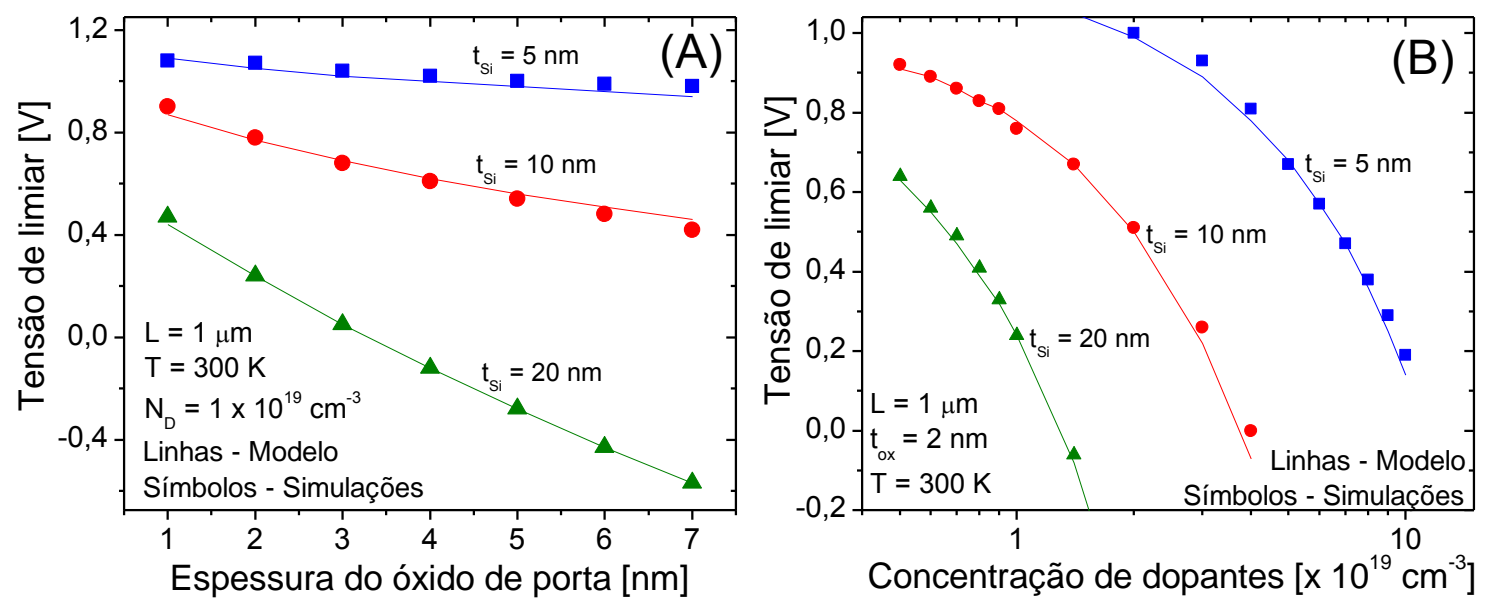

Figura 3.24 - Tensão de limiar em função da espessura do óxido de porta (A) e da concentração de dopantes (B) para dispositivos cilíndricos com diversas espessuras de silício. 
$\mathrm{Na}$ Figura 3.25, a tensão de limiar é apresentada em função da temperatura, mostrando que $\mathrm{V}_{\mathrm{TH}}$ aumenta com a redução de $\mathrm{T}$. Assim como no item 3.1.5, esse incremento em $\mathrm{V}_{\mathrm{TH}}$ se deve à redução da concentração de dopantes ionizados e ao aumento da tensão de faixa plana. Novamente, podese notar a concordância entre o modelo e as simulações. Na Figura 3.26, a variação $\left|\mathrm{dV}_{\mathrm{TH}} / \mathrm{dT}\right|$ é apresentada em função da espessura $\mathrm{t}_{\mathrm{Si}}$. Assim como no caso dos dispositivos retangulares, $\left|\mathrm{dV}_{\mathrm{TH}} / \mathrm{dT}\right|$ aumenta com $\mathrm{t}_{\mathrm{Si}}$ e com a redução de $N_{D}$.

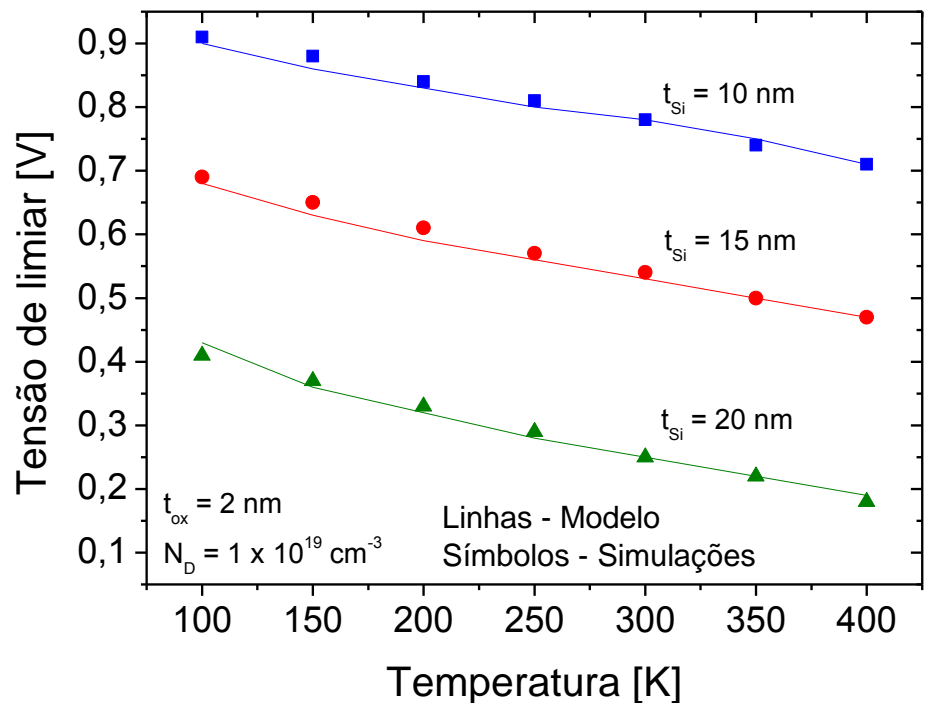

Figura 3.25 - Tensão de limiar em função da temperatura para dispositivos com diferentes espessuras $t_{\mathrm{Si}}$.

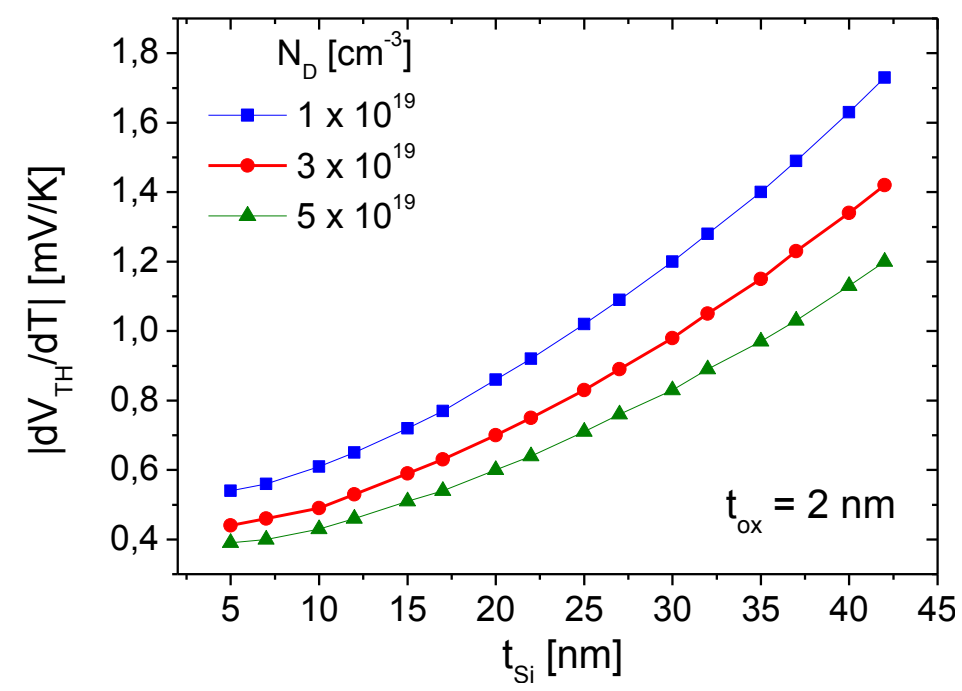

Figura 3.26 - Variação da tensão de limiar com a temperatura para JNTs cilíndricos em função da espessura $t_{\mathrm{si}}$. 


\subsection{COMPARAÇÃO ENTRE DISPOSITIVOS CILÍNDRICOS E PORTA TRIPLA}

Na Figura 3.27, a variação da tensão de limiar com a temperatura é apresentada em função da área da seção transversal (A) e do perímetro de porta (B), tanto para dispositivos porta tripla como para dispositivos cilíndricos com diversas concentrações de dopantes.

Analisando-se tanto em termos de área como de perímetro, os dispositivos cilíndricos apresentam uma menor dependência de $V_{T H}$ com a temperatura. Nos dispositivos porta tripla, a largura foi variada para se obter diferentes áreas e perímetros, sendo que a altura foi mantida igual a $10 \mathrm{~nm}$. Na Figura 3.27, são incluídos os resultados experimentais dos dispositivos portatripla, indicando a proximidade entre o modelo e os dispositivos medidos. A menor dependência de $\mathrm{V}_{\mathrm{TH}}$ com a temperatura dos dispositivos cilíndricos pode ser explicada pela equação (3.14), sendo esta variação diretamente proporcional à área e inversamente proporcional ao perímetro. Um dispositivo cilíndrico de mesma área que um dispositivo retangular com altura fixa $\left(\mathrm{H}_{\mathrm{Fin}}=\right.$ $10 \mathrm{~nm}$ ) apresenta perímetro menor, reduzindo $\left|\mathrm{dV}_{\mathrm{TH}} / \mathrm{dT}\right|$.

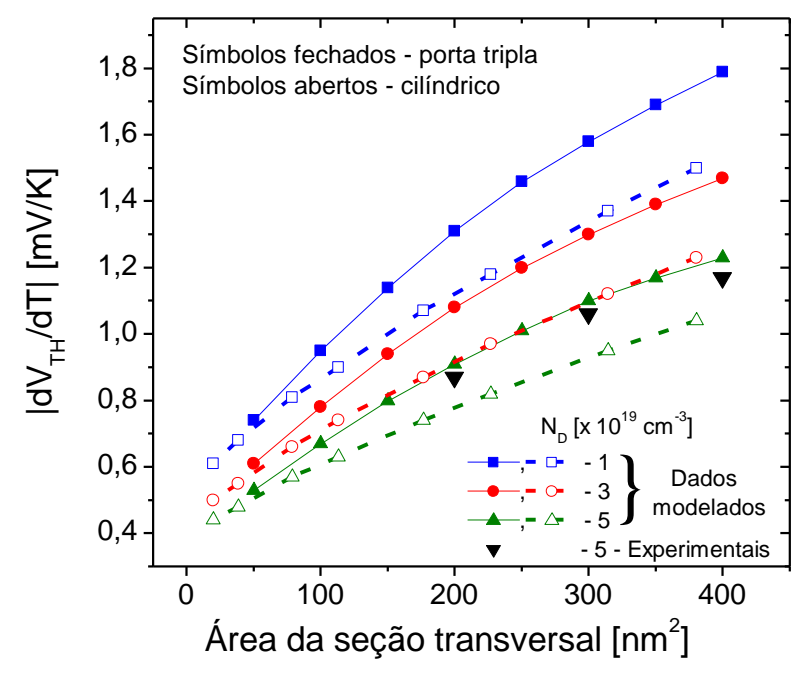

(A)

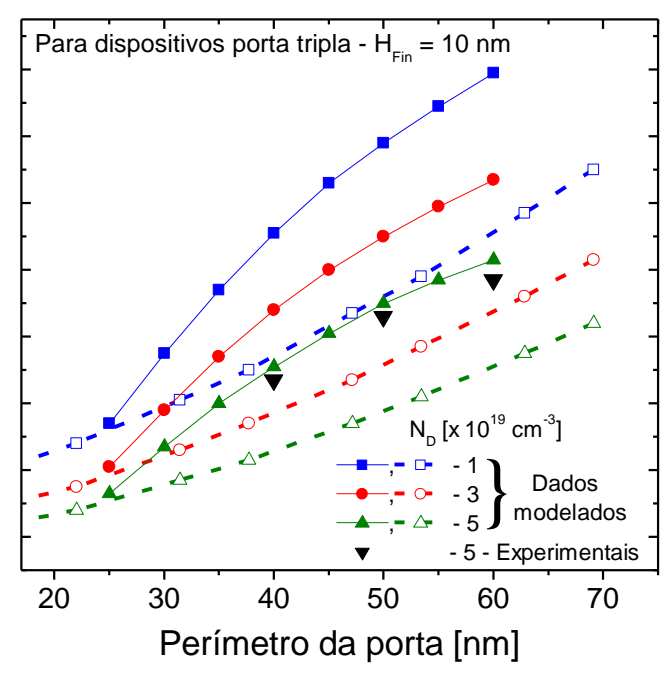

(B)

Figura 3.27 - Variação da tensão de limiar com T em função da área da seção transversal (A) e do perímetro de porta (B), comparando dispositivos porta tripla com $\mathrm{H}_{\text {Fin }}=10 \mathrm{~nm}$ e cilíndricos.

Uma segunda comparação foi realizada entre os dispositivos cilíndricos, nos quais o diâmetro foi variado, e os dispositivos porta tripla, onde a largura foi mantida em $10 \mathrm{~nm}$ enquanto $\mathrm{H}_{\mathrm{Fin}}$ foi variado. A Figura 3.28 apresenta a tensão 
de limiar em função da área de seção transversal e do perímetro de porta para diferentes concentrações de dopantes, a fim de se realizar essa comparação. Pode-se notar que, para dispositivos maiores, a variação $\left|\mathrm{dV}_{\mathrm{TH}} / \mathrm{dT}\right|$ é menor nos dispositivos porta tripla. No entanto, para dispositivos menores, transistores cilíndricos apresentam um comportamento melhor, que está relacionado ao maior perímetro para se atingir a mesma área de seção transversal. Assim, de forma geral, os dispositivos cilíndricos se mostraram menos sensíveis à variação da temperatura.

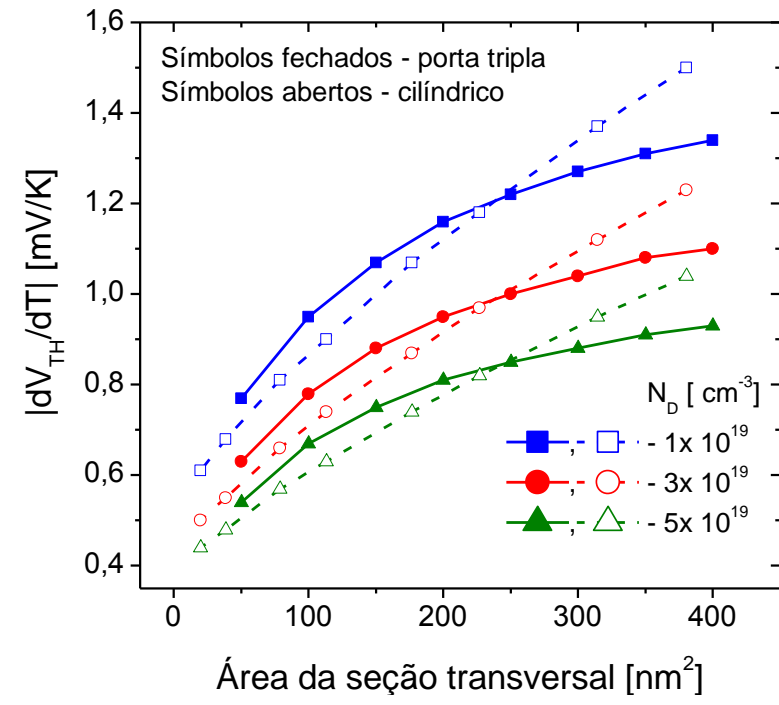

(A)

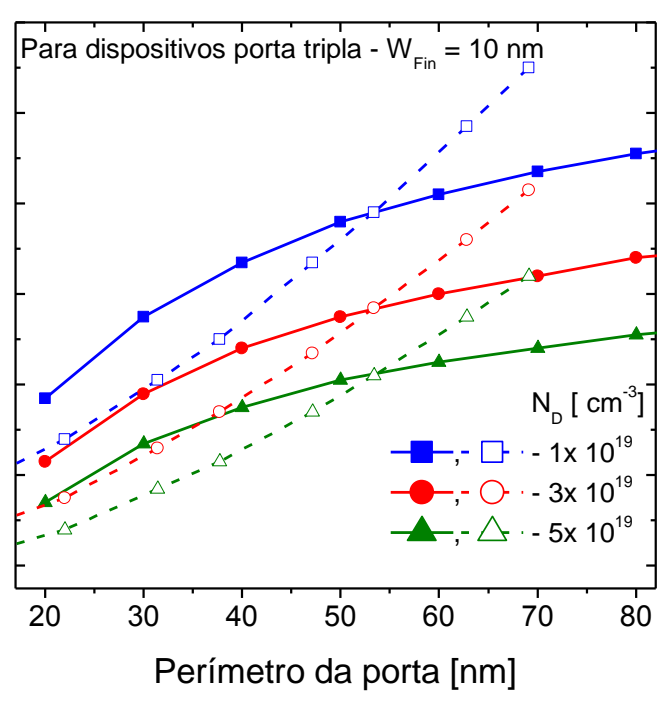

(B)

Figura 3.28 - Variação da tensão de limiar com T em função da área da seção transversal (A) e do perímetro de porta (B) comparando dispositivos porta tripla com $W_{\text {Fin }}=10 \mathrm{~nm}$ e cilíndricos.

Logo, foi apresentado neste Capítulo um modelo de tensão de limiar para dispositivos porta tripla e cilíndricos, sendo validado através de diversos resultados simulados e medidos. Através do modelo proposto, uma análise da influência dos cantos superiores e da temperatura foi realizada em um JNT porta tripla. No entanto, o modelo não permite a extração da tensão de limiar a partir das curvas $I_{D} \times V_{G s}$ de um dispositivo. Assim, uma metodologia para a extração de $\mathrm{V}_{\mathrm{TH}}$ é abordada no próximo Capítulo. 


\section{MÉTOdO DE EXTRAÇÃO DA TENSÃO DE LIMIAR}

No Capítulo 3 foi apresentado um modelo analítico para a tensão de limiar em dispositivos sem junções. Embora esteja relacionado com 0 funcionamento do dispositivo, o modelo não permite a extração de um ponto em uma curva $I_{D} \times V_{G S}$ ou suas derivadas que represente o limiar. Assim, na sequência do trabalho, foi proposto um método de extração da tensão de limiar para estes dispositivos ${ }^{115,116}$.

\subsection{DESENVOLVIMENTO DO MÉTODO}

Conforme apresentado no item 2.2.2, no regime de sublimiar, a corrente de dreno majoritária em um dispositivo MOS sem junções está relacionada com a difusão dos portadores, enquanto que acima do limiar, $I_{D}$ se deve à deriva, tanto na condução pelo corpo como pela camada de acumulação. Assim, podese utilizar como definição de limiar a igualdade das componentes de deriva e difusão da corrente de dreno ( $\left.I_{\text {Dif }}=I_{\text {Der }}\right)$.

Para identificar o ponto no qual as componentes apresentam a mesma magnitude, foi utilizado o modelo de Pao-Sah ${ }^{117}$ :

$$
I_{D}=-\mu_{\text {eff }} Q_{c} \frac{d V_{Y}}{d y}
$$

sendo $Q_{c}$ a densidade de carga de condução por unidade de comprimento e $V_{Y}$ a tensão em uma posição $y$ do canal.

A componente de difusão da corrente é descrita por:

$$
\mathrm{I}_{\text {Dif }}=\mu_{\text {eff }} \phi_{t} \frac{d Q_{c}}{d y}
$$

onde $\phi_{\mathrm{t}}$ é o potencial térmico dado por kT/q. 
Considerando que no limiar $I_{\text {Der }}=I_{\text {Dif }}$ juntamente com as equações (4.1) e (4.2), pode-se obter a condição:

$$
\frac{\mathrm{dQ}_{\mathrm{c}}}{\mathrm{dV}_{\mathrm{Y}}} \frac{1}{\mathrm{Q}_{\mathrm{c}}}=-\frac{1}{2 \phi_{t}}
$$

A equação (3.6) é a solução da equação de Poisson bidimensional considerando apenas as cargas fixas no silício (equação (3.1)) e relaciona a carga de depleção controlada pela porta com o potencial de superfície. Esta equação é utilizada na dedução do método, pois nas proximidades do limiar a condução ocorre apenas pelo corpo. Isolando-se o potencial de superfície na equação (3.6), tem-se:

$$
\phi_{\mathrm{S}}=\frac{\mathrm{Q}_{\mathrm{depl}}{ }^{2}}{\varepsilon_{\mathrm{Si}} \mathrm{qN} \mathrm{N}_{\mathrm{D}}\left(2 \mathrm{H}_{\mathrm{Fin}}+\mathrm{W}_{\mathrm{Fin}}\right)^{2}}
$$

Substituindo (4.4) na relação descrita para o capacitor MOS em (3.8):

$$
\mathrm{V}_{\mathrm{FB}}-\mathrm{V}_{\mathrm{GS}}=\frac{\mathrm{Q}_{\mathrm{depl}}}{\mathrm{C}_{\mathrm{ox}}}+\frac{\mathrm{Q}_{\mathrm{depl}}{ }^{2}}{\varepsilon_{\mathrm{Si}} \mathrm{q} \mathrm{N}_{\mathrm{D}}\left(2 \mathrm{H}_{\mathrm{Fin}}+\mathrm{W}_{\mathrm{Fin}}\right)^{2}}
$$

A equação (4.5) pode ser resolvida em relação a $Q_{\text {depl, }}$ resultando em:

$$
Q_{\text {depl }}=2 \gamma\left[-\frac{1}{C_{o x}}+\sqrt{\left(\frac{1}{C_{o x}}\right)^{2}+\frac{V_{F B}-V_{G S}}{Y}}\right]
$$

onde $\gamma=\varepsilon_{\mathrm{Si}} \cdot \mathrm{q} \cdot \mathrm{N}_{\mathrm{D}} \cdot\left(2 \cdot \mathrm{H}_{\mathrm{Fin}}+\mathrm{W}_{\mathrm{Fin}}\right)^{2} / 4$

Considerando que $Q_{c}$ no regime de depleção parcial é dado por $Q_{c}=Q_{S i}-Q_{\text {depl }}$ e acrescentando a dependência com o potencial no canal $\left(V_{Y}\right)$ em (4.6), tem-se: 
$Q_{c}=Q_{S i}-Q_{\text {depl }}=Q_{S i}-2 Y\left[-\frac{1}{C_{o x}}+\sqrt{\left(\frac{1}{C_{o x}}\right)^{2}+\frac{V_{F B}-V_{G S}+V_{Y}}{Y}}\right]$

Pela equação (4.7) pode-se observar que:

$$
\frac{d Q_{c}}{d V_{Y}}=-\frac{d Q_{c}}{d V_{G S}}
$$

Assim, a equação (4.3) pode ser reescrita como:

$$
\frac{\mathrm{dQ}_{\mathrm{c}}}{\mathrm{dV}_{\mathrm{GS}}} \frac{1}{\mathrm{Q}_{\mathrm{c}}}=\frac{1}{2 \phi_{t}}
$$

Segundo Cunha et al. ${ }^{49}$, tem-se que:

$$
\frac{d Q_{c}}{d V_{G S}} \frac{1}{Q_{c}}=\frac{g_{m}}{I_{D}}
$$

quando a dependência da mobilidade com $V_{G S}$ é desprezada.

Nos dispositivos sem junções, a dependência da mobilidade com a polarização é menor em relação aos dispositivos modo inversão, devido ao campo elétrico reduzido ${ }^{69} \mathrm{e}$ à alta concentração de dopantes ${ }^{10}$. Dessa forma, a dependência da mobilidade em $V_{G S}$ pode ser desprezada.

Substituindo a equação (4.10) em (4.9), tem-se que a igualdade das componentes da corrente de dreno ocorre na condição:

$$
\frac{g_{m}}{I_{D}}=\frac{1}{2 \phi_{t}}
$$

ou seja, quando a razão $g_{m} / l_{D}$ for a metade de seu valor máximo $\left(1 / \phi_{t}\right)$, conforme apresentado no item 2.6.3. 


\subsection{VALIDAÇÃO DO MÉTODO}

A Figura 4.1 apresenta as componentes da corrente (deriva e difusão) obtidas por simulações numéricas tridimensionais semelhantes às realizadas no item 3.1.4 em função da tensão de porta. Pode-se observar que há um ponto onde as componentes da corrente se cruzam. Abaixo desse ponto (sublimiar), há a predominância da componente de difusão enquanto que acima do mesmo a componente predominante é a de deriva. $O$ ponto onde $I_{\text {Der }}=I_{\text {Dif }}$ será utilizado como limiar. No eixo direito da mesma figura é apresentada a razão entre a transcondutância e a corrente de dreno. O máximo dessa razão $\left(\left(g_{m} / L_{D}\right)_{\max }\right)$ ocorre no sublimiar e o ponto onde a mesma diminui para a metade de seu valor máximo é destacado na figura. Pode-se notar que o ponto onde $g_{m} / I_{D}=\left(g_{m} / I_{D}\right)_{\max } / 2$ é o mesmo onde $I_{\text {Der }}=I_{\text {Dif. }}$. Deve-se ressaltar que nas simulações foi considerada a dependência da mobilidade com o campo elétrico assim como o efeito de confinamento quântico. Na Figura 4.1, a comparação do método de $\mathrm{g}_{\mathrm{m}} / \mathrm{l}_{\mathrm{D}}$ com as componentes da corrente de dreno é apresentada para duas temperaturas, indicando a validade do método em relação à $T$.

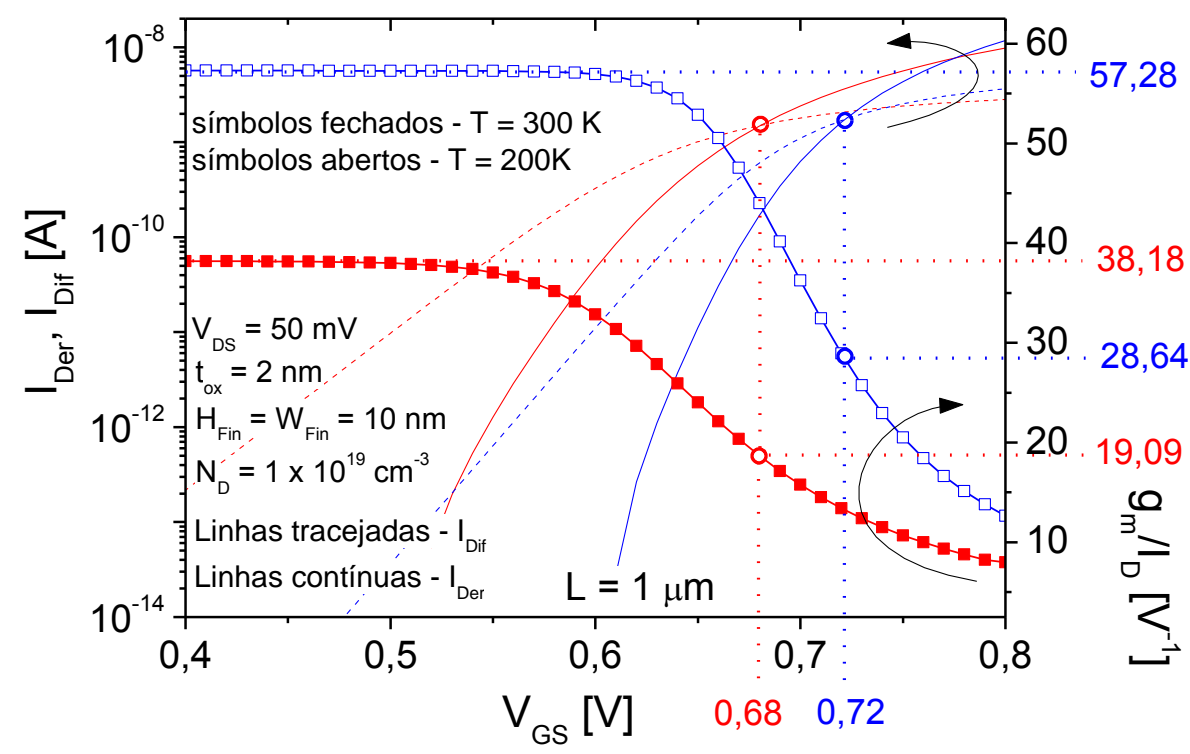

Figura 4.1 - Componentes de deriva e difusão da corrente de dreno (eixo da esquerda) e razão da transcondutância pela corrente (eixo da direita) em função da tensão de porta para duas temperaturas.

A comparação entre a tensão de limiar obtida pelo método de $\mathrm{g}_{\mathrm{m}} / \mathrm{L}_{\mathrm{D}}$ e a igualdade entre as componentes da corrente de dreno é apresentada na Figura 4.2 e na Figura 4.3 em função da largura e da altura dos dispositivos, 
respectivamente, onde a espessura do óxido de porta e a concentração de dopantes foram variadas. Pode-se perceber pelas figuras que o método concorda perfeitamente com a sua base física $\left(I_{\text {Der }}=I_{\text {Dif }}\right)$. O erro máximo obtido nessas figuras é de $3 \mathrm{mV}$, que pode ser considerado como desprezível. Esse erro pode estar relacionado com a dependência da mobilidade em $V_{G S}{ }^{49}$ que, conforme já mencionado, é pequena nesses dispositivos ${ }^{10}$. Assim, pelas Figura 4.1, Figura 4.2 e Figura 4.3, pode-se concluir que o método é preciso independentemente de qualquer uma dessas variáveis: $T, t_{\mathrm{ox}}, N_{D}, W_{\text {Fin }}$ e $H_{\text {Fin. }} . A$ tensão de limiar também foi extraída através dos métodos da segunda derivada (DD) ${ }^{110}$ e da corrente constante (CC) ${ }^{118}$. Conforme já mencionado, o primeiro é um método matemático, enquanto o segundo é um método prático utilizado principalmente nas indústrias devido à sua simplicidade ${ }^{118}$. Um valor típico de corrente de dreno a ser utilizado no método $\mathrm{CC}$ é $\mathrm{W}_{\mathrm{ox}} / \mathrm{L} \times 10^{-7} \mathrm{~A}{ }^{118}$. Este valor foi utilizado neste trabalho. As tensões de limiar extraídas por esses dois métodos também são apresentadas na Figura 4.2 e na Figura 4.3, resultando em valores próximos àqueles obtidos pelo método de $\mathrm{g}_{\mathrm{m}} / \mathrm{l}_{\mathrm{D}}$. Entretanto, ao se aumentar $\mathrm{W}_{\text {Fin }}$ ou $\mathrm{H}_{\text {Fin }}$, a diferença entre a tensão de limiar obtida pelo método da corrente constante em relação aos outros métodos aumenta para aproximadamente $70 \mathrm{mV}$. Em um dispositivo MOSFET convencional, no qual o método CC é amplamente utilizado, a corrente de dreno é proporcional à largura efetiva. No caso dos dispositivos sem junções, a componente principal da corrente de dreno, especialmente na região próxima ao limiar, é a de corpo, sendo que a mesma não é proporcional à largura efetiva, mas à área da seção transversal que não está depletada ${ }^{4}$. Assim, a definição de um nível de corrente para ser aplicado ao método da corrente constante nos JNTs pode se tornar uma difícil tarefa. Através da Figura 4.2 e da Figura 4.3, pode-se também observar o aumento da tensão de limiar com a redução da altura e de largura do transistor, o que está relacionado às diminuições da carga de depleção e do valor absoluto do potencial de superfície na condição de limiar.

O método de extração proposto também é analisado em função da temperatura na Figura 4.4. Novamente, tem-se que o método de $g_{m} / l_{D}$ apresenta grande concordância com a sua base física, com um erro máximo de $3 \mathrm{mV}$, que representa menos de 0,5\% para a tensão de limiar de 0,63 V em $400 \mathrm{~K}$. O método da dupla derivada apresenta uma maior dependência de $V_{T H}$ 
com a temperatura, o que já foi mencionado em publicações anteriores para dispositivos porta dupla modo inversão ${ }^{49,61}$. O método da corrente constante apresenta uma dependência similar com a temperatura em relação ao método de $g_{m} / l_{D}$.

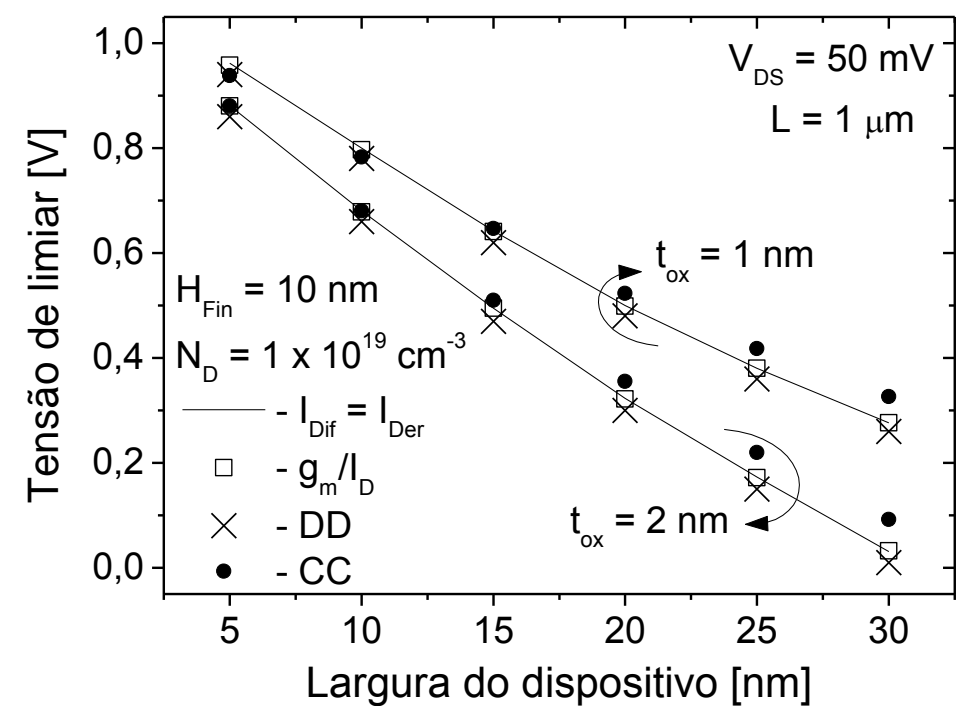

Figura 4.2 - Comparação entre a tensão de limiar extraída com os métodos de $\mathrm{g}_{\mathrm{m}} / \mathrm{l}_{\mathrm{D}}$, DD e CC e a igualdade entre as componentes da corrente de dreno obtida por simulação numérica tridimensional em função da largura do dispositivo.

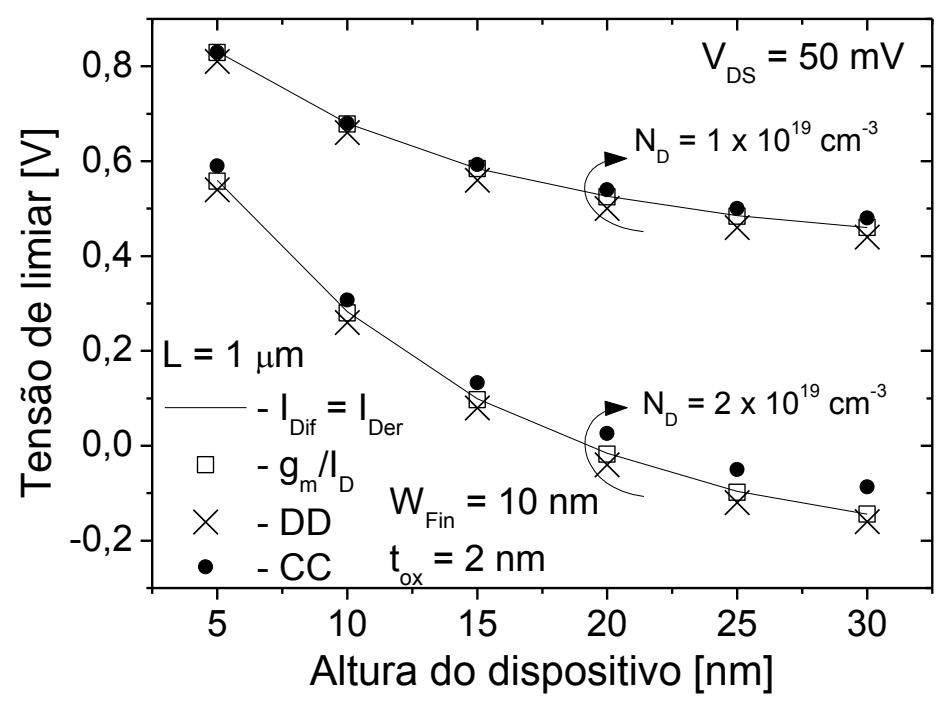

Figura 4.3 - Comparação entre a tensão de limiar extraída com os métodos de $g_{m} / I_{D}$, DD e CC e a igualdade entre as componentes da corrente de dreno obtida por simulação numérica tridimensional em função da altura do dispositivo.

A Figura 4.5 apresenta a comparação entre a tensão de limiar extraída utilizando-se os métodos de $g_{m} / l_{D}, C C$ e DD e o ponto de igualdade das componentes da corrente de dreno em função do comprimento de canal. Podese perceber que o método é válido para dispositivos de comprimento de canal extremamente reduzido. No pior caso, o erro entre o método de $\mathrm{g}_{\mathrm{m}} / \mathrm{l}_{\mathrm{D}}$ e sua 
base física foi de $8 \mathrm{mV}$ para o dispositivo com $\mathrm{L}=40 \mathrm{~nm}\left(\mathrm{~V}_{\mathrm{TH}}=0,67 \mathrm{~V}\right)$, que representa um erro menor que $1,2 \%$.

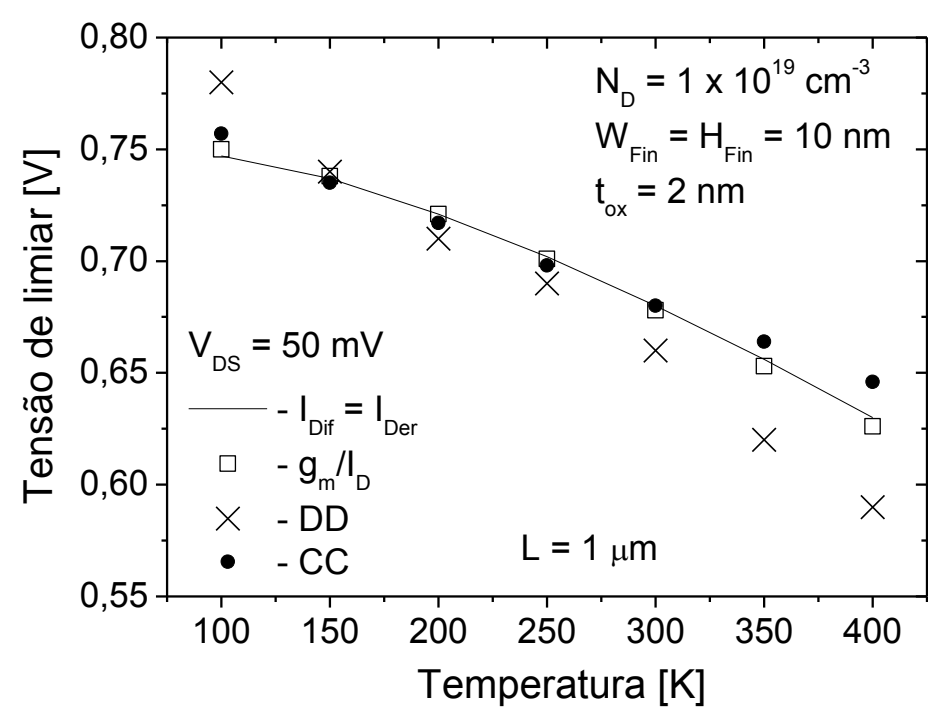

Figura 4.4 - Comparação entre a tensão de limiar extraída com os métodos de $g_{m} / l_{D}$, DD e CC e a igualdade entre as componentes da corrente de dreno obtida por simulação numérica tridimensional em função da temperatura.

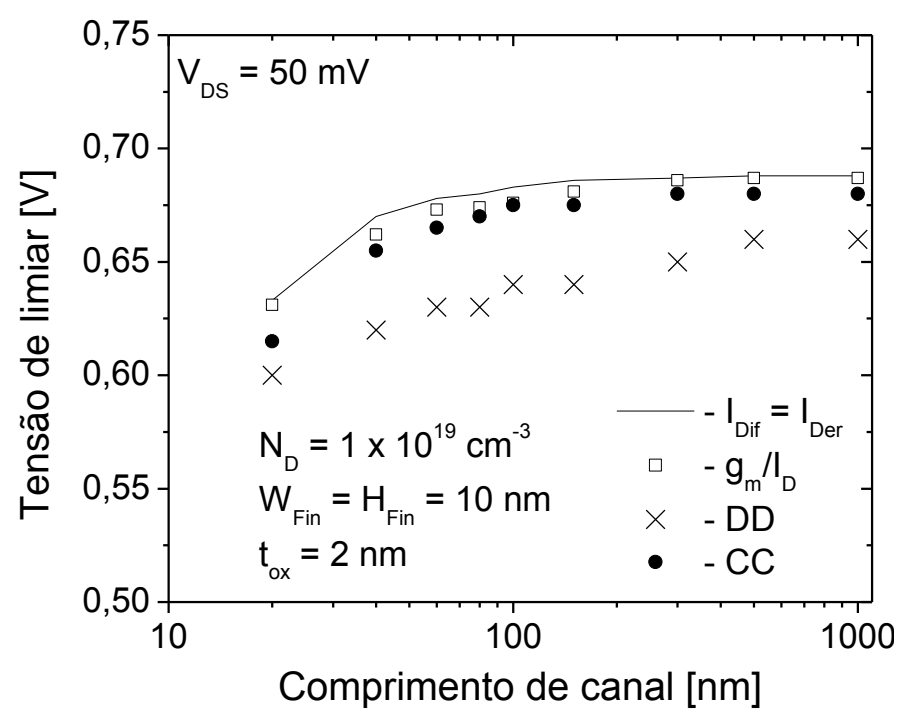

Figura 4.5 - Comparação entre a tensão de limiar extraída com os métodos de $\mathrm{g}_{\mathrm{m}} / \mathrm{I}_{\mathrm{D}}$, DD e CC e a igualdade entre as componentes da corrente de dreno obtida por simulação numérica tridimensional em função do comprimento de canal.

\subsection{MODELO ANALÍTICO DE TENSÃO DE LIMIAR BASEADO NAS COMPONENTES DA CORRENTE DE DRENO}

Conforme apresentado no item 4.1, a condição de limiar definida no ponto de igualdade das componentes de deriva e difusão da corrente de dreno é descrita pela equação (4.9). A densidade de carga de condução obtida pela 
equação (4.7) pode ser utilizada com (4.9), a fim de se obter outra equação analítica para a tensão de limiar. A tensão no canal será considerada como nula, uma vez que $V_{T H}$ é calculada para o lado da fonte do canal. Derivando (4.7) em relação à tensão de porta, tem-se:

$$
\frac{d Q_{c}}{d V_{G S}}=\left(2 Y \sqrt{\left(\frac{1}{C_{o x}}\right)^{2}+\frac{V_{F B}-V_{G S}}{Y}}\right)^{-1}
$$

Dividindo (4.12) por (4.7) e substituindo em (4.9), pode-se obter:

$$
\left(Q_{S i}+\frac{2 \gamma}{C_{o x}}\right) \sqrt{\left(\frac{2 \gamma}{C_{o x}}\right)^{2}+4 \gamma\left(V_{F B}-V_{G S}\right)}-\left(\frac{2 \gamma}{C_{o x}}\right)^{2}-4 \gamma\left(V_{F B}-V_{G S}\right)=4 Y \phi_{t}
$$

A tensão de porta na equação (4.13) é a tensão de limiar obtida pela igualdade das componentes da corrente de dreno. Isolando $V_{G S}$ em (4.13), pode-se obter:

$$
\mathrm{V}_{\mathrm{TH}}=\mathrm{V}_{\mathrm{FB}}+\frac{\mathrm{Y}}{2 \mathrm{C}_{\mathrm{ox}}{ }^{2}}-\frac{\mathrm{Q}_{\mathrm{Si}}{ }^{2}}{8 \mathrm{Y}}-\frac{\mathrm{Q}_{\mathrm{Si}}}{2 \mathrm{C}_{\mathrm{ox}}}-\frac{1}{8 \mathrm{Y}}\left(\mathrm{Q}_{\mathrm{Si}}+\frac{2 \mathrm{Y}}{\mathrm{C}_{\mathrm{ox}}}\right) \sqrt{\left(\mathrm{Q}_{\mathrm{Si}}+\frac{2 \mathrm{Y}}{\mathrm{C}_{\mathrm{ox}}}\right)^{2}-16 \mathrm{Y} \phi_{t}}+\phi_{t}
$$

Na Figura 4.6 e na Figura 4.7, as tensões de limiar extraídas no ponto de igualdade das componentes da corrente de dreno são comparadas com $V_{T H}$ calculada pela equação (4.14) para dispositivos de diferentes dimensões ( $\mathrm{W}_{\text {Fin, }}$, $H_{\text {Fin }}$ e $t_{o x}$ ) e concentração de dopantes. Os valores obtidos pelo modelo são similares aos da igualdade $I_{\text {Dif }}=I_{\text {Der, }}$, com um erro máximo de $15 \mathrm{mV}$, que representa cerca de $3 \%$ para o dispositivos com $W_{\text {Fin }}=15 n$ m e $t_{\text {ox }}=2 n m\left(V_{T H}\right.$ $=0,5 \mathrm{~V})$.

A equação (4.14) representa outra forma de se calcular analiticamente a tensão de limiar, além da apresentada no Capítulo 3. É importante ressaltar que os modelos analíticos tem bases físicas diferentes, sendo o do Capítulo 3 relacionado à profundidade da região de depleção enquanto que o desse Capítulo está relacionado às componentes da corrente de dreno. Comparandose as equações (3.10) e (4.14), pode-se notar que a (3.10) é mais simples, 
permitindo calcular a tensão de limiar de uma forma mais prática. Também por sua simplicidade, a equação (3.10) pode ser utilizada como forma de se analisar de forma qualitativa a influência de algum parâmetro na tensão de limiar. No entanto, a modelagem descrita no Capítulo 3 não permite a extração de $V_{T H}$ de uma forma simples a partir da curva $I_{D} \times V_{G s}$ característica. Já 0 modelo da equação (4.14), apesar de sua expressão um pouco mais complexa, e portanto menos intuitiva, está relacionado diretamente à um método próprio de extração, permitindo uma análise mais completa de $\mathrm{V}_{\mathrm{TH}}$.

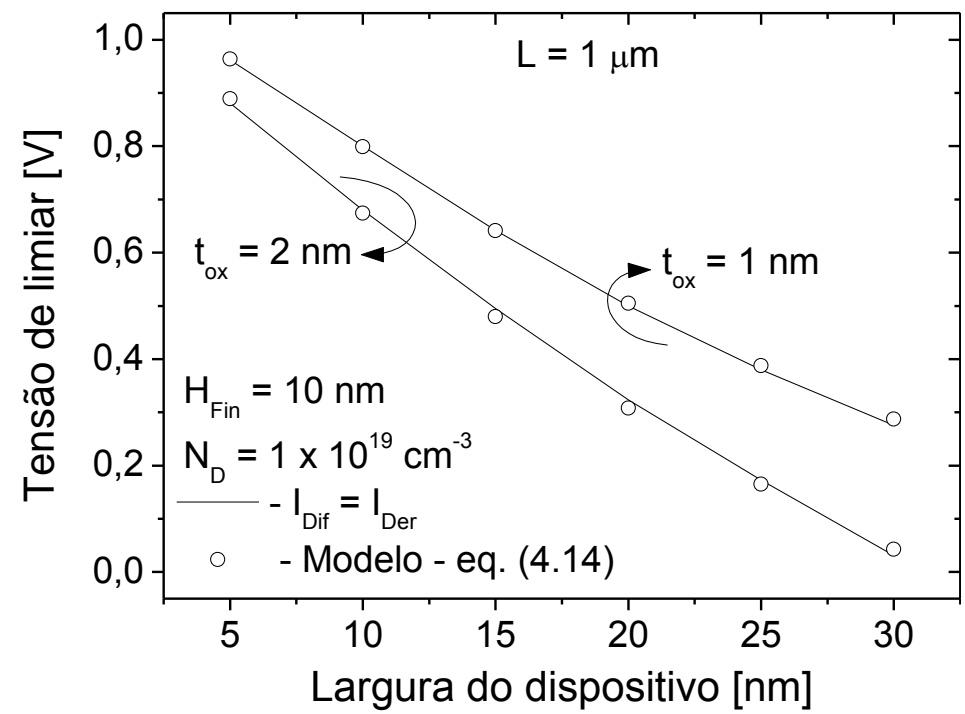

Figura 4.6 - Comparação entre o modelo de tensão de limiar descrito pela equação (4.14) e a igualdade entre as componentes da corrente de dreno obtida por simulação numérica tridimensional em função da largura do dispositivo.

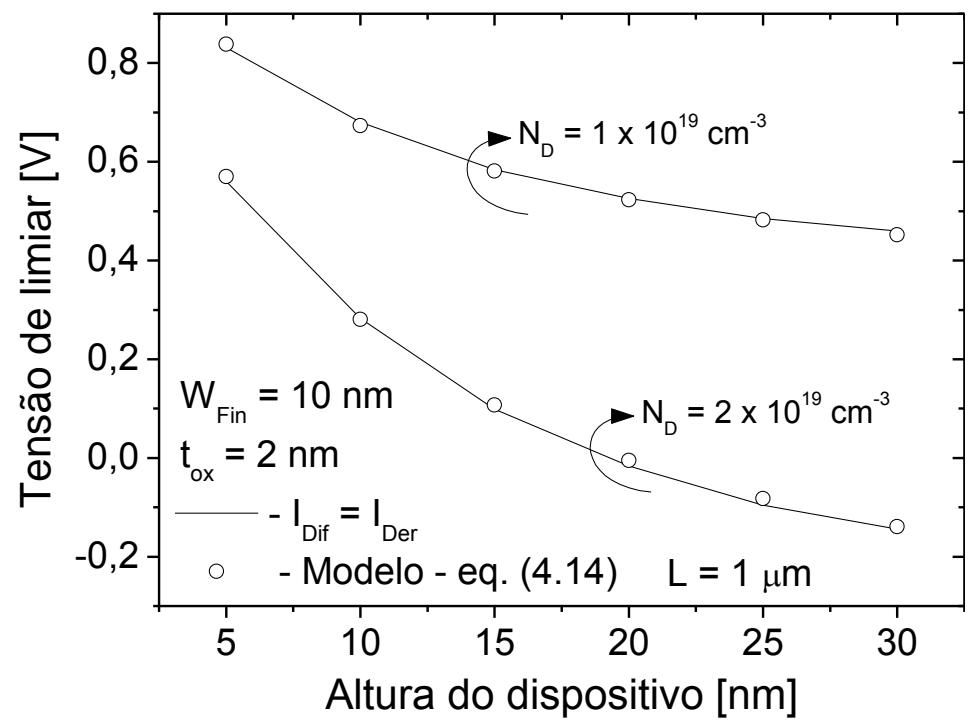

Figura 4.7 - Comparação entre o modelo de tensão de limiar descrito pela equação (4.14) e a igualdade entre as componentes da corrente de dreno obtida por simulação numérica tridimensional em função da altura do dispositivo. 


\subsection{APLICAÇÃO DO MÉTODO A DISPOSITIVOS EXPERIMENTAIS}

$\mathrm{O}$ método proposto para extrair $\mathrm{V}_{T H}$ foi aplicado a dispositivos experimentais. Os dispositivos são os mesmos do item 3.1.4, que foram fabricados de acordo com Colinge et al. ${ }^{5}$ no Tyndall National Institute, Cork, Irlanda. Na Figura 4.8, a corrente de dreno é apresentada em função da tensão de porta para dois dispositivos de diferentes larguras e para diversas temperaturas, sendo que as tensões de limiar obtidas pelo método de $\mathrm{g}_{\mathrm{m}} / \mathrm{I}_{\mathrm{D}}$ são indicadas.

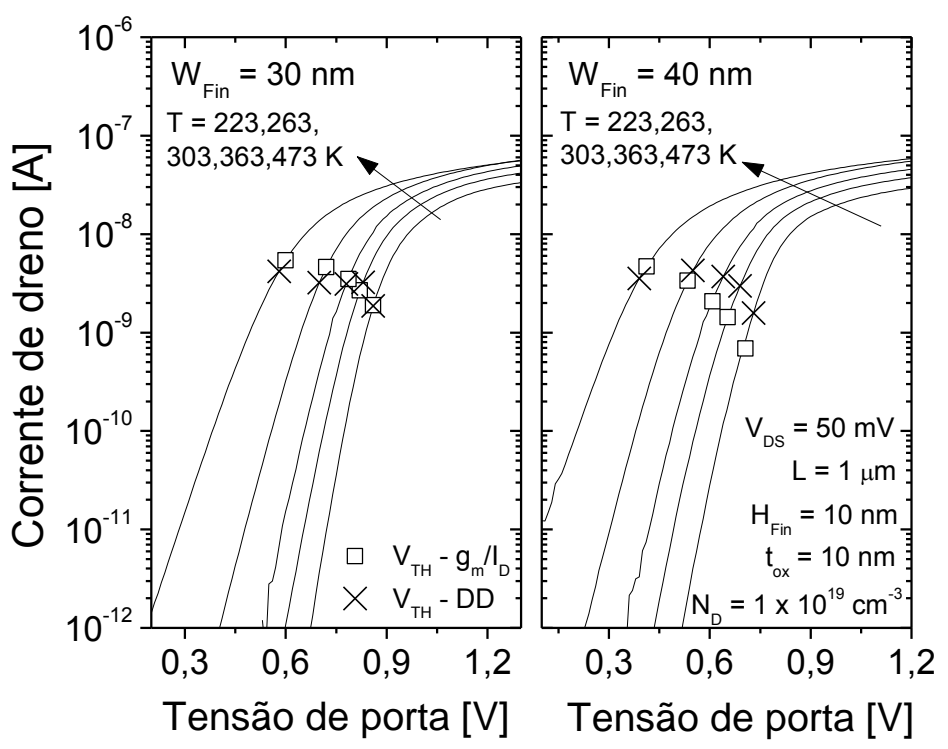

(A)

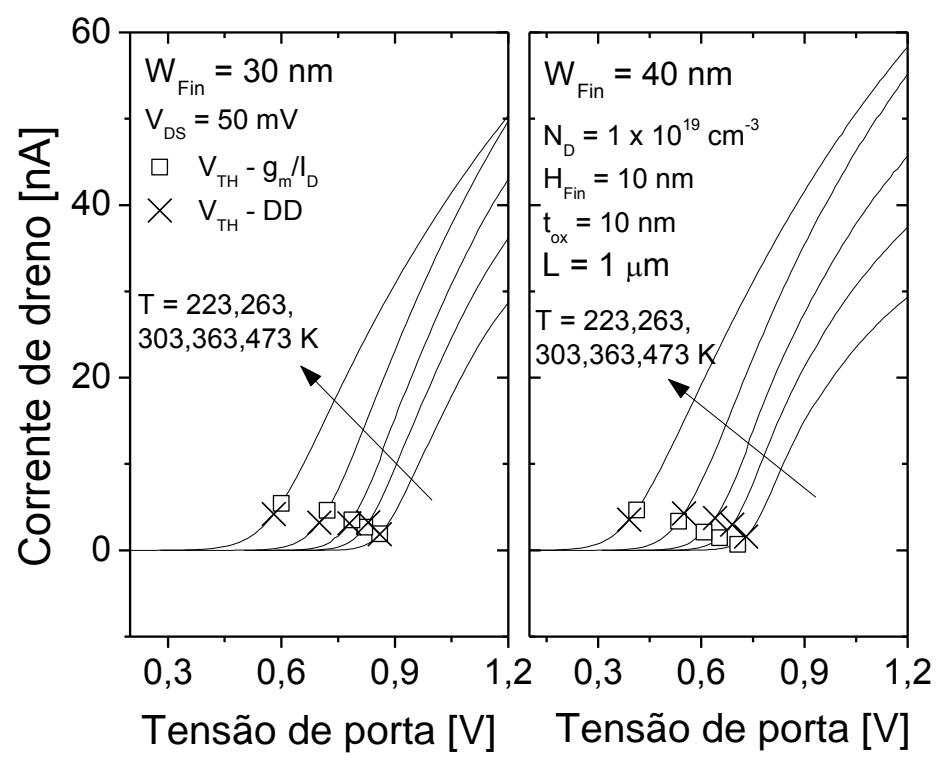

(B)

Figura 4.8 - Corrente de dreno em escalas logarítmica $(A)$ e linear (B) em função da tensão de porta de dispositivos experimentais para diferentes temperaturas indicando as tensões de limiar extraídas pelo método de $\mathrm{g}_{\mathrm{m}} / \mathrm{I}_{\mathrm{D}}$ e pelo método da segunda derivada (DD). 
As tensões de limiar também foram extraídas pelo método da segunda derivada (DD) ${ }^{110}$ e estão igualmente apresentadas na Figura $4.8 \mathrm{com}$ o propósito de uma simples comparação. Os dispositivos medidos apresentam uma severa degradação em sua curva de corrente devido à resistência série, que é da ordem de centenas de $\mathrm{k} \Omega{ }^{46,43}$. Esta resistência aumenta quando a temperatura é reduzida devido à ionização incompleta dos portadores ${ }^{43}$. Métodos de extração de $\mathrm{V}_{\mathrm{TH}}$ que são baseados na corrente do estado ligado (on-current) podem ser afetados pela resistência. $O$ método proposto é baseado no ponto de máximo da razão $g_{m} / L_{D}$, que ocorre no regime de sublimiar, de forma que a extração de $\mathrm{V}_{\mathrm{TH}}$ não é afetada pela resistência série. A severa degradação das curvas de corrente de dreno pela resistência série, principalmente para temperaturas mais baixas, pode causar a impressão de que os pontos de $\mathrm{V}_{\mathrm{TH}}$ extraídos estão no regime de sublimiar, quando as curvas são analisadas em escala logarítmica. No entanto, pela Figura 4.8(B), pode-se perceber que os valores de $\mathrm{V}_{\mathrm{TH}}$ estão adequados.

$\mathrm{Na}$ Figura 4.9 , as tensões de limiar extraídas pelos dois métodos $\left(\mathrm{g}_{\mathrm{m}} / \mathrm{l}_{\mathrm{D}} \mathrm{e}\right.$ DD) são apresentadas em função da temperatura, comparando-se com 0 modelo analítico descrito pela equação (4.14). Pode-se perceber que o modelo proposto neste capítulo também é adequado para se calcular a dependência da tensão de limiar com a temperatura.

As variações da tensão de limiar com a temperatura $\left(\mathrm{dV}_{\mathrm{TH}} / \mathrm{dT}\right)$ extraídas da Figura 4.9 são apresentadas na Tabela 4.1. A variação da tensão de limiar com $T$ calculada pela equação (3.14) também é apresentada nessa tabela. Pode-se notar que a variação $\mathrm{dV}_{\mathrm{TH}} / \mathrm{dT}$ é maior pelo método da segunda derivada em relação ao método de $\mathrm{g}_{\mathrm{m}} / \mathrm{l}_{\mathrm{D}}$ e aos modelos analíticos, sendo que esses últimos apresentaram valores muito próximos. Esta superestimação de $\mathrm{dV}_{\mathrm{TH}} / \mathrm{dT}$ obtida através do método $\mathrm{DD}$ já foi mencionada em outros trabalhos para dispositivos porta dupla modo inversão ${ }^{49,61}$. 

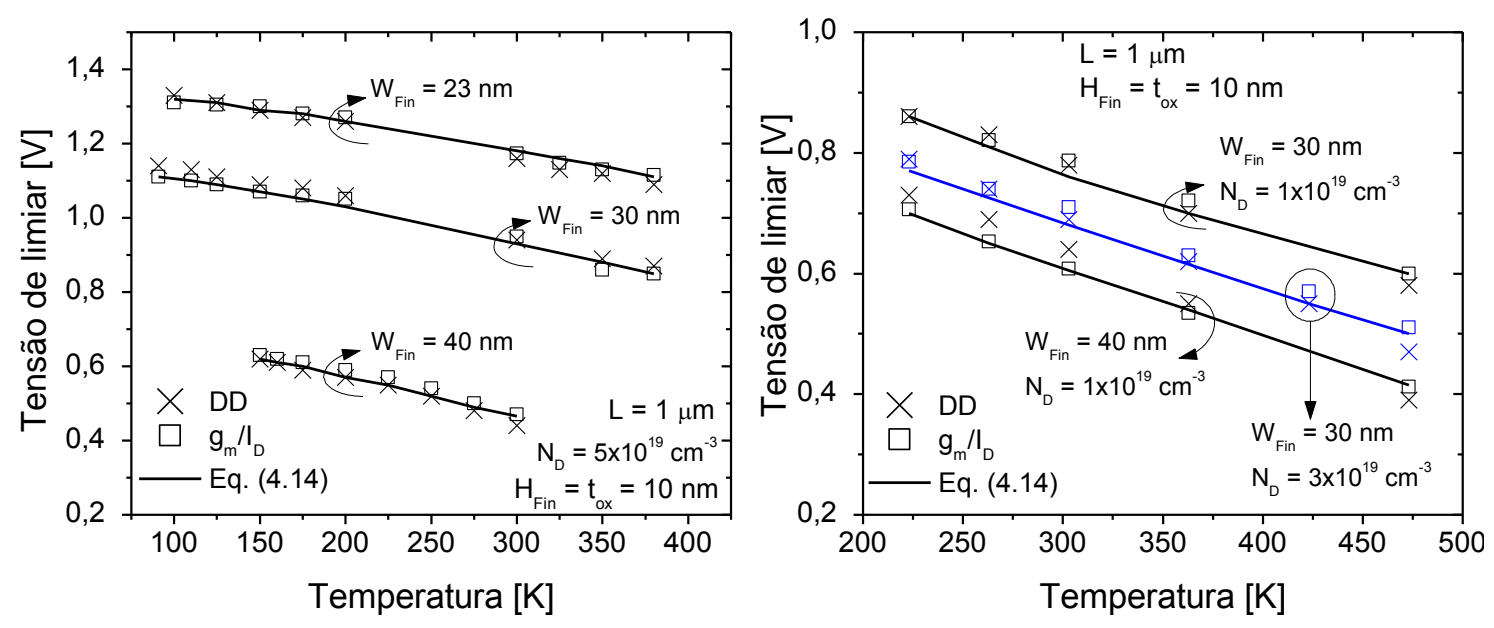

Figura 4.9 - Tensão de limiar de dispositivos experimentais extraídas usando os métodos da segunda derivada (DD) e de $\mathrm{g}_{\mathrm{m}} / \mathrm{I}_{\mathrm{D}}$ em função da temperatura comparando com o modelo de tensão de limiar da equação (4.14).

Tabela 4.1 - Variações da tensão de limiar com a temperatura extraídas da Figura 4.9 comparadas aos modelos de tensão de limiar da equação (3.14) e da equação (4.14).

\begin{tabular}{|c|c|c|c|c|c|}
\hline $\begin{array}{c}\mathbf{W}_{\text {Fin }} \\
{[\mathbf{n m}]}\end{array}$ & $\begin{array}{c}\mathbf{N}_{\mathbf{D}} \\
{\left[\mathbf{c m}^{-3}\right]}\end{array}$ & \multicolumn{4}{|c|}{$\left|\mathbf{d V}_{\mathbf{T H}} / \mathbf{d T}\right|[\mathbf{m V} / \mathbf{K}]$} \\
\hline 30 & $1 \times 10^{19}$ & 1,04 & 1,15 & 1,04 & 1,03 \\
\hline 40 & $1 \times 10^{19}$ & 1,17 & 1,38 & 1,15 & 1,13 \\
\hline 30 & $3 \times 10^{19}$ & 1,10 & 1,25 & 1,08 & 1,06 \\
\hline 23 & $5 \times 10^{19}$ & 0,77 & 0,87 & 0,77 & 0,83 \\
\hline 30 & $5 \times 10^{19}$ & 0,93 & 0,97 & 0,93 & 0,91 \\
\hline 40 & $5 \times 10^{19}$ & 1,05 & 1,15 & 1,04 & 1,05 \\
\hline
\end{tabular}

Ao longo deste Capítulo e do anterior, o estudo se concentrou na tensão de limiar, sendo propostos um método de extração e o modelo analítico. A modelagem feita para a tensão de limiar pode ser expandida para um modelo de corrente de dreno, conforme é apresentado no Capítulo a seguir. 


\section{MODELAGEM DA CORRENTE DE DRENO}

Conforme mencionado no item 2.2.2, dependendo das tensões aplicadas à porta e ao dreno do dispositivo, pode haver condução tanto pelo corpo e por uma camada de acumulação, como apenas pelo corpo do dispositivo. A Figura 2.9 apresenta o corte longitudinal de um dispositivo MOS sem junções considerando porta e dreno polarizados. Na região entre $0 \leq y<\mathrm{A}$, a condução ocorre tanto pelo corpo como pela camada de acumulação. Na região entre $\mathrm{A} \leq y \leq \mathrm{B}$, a condução de corrente ocorre apenas pelo corpo. A representação da Figura 2.9 pode ser considerada como uma generalização para qualquer forma de condução descrita em ${ }^{27}$ para um dispositivo SOI modo acumulação: se $A<0$, não há camada de acumulação, se $A=L$, o canal inteiro está acumulado e se $B=L$, não há pinçamento do canal (dispositivo não está em saturação). Para a dedução do modelo, é considerado que a tensão no ponto $A$ é $V_{A}$ e a tensão no ponto $B$ é $V_{B}$.

A corrente de dreno pode ser calculada pela equação (4.1), de acordo com o modelo de Pao-Sah ${ }^{117}$. A densidade de carga é a soma das densidades das duas regiões do canal: $Q_{1}$ para $0 \leq y<A$ e $Q_{2}$ para $A \leq y \leq L$, conforme apresentado no item 2.2.2. Então, a corrente de dreno pode ser obtida através da equação (5.1), onde o primeiro termo resulta em $\mathrm{I}_{1}$ e o segundo em $\mathrm{I}_{2}$.

$$
I_{D}=-\frac{\mu_{\text {eff }}}{L} \int_{0}^{V_{A}} Q_{1}(y) d V_{Y}-\frac{\mu_{\text {eff }}}{L} \int_{V_{A}}^{V_{B}} Q_{2}(y) d V_{Y}=I_{1}+I_{2}
$$

$A$ tensão $V_{B}$ será considerada como a tensão efetiva entre dreno e fonte $\left(V_{B}=V_{D S e}\right)$ que será descrita no item 5.4 e a tensão $V_{A}$ é dada aproximadamente por $V_{A}=V_{G S}-\Phi_{M S}$, conforme apresentado no item 2.2.2. No entanto, a fim de se obter uma transição contínua entre as componentes $I_{1}$ e $I_{2}$ da corrente, uma função de suavização será usada para $V_{A}$, conforme será mostrado no item 5.5 . 


\subsection{CONDUÇÃO PELO CORPO E PELA CAMAdA DE ACUMULAÇÃO} $(0 \leq Y<A)$

A densidade de carga $Q_{1}$ pode ser descrita por:

$$
\mathrm{Q}_{1}=\mathrm{Q}_{\mathrm{Si}}+\mathrm{C}_{\mathrm{ox}}\left(\mathrm{V}_{\mathrm{GS}}-\mathrm{V}_{\mathrm{FB}}-\mathrm{V}_{\mathrm{Y}}\right)
$$

O primeiro termo da equação (5.2) representa a condução de corpo e o segundo a condução pela camada de acumulação. Pode-se, então, integrar a equação (5.2) de 0 à $\mathrm{V}_{\mathrm{A}}$, conforme apresentado na equação (5.1), obtendo a corrente $\mathrm{I}_{1}$ :

$$
\mathrm{I}_{1}=\frac{\mu_{\text {eff }}}{\mathrm{L}}\left[\mathrm{Q}_{\mathrm{Si}} \mathrm{V}_{\mathrm{A}}+\mathrm{C}_{\mathrm{ox}}\left(\mathrm{V}_{\mathrm{GS}}-\mathrm{V}_{\mathrm{FB}}\right) \mathrm{V}_{\mathrm{A}}+\mathrm{C}_{\mathrm{ox}}\left(\frac{-\mathrm{V}_{\mathrm{A}}^{2}}{2}\right)\right]
$$

\subsection{CONDUÇÃO PELO CORPO $(\mathrm{A} \leq Y \leq \mathrm{B})$}

A carga $Q_{2}$ pode ser descrita pela carga $Q_{c}$ no regime de depleção parcial, dada pela equação (4.7). Esta equação foi obtida a partir da solução da equação de Poisson bidimensional.

Integrando $Q_{2}$ entre $V_{A}$ e $V_{B}$ conforme mostrado em (5.1), pode-se chegar em:

$$
\begin{aligned}
\mathrm{I}_{2}=\frac{\mu_{\text {eff }}}{\mathrm{L}}\left(\mathrm{V}_{\mathrm{B}}-\mathrm{V}_{\mathrm{A}}\right)\left(\frac{2 \mathrm{Y}}{\mathrm{C}_{\mathrm{ox}}}+\mathrm{Q}_{\mathrm{Si}}\right)-\frac{\mu_{\text {eff }}}{\mathrm{L}} \frac{4 \sqrt{\mathrm{V}}}{3}\left(\left(\mathrm{~V}_{\mathrm{FB}}-\mathrm{V}_{\mathrm{GS}}+\mathrm{V}_{\mathrm{B}}\right)+\frac{\mathrm{Y}}{\mathrm{C}_{\mathrm{ox}}{ }^{2}}\right)^{\frac{3}{2}}+ \\
+\frac{\mu_{\text {eff }}}{\mathrm{L}} \frac{4 \sqrt{\mathrm{V}}}{3}\left(\left(\mathrm{~V}_{\mathrm{FB}}-\mathrm{V}_{\mathrm{GS}}+\mathrm{V}_{\mathrm{A}}\right)+\frac{\mathrm{Y}}{\mathrm{C}_{\mathrm{ox}}{ }^{2}}\right)^{\frac{3}{2}}
\end{aligned}
$$

Pode-se observar que as equações (5.3) e (5.4) são similares àquelas obtidas para os dispositivos SOI modo acumulação em Colinge ${ }^{27}$. 


\subsection{TENSÃO DE SATURAÇÃO}

A tensão de saturação pode ser obtida através da relação ${ }^{119}$ :

$$
\mathrm{I}_{\text {Dsat }}=\mathrm{Q}_{\text {sat }} \mathrm{v}_{\text {sat }}
$$

onde $I_{D s a t}$ é a corrente de saturação, $Q_{\text {sat }}$ a densidade de carga de saturação e $\mathrm{v}_{\text {sat }}$ a velocidade de saturação.

A carga de saturação pode ser obtida através da carga $Q_{2}$ : $Q_{\text {sat }}=Q_{2}$ para $V_{Y}=V_{\text {Dsat. }}$ Já a corrente de saturação deve ser obtida através das somas das duas componentes de corrente: $I_{\text {Dsat }}=I_{1}+I_{2}$ para $V_{B}=V_{\text {Dsat }}$. Deve-se ressaltar que a componente $l_{1}$ da corrente não depende de $V_{B}$, dependendo apenas de $V_{A}$. Assim, substituindo as equações (4.7), (5.3) e (5.4) em (5.5) com as considerações acima, pode-se obter o polinômio de terceiro grau descrito por (5.6), onde $w$ é função da tensão de saturação.

$$
\mathrm{K}_{3} w^{3}+\mathrm{K}_{2} w^{2}+\mathrm{K}_{1} w+\mathrm{K}_{0}=0
$$

$$
\begin{aligned}
& \text { sendo } \quad \mathrm{K}_{3}=-\frac{4 \mu_{\text {eff }} \sqrt{\mathrm{V}}}{3 \mathrm{~L}}, \quad \mathrm{~K}_{2}=\frac{\mu_{\text {eff }}\left(\frac{2 \mathrm{~V}}{\mathrm{C}_{\mathrm{ox}}}+\mathrm{Q}_{\mathrm{Si}}\right)}{\mathrm{L}}, \quad \mathrm{K}_{1}=2 \mathrm{v}_{\mathrm{sat}} \sqrt{\mathrm{V}} \quad \mathrm{e} \\
& \mathrm{K}_{0}=\frac{\mu_{\text {eff }}}{\mathrm{L}}\left[\frac{4}{3} \frac{\mathrm{Y}^{2}}{\mathrm{C}_{\mathrm{ox}}{ }^{3}}-\left(\frac{2 \mathrm{~V}}{\mathrm{C}_{\mathrm{ox}}}+\mathrm{Q}_{\mathrm{Si}}\right)\left(\frac{\mathrm{Y}}{\mathrm{C}_{\mathrm{ox}}{ }^{2}}+\frac{\mathrm{L} \mathrm{v}_{\mathrm{sat}}}{\mu_{\text {eff }}}\right)+\mathrm{Q}_{\mathrm{Si}}\left(\mathrm{V}_{\mathrm{GS}}-\mathrm{V}_{\mathrm{FB}}\right)+\frac{\mathrm{C}_{\mathrm{ox}}}{2}\left(\mathrm{~V}_{\mathrm{GS}}-\mathrm{V}_{\mathrm{FB}}\right)^{2}\right]
\end{aligned}
$$

A tensão de saturação será, então, obtida através de:

$$
\mathrm{V}_{\mathrm{Dsat}}=w-\mathrm{V}_{\mathrm{FB}}+\mathrm{V}_{\mathrm{GS}}-\frac{\mathrm{Y}}{\mathrm{C}_{\mathrm{ox}}{ }^{2}}
$$

Com o intuito de limitar a tensão de saturação mínima em duas vezes o potencial térmico como em um dispositivo MOS planar, uma função de suavização foi utilizada ${ }^{120}$ : 


$$
\mathrm{V}_{\text {Dsat }}=2 \phi_{t}+\phi_{t} \ln \left[1+\exp \left(\left(\mathrm{V}_{\text {Dsat }}-\phi_{t}\right) / \phi_{t}\right)\right]
$$

\subsection{TENSÃO EFETIVA ENTRE FONTE E DRENO}

A fim de se limitar a máxima tensão entre fonte e dreno na tensão de saturação, uma função de suavização foi utilizada ${ }^{120}$ :

$$
V_{\text {DSe }}=V_{B}=V_{\text {Dsat }}\left[1-\frac{\ln \left[1+\exp \left(A_{1}\left(1-V_{\text {DS }} N_{\text {Dsat }}\right)\right)\right]}{\ln \left(1+\exp \left(A_{1}\right)\right)}\right]
$$

onde $A_{1}$ é um parâmetro que controla a transição entre triodo e saturação e $V_{\text {Dsat }}$ é calculado pela equação (5.8). Neste trabalho, $A_{1}$ foi adotado como 4.

\subsection{TENSÃO $V_{A}$}

A transição entre os regimes de condução de corpo e corpo mais camada de acumulação ocorre em $V_{Y}=V_{G S}-V_{F B}$ para $V_{G S}>V_{F B}$. Para $V_{G S}<V_{F B}$ haverá condução apenas pelo corpo. Nesta condição, $V_{A}$ deve tender à tensão na fonte $\left(V_{S}\right)$, fazendo com que a componente $I_{1}$ tenda à zero. Por outro lado, para $V_{\mathrm{GS}}>\mathrm{V}_{\mathrm{FB}}$, uma camada de acumulação é formada pelo menos do lado da fonte do canal. Dependendo das tensões $V_{G S}$ e $V_{D S}$, essa camada de acumulação pode se estender através do canal inteiro. $O$ valor máximo que $V_{A}$ pode assumir é $V_{B}$. Quando isso ocorre, o canal inteiro está acumulado, desde a fonte até o dreno, indicando que não há pinçamento do canal. Para se obter uma transição contínua entre essas condições, a equação (5.10) foi usada para $V_{A}$, onde $A_{2}$ e $A_{3}$ controlam a suavidade da função e foram adotados como 6 e 6 , respectivamente.

$$
\mathrm{V}_{\mathrm{A}}=\mathrm{V}_{\mathrm{S}}+\frac{\mathrm{V}_{\mathrm{DSe}}}{\left(1+\mathrm{A}_{2} \exp \left(-\mathrm{A}_{3}\left(\mathrm{~V}_{\mathrm{GS}}-\mathrm{V}_{\mathrm{FB}}\right)\right)\right)^{0,5}}
$$




\subsection{SUBLIMIAR}

A corrente total obtida pela soma das componentes $I_{1}$ e $I_{2}$ é válida para 0 regime acima do limiar. Para a região de sublimiar, a corrente varia exponencialmente com $V_{G S}$ devido à difusão dos portadores. Para realizar a continuidade entre os regimes acima e abaixo do limiar, uma função de transição foi usada para a variável $V_{G 1}$ :

$$
\mathrm{V}_{\mathrm{G} 1}=\mathrm{V}_{\mathrm{TH}}+\mathrm{V}_{\mathrm{TH}} \frac{\ln \left[1+\exp \left(\mathrm{A}_{4}\left(\mathrm{~V}_{\mathrm{GS}} \mathrm{V}_{\mathrm{TH}}-1\right)\right)\right]}{\ln \left(1+\exp \left(\mathrm{A}_{4}\right)\right)}
$$

onde $\mathrm{A}_{4}$ controla a transição e $\mathrm{V}_{\mathrm{TH}}$ é calculado conforme visto no item 3.1.1.

A equação (5.11) é usada para $V_{G S}$ em (5.3), (5.4), (5.7) e (5.10) e $A_{4}$ foi usado como 12. A corrente total de dreno é finalmente calculada por:

$$
I_{D}=\left(I_{1}+I_{2}\right) e^{\frac{V_{G S}-V_{G 1}}{n \phi_{t}}}
$$

Assim, a equação da corrente é contínua do sublimiar à saturação. Para $V_{G S}$ muito menor que a tensão de limiar, $V_{G 1}$ tende a $V_{T H}$ pela equação (5.11). Assim, $V_{G 1}$ será constante e a soma $I_{1}+l_{2}$ também será constante, e $I_{D}$ varia exponencialmente com $\mathrm{V}_{\mathrm{GS}}-\mathrm{V}_{\mathrm{TH}}$. Para $\mathrm{V}_{\mathrm{GS}}$ muito maior que $\mathrm{V}_{\mathrm{TH}}, \mathrm{V}_{\mathrm{G} 1}$ tende à $V_{G S}$ e o termo exponencial em (5.12) tende à unidade. Assim, $I_{D}$ é dado pela soma $I_{1}+I_{2}$. É importante ressaltar que os valores de $A_{1}, A_{2}, A_{3}$ e $A_{4}$ foram adotados a partir da comparação entre o modelo com simulações numéricas, visando os melhores resultados.

\subsection{MODULAÇÃO DO COMPRIMENTO DE CANAL}

Conforme mencionado no item 2.2.2, quando o dispositivo MOS sem junções opera em saturação, ocorre o pinçamento do canal de forma similar a 
um dispositivo MOS convencional. Quanto maior for a tensão aplicada ao dreno, maior será a região de depleção entre canal e dreno, fazendo com que o ponto do pinçamento se desloque mais para dentro do canal. Assim, o comprimento efetivo de canal diminui com a tensão de dreno, ocorrendo a modulação do comprimento de canal. A fim de se considerar a modulação de comprimento de canal nesses dispositivos, o modelo descrito por Foty ${ }^{119}$, baseado no trabalho de Baum e Beneking ${ }^{121}$, pode ser utilizado. $O$ comprimento efetivo de canal será descrito por:

$$
L_{\text {eff }}=L-\left[\sqrt{\left(\frac{E_{\text {sat }}}{2 a}\right)^{2}+\frac{V_{D S}-V_{\text {Dsat }}}{a}}-\frac{E_{\text {sat }}}{2 a}\right]
$$

onde $E_{\text {sat }}$ é o campo elétrico de saturação que pode ser simplificado por $E_{\text {sat }}=$ $\mathrm{V}_{\text {Dsat }} / \mathrm{L}$ e $\mathrm{a}=\mathrm{qN} \mathrm{N}_{\mathrm{D}} /\left(2 \varepsilon_{\mathrm{Si}}\right)^{119}$.

Deve-se ressaltar que a modulação do comprimento de canal, conforme descrito pela equação (5.13), é utilizada principalmente para a determinação da condutância de saída na região de saturação para dispositivos de canal longo. Em dispositivos de canal curto, a variação do potencial mínimo é responsável pela determinação do efeito de modulação do comprimento de canal. Este assunto será tratado no item 5.9 e no Capítulo 6, onde a correção de efeitos de canal curto será aplicada ao modelo do potencial de superfície.

\subsection{VALIDAÇÃO DO MODELO}

Para validar o modelo, foram utilizadas simulações tridimensionais de dispositivos semelhantes aos do item 3.1.4, sendo que a mobilidade foi considerada como constante e igual a $100 \mathrm{~cm}^{2} / \mathrm{V}$.s, que é um valor típico de mobilidade nestes dispositivos ${ }^{10}$.

A Figura 5.1 apresenta as componentes $I_{1}$ e $I_{2}$ da corrente de dreno, juntamente com $I_{D}$ em escala linear (A) e logarítmica (B). Pode-se observar que para $V_{G S}$ menor que a tensão de faixa plana, a componente de corpo $\left(I_{2}\right)$ é dominante, enquanto que para $\mathrm{V}_{\mathrm{GS}}$ maior que $\mathrm{V}_{\mathrm{FB}}$ a componente que considera 
a soma das conduções pelo corpo e pela camada de acumulação $\left(\mathrm{I}_{1}\right)$ é predominante.

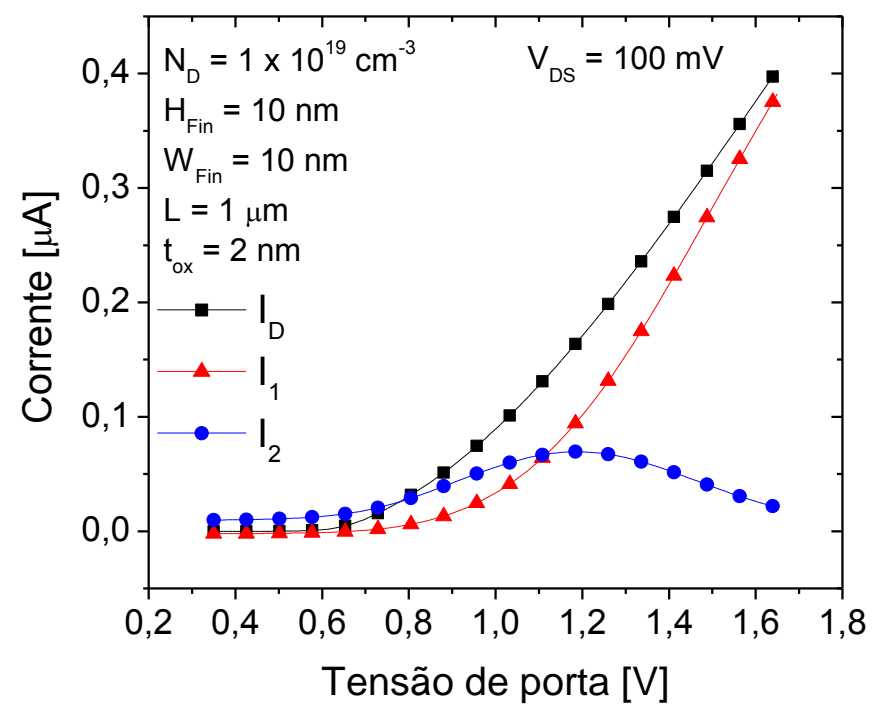

(A)

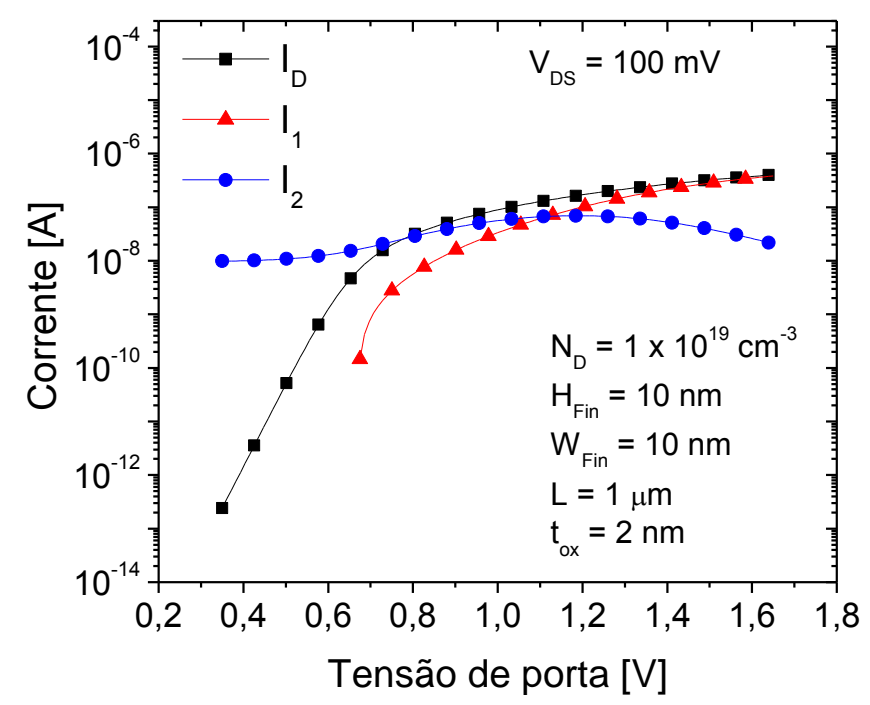

(B)

Figura 5.1 - Corrente em escalas linear (A) e logarítmica (B) em função da tensão de porta mostrando as contribuições das componentes $I_{1}$ e $I_{2}$ na corrente de dreno.

A Figura 5.2 apresenta a corrente de dreno em escalas linear e logarítmica em função da tensão de porta para diferentes polarizações de dreno, comparando resultados simulados e modelados. Na Figura 5.2, a transcondutância é também apresentada em função de $V_{G s}$. Pelas figuras, pode-se observar que $I_{D}$ e $g_{m}$ são corretamente previstas pelo modelo, tanto no sublimiar como acima do limiar.

A razão entre a transcondutância e a corrente de dreno é apresentada na Figura 5.3 em função da corrente de dreno, mostrando que o modelo prevê 
adequadamente esta figura de mérito, que é importante em circuitos analógicos.

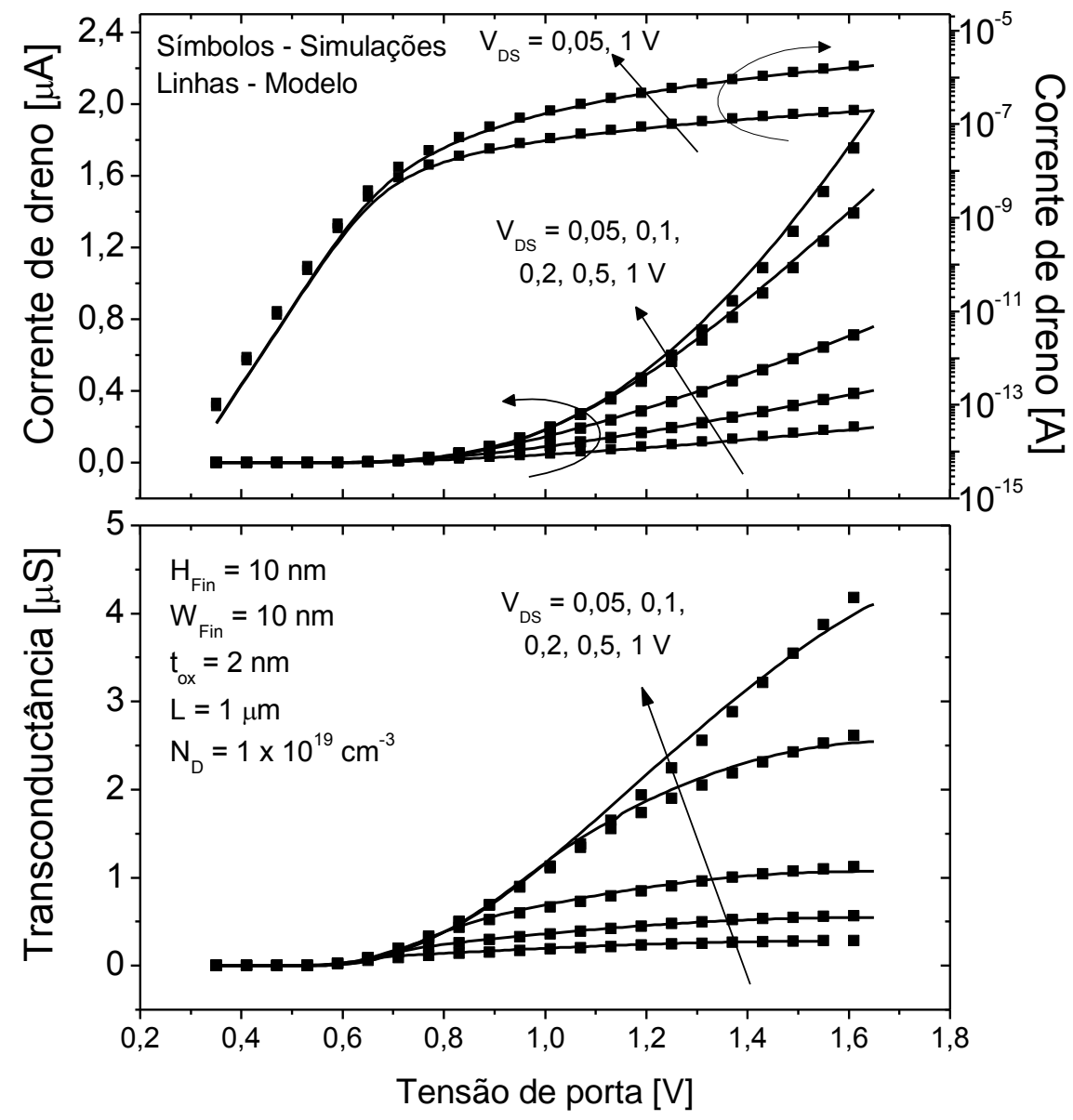

Figura 5.2 - Corrente de dreno e transcondutância modeladas e simuladas em função da tensão de porta.

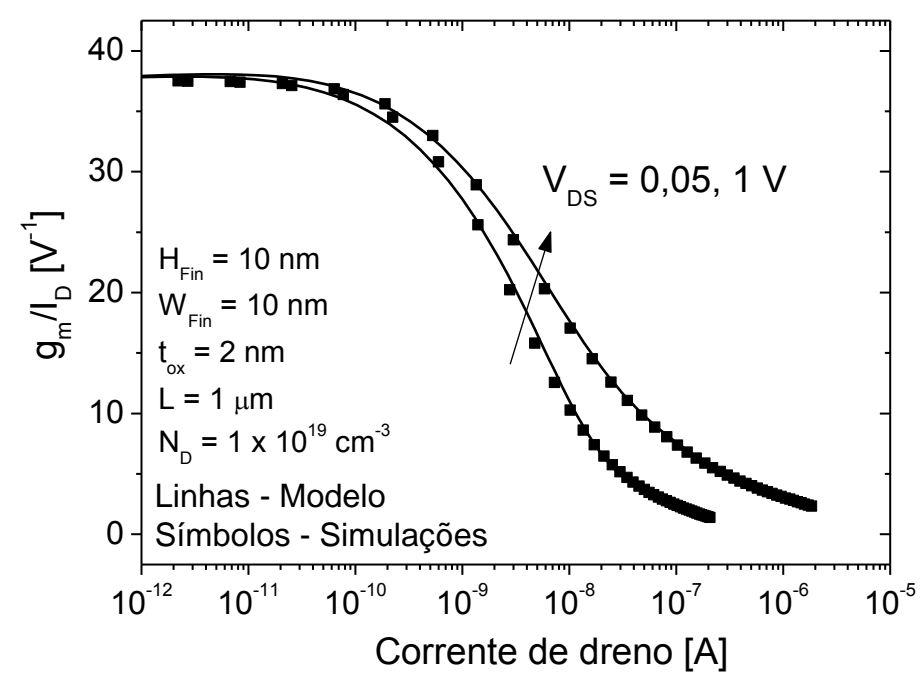

Figura 5.3 - Razão entre transcondutância e corrente de dreno em função da corrente de dreno comparando o modelo com resultados simulados.

Na Figura 5.4, a corrente e a condutância de saída são apresentadas em função da tensão de dreno para diferentes valores de sobretensão de porta 
$\left(\mathrm{V}_{\mathrm{GT}}=\mathrm{V}_{\mathrm{GS}}-\mathrm{V}_{\mathrm{TH}}\right)$. Pelos gráficos, pode-se observar que a corrente e a condutância de dreno são corretamente modeladas.

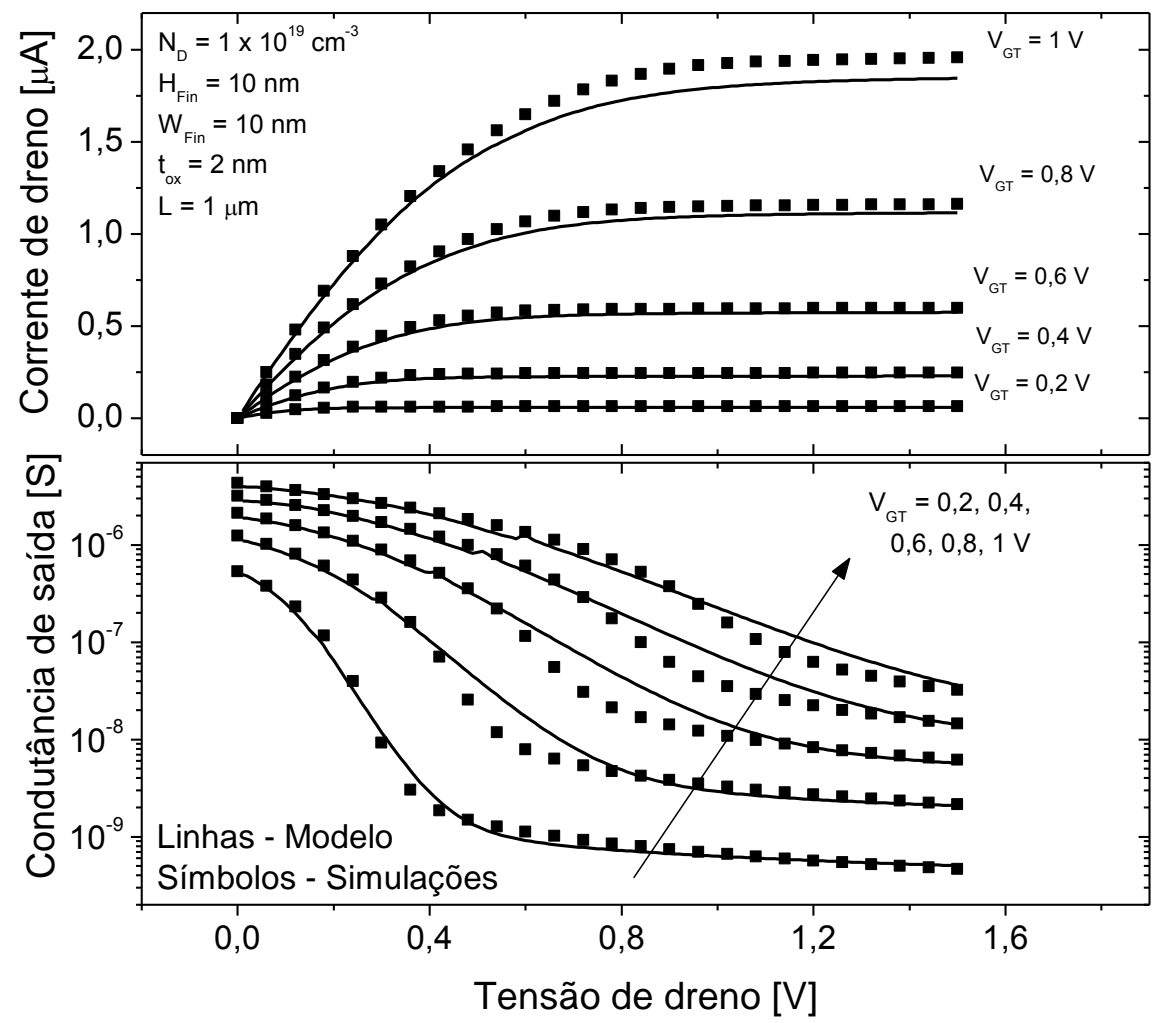

Figura 5.4 - Corrente e condutância de dreno modeladas e simuladas em função da tensão de dreno para diversos $\mathrm{V}_{\mathrm{GT}}\left(\mathrm{V}_{\mathrm{GT}}=\mathrm{V}_{\mathrm{GS}}-\mathrm{V}_{\mathrm{TH}}\right)$.

Os erros entre os resultados simulados e modelados foram calculados para as curvas da Figura 5.2 e da Figura 5.4. O erro máximo é apresentado na Tabela 5.1 para cada curva. O erro máximo é menor que $15 \%$ para $I_{D}$ e $g_{m}$ em todos os casos. Já o erro médio das curvas foi menor ou igual a 8,1\%.

Tabela 5.1 - Erro máximo absoluto entre os dados simulados e modelados da Figura 5.2 e da Figura 5.4.

\begin{tabular}{|c|c|c|c|c|c|}
\hline \multicolumn{2}{|c|}{ Curva $\mathbf{I}_{\mathbf{D}} \mathbf{x} \mathbf{V}_{\mathbf{G S}}$} & \multicolumn{2}{c|}{ Curva $\mathbf{g}_{\mathbf{m}} \mathbf{\times} \mathbf{V}_{\mathbf{G S}}$} & \multicolumn{2}{c|}{ Curva $\mathbf{I}_{\mathbf{D}} \mathbf{x} \mathbf{V}_{\mathbf{D S}}$} \\
\hline $\mathbf{V}_{\mathbf{D S}}[\mathbf{V}]$ & Erro [\%] & $\mathbf{V}_{\mathbf{D S}}[\mathbf{V}]$ & Erro [\%] & $\mathbf{V}_{\text {GT }}[\mathbf{V}]$ & Erro [\%] \\
\hline 0,05 & 8,9 & 0,05 & 12,9 & 0,2 & 9,1 \\
\hline 0,10 & 8,1 & 0,10 & 11,2 & 0,4 & 9,2 \\
\hline 0,20 & 9,4 & 0,20 & 14,3 & 0,6 & 10,4 \\
\hline 0,50 & 9,6 & 0,50 & 14,1 & 0,8 & 10,4 \\
\hline 1,00 & 9,8 & 1,00 & 14,4 & 1,0 & 7,6 \\
\hline
\end{tabular}


Assim como mencionado no item 3.1.1, a aplicação do modelo a dispositivos pMOS é análoga à aplicação a dispositivos nMOS. Dessa forma, a Figura 5.5 apresenta a corrente de dreno e a transcondutância para dispositivos pMOS polarizados em diversas tensões de dreno, mostrando que a aplicação do modelo e os resultados obtidos são similares aos dos dispositivos nMOS.
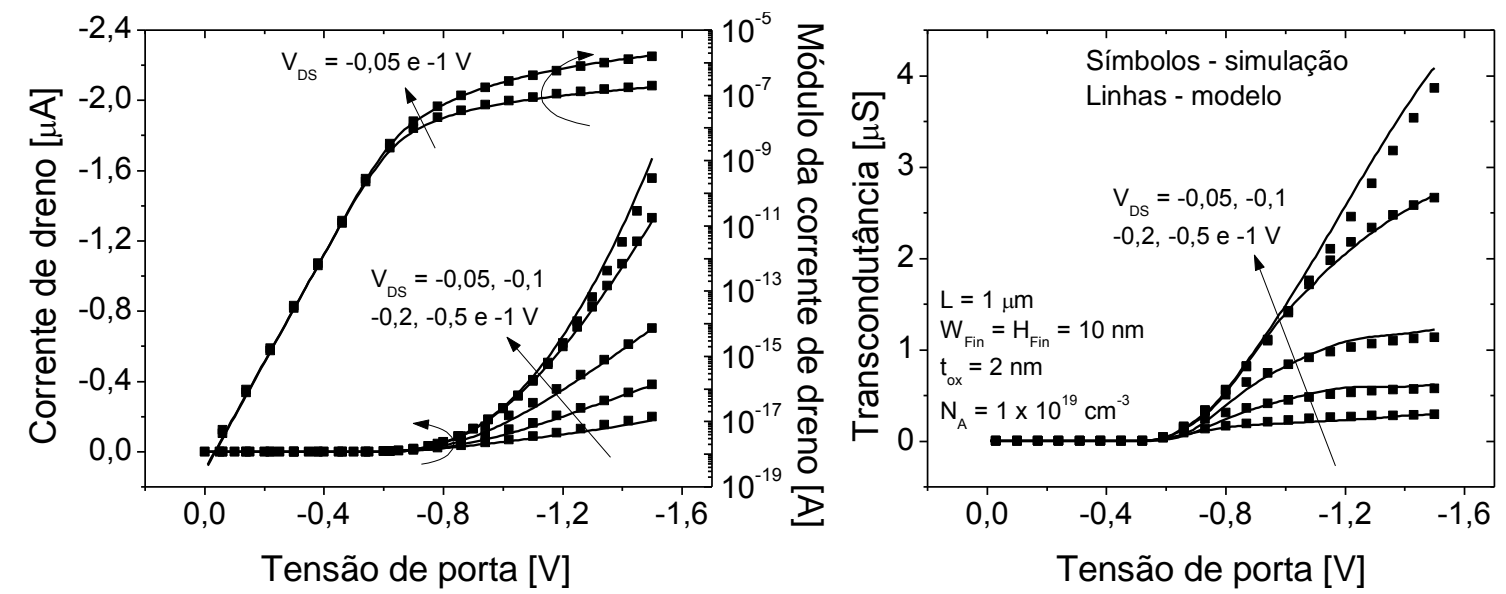

Figura 5.5 - Corrente de dreno e transcondutância em função da tensão de porta para diversas tensões de dreno mostrando a aplicação do modelo a dispositivos pMOS.

Depois da validação com as simulações TCAD, o modelo foi comparado com resultados experimentais. Os dispositivos foram os mesmos do item 3.1.4. A mobilidade de baixo campo foi calculada considerando os modelos de espalhamento de rede, por impurezas ionizadas e portador-portador descritos no item 2.4.2. Também foi considerada a resistência série, sendo que a equação da corrente foi resolvida de forma iterativa. Foi considerada uma resistência de fonte/dreno de $100 \mathrm{k} \Omega$, que equivale à resistência de uma região de $150 \mathrm{~nm}$ de comprimento com $\mathrm{N}_{\mathrm{D}}=1 \times 10^{19} \mathrm{~cm}^{-3}$ e uma mobilidade de 100 $\mathrm{cm}^{2} / \mathrm{V}$.s, que é um valor típico de mobilidade nestes dispositivos ${ }^{10}$. A Figura 5.6 apresenta a corrente de dreno para $V_{D S}=50 \mathrm{mV}$ enquanto a Figura 5.7 apresenta $I_{D}$ e $g_{m}$ para $V_{D S}=1 \mathrm{~V}$ em função da tensão de porta para diversas temperaturas, comparando os resultados do modelo proposto com resultados experimentais. A mobilidade de baixo campo foi calculada utilizando-se os modelos propostos por Caughey et al. ${ }^{65}$ e por Dorkel et al. ${ }^{67}$. Pode-se notar que o modelo apresenta boa concordância com os resultados experimentais. 


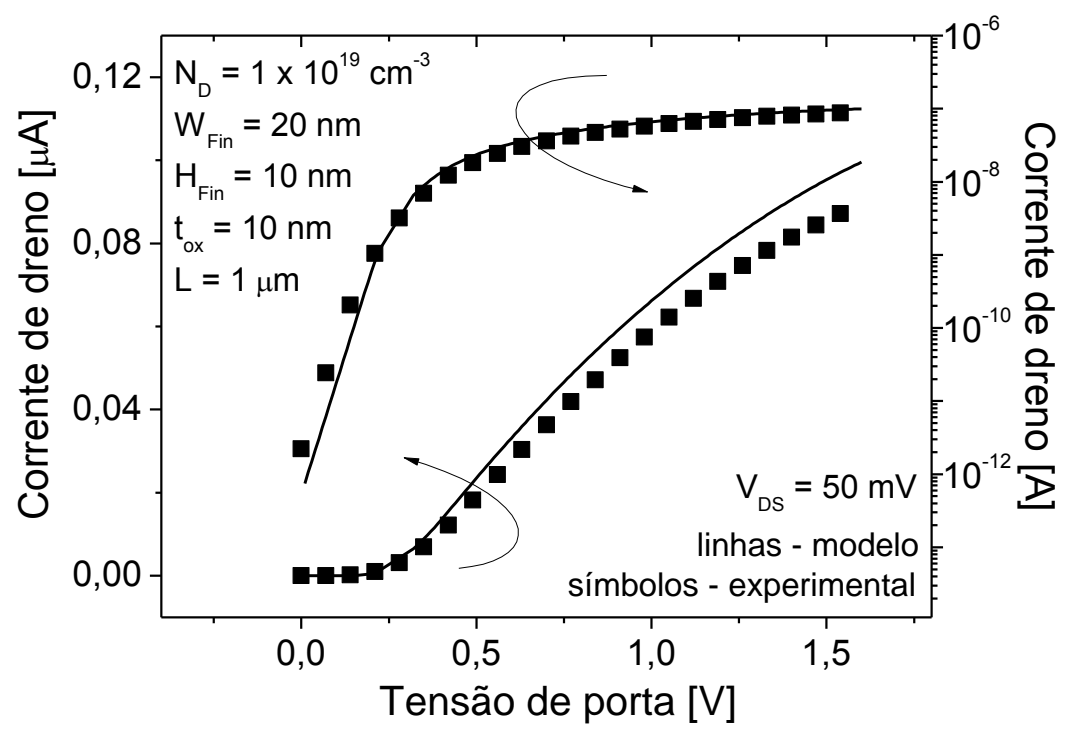

Figura 5.6 - Corrente de dreno em escalas linear e logarítmica em função da tensão de porta comparando o modelo com resultados experimentais para $\mathrm{V}_{\mathrm{DS}}=50 \mathrm{mV}$.
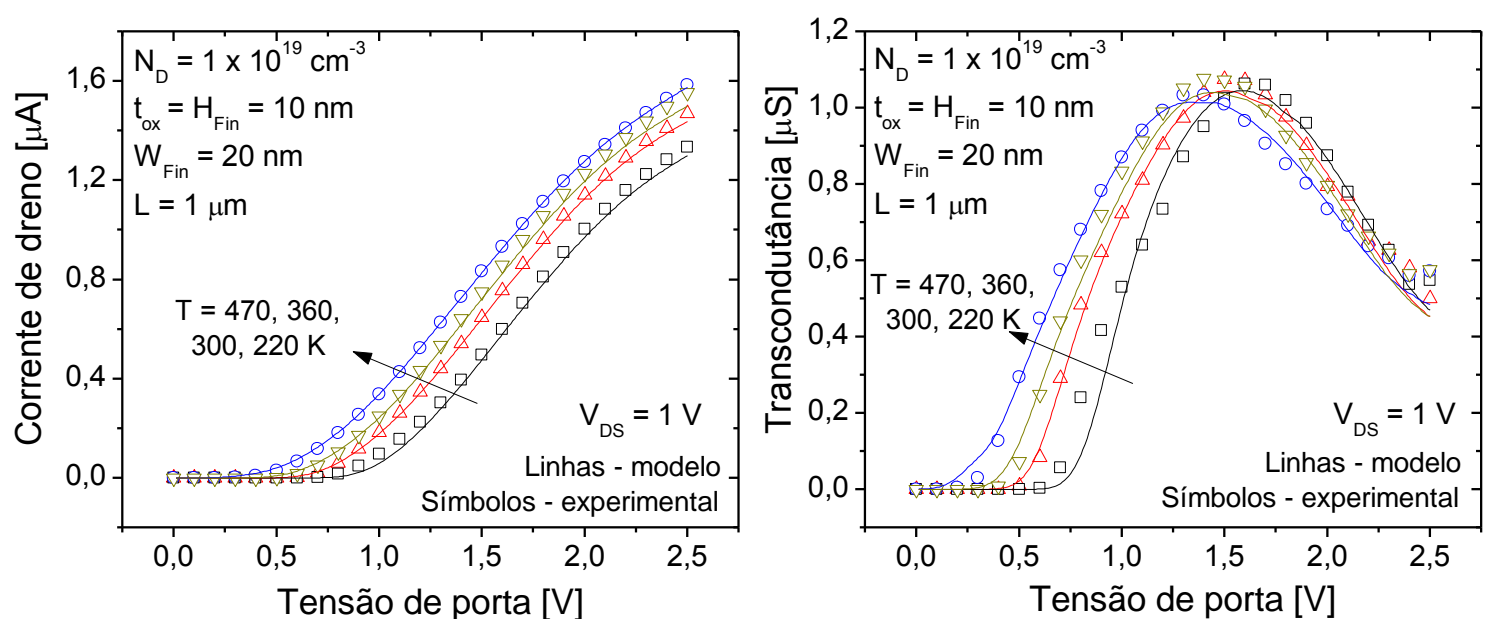

Figura 5.7 - Corrente de dreno e transcondutância em função da tensão de porta comparando os resultados do modelo com resultados experimentais para diversas temperaturas e $V_{D S}=1 \mathrm{~V}$.

\subsection{EFEITOS DE CANAL CURTO}

Com o intuito de obter uma expressão analítica para a inclusão dos efeitos de canal curto na modelagem da corrente de dreno, ou seja, a influência da polarização do dreno no potencial do canal, a equação tridimensional de Poisson deve ser resolvida:

$$
\frac{d^{2} \phi}{d x^{2}}+\frac{d^{2} \phi}{d y^{2}}+\frac{d^{2} \phi}{d z^{2}}=-\frac{q N_{D}}{\varepsilon_{S i}}
$$

onde y representa a direção do comprimento do canal. 
A equação (5.14) pode ser resolvida utilizando-se o principio da superposição, de forma que a solução é obtida pela soma da solução da equação (3.1) com a solução da equação tridimensional de Laplace descrita por:

$$
\frac{d^{2} \phi}{d x^{2}}+\frac{d^{2} \phi}{d y^{2}}+\frac{d^{2} \phi}{d z^{2}}=0
$$

A solução da equação (5.15) para o potencial mínimo $\left(\phi_{\min }\right)$ no canal é dada por ${ }^{3,122,123}$ :

$$
\phi_{\min }=\frac{V \sinh \left(\mathrm{y}_{\min } / \lambda\right)+U \sinh \left(\left(L-y_{\min }\right) / \lambda\right)}{\sinh (\mathrm{L} / \lambda)}
$$

onde $\mathrm{U}$ e $\mathrm{V}$ são os potenciais na fonte e no dreno, respectivamente, $\lambda$ é o comprimento característico e $y_{\min }$ é o ponto do potencial mínimo no canal.

O ponto $y_{\min }$ pode ser obtido por ${ }^{123}$ :

$$
\mathrm{y}_{\min }=\frac{\lambda}{2} \ln \left[\frac{\mathrm{U} \exp (\mathrm{L} / \lambda)-\mathrm{V}}{\mathrm{V}-\mathrm{U} \exp (-\mathrm{L} / \lambda)}\right]
$$

O comprimento característico $\lambda$ para um dispositivo porta tripla pode ser obtido pela média dos dois comprimentos característicos $\lambda_{1}$ e $\lambda_{2}$ relacionados à largura e à altura, respectivamente ${ }^{3}$ :

$$
\lambda=\frac{1}{\sqrt{\lambda_{1}^{-2}+\left(2 \lambda_{2}\right)^{-2}}}
$$

sendo $\lambda_{1}$ e $\lambda_{2}$ descritos por ${ }^{3}$ :

$$
\begin{aligned}
& \lambda_{1}=\sqrt{\frac{\varepsilon_{\mathrm{Si}} W_{\text {Fin }} t_{\mathrm{ox}}}{2 \varepsilon_{\mathrm{ox}}}\left(1+\frac{\varepsilon_{\mathrm{ox}} W_{\text {Fin }}}{4 \varepsilon_{\mathrm{Si}} t_{\mathrm{ox}}}\right)^{2}} \\
& \lambda_{2}=\sqrt{\frac{\varepsilon_{\mathrm{Si}} \mathrm{H}_{\mathrm{Fin}} \mathrm{t}_{\mathrm{ox}}}{4 \varepsilon_{\mathrm{ox}}}\left(1+\frac{\varepsilon_{\mathrm{ox}} \mathrm{H}_{\mathrm{Fin}}}{2 \varepsilon_{\mathrm{Si}} \mathrm{t}_{\mathrm{ox}}}\right)^{2}}
\end{aligned}
$$


O potencial U, quando o dispositivo opera em depleção parcial, pode ser obtido isolando-se a densidade de cargas de depleção na equação (4.4) e substituindo-a em (3.8), resultando em:

$$
U=-\left[V_{G S}-V_{F B}-\frac{Y}{2 C_{o x}^{2}}+\sqrt{\frac{Y}{C_{o x}^{2}}} \sqrt{\frac{Y}{4 C_{o x}^{2}}-\left(V_{G S}-V_{F B}\right)}\right]
$$

Já o potencial $\mathrm{V}$ é descrito por $\mathrm{V}=\mathrm{U}+\mathrm{V}_{\mathrm{DS}}$. Assim, primeiramente devem-se calcular os potenciais $U$ e V. Então, o ponto $y_{\min }$ e o potencial mínimo no canal podem ser obtidos pelas equações (5.17) e (5.16), respectivamente. $\mathrm{Na}$ sequência, a corrente de dreno com a correção dos efeitos de canal curto pode ser calculada substituindo-se $\mathrm{V}_{\mathrm{GS}}$ por $\mathrm{V}_{\mathrm{GS}}+\phi_{\text {min }}$.

A relação entre a velocidade (v) e o campo elétrico que considera a velocidade de saturação é descrita por ${ }^{120}$ :

$$
v=\mu_{0} E_{\text {eff }}\left(1+\mu_{0} E_{\text {eff }} / v_{\text {sat }}\right)^{-1}
$$

A mobilidade efetiva será então obtida por:

$$
\mu_{\text {eff }}=\mu_{0}\left(1+V_{\text {DS }} \mu_{0} /\left(\operatorname{Lv}_{\text {sat }}\right)\right)^{-1}
$$

$\mathrm{Na}$ Figura 5.8, a corrente de dreno e a transcondutância de um dispositivo com $L=40 \mathrm{~nm}$ são apresentadas em função de $V_{G s}$, onde são comparados os resultados simulados com as simulações numéricas.

$\mathrm{Na}$ Figura 5.9, a corrente de dreno e a condutância de saída são mostradas em função da tensão de dreno. Pelas figuras, pode-se notar que 0 modelo com a correção de efeito de canal curto descreve adequadamente a corrente de dreno para todas as polarizações analisadas. Há apenas uma pequena descontinuidade nas curvas da condutância de saída, causada pela transição no início da região de saturação. 


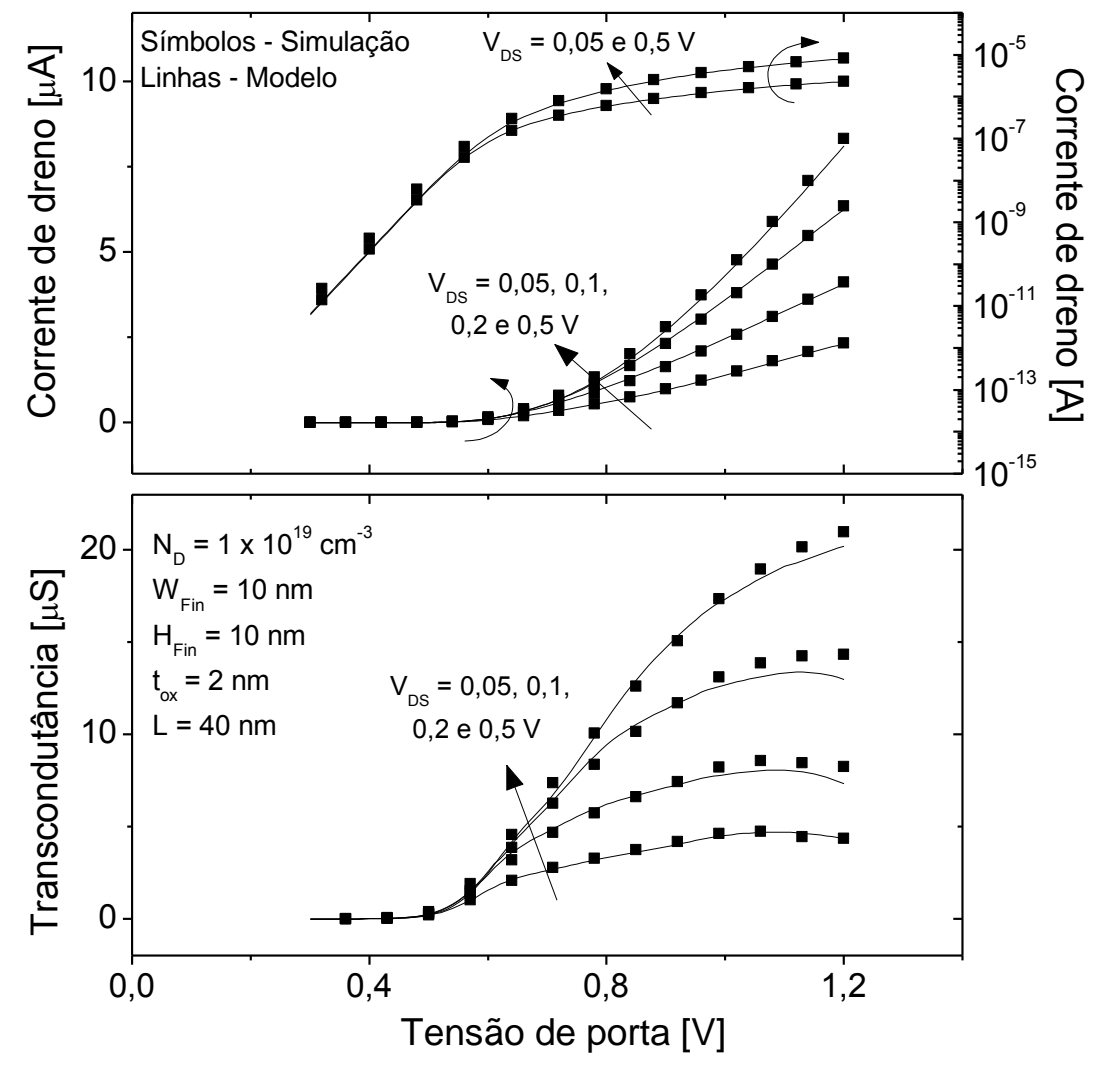

Figura 5.8 - Corrente de dreno em escalas linear e logarítmica e transcondutância em função da tensão $V_{G S}$ apresentando resultados modelados e simulados para um JNT de $L=40 \mathrm{~nm}$.

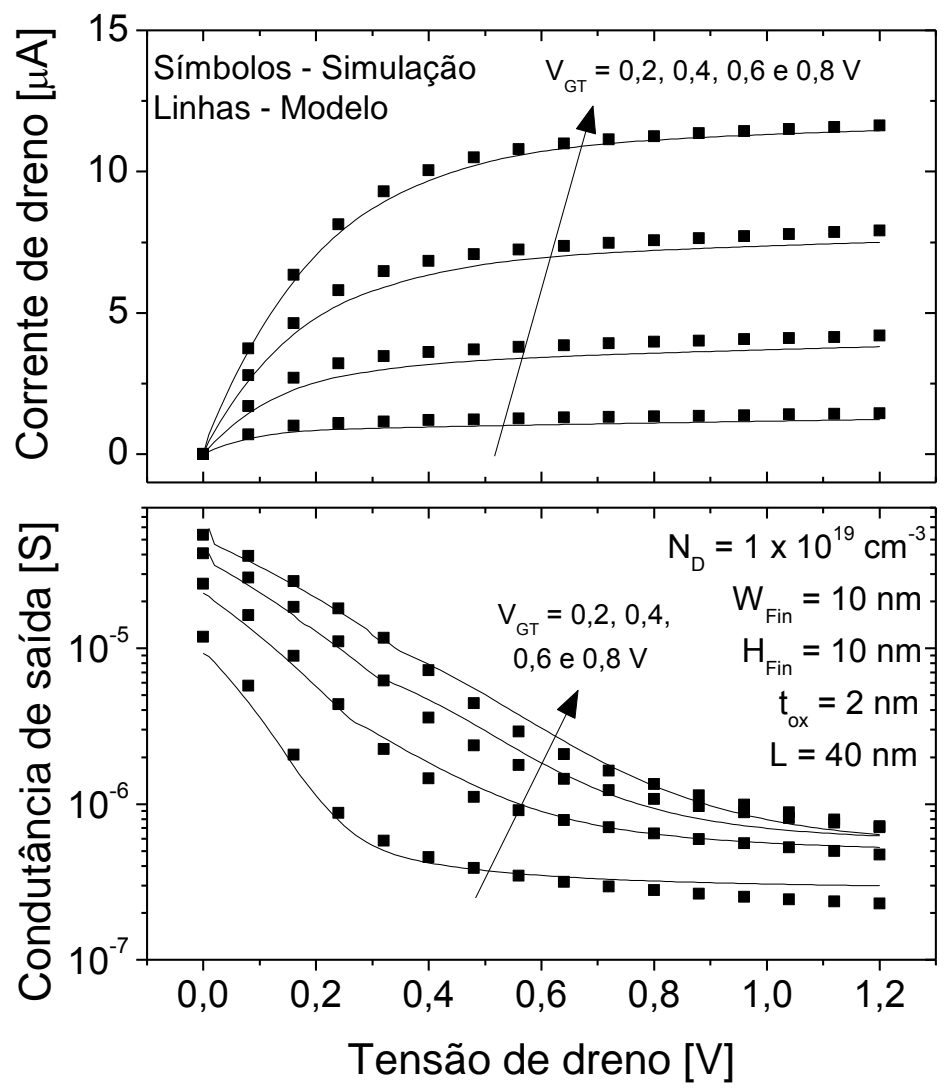

Figura 5.9 - Corrente de dreno e condutância de saída em função da tensão aplicada ao dreno mostrando resultados modelados e simulados para um dispositivo de $\mathrm{L}=40 \mathrm{~nm}$. 


\subsubsection{Inclinação de sublimiar}

A equação (5.16) pode ser utilizada a fim de se obter uma expressão para a dependência da inclinação de sublimiar no comprimento do canal. Para se desenvolver esta expressão, a variação do potencial mínimo no canal deve ser analisada. O ponto do mínimo potencial no canal normalizado pelo comprimento do mesmo é apresentado na Figura 5.10 em função de tensão de porta para dispositivos com diferentes comprimentos de canal e considerando uma baixa tensão de dreno. As tensões de limiar desses dispositivos estão próximas de 0,65 V. Para tensões de porta bem abaixo do limiar $\left(\mathrm{V}_{\mathrm{GS}} \ll<\mathrm{V}_{\mathrm{TH}}\right)$, o ponto do potencial mínimo no canal tende à metade do comprimento do canal $\left(y_{\min } / L=0,5\right)$, ou seja, o menor potencial se encontra no centro do canal. Esse fato se deve à pequena diferença entre as barreiras de potencial do dreno e da fonte.

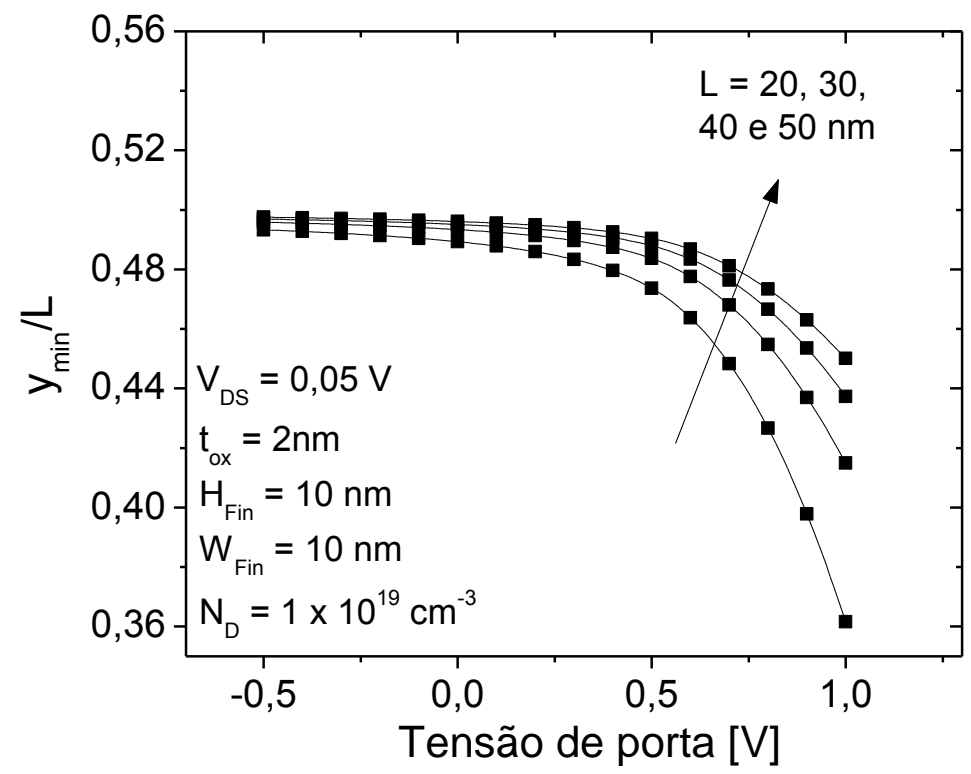

Figura 5.10 - Ponto do potencial mínimo no canal normalizado pelo comprimento de canal em função da tensão de porta.

Dessa forma, para se obter uma expressão para $\mathrm{S}$, o ponto do potencial mínimo pode ser considerado como $y_{\min }=L / 2$. Com esta aproximação, $a$ equação (5.16) pode ser reescrita para a região de sublimiar considerando baixo $V_{D S}$ como: 


$$
\phi_{\text {min, sub }}=\frac{\sinh (\mathrm{L} /(2 \lambda))}{\sinh (\mathrm{L} / \lambda)}(\mathrm{V}+\mathrm{U})
$$

Na Figura 5.11, o potencial mínimo na região de sublimiar $\left(\phi_{\min , \text { sub }}\right)$ obtido pela equação (5.16) é apresentado em função da tensão de porta para dispositivos de diferentes comprimentos de canal. Pode-se observar que 0 potencial varia linearmente com $V_{G S}$ na região de sublimiar. Também se pode observar que o potencial mínimo e sua variação com a tensão de porta aumentam com a redução do comprimento do canal.

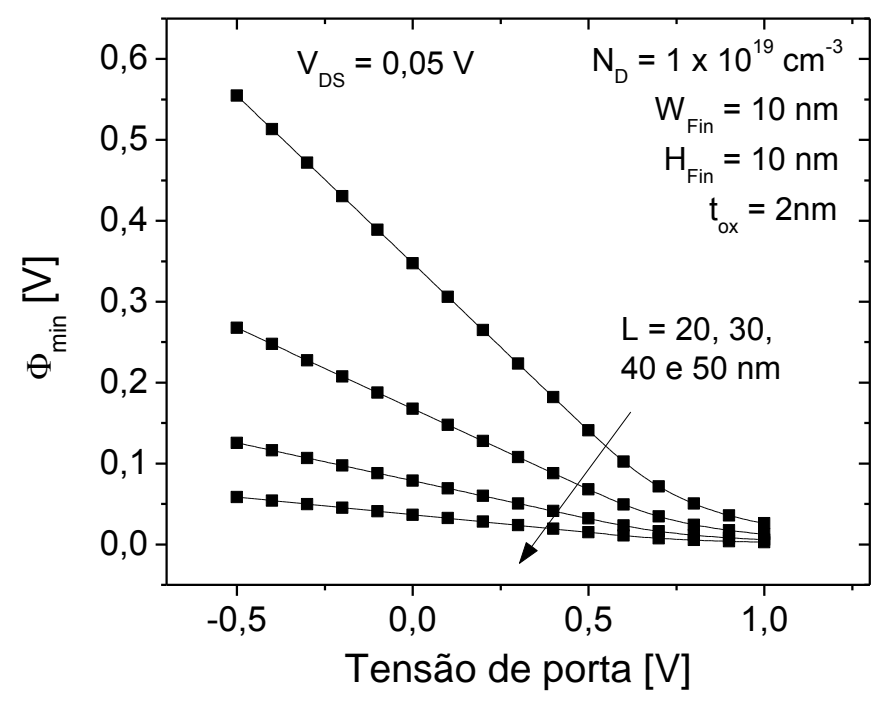

Figura 5.11 - Potencial mínimo no canal em função da tensão de porta para dispositivos de diferentes comprimentos de canal considerando uma baixa polarização de dreno.

A variação da inclinação de sublimiar com as dimensões dos dispositivos $(\Delta S)$ está relacionada com a variação de $\phi_{\text {min,sub }}$ com $V_{\mathrm{GS}}$ :

$$
\Delta \mathrm{S}=\mathrm{S}\left(\frac{\mathrm{d} \phi_{\text {min,sub }}}{\mathrm{dV}_{\mathrm{GS}}}\right)
$$

Derivando a equação (5.24) em relação à tensão de porta, pode-se obter:

$$
\frac{\mathrm{d} \phi_{\text {min, sub }}}{\mathrm{dV}_{\mathrm{GS}}}=\frac{\sinh (\mathrm{L} /(2 \lambda))}{\sinh (\mathrm{L} / \lambda)} \frac{\mathrm{d}(2 \mathrm{U})}{\mathrm{dV}_{\mathrm{GS}}}
$$


No regime de sublimiar, o potencial de superfície varia linearmente com a tensão de porta $\left(U \propto V_{G S}\right)$, uma vez que todas as cargas no canal estão depletadas, de forma que não há variação de cargas no canal com $V_{G S}{ }^{16,122}$. Assim, a inclinação de sublimiar considerando os efeitos de canal curto (Short Channel Effects - SCE) pode ser calculada por:

$$
\mathrm{S}_{\mathrm{SCE}}=\mathrm{S}+\Delta \mathrm{S}=\mathrm{S}\left(1+2 \frac{\sinh (\mathrm{L} /(2 \lambda))}{\sinh (\mathrm{L} / \mathrm{\lambda})}\right)
$$

A inclinação de sublimiar calculada pela equação (5.27) foi comparada aos valores extraídos dos dispositivos simulados para $\mathrm{V}_{\mathrm{DS}}=50 \mathrm{mV}$ na Figura 5.12. Foram comparados dispositivos de diferentes dimensões $\left(\mathrm{W}_{\mathrm{Fin}}, \mathrm{H}_{\mathrm{Fin}}\right.$ e $\mathrm{t}_{\mathrm{ox}}$ foram variados), sendo que o modelo apresentou concordância em todos os casos.

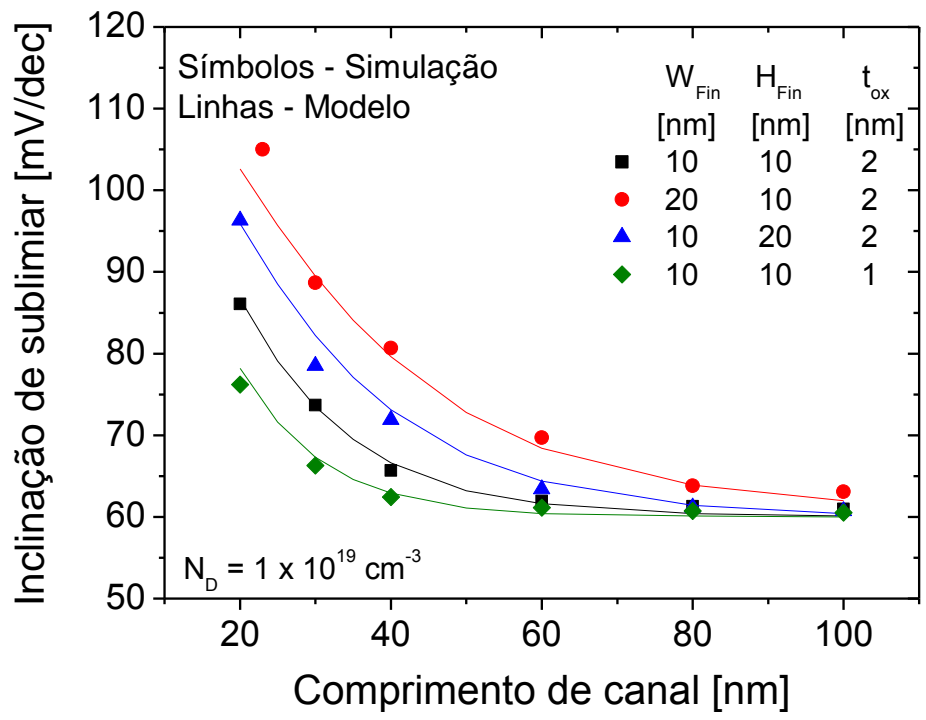

Figura 5.12 - Inclinação de sublimiar em função do comprimento de canal para dispositivos de diferentes dimensões comparando o modelo analítico com os resultados simulados.

\subsubsection{Redução da Tensão de Limiar e da Barreira Induzida pelo Dreno}

A equação (5.16) também pode ser utilizada para se desenvolver uma expressão analítica para a redução da tensão de limiar com a diminuição do comprimento de canal e para a redução da barreira induzida pelo dreno. Para desenvolver esta expressão, o potencial de superfície na condição de limiar é 
necessário. Conforme apresentado no Capítulo 3, este potencial é descrito pela equação (3.7) para um dispositivo longo.

Entretanto, este potencial é alterado pela variação do potencial mínimo no canal. Assim, o potencial na condição de limiar, considerando os efeitos de canal curto $\left(\phi_{S, S C E}\right)$, pode ser obtido pela diferença entre o potencial de superfície para dispositivos longos e o potencial mínimo na condição de limiar $\left(\phi_{\min , \mathrm{Vth}}\right)$ :

$$
\phi_{\mathrm{S}, \mathrm{SCE}}=\phi_{\mathrm{S}}-\phi_{\mathrm{min}, \mathrm{Vth}}
$$

Considerando que a tensão de limiar é extraída com uma tensão baixa no dreno, o ponto do potencial mínimo no canal ocorre no centro do dispositivo $\left(y_{\min }=L / 2\right.$, conforme apresentado na Figura 5.10). O potencial $\phi_{\min , \mathrm{Vth}}$, que representa a redução da tensão de limiar com o comprimento de canal (Threshold Voltage roll-off) pode ser obtido pela equação (5.24) com $U=\phi_{S, S C E}$ e $\mathrm{V}=\phi_{\mathrm{S}, S C E}+\mathrm{V}_{\mathrm{DS}}$ :

$$
\phi_{\min , \mathrm{Vth}}=\frac{\sinh (\mathrm{L} /(2 \lambda))}{\sinh (\mathrm{L} / \lambda)}\left(2 \phi_{\mathrm{S}, \mathrm{SCE}}+\mathrm{V}_{\mathrm{DS}}\right)
$$

Se o potencial no dreno é muito menor que o potencial de superfície, a equação (5.29) pode ser reescrita como:

$$
\phi_{\text {min, Vth }}=\frac{\sinh (\mathrm{L} /(2 \lambda))}{\sinh (\mathrm{L} / \lambda)} 2 \phi_{\mathrm{S}, \mathrm{SCE}}
$$

Substituindo (5.30) em (5.28), o potencial na condição de limiar, considerando os efeitos de canal curto, é descrito por:

$$
\phi_{\mathrm{S}, \mathrm{SCE}}=\frac{\phi_{\mathrm{S}}}{1+2 \frac{\sinh (\mathrm{L} /(2 \lambda))}{\sinh (\mathrm{L} / \lambda)}}
$$

Então, o potencial $\phi_{\min , \text { vth }}$ é obtido substituindo (5.31) em (5.30):

$$
\phi_{\text {min, }, \mathrm{th}}=\frac{\phi_{\mathrm{S}}}{1+\frac{\sinh (\mathrm{L} / \Lambda)}{2 \sinh (\mathrm{L} /(2 \lambda))}}
$$


onde $\phi_{\mathrm{s}}$ é calculado pela equação (3.7).

Na Figura 5.13, o potencial $\phi_{\text {min,vth }}$ calculado pela equação (5.32) é apresentado em função do comprimento de canal para dispositivos de diferentes dimensões.
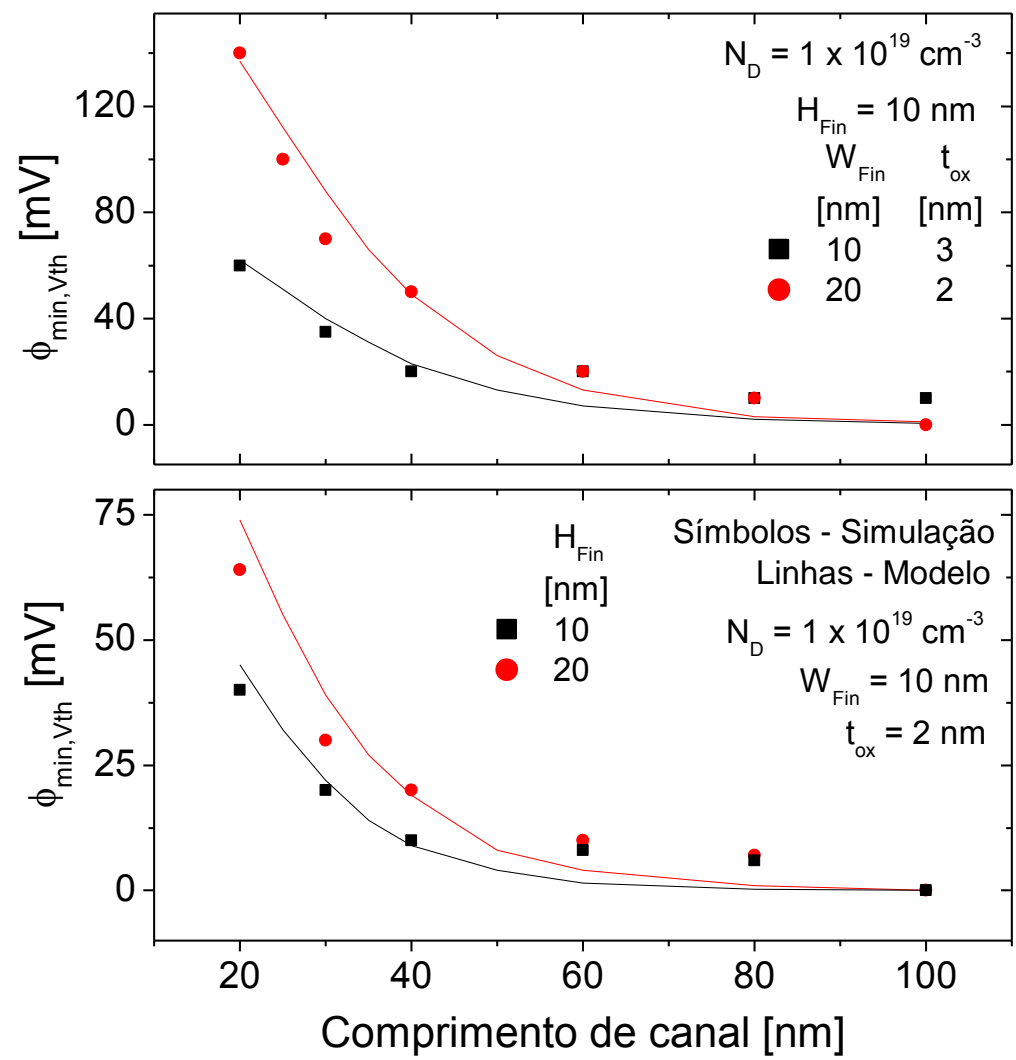

Figura 5.13 - Potencial $\phi_{\min , \text { th }}$ (Threshold Voltage Roll-off) em função do comprimento de canal obtido pelas simulações e pelo modelo analítico para dispositivos de diferentes dimensões.

Nos dispositivos simulados, a tensão de limiar foi extraída utilizando o método da segunda derivada ${ }^{110}$ para uma polarização $V_{D S}=50 \mathrm{mV}$. Entretanto, deve-se ressaltar que diferentes métodos de extração podem resultar em dependências relativamente diferentes em relação ao comprimento de canal, conforme pode ser notado na Figura 4.5. No entanto, o potencial $\phi_{\min , v t h}$ é muito importante, pois permite o cálculo da redução da barreira induzida pelo dreno.

Primeiramente, o potencial U é calculado através da equação (5.21) para $V_{G S}=V_{T H}-\phi_{\min , V t h}$. Então, o ponto $y_{\min }$ é obtido através da equação (5.17) para uma determinada polarização de dreno, por exemplo $\mathrm{V}_{\mathrm{DS}}=1 \mathrm{~V}$. O potencial $\phi_{\min }$ para esta polarização é calculado por (5.16). O DIBL será calculado por: 


$$
\mathrm{DIBL}=\left.\phi_{\min }\right|_{\mathrm{V}_{\mathrm{DS}}=1 \mathrm{~V}}-\phi_{\min , \mathrm{Vth}}+\mathrm{DIBL}_{\mathrm{L}}
$$

onde $D_{I B L_{L}}$ é a redução da barreira induzida pelo dreno extraída para os dispositivos de canal longo.

Na Figura 5.14, a redução da barreira induzida pelo dreno é apresentada em função do comprimento de canal para dispositivos de diferentes dimensões, comparando o cálculo do DIBL pela equação (5.33), conforme descrito acima, com resultados simulados. Na figura, pode-se observar que o modelo descreve adequadamente o DIBL em todos os casos analisados. $O$ valor de $D I B L_{L}$ é de $15 \mathrm{mV} / \mathrm{V}$ para todos os dispositivos considerados e pode ser considerado como um parâmetro de ajuste. É importante mencionar que, mesmo se a tensão de limiar for extraída por outro método como o descrito no Capítulo 4, os valores do DIBL são muito próximos.

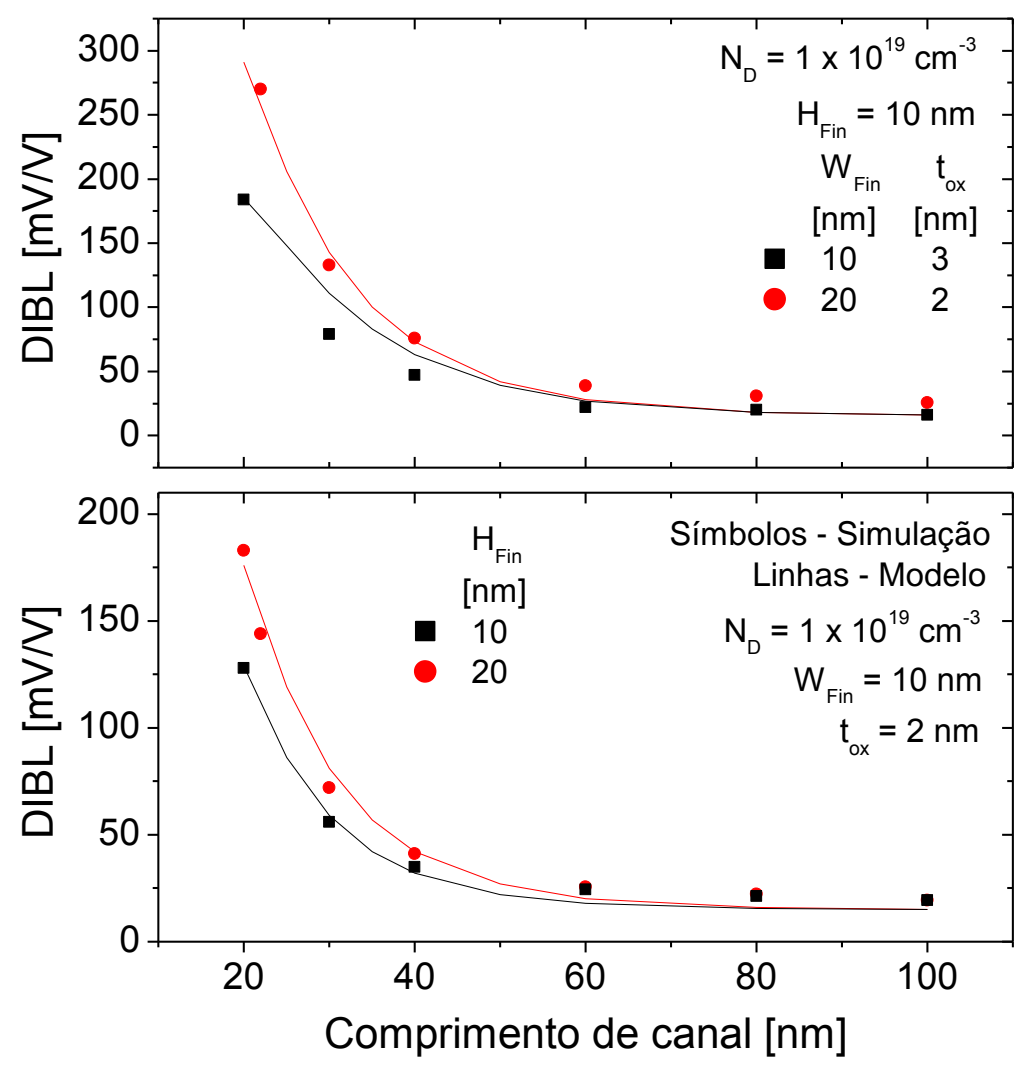

Figura 5.14 - Redução da barreira induzida pelo dreno (DIBL) em função do comprimento de canal para dispositivos de diferentes dimensões.

A modelagem de corrente de dreno proposta neste Capítulo se mostrou bastante eficiente quando comparada a resultados simulados e experimentais. 
Através da modelagem dos efeitos de canal curto também foi possível determinar funções analíticas para o cálculo da dependência da inclinação de sublimiar, da redução de barreira induzida pelo dreno e da tensão de limiar no comprimento de canal. No entanto, este modelo não pode ser utilizado para a obtenção de variáveis como potencial de superfície e carga de condução, que serão analisados no próximo Capítulo. 


\section{MODELO DE POTENCIAL DE SUPERFícIE E DENSIDADE DE CARGAS}

No Capítulo 5, foi apresentada uma modelagem para a corrente de dreno em dispositivos MOS sem junções de porta tripla. No entanto, o modelo desenvolvido não pode ser utilizado para a obtenção de outras variáveis como potencial de superfície e densidade de cargas em função das polarizações de porta e dreno. Dessa forma, deu-se sequência à etapa de modelagem procurando-se obter uma forma analítica de se calcular o potencial de

superfície e a densidade de cargas. Assim como realizado no Capítulo 5, a modelagem será dividida por modo de funcionamento (condução pelo corpo e por camada de acumulação).

\subsection{CONDUÇÃO DE CORPO}

O potencial de superfície no regime de condução pelo corpo pode ser obtido através da solução da equação bidimensional de Poisson (equação (3.1)), onde apenas a carga de depleção é considerada, conforme apresentado no item 3.1.1. A equação (3.1) pode ser integrada como apresentado em (3.3), resultando na relação entre potencial de superfície e campo elétrico descrita em (3.4) e na relação entre densidade de cargas e potencial descrita por (3.6). Substituindo (3.6) na relação do capacitor MOS (equação (3.8)), pode-se obter:

$$
\left(\mathrm{V}_{\mathrm{FB}}-\mathrm{V}_{\mathrm{GS}}-\phi_{\mathrm{S}}\right) \mathrm{C}_{\mathrm{ox}}=\varepsilon_{\mathrm{Si}}\left(2 \mathrm{H}_{\mathrm{Fin}}+\mathrm{W}_{\mathrm{Fin}}\right) \sqrt{\frac{\mathrm{qN}_{\mathrm{D}}}{\varepsilon_{\mathrm{Si}}} \phi_{\mathrm{S}}}
$$

Isolando-se o potencial em (6.1), pode-se obter o potencial de superfície no regime de depleção parcial $\left(\phi_{\mathrm{S}, \mathrm{dep})}\right)$ :

$$
\phi_{\mathrm{S}, \mathrm{depl}}=\mathrm{V}_{\mathrm{GS}}-\mathrm{V}_{\mathrm{FB}}-\frac{\mathrm{V}_{\mathrm{pot}}}{2}+\sqrt{\left(\frac{\mathrm{V}_{\mathrm{pot}}}{2}\right)^{2}-\mathrm{V}_{\mathrm{pot}}\left(\mathrm{V}_{\mathrm{GS}}-\mathrm{V}_{\mathrm{FB}}\right)}
$$

onde $\gamma_{\text {pot }}=\varepsilon_{\text {Si }} \cdot q \cdot N_{D} \cdot\left(2 \cdot H_{\text {Fin }}+W_{\text {Fin }}\right)^{2} / C_{o x}{ }^{2}$. 


\subsection{CONDUÇÃO PELA CAMADA DE ACUMULAÇÃO}

No regime de condução pela camada de acumulação, a equação de Poisson bidimensional pode ser escrita como ${ }^{47}$ :

$$
\frac{d^{2} \phi}{d x^{2}}+\frac{d^{2} \phi}{d z^{2}}=\frac{q N_{D}}{\varepsilon_{S i}} e^{\frac{\phi}{\phi_{t}}}
$$

Neste regime de condução, apenas a densidade de elétrons é considerada (a carga de depleção é desprezada), pois não há região de depleção. Utilizando-se as mesmas condições de contorno descritas no item 3.1.1 (potencial e campo elétrico nulos no centro de seção transversal do dispositivo), a equação (6.3) pode ser integrada da seguinte forma:

$$
\int_{0}^{E_{S}} d\left(\frac{d \phi}{d x}\right)^{2}=\frac{q N_{D}}{\varepsilon_{S i}} \int_{0}^{\phi_{S}} e^{\frac{\phi}{\phi_{i}}} \mathrm{~d} \phi
$$

A relação entre o potencial de superfície e o campo elétrico de superfície será descrita por:

$$
E_{\mathrm{S}}=\sqrt{\frac{\mathrm{qN} N_{\mathrm{D}} \phi_{t}}{\varepsilon_{\mathrm{Si}}}\left(e^{\frac{\phi_{\mathrm{S}}}{\phi_{\mathrm{t}}}}-1\right)}
$$

Substituindo (6.5) em (3.5) e em (3.8), tem-se:

$$
\left(\mathrm{V}_{\mathrm{FB}}-\mathrm{V}_{\mathrm{GS}}-\phi_{\mathrm{S}}\right) \mathrm{C}_{\mathrm{ox}}=\varepsilon_{\mathrm{Si}}\left(2 \mathrm{H}_{\mathrm{Fin}}+\mathrm{W}_{\mathrm{Fin}}\right) \sqrt{\frac{\mathrm{q} \mathrm{N}_{\mathrm{D}} \phi_{t}}{\varepsilon_{\mathrm{Si}}}\left(e^{\frac{\phi_{\mathrm{S}}}{\phi_{i}}}-1\right)}
$$

O potencial de superfície na equação (6.6) equivale ao potencial no regime de acumulação $\left(\phi_{\mathrm{S}, \mathrm{acc}}\right)$. Isolando o potencial do termo exponencial:

$$
\phi_{\mathrm{S}, \mathrm{acc}}=\phi_{t} \ln \left[1+\frac{\left(\mathrm{V}_{\mathrm{GS}}-\mathrm{V}_{\mathrm{FB}}-\phi_{\mathrm{S}, \mathrm{acc}}\right)^{2}}{\mathrm{~V}_{\mathrm{pot}} \phi_{t}}\right]
$$


O valor do potencial $\phi_{\mathrm{S} \text {,acc }}$ é de no máximo algumas vezes o potencial térmico em acumulação forte, assim $\phi_{\mathrm{S}, \text { acc }}$ pode ser desprezado para $\mathrm{V}_{\mathrm{GS}} \gg$ $V_{F B}$ no termo logarítmico.

\subsection{TRANSIÇÃO CONTÍNUA ENTRE OS REGIMES DE CONDUÇÃO}

Como forma de se obter uma transição contínua entre os diferentes regimes de condução, uma função de suavização foi utilizada para descrever a tensão de porta:

$$
\mathrm{V}_{\mathrm{G} 2}=\mathrm{V}_{\mathrm{FB}}\left[1-\frac{\ln \left[1+\exp \left(\mathrm{A}_{5}\left(1-\left(\mathrm{V}_{\mathrm{GS}}-\mathrm{V}_{\mathrm{Y}}\right) / \mathrm{V}_{\mathrm{FB}}\right)\right)\right]}{\ln \left(1+\exp \left(\mathrm{A}_{5}\right)\right)}\right]
$$

onde $A_{5}$ é um parâmetro que controla a suavidade da transição e é ajustado com base nas simulações. $O$ valor do $V_{Y}$ deve ser utilizado como $V_{S}$ (geralmente $0 \mathrm{~V}$ ) e $V_{D S e}$ para o cálculo dos potenciais de superfície na fonte e no dreno, respectivamente.

A equação (6.8) é utilizada a fim de se limitar a máxima tensão de porta em $V_{F B}$, de forma que a carga de depleção tenda à zero na condição de faixa plana. A equação (6.9) é usada na transição entre o sublimiar e a região de condução do dispositivo. Esta expressão limita a mínima tensão de porta $\left(\mathrm{V}_{\mathrm{G} 3}\right)$ na tensão de limiar.

$$
\mathrm{V}_{\mathrm{G} 3}=\mathrm{V}_{\mathrm{TH}}\left[1+\frac{\ln \left[1+\exp \left(\mathrm{A}_{6}\left(-1+\mathrm{V}_{\mathrm{G} 2} \mathrm{~N}_{\mathrm{TH}}\right)\right)\right]}{\ln \left(1+\exp \left(\mathrm{A}_{6}\right)\right)}\right]
$$

onde $A_{6}$ é um parâmetro que controla a transição para a região de sublimiar.

O parâmetro $A_{6}$ está relacionado com a inclinação de sublimiar do dispositivo. Assim, este não é um parâmetro de ajuste e deve ter um valor fixo. Este parâmetro será discutido no item 6.5.

O potencial de superfície para dispositivos longos pode ser calculado por 


$$
\phi_{\mathrm{S}}=\phi_{\mathrm{S}, \mathrm{depl}}+\phi_{\mathrm{S}, \mathrm{acc}}
$$

Considerando as equações (6.8) e (6.9) para a continuidade do potencial de superfície nas transições da região de limiar e no início da formação da camada de acumulação, os potenciais de superfície podem ser calculados por:

$$
\begin{gathered}
\phi_{\mathrm{S}, \mathrm{depl}}=\mathrm{V}_{\mathrm{G} 2}-\mathrm{V}_{\mathrm{FB}}+\mathrm{V}_{\mathrm{Y}}-\frac{\mathrm{Y}_{\mathrm{pot}}}{2}+\sqrt{\left(\frac{\mathrm{V}_{\mathrm{pot}}}{2}\right)^{2}-\mathrm{V}_{\mathrm{pot}}\left(\mathrm{V}_{\mathrm{G} 3}-\mathrm{V}_{\mathrm{FB}}\right)} \\
\phi_{\mathrm{S}, \mathrm{acc}}=\phi_{t} \ln \left[1+\frac{\left(\mathrm{V}_{\mathrm{GS}}-\mathrm{V}_{\mathrm{G} 2}\right)^{2}}{\mathrm{Y}_{\mathrm{pot}} \phi_{\mathrm{t}}}\right]
\end{gathered}
$$

Estas equações foram derivadas das equações (6.2) e (6.7), adicionando-se a dependência da tensão no canal $V_{Y}$.

Com o objetivo de se analisar a capacidade do modelo em descrever o potencial de superfície, simulações tridimensionais foram utilizadas considerando-se um dispositivo nMOS longo $(L=1 \mu \mathrm{m})$. O potencial efetivo de superfície foi extraído da estrutura simulada como o potencial médio ao longo da interface silício/óxido de porta. Este potencial efetivo foi extraído tanto do lado da fonte como do lado do dreno e é apresentado na Figura 6.1 juntamente com o potencial calculado pela equação (6.10).

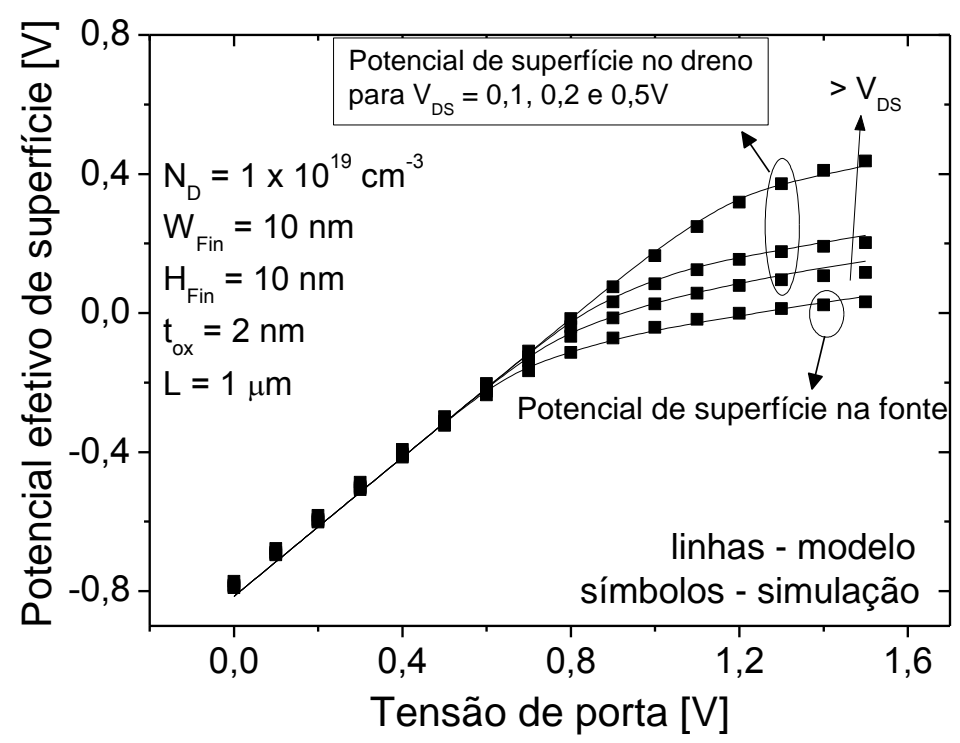

Figura 6.1 - Potencial efetivo de superfície extraído na fonte e no dreno de um dispositivo sem junções em função da tensão de porta comparando o modelo com as simulações numéricas. 
Pela figura, pode-se notar que o potencial de superfície é corretamente descrito pela equação tanto no lado da fonte como no dreno para todas as polarizações analisadas.

\subsection{EXPRESSÃO ANALÍTICA PARA CORRENTE DE DRENO}

A corrente de dreno pode ser obtida pela equação (4.1), descrita anteriormente. A densidade absoluta de carga de condução $\left(Q_{C}\right)$ pode ser obtida pela soma da carga $Q$, que é a carga controlada pela porta, com a carga fixa $Q_{\mathrm{si}}$ :

$$
\mathrm{Q}_{\mathrm{c}}=\mathrm{Q}_{\mathrm{Si}}+\mathrm{Q}=\mathrm{qN}_{\mathrm{D}} \mathrm{W}_{\mathrm{Fin}} \mathrm{H}_{\mathrm{Fin}}-\left(\mathrm{V}_{\mathrm{FB}}-\mathrm{V}_{\mathrm{GS}}+\phi_{\mathrm{S}}\right) \mathrm{C}_{\mathrm{ox}}
$$

A densidade de cargas móveis obtida nas simulações numéricas foi integrada na área da seção transversal tanto no lado da fonte como no lado do dreno do dispositivo, a fim de se obter a densidade de carga de condução por unidade de comprimento. Na Figura 6.2, a densidade de carga de condução $Q_{C}$ é apresentada em função da tensão de porta para diferentes polarizações de dreno, comparando as simulações com o cálculo das cargas através da equação (6.13). Pode-se perceber que a densidade de cargas é corretamente descrita pelo modelo em ambos os lados do dispositivo.

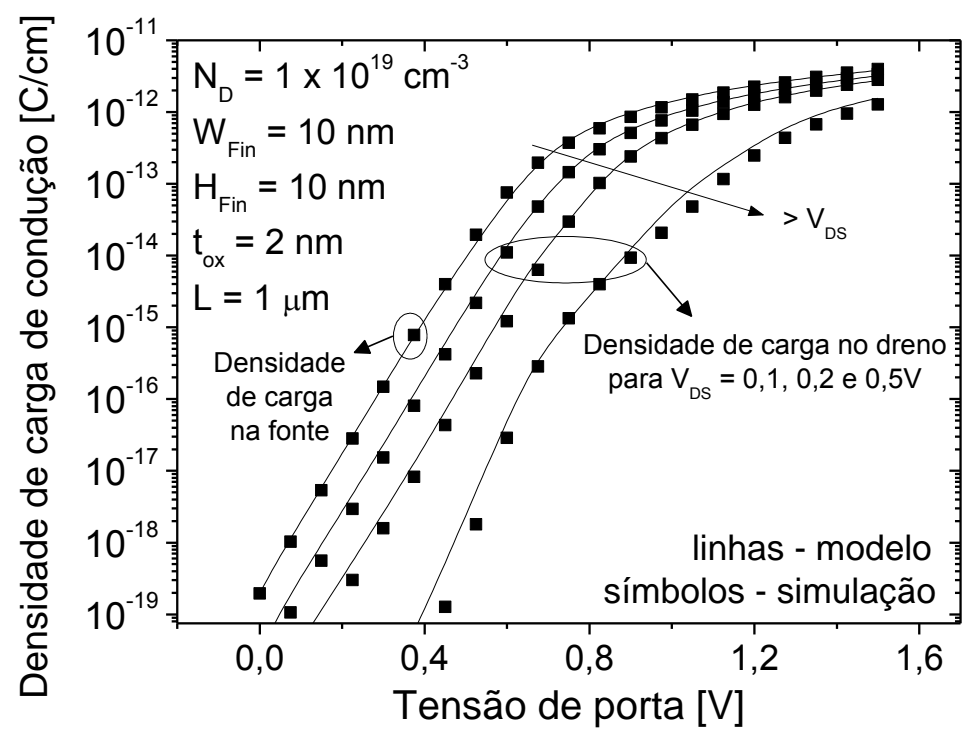

Figura 6.2 - Densidade de carga de condução por unidade de comprimento obtida por simulações numéricas e pelo modelo proposto em função da tensão de porta. 
A capacitância de porta por unidade de comprimento $\left(\mathrm{C}_{G}\right)$ pode ser obtida pela derivada das cargas:

$$
C_{G}=\frac{d Q_{C}}{d V_{G S}}
$$

Na Figura 6.3, a capacitância de porta por unidade de comprimento calculada pela equação (6.14) foi multiplicada pelo comprimento do canal como forma de se obter a capacitância total de porta, que é apresentada em função da tensão de porta. Deve-se ressaltar que essa multiplicação pelo comprimento do canal só pode ser feita, pois a diferença de potencial entre dreno e fonte é nula. Caso uma tensão seja aplicada ao dreno, a capacitância total deve ser obtida pela integral de $\mathrm{C}_{\mathrm{G}}$ entre a fonte e o dreno. Pela Figura 6.3, pode-se notar que a capacitância de porta é corretamente descrita pelo modelo, com erro máximo menor que $10 \%$ na região acima do limiar, e que não apresenta descontinuidades nas transições entre as diferentes regiões de operação.

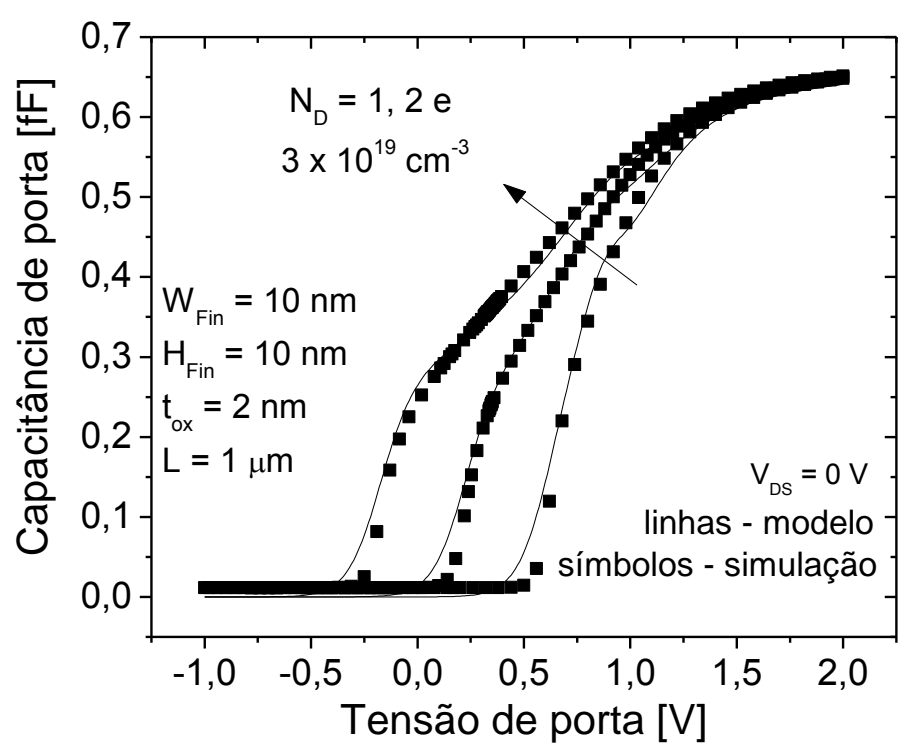

Figura 6.3 - Capacitância de porta em função da tensão aplicada à mesma obtida pelas simulações numéricas e pelo modelo analítico para dispositivos de diferentes concentrações de dopantes.

A capacitância máxima na curva é a capacitância do óxido de porta, que é afetada pela capacitância dos cantos, conforme visto no item 3.1.2. Na região entre a capacitância máxima e a mínima, a curva apresenta duas inclinações, sendo que o ponto de transição entre elas ocorre no limiar. A inclinação na região acima do limiar é menor, pois a camada de silício se encontra 
parcialmente depletada e a variação do potencial de superfície depende da depleção. A inclinação na região abaixo do limiar é maior porque o silício se encontra totalmente depletado, fazendo com que a variação do potencial de superfície seja proporcional à $\mathrm{V}_{\mathrm{GS}}$.

Considerando a relação linear entre a tensão no canal e a densidade de cargas descrita por:

$$
\mathrm{dV}_{\mathrm{Y}}=-\frac{\mathrm{dQ}_{\mathrm{c}}}{\mathrm{C}_{\mathrm{ox}}},
$$

a equação (4.1) pode ser integrada em relação à densidade de cargas, obtendo-se:

$$
\mathrm{I}_{\mathrm{D}}=\frac{\mu_{\mathrm{eff}}}{\mathrm{L}}\left[\frac{\mathrm{Q}_{\mathrm{c}, \mathrm{F}}{ }^{2}-\mathrm{Q}_{\mathrm{c}, \mathrm{D}}{ }^{2}}{2 \mathrm{C}_{\mathrm{ox}}}\right]
$$

onde $Q_{c, D}$ e $Q_{c, F}$ são as densidades de carga de condução por unidade de comprimento no dreno e na fonte, respectivamente, que podem ser obtidas pela equação (6.13), utilizando-se $\phi_{S}$ na fonte para $Q_{C, F}$ e no dreno para $Q_{c, D}$.

\subsection{PARÂMETRO $A_{6}$}

Como mencionado no item 6.3 , o parâmetro $A_{6}$ está relacionado à inclinação de sublimiar nos dispositivos de canal longo. Como forma de se determinar o parâmetro $A_{6}$, a corrente de dreno na região de sublimiar foi obtida através da equação (6.16) para um dispositivo longo $(L=1 \mu \mathrm{m})$ e $V_{D S}=$ $50 \mathrm{mV}$ para diversos valores de $A_{6}$. A Figura 6.4 apresenta o logaritmo da diferença entre $V_{G 3}$ e a tensão de limiar em função da tensão de porta na condição em que a inclinação de sublimiar da corrente de dreno foi próxima ao limite mínimo teórico. Pela Figura 6.4, pode-se notar que para se obter uma inclinação $S$ de $60 \mathrm{mV} /$ déc., a variação do $\log \left(\mathrm{V}_{\mathrm{G} 3}-\mathrm{V}_{\mathrm{TH}}\right)$ com a tensão de porta deve ser de $120 \mathrm{mV} /$ déc.. 


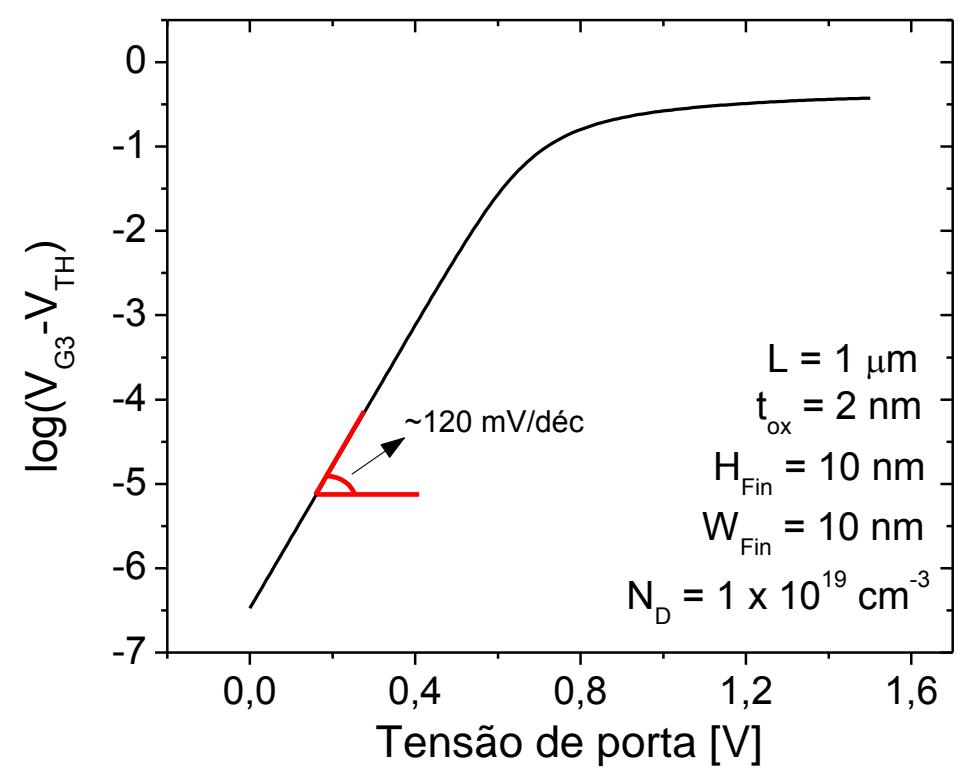

Figura 6.4 - Curva do logaritmo da diferença entre a tensão $V_{\mathrm{G} 3}$ e a tensão de limiar em função da tensão de porta.

Assim, para se obter o parâmetro $A_{6}$ pode-se utilizar a relação

$$
\frac{\operatorname{dlog}\left(\mathrm{V}_{\mathrm{G} 3}-\mathrm{V}_{\mathrm{TH}}\right)}{\mathrm{dV}_{\mathrm{GS}}}=\frac{1}{2 \mathrm{n} \phi_{t} \ln (10)}
$$

Diferenciando a equação (6.9) com relação à $\mathrm{V}_{\mathrm{GS}}$, pode-se obter:

$$
\frac{\operatorname{dlog}\left(\mathrm{V}_{\mathrm{G} 3}-\mathrm{V}_{\mathrm{TH}}\right)}{\mathrm{dV}_{\mathrm{GS}}}=\frac{\mathrm{A}_{6}}{\ln (10)} \frac{\exp \left(\mathrm{A}_{6}\left(-1+\mathrm{V}_{\mathrm{GS}} \mathrm{N}_{\mathrm{TH}}\right)\right)}{\ln \left[1+\exp \left(\mathrm{A}_{6}\left(-1+\mathrm{V}_{\mathrm{GS}} \mathrm{V}_{\mathrm{TH}}\right)\right)\right]} \frac{1}{\left(1+\exp \left(\mathrm{A}_{6}\left(-1+\mathrm{V}_{\mathrm{GS}} \mathrm{N}_{\mathrm{TH}}\right)\right)\right)} \frac{1}{\mathrm{~V}_{\mathrm{TH}}}
$$

$\mathrm{Na}$ região de sublimiar, o termo $\exp \left(\mathrm{A}_{6}\left(-1+\mathrm{V}_{\mathrm{GS}} / \mathrm{V}_{\mathrm{TH}}\right)\right)$ é muito menor que a unidade, de forma que $\ln \left[1+\exp \left(\mathrm{A}_{6}\left(-1+\mathrm{V}_{\mathrm{GS}} / \mathrm{V}_{\mathrm{TH}}\right)\right)\right]=\exp \left(\mathrm{A}_{6}\left(-1+\mathrm{V}_{\mathrm{GS}} / \mathrm{V}_{\mathrm{TH}}\right)\right)$. Assim, a equação (6.18) pode ser simplificada:

$$
\frac{\mathrm{dlog}\left(\mathrm{V}_{\mathrm{G} 3}-\mathrm{V}_{\mathrm{TH}}\right)}{\mathrm{dV}_{\mathrm{GS}}}=\frac{\mathrm{A}_{6}}{\ln (10)} \frac{1}{\mathrm{~V}_{\mathrm{TH}}}
$$

Substituindo (6.19) em (6.17), pode-se obter que:

$$
\mathrm{A}_{6}=\frac{\mathrm{V}_{\mathrm{TH}}}{2 \mathrm{n} \phi_{t}}
$$




\subsection{TENSÃO DE SATURAÇÃO}

Assim como no item 5.3, a relação (5.5) pode ser utilizada para se obter a tensão de saturação. A corrente $I_{\text {Dsat }}$ é obtida através da equação (6.16), considerando $Q_{c, D}=Q_{s a t}$. Então, $Q_{\text {sat }}$ pode ser isolado, resultando em:

$$
Q_{\text {sat }}=-v_{\text {sat }} L C_{o x} \mu_{\text {eff }}+\sqrt{\left(v_{\text {sat }} L C_{o x} \mu_{\text {eff }}\right)^{2}+Q_{c, F}{ }^{2}}
$$

A densidade de cargas $Q_{\text {sat }}$ pode ser usada na equação (6.13) como forma de se calcular o potencial de superfície no dreno na condição de saturação. Este potencial pode ser substituído em (6.11) para obter $V_{Y}$, que nesta condição será a tensão de saturação:

$$
V_{\text {Dsat }}=\left(\frac{1}{V_{\text {pot }}}\right)\left[\left(-\frac{Q_{\text {sat }}}{C_{\text {ox }}}+\frac{Q_{S i}}{C_{\text {ox }}}+\frac{V_{\text {pot }}}{2}\right)^{2}-\left(\frac{V_{\text {pot }}}{2}\right)^{2}\right]-V_{F B}+V_{G}
$$

A equação (5.9) é utilizada como forma de se limitar a máxima tensão de dreno na tensão de saturação.

\subsection{COMPARAÇÃO COM SIMULAÇÕES NUMÉRICAS}

A fim de se analisar a capacidade do modelo em calcular a corrente de dreno, simulações numéricas tridimensionais e resultados modelados foram comparados, considerando-se uma mobilidade constante de $100 \mathrm{~cm}^{2} / \mathrm{V}$.s, que é um valor típico nestes dispositivos ${ }^{10}$. Esta consideração foi a mesma utilizada no Capítulo 5 e está baseada no fato de que a mobilidade na condução de corpo, que é a principal nos JNTs, não é afetada pela polarização de porta ${ }^{4}$. 0 material de porta dos dispositivos é o silício policristalino tipo $P$. A velocidade de saturação foi considerada como $10^{7} \mathrm{~cm} / \mathrm{s}^{95}$, uma vez que este é o valor padrão utilizado pelo simulador numérico. Na Figura 6.5 a corrente é apresentada tanto em escala linear com em escala logarítmica em função da tensão de porta para diferentes polarizações de dreno. 


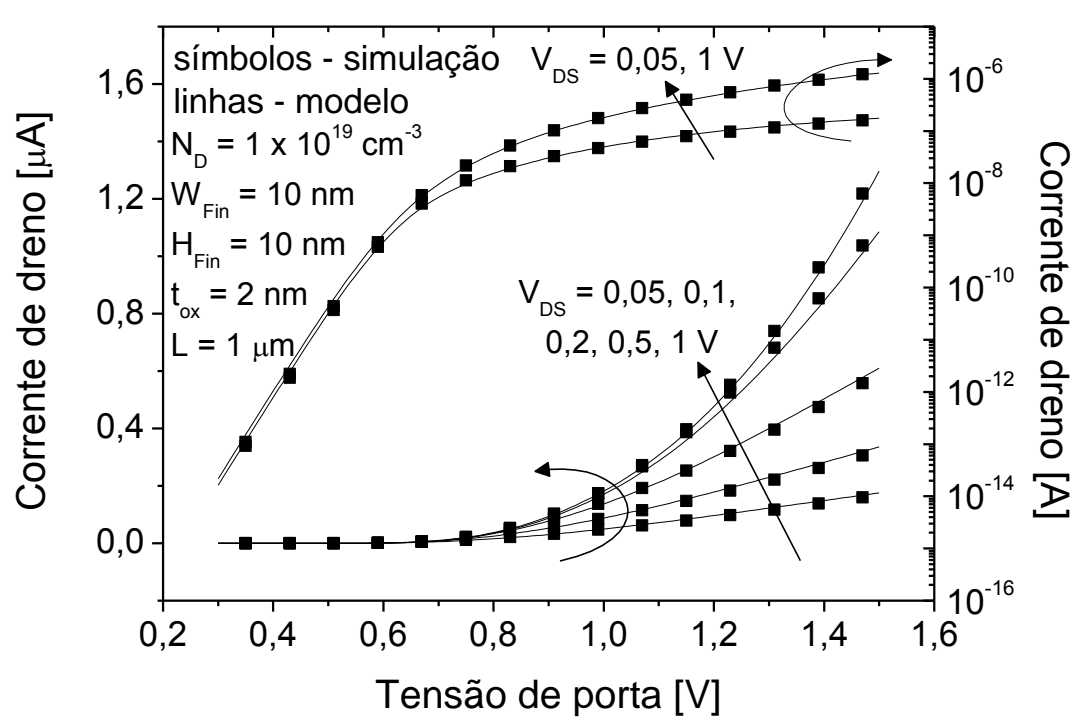

Figura 6.5 - Corrente de dreno em escalas linear e logarítmica em função da tensão de porta mostrando resultados simulados e obtidos com o modelo analítico desenvolvido com base nos potenciais de superfície.

Já na Figura 6.6, a transcondutância é apresentada em função da tensão de porta. Pode-se observar que a modelagem da corrente de dreno descrita neste capítulo apresenta uma excelente concordância com as simulações numéricas, com erros máximos de $11 \%$ para $I_{D}$ e $13 \%$ para $g_{m}$ acima do limiar.

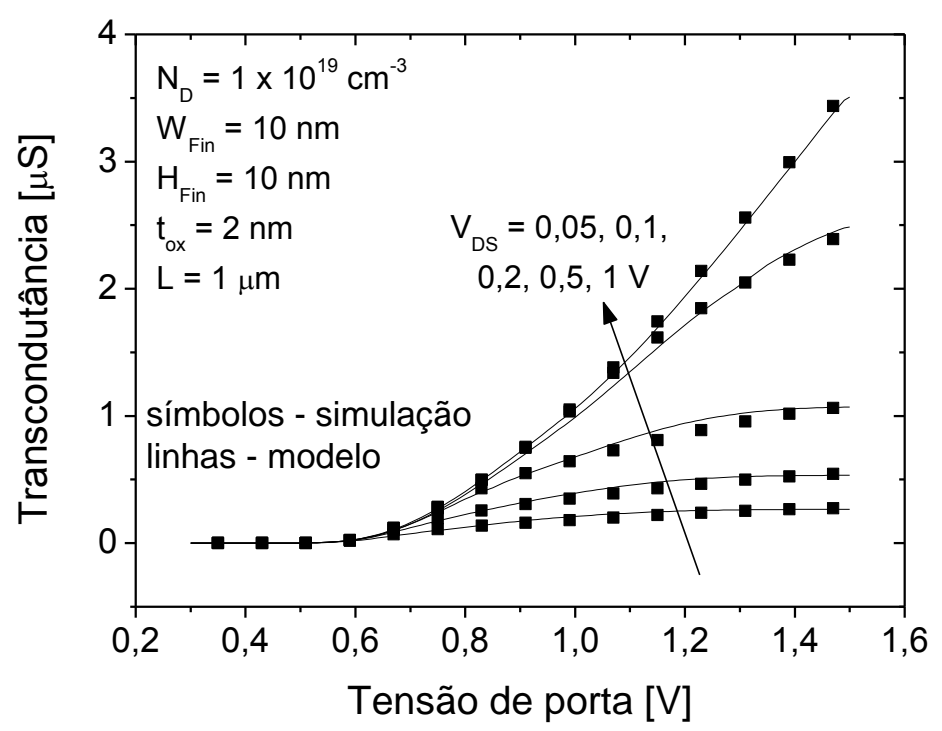

Figura 6.6 - Transcondutância em função da tensão aplicada à porta comparando-se as simulações numéricas com o modelo analítico desenvolvido com base nos potenciais de superfície.

Na Figura 6.7, a corrente de dreno é apresentada em função da tensão de dreno para diversas sobretensões de porta enquanto que na Figura 6.8 a condutância de saída é apresentada em escala logarítmica em função de $V_{D S}$. 
Pelas figuras, pode-se concluir que a dependência de $I_{D}$ e sua derivada com a tensão de dreno são precisamente descritas pelo modelo. O erro máximo para a corrente de dreno nesta figura foi de $9 \%$.

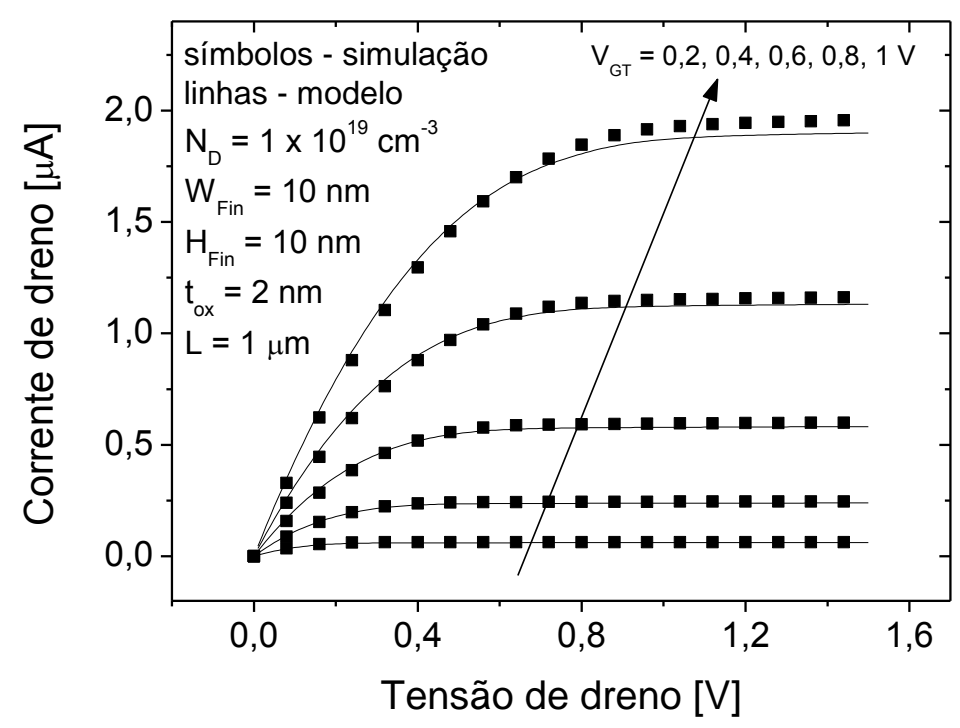

Figura 6.7 - Corrente de dreno em função da tensão $V_{D S}$ apresentando resultados simulados e obtidos com o modelo analítico desenvolvido com base nos potenciais de superfície.

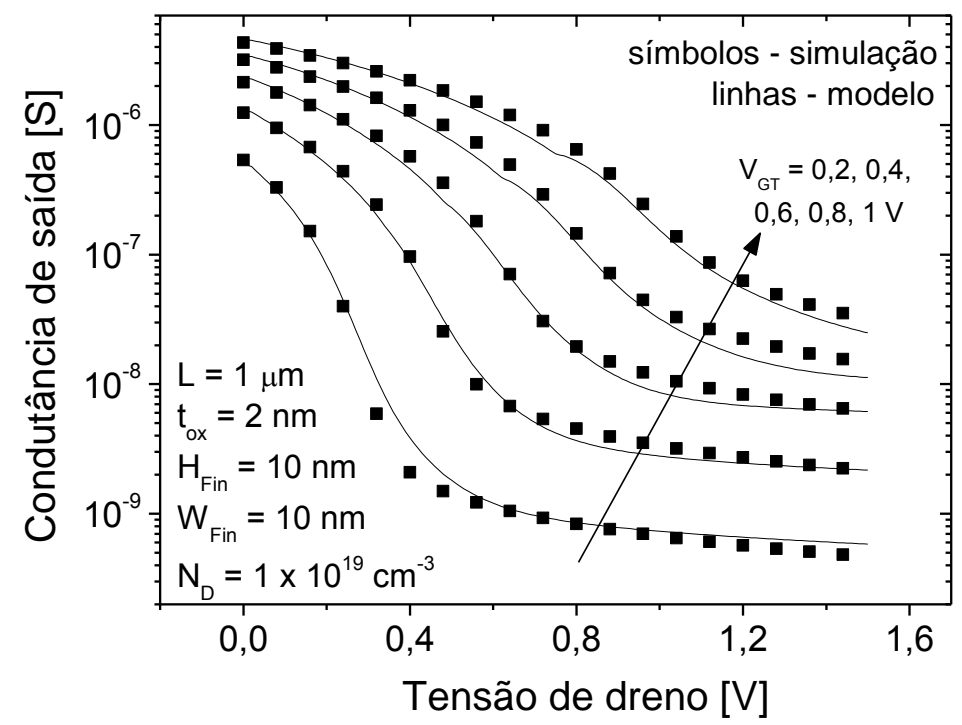

Figura 6.8 - Condutância de saída em função da tensão de dreno obtidas através da derivada das curvas da Figura 6.7.

Uma importante característica de modelos analíticos é a simetria em relação ao ponto $\mathrm{V}_{\mathrm{DS}}=0 \mathrm{~V}$. Na Figura 6.9 , a corrente de dreno é apresentada em função da tensão de dreno para diversas sobretensões de porta, mostrando que 0 modelo descreve adequadamente a região para tensões de dreno negativas, com erro máximo de $5 \%$. 


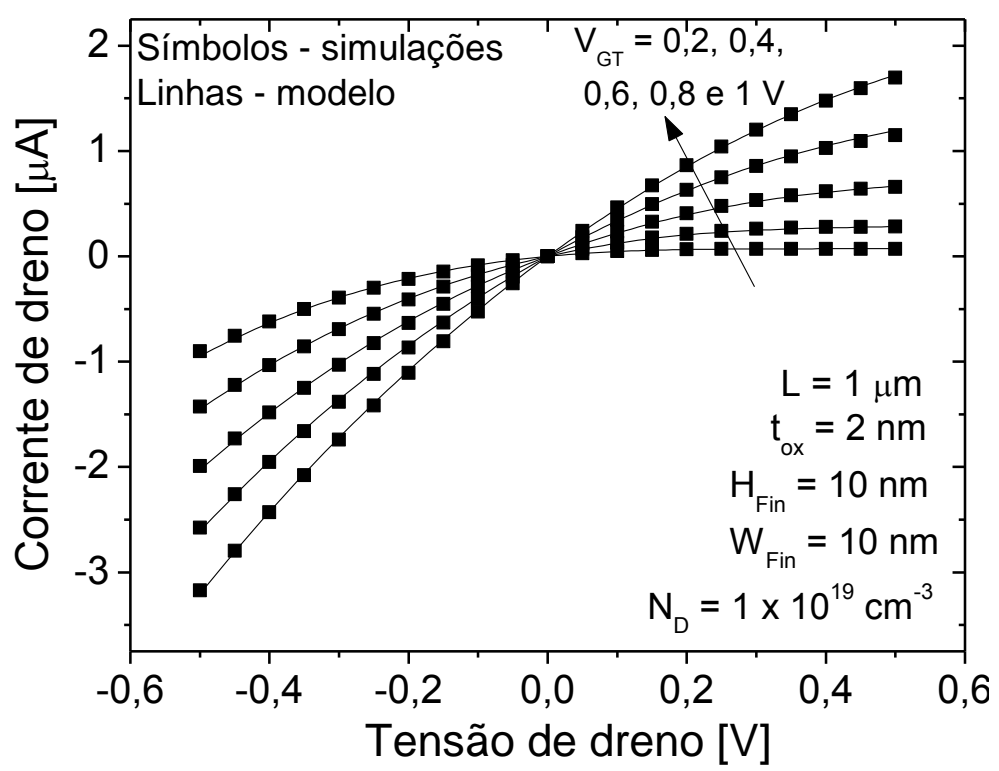

Figura 6.9 - Corrente de dreno em função da tensão de dreno para diversas sobretensões de porta mostrando a continuidade do modelo em torno da tensão $V_{D S}=0 \mathrm{~V}$.

Com o intuito de analisar se o controle eletrostático das cargas é descrito adequadamente, foram realizadas diversas simulações variando-se a altura e a largura do dispositivo conforme apresentado na Figura 6.10, onde a corrente de dreno é apresentada em função da tensão de porta.

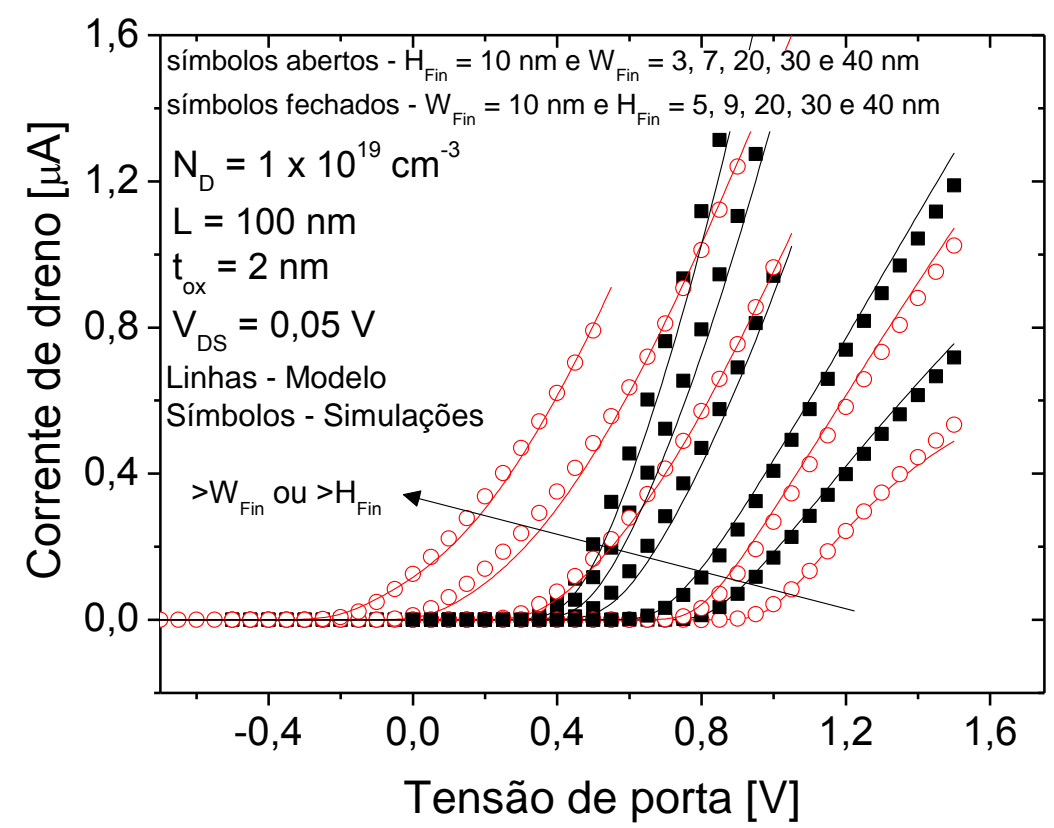

Figura 6.10 - Corrente de dreno em função da tensão de porta para dispositivos de diferentes larguras e alturas comparando simulações numéricas com o modelo analítico desenvolvido em função dos potenciais de superfície. 
Para os dispositivos com altura e/ou largura menores que $10 \mathrm{~nm}$, a variação do potencial devido à quantização $\left(\Delta \phi_{\mathrm{QM}}\right)$ pode ser somada ao potencial de superfície. Esta variação pode ser obtida pela soma do confinamento estrutural (equação (2.30)) com o confinamento elétrico (equação (2.32)) $)^{3}$ :

$$
\Delta \phi_{\mathrm{QM}}=\frac{\hbar^{2} \pi^{2}}{2 \mathrm{~m}^{*}}\left(\frac{1}{\mathrm{~W}_{\mathrm{Fin}}{ }^{2}}+\frac{1}{\mathrm{H}_{\mathrm{Fin}}^{2}}\right)+\beta_{\mathrm{E} 0}\left(\frac{\varepsilon_{\mathrm{Si}}}{4 \mathrm{qkT}}\right)^{1 / 3}\left(\mathrm{E}_{\mathrm{S}}\right)^{0,63}+\delta
$$

Assim, as curvas $I_{D} \times V_{G S}$ da Figura 6.10 para $W_{\text {Fin }}=3 \mathrm{~nm}$ e $7 \mathrm{~nm}$ e para $\mathrm{H}_{\text {Fin }}=5 \mathrm{~nm}$ e $9 \mathrm{~nm}$ foram obtidas somando-se a equação (6.23) ao potencial de superfície. As curvas simuladas para os dispositivos com essas dimensões foram realizadas considerando o modelo de quantização do gradiente da densidade de cargas conforme descrito no item 2.7.

A Figura 6.11 apresenta as curvas da corrente de dreno em função da tensão aplicada à porta para dispositivos de diferentes concentrações de dopantes e espessuras de óxido de porta. Pela Figura 6.10 e pela Figura 6.11 pode-se concluir que o controle eletrostático das cargas no canal pela estrutura de porta tripla está sendo devidamente considerado pelo modelo.

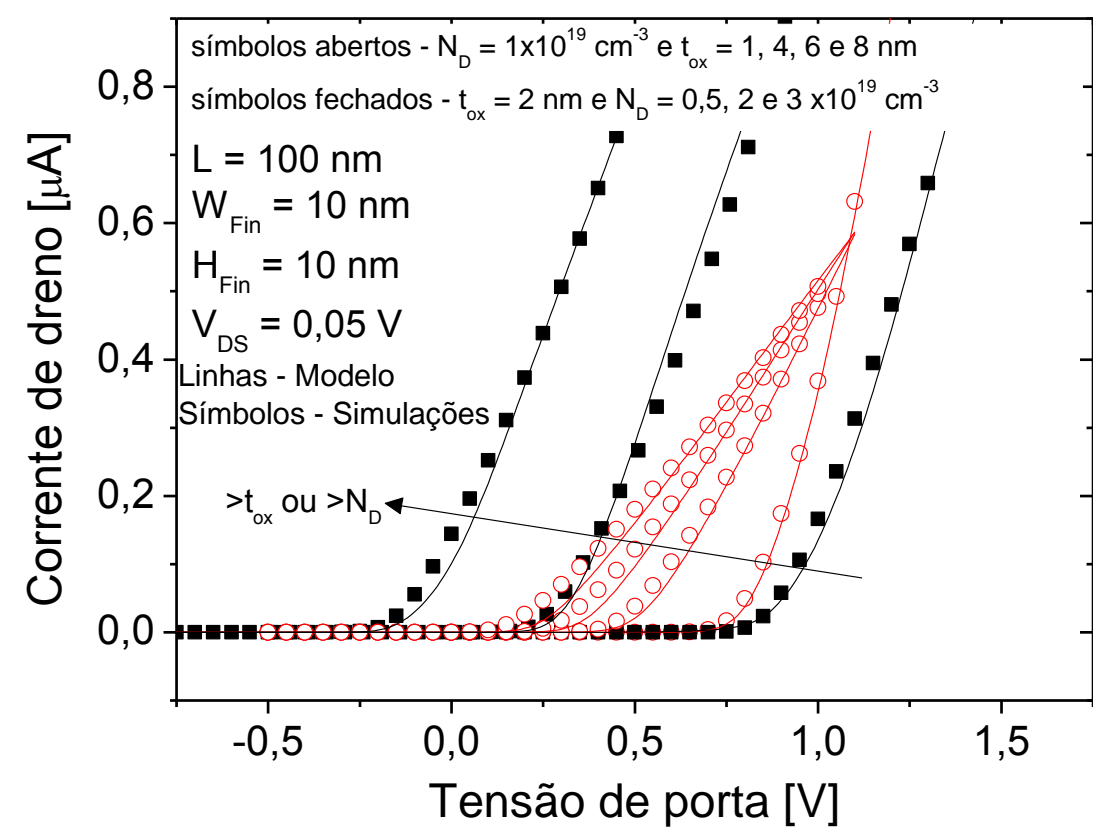

Figura 6.11 - Corrente de dreno em função da tensão de porta para dispositivos de diferentes espessuras de óxido de porta e concentrações de dopantes comparando simulações numéricas com o modelo analítico desenvolvido em função dos potenciais de superfície. 


\subsection{DISPOSITIVO DE CANAL CURTO}

Como forma de se considerar os efeitos de canal curto, será utilizado o mesmo procedimento descrito no item 5.9. O ponto do potencial mínimo é obtido pela equação (5.17) e o potencial pela equação (5.16). No entanto, o modelo desenvolvido ao longo deste Capítulo é baseado nos potenciais de superfície. Assim, o potencial $U$ pode ser considerado como $U=-\phi_{S, \text { depl }}$, sendo este último calculado por (6.11). O potencial $\mathrm{V}$ será descrito por $\mathrm{V}=\mathrm{U}+\mathrm{V}_{\mathrm{DS}}$. $\mathrm{O}$ potencial $\phi_{\min }$ é, então, adicionado à tensão $V_{G S}$ no cálculo dos potenciais e, consequentemente, da corrente de dreno. A influência da velocidade de saturação na mobilidade é calculada pela equação (5.23) conforme apresentado no item 5.9. Deve-se ressaltar que se pode utilizar outros modelos de mobilidade da literatura, como, por exemplo, os propostos por Lundstrom ${ }^{124}$ e por Kuo et al. ${ }^{125}$, a fim de se considerar outros efeitos como balística e acréscimo de mobilidade (overshoot), respectivamente.

$\mathrm{Na}$ Figura 6.12, a corrente de dreno e a transcondutância são apresentadas em função da tensão de porta para diversas polarizações de dreno. As simulações numéricas são comparadas com o modelo analítico considerando e desprezando a correção de efeitos de canal curto. Pode-se notar que a correção dos SCE afeta principalmente a região de sublimiar, onde a inclinação de sublimiar aumenta de $60 \mathrm{mV} /$ déc. para $84 \mathrm{mV} /$ déc. com a inclusão dos efeitos de canal curto. Nesta região da curva, a polarização de dreno influência a barreira de potencial induzida pela porta. Já quando o dispositivo está conduzindo pelo corpo, a região de condução se comporta como um resistor, conforme visto no item 2.2.2, não havendo influência de potencial de dreno no canal.

Na Figura 6.13, a corrente de dreno e a condutância de saída são apresentadas em função da tensão de dreno, realizando a mesma comparação entre modelo analítico e simulações. Neste caso, a principal influência da polarização de dreno ocorre na região de saturação, onde pelo menos parte do canal opera em depleção parcial. Pode-se ainda notar que a modulação do comprimento de canal é determinada pela correção de efeitos de canal curto. 


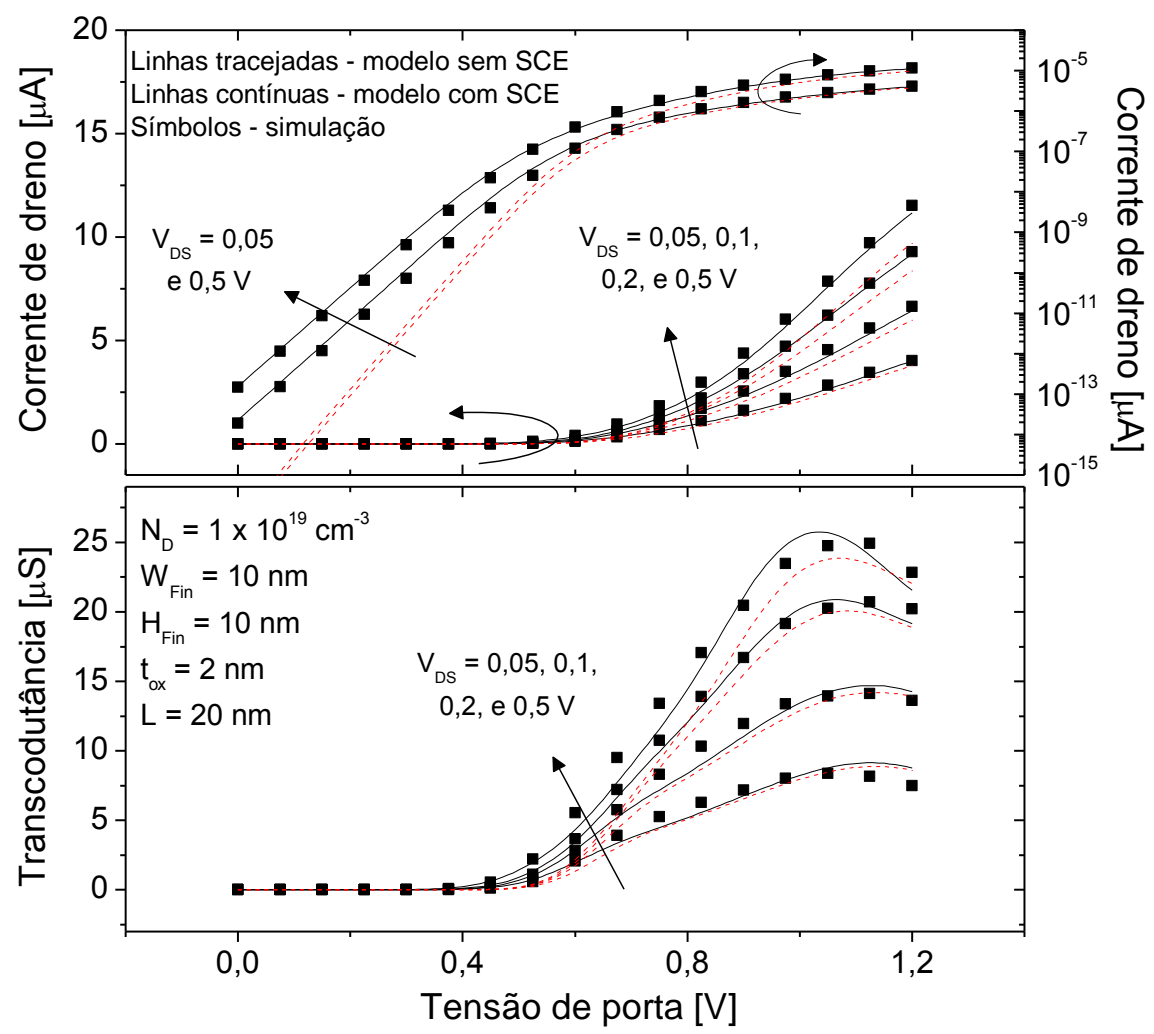

Figura 6.12 - Corrente de dreno e transcondutância em função da tensão de porta mostrando resultados modelados e simulados para um dispositivo com $L=20 \mathrm{~nm}$.

Pelas figuras, pode-se concluir que os efeitos de canal curto são adequadamente modelados pelo termo de correção proposto. Tem-se, por exemplo, que o erro médio foi reduzido de $40 \%$ para menos de $10 \%$ na condutância de saída para $\mathrm{V}_{\mathrm{GT}}=0,4 \mathrm{~V}$. Essa redução se deve a região da curva em que o dispositivo opera em saturação. Nesta região, a extremidade do canal próxima ao dreno se encontra totalmente depletada (pinçamento do canal), havendo uma barreira de potencial que é afetada pela tensão aplicada ao dreno.

A razão entre a transcondutância e a corrente de dreno é apresentada na Figura 6.14 em função da corrente de dreno comparando a modelagem com dispositivos de canal curto e longo. O platô na região de baixa corrente da curva de $g_{m} / l_{D}$ é inversamente proporcional à inclinação de sublimiar. Pela figura, pode-se notar que o modelo diminui de forma adequada a razão nesta região da curva, indicando a degradação de S. Deve-se ainda mencionar a concordância entre simulações e modelagem em toda a curva. 


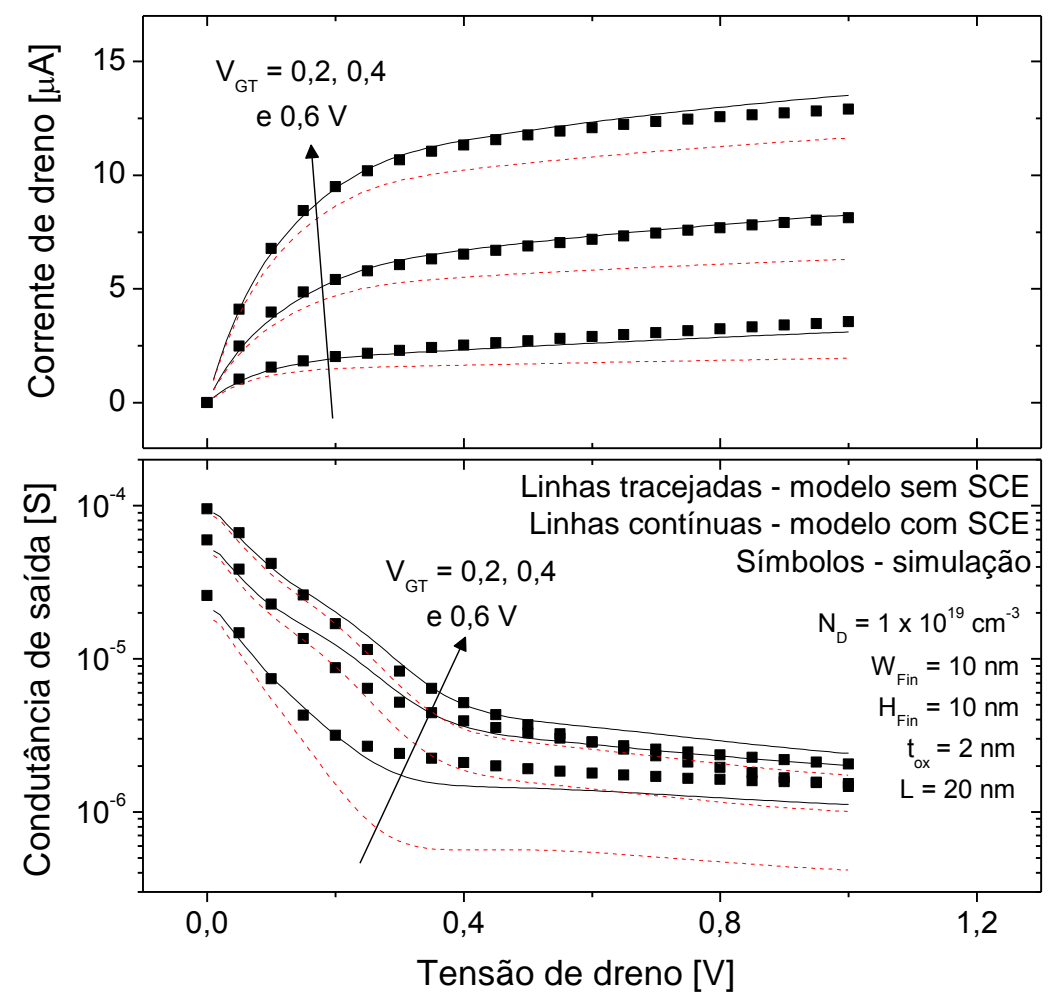

Figura 6.13 - Corrente de dreno e condutância de saída em função da tensão de dreno obtidas pelo modelo analítico e por simulações para um dispositivo com $L=20 \mathrm{~nm}$.

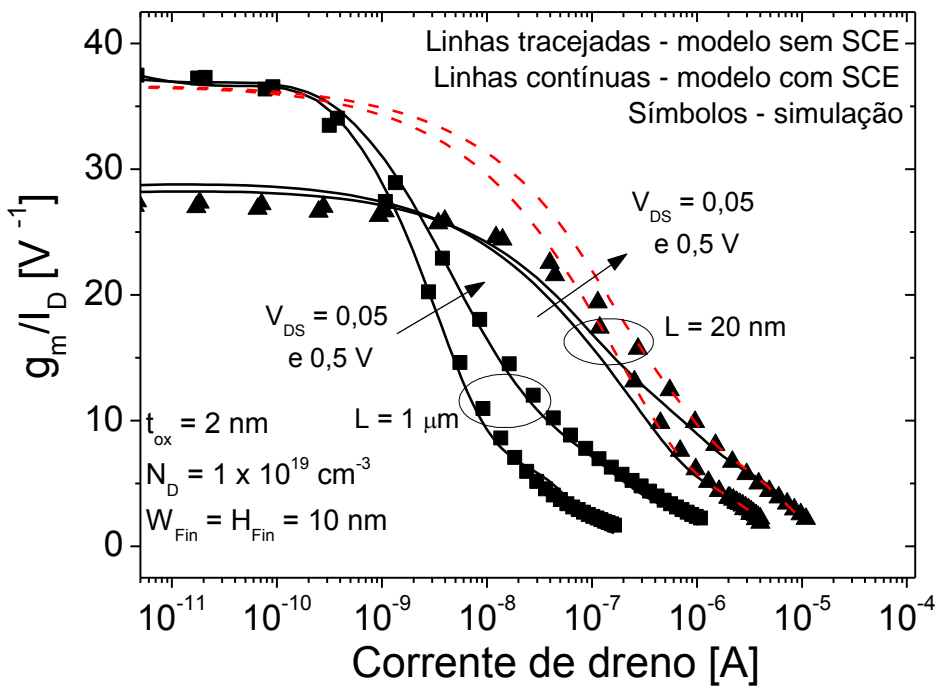

Figura 6.14 - Razão $\mathrm{g}_{\mathrm{m}} / \mathrm{I}_{\mathrm{D}}$ em função da corrente de dreno obtida pelo modelo analítico e por simulações para dispositivos de diferentes comprimentos de canal.

\subsection{DETERMINAÇÃO DOS PARÂMETROS DE AJUSTE}

Conforme apresentado ao longo deste Capítulo, o modelo proposto apresenta alguns parâmetros de ajuste. $\mathrm{O}$ modelo também apresenta alguns 
parâmetros físicos como mobilidade de baixo campo e velocidade de saturação que também podem ser ajustados de forma a se obter uma melhor concordância entre modelo e resultados experimentais. Esses parâmetros físicos são conhecidos quando são realizadas simulações numéricas, conforme descrito no item 2.7. Assim, os resultados das simulações numéricas podem ser utilizados como forma de se obter os parâmetros de ajuste que melhor descrevem o funcionamento dos dispositivos MOS sem junções.

O método de ajuste bidimensional (bidimensional fitting) é utilizado como forma de se extrair parâmetros de dispositivos experimentais, conforme proposto por Ortiz-Conde et al. ${ }^{126,127}$. Neste método, as curvas da corrente de dreno em função da tensão de porta e da tensão de dreno são utilizadas juntas na obtenção dos parâmetros. É utilizado o algoritmo Levenberg-Marquardt ${ }^{128}$ como forma de se fazer o ajuste e obter os parâmetros que apresentam os melhores resultados. Uma abordagem semelhante pode ser utilizada para a obtenção dos parâmetros no modelo proposto.

Uma consideração deve ser feita sobre o parâmetro $A_{5}$ : caso o seu valor seja relativamente pequeno, a região de sublimiar pode ser afetada por esse parâmetro. É difícil determinar qual seria um valor relativamente pequeno, pois esse valor depende da diferença entre a tensão de limiar e a tensão de faixa plana, dependendo assim das características do dispositivo. No entanto, valores relativamente baixos de $A_{5}(<8)$ modelam melhor os dispositivos. Dessa forma, o valor $A_{5}$ será substituído por uma função com três parâmetros de ajuste:

$$
A_{5}=A_{7}-\frac{A_{8}}{1+\exp \left(-A_{9}\left(V_{G S}-V_{T H}\right)\right)}
$$

onde $A_{7}$ será mantido fixo em 18 garantindo que $A_{5}$ não irá afetar o sublimiar, 0 parâmetro $A_{8}$ ajusta o valor do parâmetro $A_{5}$ na transição entre condução de corpo e camada de acumulação enquanto $A_{9}$ controla a transição entre $A_{7}$ e $A_{8}$.

Assim, têm-se três parâmetros de ajuste que podem ser determinados: $A_{1}, A_{8}$ e $A_{9}$. O método de determinação será similar ao utilizado por OrtizConde et al. ${ }^{126}$. Entretanto, serão utilizadas as curvas $I_{D} \times V_{G S}$ e $I_{D} \times V_{D S}$ para dispositivos de diferentes dimensões. Todos os dados simulados utilizados na 
Figura 6.5, na Figura 6.7, na Figura 6.10 e na Figura 6.11 foram utilizados em conjunto, a fim de se determinar os parâmetros que melhor ajustam todos os dispositivos. Utilizando-se o algoritmo Levenberg-Marquardt ${ }^{128}$, os parâmetros foram extraídos, conforme apresentado na Tabela 6.1. Esses valores são os que apresentaram melhores resultados para os dispositivos de diferentes características em diferentes condições de polarização.

Tabela 6.1 - Parâmetros extraídos utilizando o algoritmo Levenberg-Marquardt ${ }^{128}$.

\begin{tabular}{|l|l|}
\hline Parâmetro & Valor \\
\hline$A_{1}$ & 1,18 \\
\hline$A_{8}$ & 14,16 \\
\hline$A_{9}$ & 8,88 \\
\hline
\end{tabular}

\subsection{COMPARAÇÃO COM RESULTADOS EXPERIMENTAIS}

O modelo proposto baseado nos potenciais de superfície também foi comparado a resultados experimentais. Os dispositivos utilizados foram fabricados no Commissariat à l'Energie Atomique et aux Energies Alternatives - Laboratoire d'Électronique des Technologies de I'Information (CEA-LETI Comissão de Energia Atômica e Energias Alternativas - Laboratório de Eletrônica da Tecnologia da Informação), Grenoble, França, e medidos no Tyndall National Institute, Cork, Irlanda, utilizando o equipamento Agilent B1500A. Estes dispositivos foram fabricados em lâminas SOI com óxido enterrado de $145 \mathrm{~nm}$. A altura do dispositivo medido é de $10 \mathrm{~nm}$ e a largura de máscara é de $80 \mathrm{~nm}$. Como é esperada uma redução de $\sim 60 \mathrm{~nm}$ devido ao processo de fabricação, a largura efetiva é de aproximadamente $20 \mathrm{~nm}{ }^{129} .0$ dispositivo apresenta estrutura de porta composta por HfSiON/TiN/Silício policristalino com espessura efetiva de óxido de porta (Effective Oxide Thickness - EOT) de 1,5 nm. Neste caso, foram medidos os dispositivos com concentração de dopantes de $1 \times 10^{19} \mathrm{~cm}^{-3}$ e com 50 nanofios em paralelo. $O$ comprimento de canal de máscara é de $40 \mathrm{~nm}$, sendo esperado uma redução de $\sim 10 \mathrm{~nm}$, resultando em comprimento efetivo de $30 \mathrm{~nm}{ }^{129}$. Os JNTs, que 
possuem $10 \mathrm{~nm}$ de nitreto espaçador entre o fim do canal e as regiões de fonte e dreno, foram medidos em uma faixa de temperatura entre $300 \mathrm{~K}$ e $420 \mathrm{~K}$.

A resistência série foi considerada iterativamente, levando-se em conta a camada de silício abaixo do nitreto espaçador, que gera uma resistência em torno de $8 \mathrm{k} \Omega$ em cada nanofio ( $160 \Omega$ na arquitetura de multi-nanofios). Assim como no item 5.8, foram utilizados os modelos proposto por Caughey et al. ${ }^{65} \mathrm{e}$ por Dorkel et al. ${ }^{67}$ no cálculo da mobilidade de baixo campo, considerando portanto os espalhamentos por fônons, por impurezas ionizadas e portadorportador. É importante ressaltar que esses modelos apresentam dependência com a temperatura. Os parâmetros $A_{1}, A_{8}$ e $A_{9}$ utilizados foram similares àqueles obtidos pelo ajuste bidimensional. Já a velocidade de saturação foi ajustada em $v_{\text {sat }}=0,8 \times 10^{7} \mathrm{~cm} / \mathrm{s}$.

A corrente de dreno e a transcondutância são apresentadas na Figura 6.15 em função da tensão $V_{G S}$ para diferentes temperaturas entre $300 \mathrm{~K} \mathrm{e} 420$ K. Pode-se observar que as curvas são modeladas corretamente, incluindo a dependência da inclinação de sublimiar com a temperatura. $O$ erro médio nesta curva foi menor que $9 \%$, tanto para a corrente de dreno como para a transcondutância, em toda a variação de $V_{G S}$ analisada. Ao se considerar apenas a região da curva acima do limiar, o erro médio para $I_{D}$ foi menor que 7 $\%$. O erro máximo obtido nessas curvas foi de $13 \%$ na região da curva acima do limiar. Na Figura 6.16, a corrente de dreno e a condutância de saída são apresentadas em função da tensão de dreno para alguns valores de $V_{G T}$. Podese notar que para $\mathrm{V}_{\mathrm{GT}}=0,2 \mathrm{~V}$ e $0,4 \mathrm{~V}$, a corrente de dreno aumenta com $\mathrm{T}$. Já para $V_{G T}=0,6 \mathrm{~V}$, a corrente é maior em temperatura ambiente. Esta variação da corrente está relacionada ao ponto invariante com a temperatura e será analisada detalhadamente no Capítulo 7. Novamente, tem-se que o modelo prevê de forma muito satisfatória a dependência da corrente e de sua derivada com a polarização de dreno. $O$ erro médio foi menor que $6 \%$ na corrente de dreno e menor que $12 \%$ em gd para todas as polarizações analisadas. $O$ erro máximo obtido para a corrente de dreno na Figura 6.16 foi similar ao obtido na Figura 6.15. Já o erro máximo em $g_{d}$ não foi extraído devido à grande dispersão dos pontos na região de saturação. 


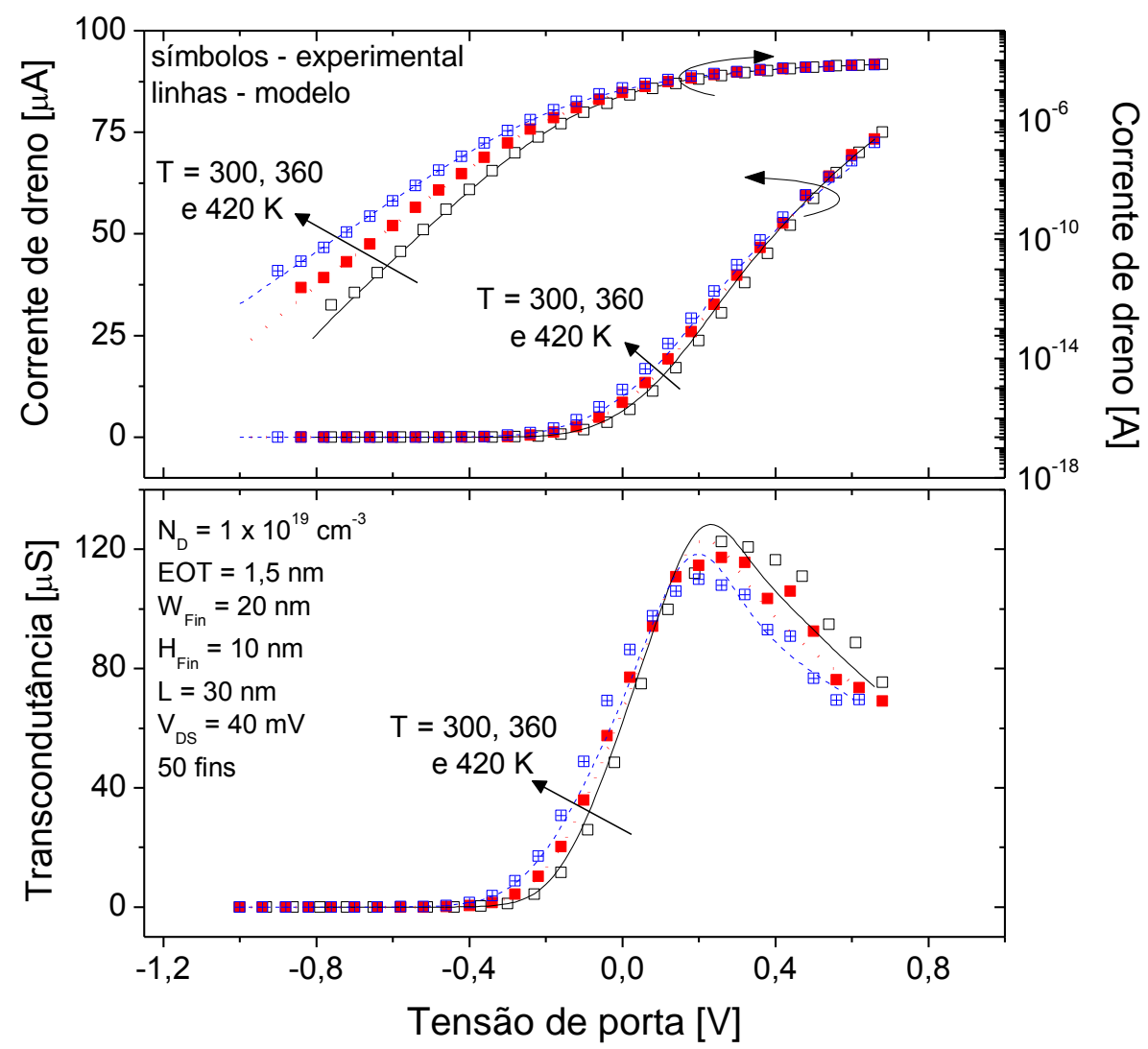

Figura 6.15 - Corrente de dreno e transcondutância em função da tensão de porta comparando o modelo analítico com resultados experimentais para dispositivos com $\mathrm{L}=30 \mathrm{~nm}$.

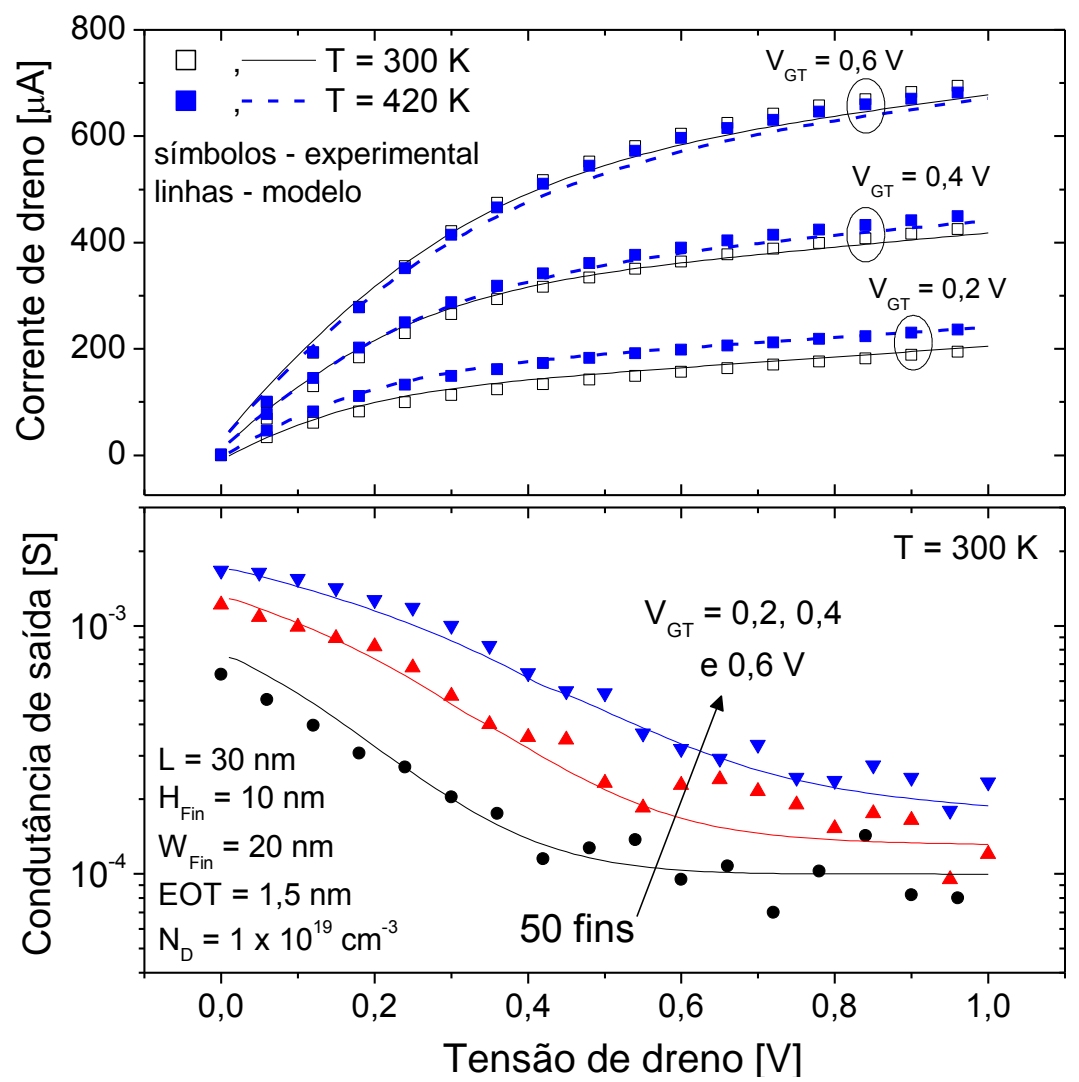

Figura 6.16 - Corrente de dreno e condutância de saída em função da tensão de dreno apresentando dados modelados e experimentais para dispositivos com $L=30 \mathrm{~nm}$. 


\subsection{POLARIZAÇÃO DE SUBSTRATO}

As equações (3.15) e (3.16) podem ser utilizadas juntamente com o modelo proposto de corrente de dreno, com o intuito de se obter a influência da polarização de substrato em $\mathrm{I}_{\mathrm{D}}$. Assim, da mesma forma como descrito no item 3.1.6, a carga fixa é substituída pela equação (3.15) e a altura efetiva do dispositivo será calculada por $\left(\mathrm{H}_{\text {Fin }}-\mathrm{x}_{\text {depl }}\right)$ no termo relacionado à carga de depleção. Dessa forma, a aplicação de uma tensão ao substrato maior que a tensão de faixa plana seria equivalente à um dispositivo com concentração de dopantes maior. No caso da aplicação de uma tensão menor que a tensão de faixa plana, há uma redução da altura efetiva do dispositivo devido à presença de uma região de depleção. A Figura 6.17 apresenta a corrente de dreno, comparando os resultados do modelo e das simulações numéricas para diferentes polarizações de substrato. Pode-se observar que a influência do substrato é corretamente descrita pelas equações (3.15) e (3.16), tanto para tensões $V_{B S}$ acima como abaixo da tensão de faixa plana.

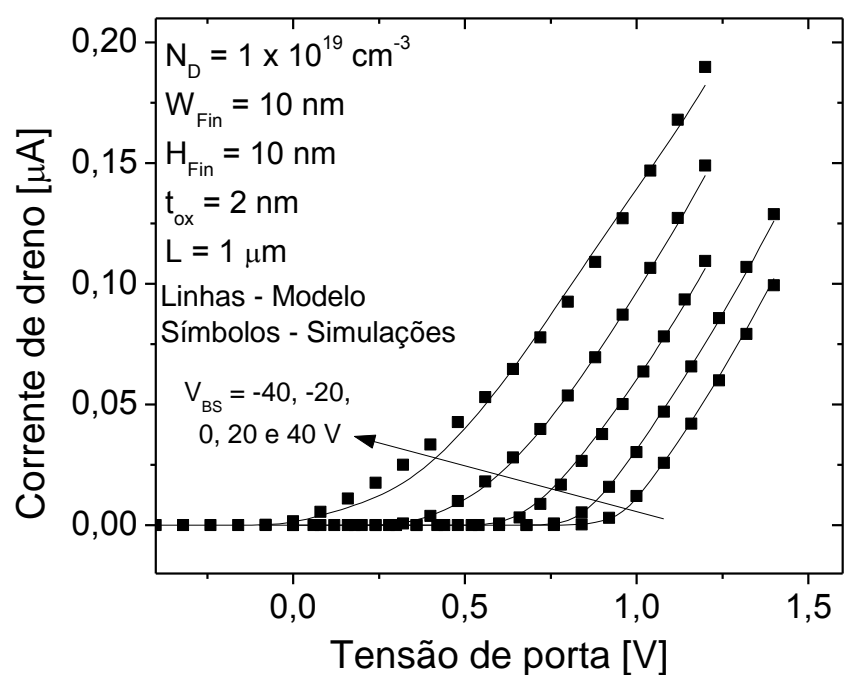

Figura 6.17 - Corrente de dreno em função da tensão de porta exibindo resultados modelados e simulados para diversas polarizações de substrato.

Ao longo dos Capítulos 3, 4, 5 e 6, foram analisadas e modeladas as principais características básicas dos dispositivos, como tensão de limiar, corrente de dreno, potencial de superfície e carga de condução. Nos próximos Capítulos, o estudo se concentra no funcionamento dos dispositivos MOS sem junções. 


\section{PONTO INVARIANTE COM A TEMPERATURA}

A variação da temperatura de operação altera as características elétricas dos transistores, conforme apresentado no item 2.4.2. Ao se reduzir a temperatura, tem-se um aumento tanto da mobilidade como da tensão de limiar. Nos dispositivos modo inversão, essas variações de $\mathrm{V}_{T H}$ e $\mu_{\text {eff }}$ causam o aparecimento do ponto invariante com a temperatura (ZTC), indicando que existe uma tensão de porta na qual a corrente de dreno se mantém constante independente da temperatura. Quanto aos dispositivos MOS sem junções, estudos mostram a ausência do ponto ZTC, relacionado à maior dependência da tensão de limiar e à menor dependência da mobilidade com a temperatura ${ }^{10}$. Neste capítulo, é analisado o ponto invariante com a temperatura mostrando que os JNTs podem apresentar o ponto ZTC, que está relacionado não apenas com a tensão de limiar e com a mobilidade, mas também com a resistência série dos dispositivos ${ }^{130,131}$.

\subsection{CURVAS CARACTERÍSTICAS DOS DISPOSITIVOS}

Para a análise do ZTC, foram utilizadas medidas experimentais de dispositivos fabricados no CEA-LETI em Grenoble, França, que apresentam altura de $10 \mathrm{~nm}$, largura de máscara variando entre $80 \mathrm{~nm}$ e $1 \mu \mathrm{m}$, sendo esperada uma redução de $\sim 60 \mathrm{~nm}$ na largura efetiva dos dispositivos ${ }^{129}$. Foram medidos dispositivos nMOS e pMOS para duas concentrações de dopantes (5 $\times 10^{18} \mathrm{~cm}^{-3}$ e $1 \times 10^{19} \mathrm{~cm}^{-3}$ ) e de diferentes comprimentos de canal entre $30 \mathrm{~nm}$ e $10 \mu \mathrm{m}$. A estrutura de porta é composta por HfSiON/TiN/Silício policristalino com EOT $=1,5 \mathrm{~nm}$, conforme apresentado no item 6.10.

A Figura 7.1 apresenta as curvas $I_{D}$ versus $V_{G S}$ para dispositivos nMOS e pMOS de diferentes comprimentos de canal e concentrações de dopantes para $\left|V_{D S}\right|=40 \mathrm{mV}$ em diversas temperaturas. Pode-se observar que todos os dispositivos nMOS apresentaram o ponto de ZTC. No caso dos dispositivos pMOS, apenas os mais longos $(\mathrm{L}=10 \mu \mathrm{m})$ apresentaram esse ponto. Dessa forma, tem-se que os JNTs podem ou não apresentar o ponto de ZTC. 

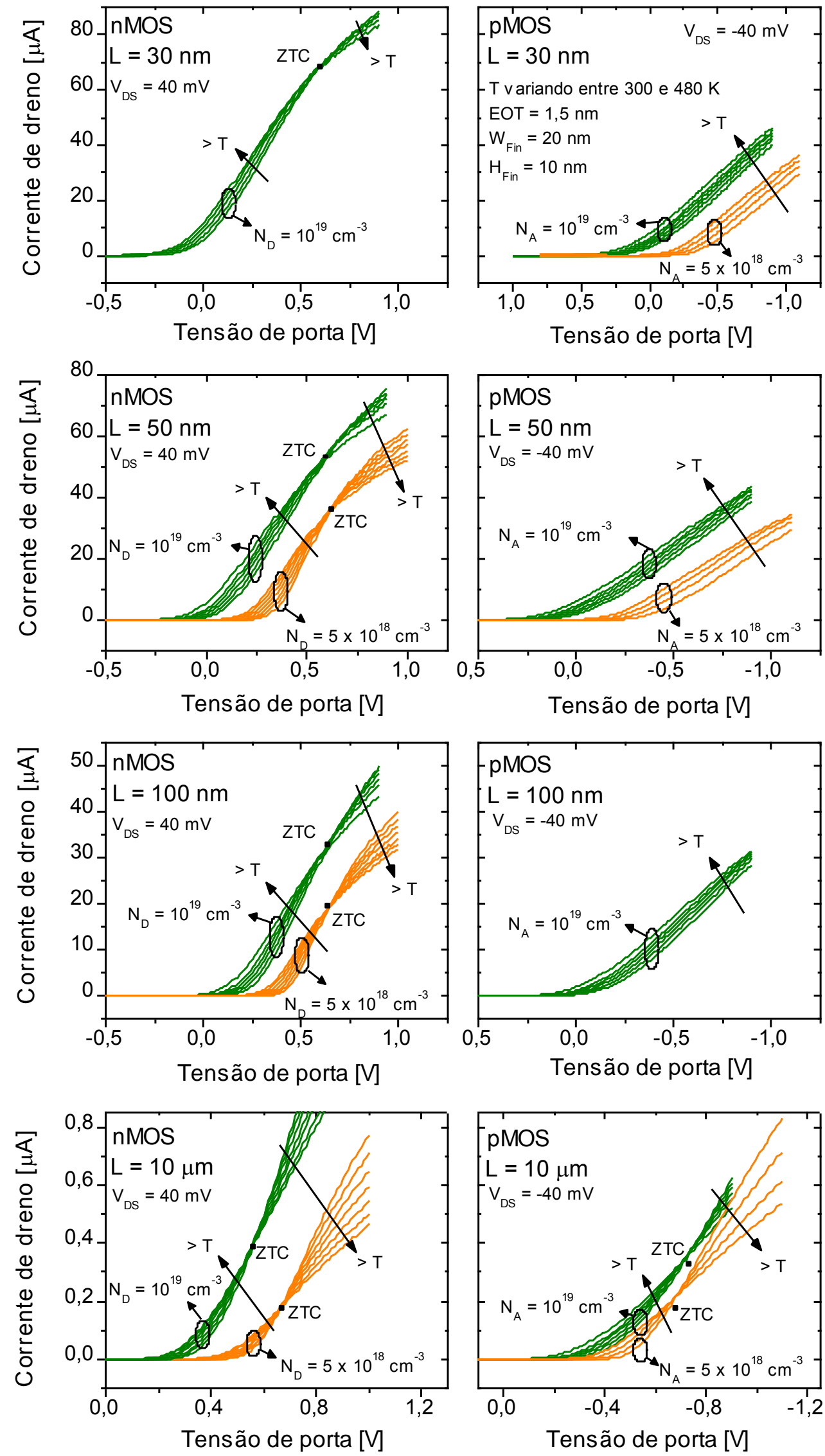

Figura 7.1 - Curvas características experimentais $I_{D} \times V_{G S}$ para dispositivos $n M O S$ e pMOS com $L=30 \mathrm{~nm}, 50 \mathrm{~nm}, 100 \mathrm{~nm}$ e $10 \mu \mathrm{m}$ variando-se a temperatura e a concentração de dopantes. 
O valor de tensão na qual ocorre o ponto de ZTC foi extraído dos dispositivos nMOS da Figura 7.1, sendo que a diferença entre esse ponto e a tensão de limiar extraída em temperatura ambiente é apresentada na Tabela 7.1. O método de extração utilizado foi o de $\mathrm{g}_{\mathrm{m}} / \mathrm{l}_{\mathrm{D}}$. Pela tabela, pode-se notar que a diferença aumenta conforme o comprimento de canal é reduzido. Também se pode observar que ( $\mathrm{ZTC}-\mathrm{V}_{\mathrm{TH}, @ \mathrm{~T}=300 \mathrm{~K}}$ ) é maior para o dispositivo com maior concentração de dopantes. Já para os dispositivos pMOS com comprimento de canal de $L=10 \mu \mathrm{m}$, o valor absoluto da diferença foi de $0,17 \mathrm{~V}$ para a menor concentração de dopantes e de 0,37 $\mathrm{V}$ para maior $\mathrm{N}_{\mathrm{A}}$. Assim, da mesma forma que nos dispositivos nMOS, quanto maior a concentração de dopantes, maior será a diferença entre o ponto de ZTC e a tensão de limiar.

$\mathrm{Na}$ Figura 7.1, pode-se ainda notar que, embora os dispositivos pMOS com comprimento de canal menor que $10 \mu \mathrm{m}$ não apresentam o ZTC, os dispositivos com $L=100 \mathrm{~nm}$ mostram uma tendência de convergência da corrente de dreno ao se diminuir $\mathrm{V}_{\mathrm{GS}}$. Ou seja, a curva está tendendo a um ponto onde a corrente seria a mesma independente da temperatura. Esta tendência já não pode ser facilmente observada para os dispositivos pMOS com $L=30 \mathrm{~nm}$. Dessa forma, é provável que se tivesse sido aplicada uma tensão de porta mais negativa no dispositivo com $L=100 \mathrm{~nm}$, seria possível observar o ponto de ZTC. No entanto, devido à utilização de um óxido fino com alta constante dielétrica ( $h i g h-\kappa)$, procurou-se limitar as tensões aplicadas nos dispositivos, de forma a não danificá-los.

Tabela 7.1 - Diferença entre o ponto de ZTC e a tensão de limiar em temperatura ambiente para os dispositivos de diferentes concentrações de dopantes da Figura 7.1.

\begin{tabular}{|c|c|c|c|}
\hline & \multirow{2}{*}{ L [nm] } & \multicolumn{2}{|c|}{$\mathrm{ZTC}-\mathrm{V}_{\mathrm{TH}, @ \mathrm{~T}=300 \mathrm{~K}}[\mathrm{~V}]$} \\
\hline & & $N_{D}=5 \times 10^{18} \mathrm{~cm}^{-3}$ & $N_{D}=1 \times 10^{19} \mathrm{~cm}^{-3}$ \\
\hline \multirow{4}{*}{ nMOS } & 30 & & 0,70 \\
\hline & 50 & 0,29 & 0,58 \\
\hline & 100 & 0,21 & 0,43 \\
\hline & 10000 & 0,10 & 0,21 \\
\hline pMOS & 10000 & 0,17 & 0,37 \\
\hline
\end{tabular}




\subsection{DEPENDÊNCIA DA TENSÃO DE LIMIAR E DA TRANSCONDUTÂNCIA MÁXIMA COM A TEMPERATURA}

Conforme já mencionado, em dispositivos MOS convencionais, os parâmetros que afetam o ponto de ZTC são a tensão de limiar e a mobilidade. Nos JNTs, a ausência do ZTC foi atribuída a uma maior dependência da tensão de limiar com a temperatura, quando comparados a dispositivos modo inversão de mesmas dimensões ${ }^{10}$. Assim, as tensões de limiar foram extraídas para os dispositivos com comprimento de canal de $50 \mathrm{~nm}$ utilizando-se o método descrito no Capítulo 4, as quais são apresentadas na Figura 7.2. Considerando que a dependência da tensão de limiar com a temperatura seja linear, os coeficientes angulares podem ser extraídos, conforme apresentado na mesma figura. Os valores de $\left|d V_{T H} / d T\right|$ obtidos em trabalhos anteriores em que os JNTs não apresentavam o ponto de ZTC variavam entre 0,6 e 1,9 mV/K ${ }^{10,63}$, conforme mostrado no item 3.1.5. Assim, os valores de $\left|\mathrm{dV}_{\mathrm{TH}} / \mathrm{dT}\right|$ obtidos para os dispositivos fabricados no CEA-LETI são consideravelmente menores que aqueles apresentados anteriormente.

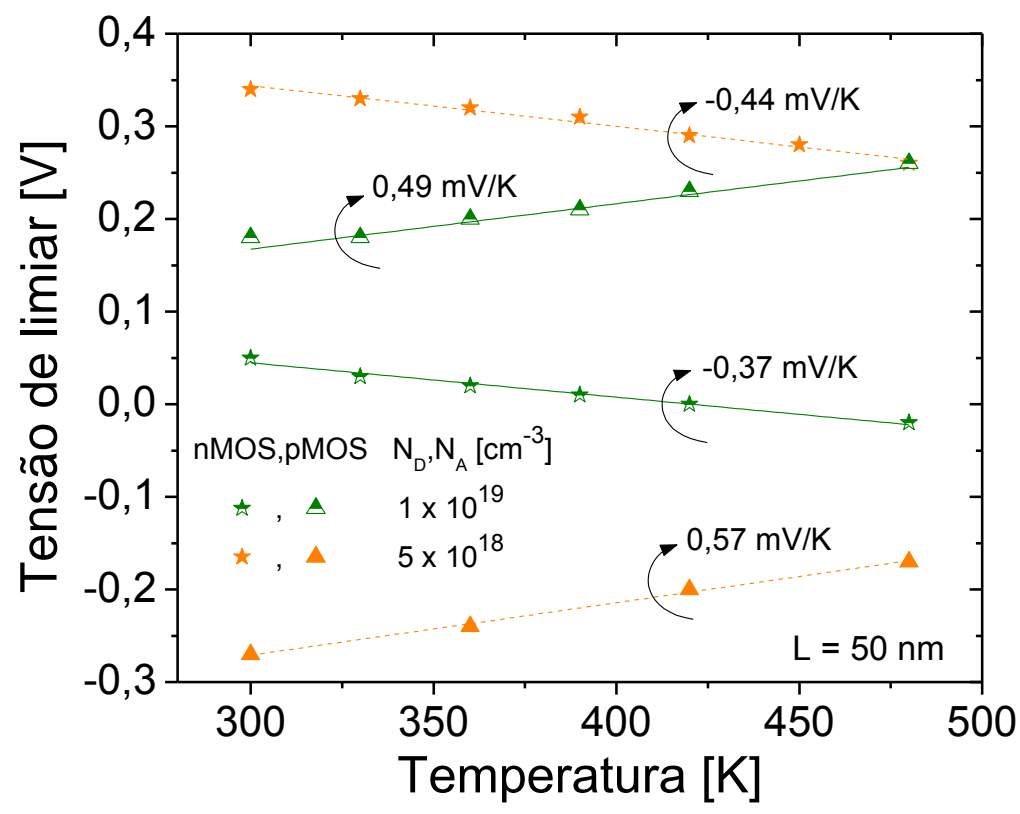

Figura 7.2 - Tensão de limiar em função da temperatura extraída das curvas da Figura 7.1 para dispositivos com comprimento de canal de $50 \mathrm{~nm}$.

Esta diferença de dependência com a temperatura pode ser entendida analisando a equação (3.14). O primeiro termo nessa equação representa a 
dependência da tensão de faixa plana com a temperatura. Nos dispositivos analisados neste Capítulo, é utilizado um material metálico na porta. Sendo assim, a dependência de $V_{F B}$ com $T$ é descrita apenas pela variação do nível de Fermi com a temperatura. Já nos dispositivos anteriores, que apresentavam silício policristalino como material de porta, havia também uma dependência do nível de Fermi da porta com a temperatura. O segundo termo da equação (3.14) representa as dependências da carga de depleção e do potencial de superfície com a temperatura. Este termo está relacionado com a variação $\mathrm{dN} / \mathrm{dT}$. Considerando que tanto os JNTs analisados neste Capítulo como os outros analisados anteriormente apresentam similar concentração de dopantes, o termo $\mathrm{dN} / \mathrm{dT}$ também será similar. No entanto, este termo está multiplicado por um fator que depende das dimensões dos dispositivos. A espessura do óxido de porta dos dispositivos analisados anteriormente é de $10 \mathrm{~nm}$ enquanto que os dispositivos fabricados no CEA-LETI apresentam espessura efetiva de $1,5 \mathrm{~nm}$. Ao se reduzir a espessura efetiva do óxido de porta, há um aumento em $C_{o x}$, reduzindo o fator que multiplica $d N_{D} / d T$ na equação (3.14). Dessa forma, é esperado que os dispositivos fabricados no CEA-LETI apresentem uma menor dependência da tensão de limiar com a temperatura. As tensões de limiar extraídas para as outras curvas da Figura $7.1 \mathrm{com}$ dispositivos de diferentes comprimentos de canal apresentam uma dependência com a temperatura similar à apresentada na Figura 7.2.

O segundo parâmetro relacionado com o ponto de ZTC nos dispositivos modo inversão é a mobilidade dos portadores. De acordo com Lee et al. ${ }^{10}$, a mobilidade apresenta um fraca dependência com a temperatura em JNTs, uma vez que em seus dados a transcondutância máxima não sofreu variação significativa ao se variar T. A fim de analisarmos a dependência da mobilidade com a temperatura nos dispositivos fabricados no CEA-LETI, a transcondutância máxima $\left(g_{m, \max }\right)$ foi extraída para os dispositivos longos $(\mathrm{L}=$ $10 \mu \mathrm{m}$ ), conforme apresentado na Figura 7.3. Foram utilizados tais dispositivos de forma a se minimizar os efeitos da resistência série em $g_{m \text {,max }}$. Pela figura, pode-se observar que $g_{m, m a x}$ apresenta uma grande dependência com a temperatura, diferentemente do observado por Lee et al. ${ }^{10}$. Para os dispositivos nMOS com $N_{D}=5 \times 10^{18} \mathrm{~cm}^{-3}$, ao se reduzir $\mathrm{T}$ de $480 \mathrm{~K}$ para temperatura ambiente, houve um aumento aproximado de $110 \%$ em $g_{\mathrm{m}, \max }$, 
enquanto que para o dispositivo tipo $\mathrm{n}$ de similar concentração de dopantes esse aumento foi de $90 \%$. Já para a concentração de dopantes de $N_{A}=N_{D}=1$ $\times 10^{19} \mathrm{~cm}^{-3}$, o aumento foi de $65 \%$ e $80 \%$ para os dispositivos pMOS e nMOS, respectivamente. Assim, tem-se que nos JNTs a mobilidade também apresenta uma considerável dependência com a temperatura, contrariando alguns resultados da literatura, onde a mesma não variou de forma significativa com $T$ 10 .

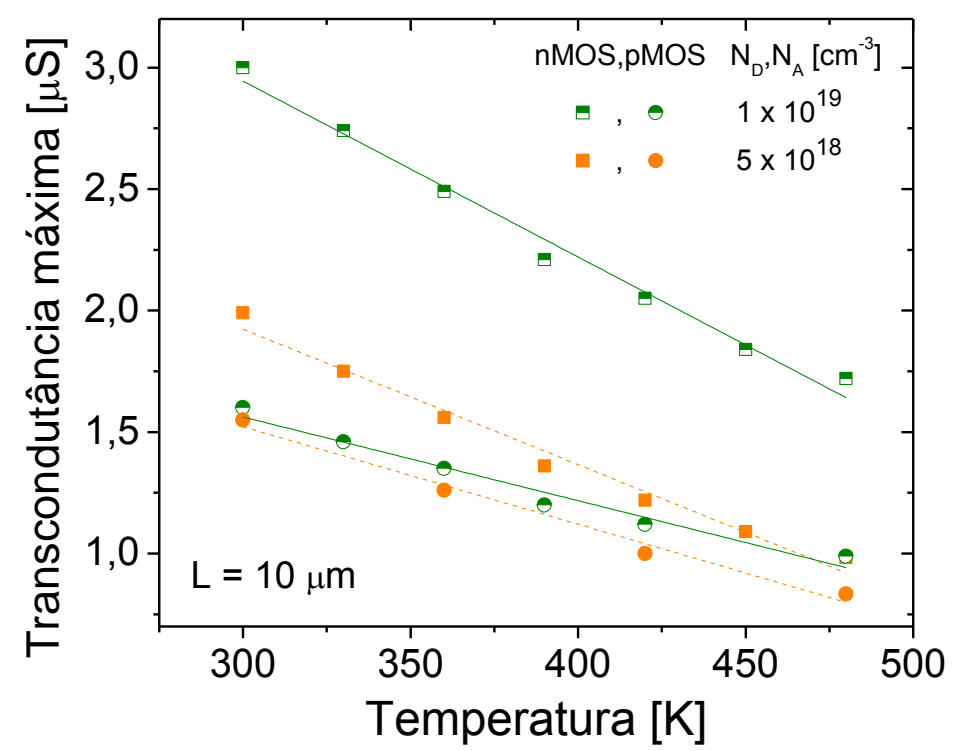

Figura 7.3 - Transcondutância máxima em função da temperatura para os dispositivos longos $(\mathrm{L}=10 \mu \mathrm{m})$.

No entanto, nem todo o aumento da transcondutância máxima deve ser creditado à mobilidade. A Figura 7.4 apresenta a transcondutância máxima obtida por simulações numéricas considerando diferentes concentrações de dopantes. A mobilidade foi considerada como constante para todos os dispositivos e também em todas as temperaturas $\left(\mu=100 \mathrm{~cm}^{2} / \mathrm{V}\right.$.s). Pode-se observar que mesmo com a imposição de que a mobilidade não varie com a temperatura, há um aumento de $\mathrm{g}_{\mathrm{m}, \max }$ ao se reduzir $\mathrm{T}$, o que está relacionado com a dependência do potencial de superfície em $T$.

Dessa forma, os resultados apresentados demonstram que as dependências da tensão de limiar e da transcondutância máxima com a temperatura são responsáveis pela existência do ponto de ZTC, da mesma forma que em um dispositivo MOSFET convencional. Entretanto, esses parâmetros não explicam a ausência do ponto invariante com a temperatura 
em determinados dispositivos. A fim de se analisar o porquê da não ocorrência do ponto de ZTC em determinados dispositivos, a resistência série é analisada no próximo tópico.

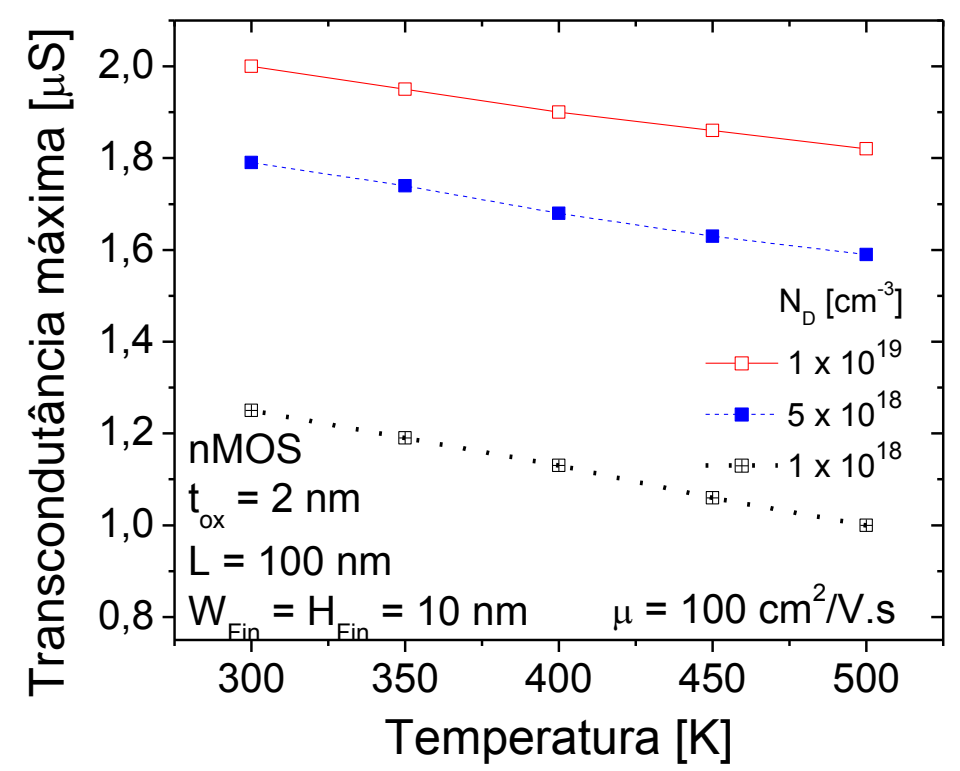

Figura 7.4 - Transcondutância máxima em função da temperatura para dispositivos simulados considerando mobilidade de baixo campo constante.

\subsection{INFLUÊNCIA DA RESISTÊNCIA SÉRIE}

Os dispositivos sem junções fabricados no CEA-LETI apresentam uma região de $10 \mathrm{~nm}$ abaixo de um nitreto espaçador entre o canal e as regiões de fonte e dreno. Essa região, que apresenta a mesma concentração de dopantes do canal, gera uma resistência parasita, que pode afetar o comportamento do dispositivo. As resistências série de todos os dispositivos foram extraídas utilizando-se o método proposto por Dixit et al. ${ }^{132}$ e são apresentadas na Figura 7.5. Pode-se observar que $R_{S}$ apresenta diferentes tendências para os dispositivos pMOS e nMOS: nos primeiros a resistência aumenta ao se reduzir a temperatura, enquanto que nos últimos $R_{S}$ diminui quando $T$ é reduzido. Este comportamento dos dispositivos nMOS já foi observado em dispositivos portatripla modo inversão ${ }^{88}$ e está relacionado ao aumento da mobilidade ao se reduzir $\mathrm{T}$.

A resistência de uma camada de silício é inversamente proporcional à mobilidade e à concentração de dopantes. Quando a temperatura é reduzida, 
ocorre um aumento na mobilidade dos portadores, devido ao menor espalhamento, e uma redução na concentração de dopantes devido à ionização incompleta dos portadores. Assim, tem-se dois efeitos contrários ao se diminuir a temperatura: a variação da mobilidade tende à diminuir a resistência série enquanto que a variação da concentração de dopantes tende à aumentar $R_{s}$. Dessa forma, analisando a Figura 7.5 pode-se concluir que 0 efeito da mobilidade é dominante nos dispositivos nMOS medidos enquanto que a dependência da concentração de dopantes com a temperatura é dominante nos dispositivos pMOS.

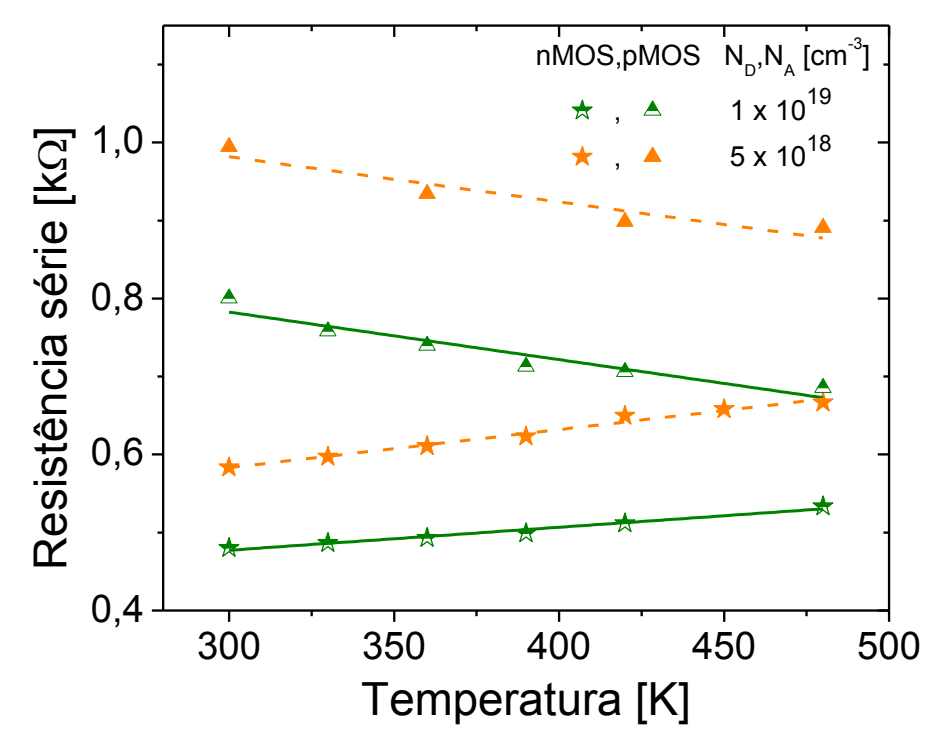

Figura 7.5 - Resistência série extraída dos dispositivos em função da temperatura.

Utilizando o modelo proposto por Altermatt et al. ${ }^{58,59}$ conforme descrito no item 2.4.1, pode-se obter a taxa de ionização dos portadores para diferentes elementos dopantes e com diferentes concentrações. A Figura 7.6 apresenta a taxa de ionização em função da temperatura. Pode-se observar que dispositivos dopados com boro apresentam um maior efeito da ionização incompleta dos portadores (maior redução na taxa de ionização) e também uma maior dependência com a temperatura. Então, é esperado um efeito maior da ionização incompleta dos portadores nos dispositivos pMOS, o que concorda com os dados da Figura 7.5.

A fim de se analisar a influência da resistência série na transcondutância máxima, foram realizadas simulações numéricas de dispositivos de diferentes comprimentos de fonte e dreno (Lfd). Na Figura 7.7, a transcondutância 
máxima normalizada por $g_{\mathrm{m} \text {,max }}$ para 0 menor Lfd simulado $(1 \mathrm{~nm})$ é apresentada em função do comprimento de fonte e dreno para três concentrações de dopantes. Pode-se observar que $g_{m, \max }$ sofre uma grande redução quando o comprimento Lfd é aumentado, sendo a redução ainda maior quando o efeito de ionização incompleta é considerado nas simulações. Por exemplo, para uma concentração de $N_{D}=1 \times 10^{19} \mathrm{~cm}^{-3}$, há uma redução de 17 $\%$ em $g_{m, \max }$ quando $\mathrm{Lfd}=10 \mathrm{~nm}$ (como o comprimento de canal é $1 \mu \mathrm{m}$, Lfd $=$ $10 \mathrm{~nm}$ representa $1 \%$ de L) considerando o efeito da ionização incompleta. Para uma concentração de dopantes de $N_{D}=1 \times 10^{18} \mathrm{~cm}^{-3}$, essa redução chega a $25 \%$ para o mesmo Lfd.

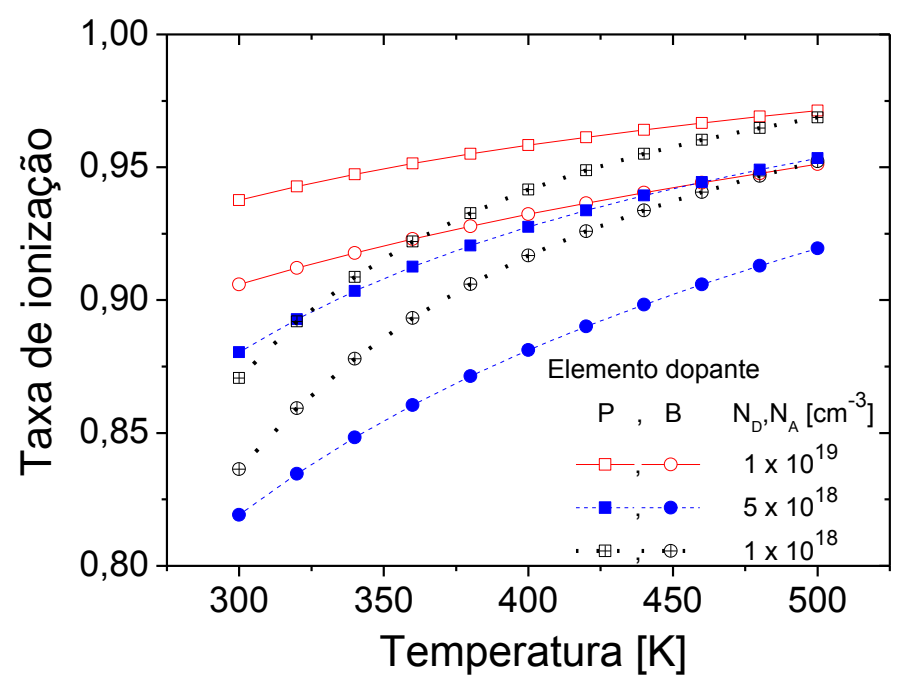

Figura 7.6 - Taxa de ionização incompleta dos portadores em função da temperatura para boro e fósforo considerando diferentes concentrações de dopantes.

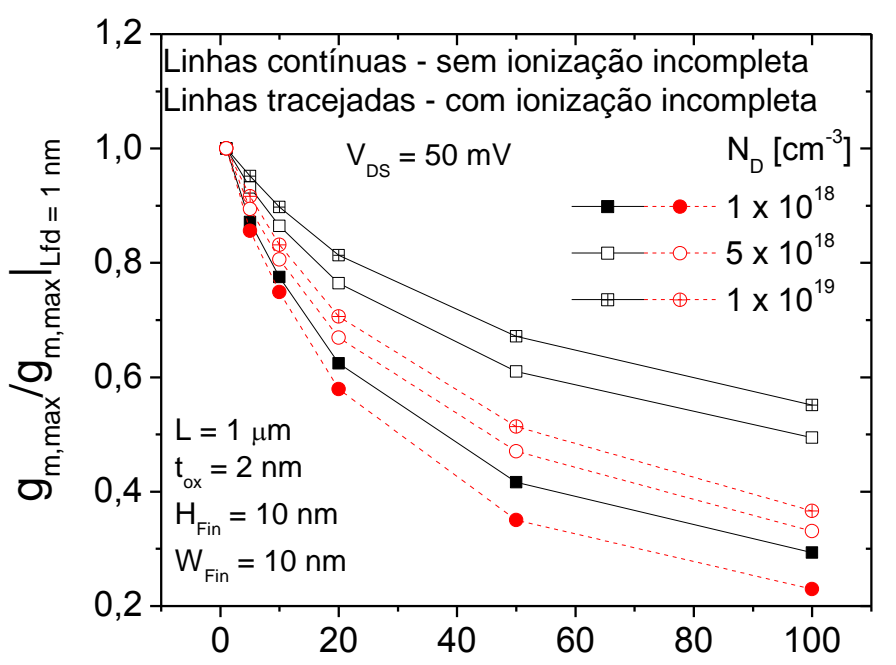

Comprimento das regiões de fonte e dreno [nm]

Figura 7.7 - Razão entre a transcondutância máxima e $g_{m \text {,max }}$ para $L f d=1 \mathrm{~nm}$ em função do comprimento das regiões de fonte e dreno. 
Assim, foi demonstrado que os dispositivos MOS junções podem apresentar o ponto invariante com a temperatura. Nestes dispositivos, não apenas as dependências da tensão de limiar e da mobilidade com a temperatura são importantes, mas a resistência série também é fundamental. Como a resistência série varia com a temperatura, as curvas $I_{D} \times V_{G S}$ são degradadas de forma diferente para temperaturas diferentes. Assim, o ponto de ZTC pode se deslocar para tensões $\left|V_{G S}\right|$ mais altas. Quando o deslocamento é significativo, a curva deixa de apresentar o ponto de ZTC. No próximo Capítulo, é feita uma análise da operação destes dispositivos em aplicações analógicas. 


\section{OPERAÇÃO EM APLICAÇÕES ANALÓGICAS}

A análise da operação dos dispositivos MOS sem junções operando como amplificadores também foi realizada utilizando-se os dispositivos fabricados no CEA-LETI e medidos no Tyndall National Institute.

\subsection{CURVAS CARACTERÍSTICAS DOS DISPOSITIVOS}

$\mathrm{Na}$ Figura 8.1, a corrente de dreno é apresentada para dispositivos nMOS e pMOS sem junções com $W_{\text {Fin }}=20 \mathrm{~nm}$ e $L=50 \mathrm{~nm}$ para diferentes concentrações de dopantes em função da sobretensão de porta. A transcondutância também é apresentada nessa figura. Pode-se observar que a transcondutância máxima é maior para o dispositivo com maior concentração de dopantes, de forma similar ao apresentado na Figura 7.3 para dispositivos longos polarizados com baixa tensão de dreno.

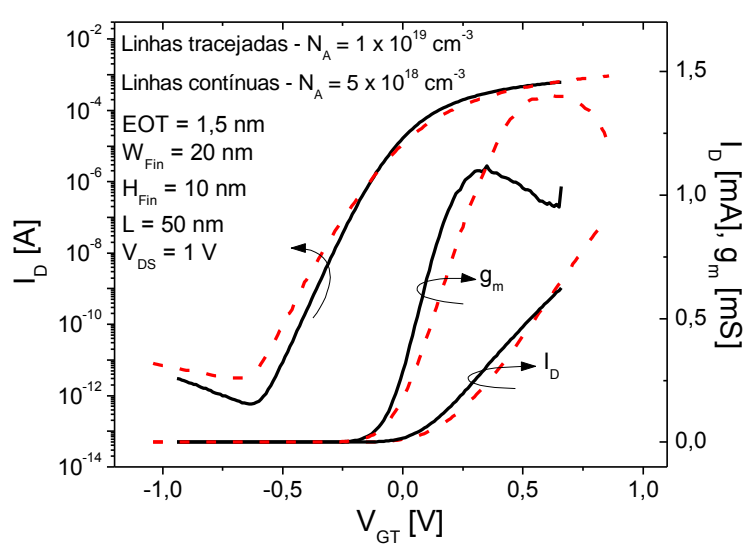

(A)

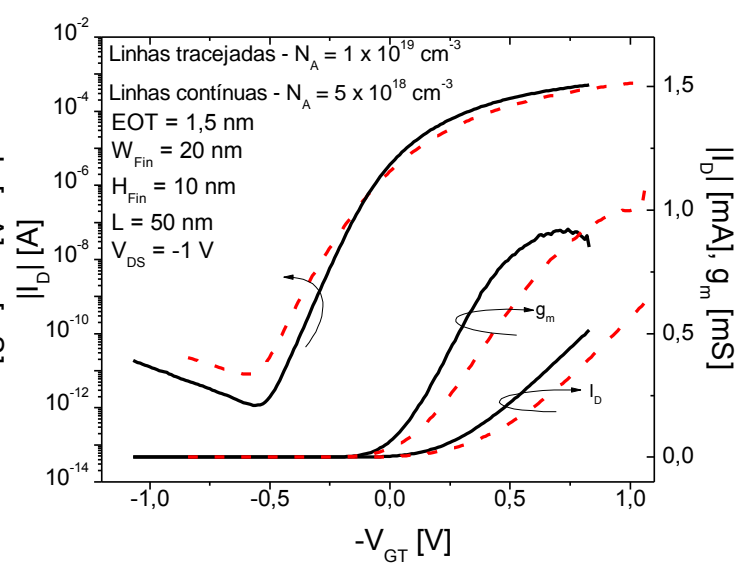

(B)

Figura 8.1 - Corrente de dreno e transcondutância em função de $V_{G T}$ para dispositivos de diferentes concentrações de dopantes do tipo $n(A)$ e do tipo $p(B)$.

Considerando que a transcondutância máxima é proporcional à mobilidade, seria esperado que $g_{m, \max }$ aumentasse com a redução da concentração de dopantes, conforme apresentado no item 2.4.2. No entanto, o resultado da Figura 8.1 mostra o contrário, concordando com os dados anteriores apresentados na Figura 7.3. Nos dispositivos menos dopados o início da formação de uma camada de acumulação ocorre para sobretensões 
de porta menores, devido à maior proximidade entre a tensão de limiar e a tensão de faixa plana. Assim, é esperado que esses dispositivos sofram uma maior degradação de mobilidade nas interfaces em relação aos dispositivos com maiores concentrações de dopantes. Além disso, esses dispositivos com menores $N_{D}$ também sofrem um impacto maior da resistência série, conforme mostrado na Figura 7.7. Pode-se ainda notar que a inclinação de sublimiar degrada quando a concentração de dopantes é aumentada.

\subsection{PARÂMETROS DE INTERESSE EM APLICAÇÕES ANALÓGICAS}

A razão entre a transcondutância e a corrente de dreno é apresentada na Figura 8.2 em função da corrente de dreno normalizada para dispositivos nMOS e pMOS de diferentes concentrações de dopantes. Pela figura, pode-se notar que JNTs menos dopados apresentam uma maior razão $\left|g_{m} / I_{D}\right|$ para correntes mais baixas, que está relacionado à degradação da inclinação de sublimiar com a concentração de dopantes. Como a razão $g_{m} / l_{D}$ está relacionada ao nível de condução do dispositivo, os parâmetros serão analisados em função dessa razão. Quando polarizados em uma mesma razão $\mathrm{g}_{\mathrm{m}} / \mathrm{I}_{\mathrm{D}}$, os JNTs mais dopados apresentam uma menor capacidade de fornecer corrente. Ao se aumentar a concentração de dopantes, a variação da corrente de dreno com a tensão de porta é menor na região próxima do limiar, conforme pode ser visto na Figura 8.1. Isto está relacionado ao potencial, que possui uma maior variação entre centro e superfície nos dispositivos mais dopados. Da mesma forma, a variação de $\left|\mathrm{g}_{\mathrm{m}} / \mathrm{l}_{\mathrm{D}}\right|$ com a corrente de dreno é menor nos dispositivos com maior concentração de dopantes. Comparando-se dispositivos tipo $n$ e $p$, tem-se que os nMOS exibem uma razão maior, que pode estar relacionada com a mobilidade dos elétrons.

$\mathrm{Na}$ Figura 8.3, a condutância de saída e a transcondutância são apresentadas em função de $\left|g_{m} / l_{D}\right|$ para os mesmos dispositivos cujas curvas são mostradas na Figura 8.2. Os dispositivos mais dopados apresentam menores $g_{m}$ e $g_{d}$ para razões $\left|g_{m} / I_{D}\right|$ maiores (menores $V_{G T}$ ). Para se obter uma mesma razão $\left|g_{m} / l_{D}\right|$, os dispositivos com maior concentração de dopantes estão polarizados em um menor $\mathrm{V}_{\mathrm{GT}}$, apresentando um menor nível de corrente e transcondutância. Em razões $\left|g_{m} / l_{D}\right|$ menores ( $V_{G T}$ mais altos), os JNTs 
nMOS com maior concentração de dopantes apresentam maior $g_{m}$ e $g_{d}$ que os menos dopados. Para os dispositivos pMOS, valores similares de $g_{m}$ e $g_{d}$ são obtidos em razões $\left|g_{m} / l_{D}\right|$ menores, para ambos $N_{A}$.

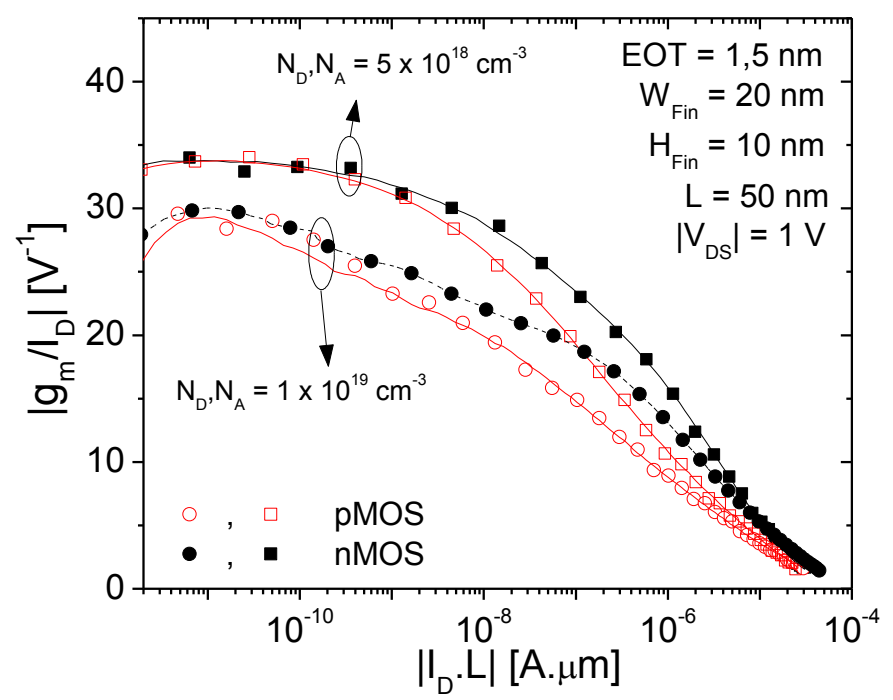

Figura 8.2 - Razão entre a transcondutância e a corrente de dreno em função da corrente de dreno para dispositivos nMOS e pMOS de diferentes concentrações de dopantes.

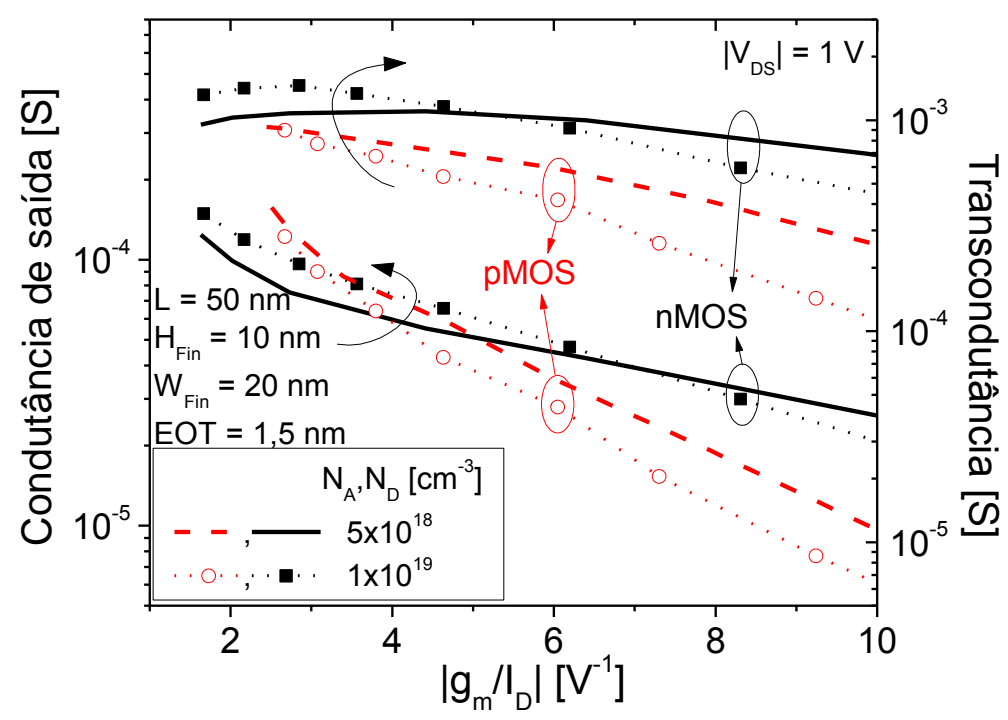

Figura 8.3 - Condutância de saída e transcondutância em função da razão $\left|g_{m} / I_{D}\right|$ comparando os dispositivos de diferentes concentrações de dopantes.

O ganho de tensão do amplificador mostrado na Figura 2.16 e a tensão Early são mostrados na Figura 8.4 em função da razão $\left|g_{m} / I_{D}\right|$. Pode-se notar que os dispositivos com $\mathrm{N}_{\mathrm{A}}, \mathrm{N}_{\mathrm{D}}=5 \times 10^{18} \mathrm{~cm}^{-3}$ demonstram um maior ganho $A_{\vee}$ para razões $\left|g_{m} / I_{D}\right|$ mais altas, o que está relacionado à maior tensão Early (menor $\mathrm{g}_{\mathrm{d}}$ ). Para razões menores, os JNTs mais dopados exibem valores $A_{V}$ ligeiramente superiores, seguindo a tendência da tensão Early. 
O ganho de tensão de malha aberta é apresentado em função de $g_{m} / l_{D}$ para dispositivos nMOS de diferentes dimensões (variando $L$ e $W_{\text {Fin }}$ ) na Figura 8.5. Como esperado, quando o comprimento de canal é reduzido, há uma redução em $A_{v}$ devido ao aumento da influência da modulação do comprimento de canal, que degrada $g_{d}$. $O$ ganho de tensão é reduzido em $10 \mathrm{~dB}$ em g $\mathrm{g}_{\mathrm{m}} / \mathrm{l}_{\mathrm{D}}=$ $8 \mathrm{~V}^{-1}$ quando $\mathrm{L}$ é diminuído de $100 \mathrm{~nm}$ para $50 \mathrm{~nm}$. Quando a largura é variada de $20 \mathrm{~nm}$ para $40 \mathrm{~nm}$, o ganho de tensão não sofreu influência significativa. Para dispositivos mais largos ( $\mathrm{W}_{\mathrm{Fin}}=200 \mathrm{~nm}$ e $300 \mathrm{~nm}$ ), há uma redução em $A_{V}$. Estes dispositivos mais largos se comportam como transistores planares, já que a influência das portas laterais se tornam desprezíveis, e não possuem os benefícios da estrutura de múltiplas portas como melhor controle das cargas no canal.

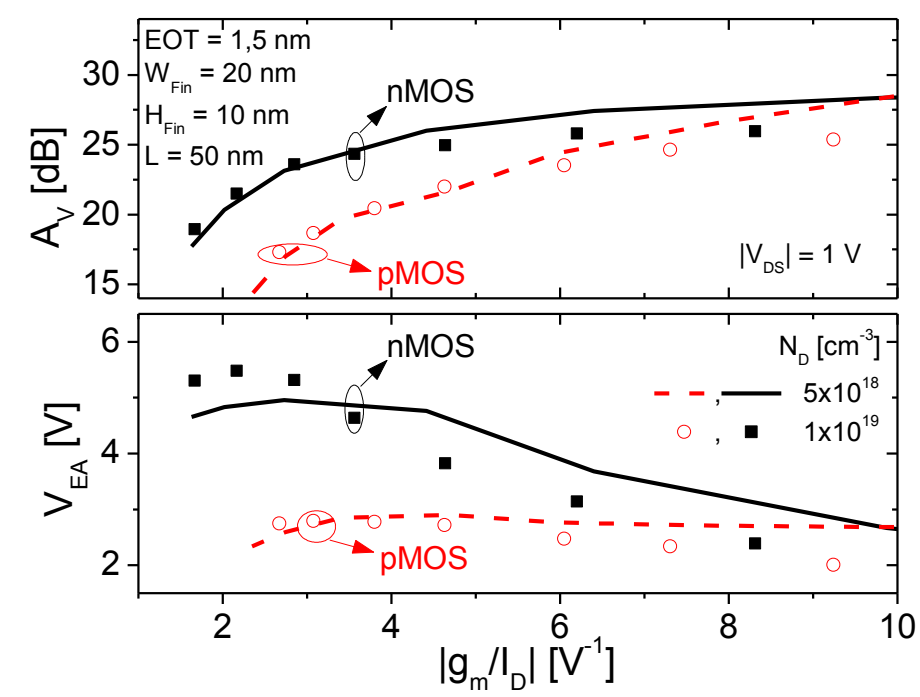

Figura 8.4 - Ganho de tensão de malha aberta e tensão Early em função da razão $\left|g_{m} / l_{D}\right|$ para JNTs de diferentes concentrações de dopantes.

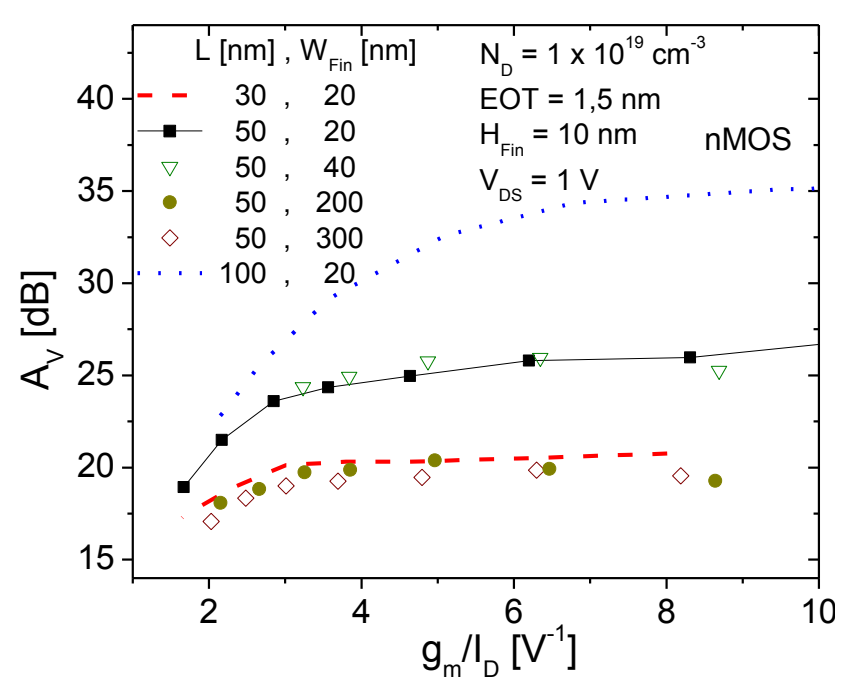

Figura 8.5 - Ganho de tensão de malha aberta em função de $g_{m} / l_{D}$ para dispositivos de diferentes dimensões. 


\subsection{INFLUÊNCIA DA TEMPERATURA}

A Figura 8.6 apresenta a razão $\left|g_{m} / I_{D}\right|$ em função da corrente de dreno normalizada para dispositivos nMOS e pMOS em duas temperaturas diferentes. Pela curva, pode-se perceber que na região de inversão forte os dispositivos apresentam uma similar razão $\left|g_{m} / l_{D}\right|$ independente da temperatura, o que está relacionado à fraca dependência da degradação da mobilidade em $T{ }^{11}$. Já na região de inversão fraca, a razão $\left|g_{m} / I_{D}\right|$ é inversamente proporcional ao potencial térmico e, consequentemente, inversamente proporcional à temperatura.

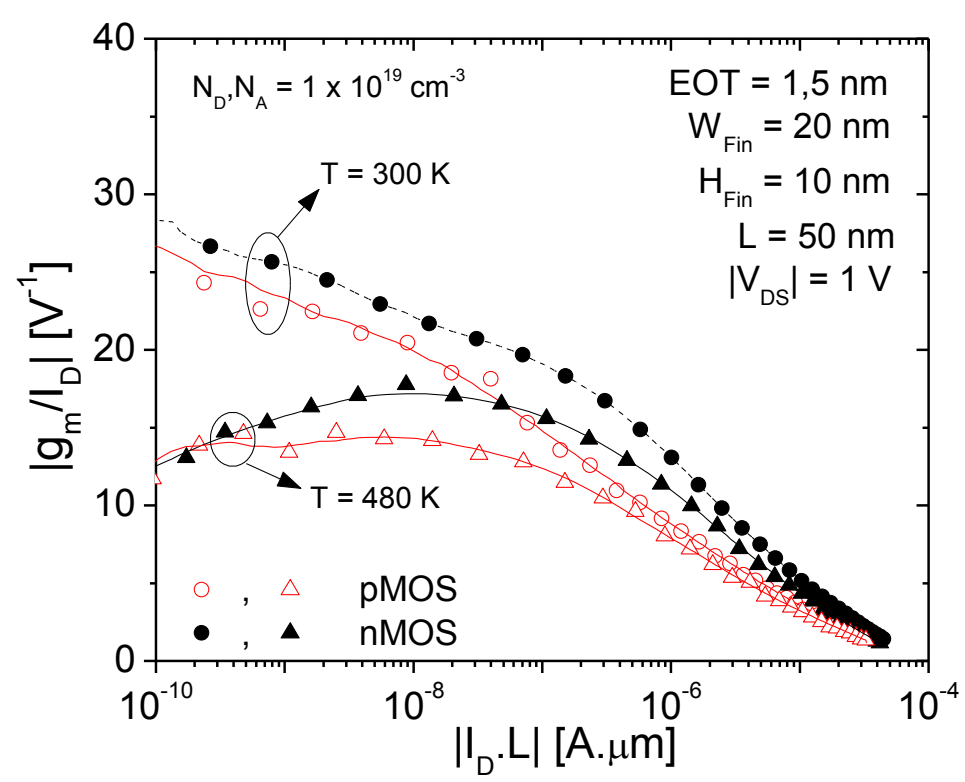

Figura 8.6 - Razão entre a transcondutância e a corrente de dreno em função da corrente de dreno para dispositivos nMOS e pMOS em diferentes temperaturas.

Na Figura 8.7, o ganho de tensão de malha aberta e a tensão Early são apresentados em função da razão $\left|g_{m} / I_{D}\right|$. Pode-se observar que não há uma influência significativa da temperatura, sendo que o ganho $A_{\vee}$ e a tensão Early se mantêm praticamente constante independentemente de $T$. Apenas para 0 dispositivo pMOS há um ligeiro aumento de $A_{V}(\sim 1 \mathrm{~dB})$ quando a temperatura varia de $300 \mathrm{~K}$ para $480 \mathrm{~K}$.

A transcondutância e a condutância de saída são mostradas na Figura 8.8 em função da razão $\left|g_{m} / I_{D}\right|$ para os dispositivos pMOS e nMOS em duas temperaturas. Pode-se notar que o aumento da temperatura reduz tanto $g_{m}$ 
como $g_{d}$ devido à redução da mobilidade. No entanto, o aumento da mobilidade não afeta o ganho $A_{v}$, pois o ganho de tensão é descrito pela razão $g_{m} / g_{d}$.

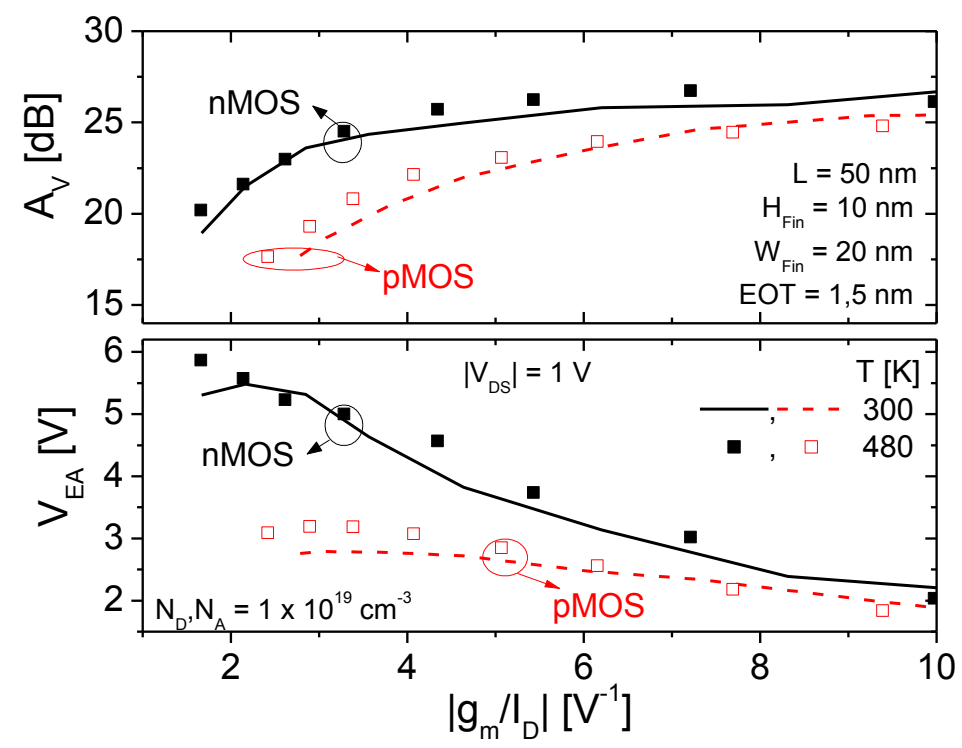

Figura 8.7 - Ganho de tensão de malha aberta e tensão Early em função da razão $\left|g_{m} / I_{D}\right|$ para dispositivos nMOS e pMOS em diferentes temperaturas.

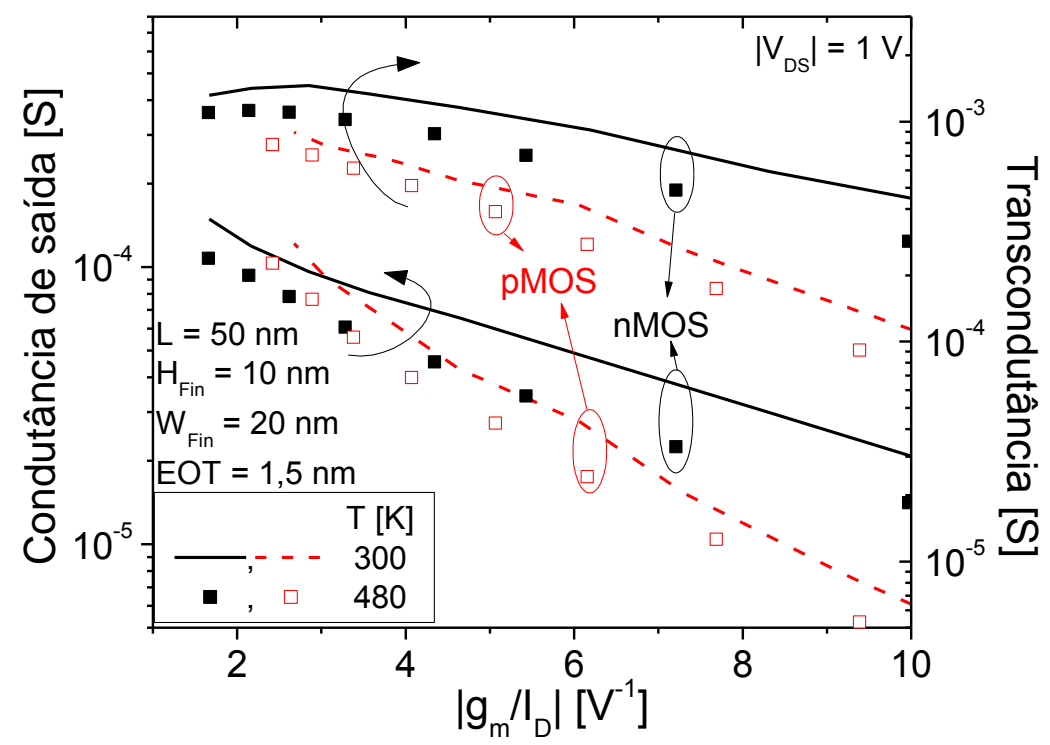

Figura 8.8 - Condutância de saída e transcondutância em função da razão $\left|g_{m} / I_{D}\right|$ comparando os dispositivos nMOS e pMOS em diferentes temperaturas.

Com base nos resultados apresentados, tem-se que os dispositivos menos dopados apresentaram uma pequena vantagem quanto ao ganho de tensão em relação aos JNTs com maior concentração de dopantes. Já a variação da temperatura não afetou significativamente o comportamento dos dispositivos. 


\section{CONCLUSÕES}

Neste trabalho, foi apresentado um estudo sobre os transistores SOI MOS sem junções com ênfase na modelagem dos dispositivos. Foi proposto um modelo de tensão de limiar e um método de extração da mesma. Também foram propostas modelagens para o potencial de superfície, carga de condução e de corrente de dreno. Os modelos foram comparados com dados simulados utilizando as ferramentas da Synopsys, bem como dados experimentais dos dispositivos fabricados no Tyndall National Institute da University College Cork, Irlanda e dos dispositivos fabricados no CEA-LETI, Grenoble, França. Por fim, foram realizadas análises do funcionamento dos mesmos quanto ao ponto invariante com a temperatura e em relação à operação analógica.

O primeiro modelo proposto foi o de tensão de limiar para dispositivos porta tripla. Este modelo foi desenvolvido a partir da equação bidimensional de Poisson utilizando como definição de limiar o início da redução da camada de depleção controlada pela porta. Também foi acrescentado um termo derivado da solução da equação de Schrödinger, adicionando os efeitos quânticos advindos das reduções da largura e/ou da altura dos dispositivos para valores menores que $10 \mathrm{~nm}$. O modelo foi validado utilizando-se resultados experimentais de dispositivos pMOS e nMOS, assim como resultados de simulações numéricas tridimensionais onde a altura e a largura do dispositivo, a espessura do óxido de porta, a concentração de dopantes e a temperatura foram variadas. Quando comparados com os dispositivos simulados, o maior erro obtido foi de $33 \mathrm{mV}$, o que representa menos de $5 \%$ para uma tensão de limiar em torno de $0,7 \mathrm{~V}$. No modelo, também foi proposta a inclusão de um fator $f$ no cálculo da capacitância do óxido de porta por unidade de comprimento, a fim de se contabilizar a capacitância dos cantos superiores do óxido de porta nos dispositivos porta tripla. Para a obtenção de $f$, foi utilizado como base a capacitância de um quadrado unitário descrita na literatura. Para validar o fator $f$, as tensões de limiar obtidas por simulação numérica foram comparadas ao modelo considerando e desprezando o fator. Ao se desprezar $f$, um erro máximo de $340 \mathrm{mV}$ foi obtido ao se aumentar a espessura do óxido de 
porta. Quando $f$ foi considerado, o erro obtido para o mesmo dispositivo foi menor que $10 \mathrm{mV}$. Resultados simulados também mostraram que o fator é adequado para dispositivos com óxido de cantos arredondados e também com os cantos superiores do silício ligeiramente arredondados. O modelo proposto foi utilizado para se analisar a dependência da tensão de limiar com a temperatura. Pôde-se perceber que a variação de $d V_{T H} / d T$ possui uma grande dependência com a variação da concentração de dopantes com a temperatura $\mathrm{dN}_{\mathrm{D}} / \mathrm{dT}$, que está relacionada à ionização incompleta dos portadores. Quanto menor for a concentração de dopantes, maior será a variação $d N_{D} / d T$ e, portanto, maior será $d V_{T H} / d T$. A variação $d N_{D} / d T$ é amplificada com o aumento da altura, da largura e da espessura do óxido de porta. Na sequência o modelo de tensão de limiar foi deduzido para um dispositivo cilíndrico. A obtenção do modelo foi similar à dos dispositivos porta tripla e a validação foi realizada utilizando simulações numéricas, onde foram variadas as espessuras da camada de silício e do óxido de porta, a concentração de dopantes e a temperatura. A influência da polarização do substrato também foi considerada no modelo.

Foi também proposto um método de extração da tensão de limiar nos dispositivo MOS sem junções. O método se baseia na definição de limiar como a igualdade das componentes de deriva e difusão da corrente de dreno, sendo que abaixo do limiar a componente de difusão é a principal, enquanto acima de $\mathrm{V}_{\mathrm{TH}}$ a de deriva é dominante. Segundo o método, a tensão de porta na qual a razão entre a transcondutância e a corrente de dreno diminui à metade de seu valor máximo representa a igualdade das componentes. O ponto em que $\mathrm{g}_{\mathrm{m}} / \mathrm{l}_{\mathrm{D}}$ é a metade de seu valor máximo foi comparado com a igualdade das componentes da corrente através de simulações numéricas variando-se $T, t_{0 x}$, $\mathrm{N}_{\mathrm{D}}, \mathrm{W}_{\text {Fin }}$ e $\mathrm{H}_{\text {Fin }}$, sendo que o erro máximo obtido foi de $3 \mathrm{mV}$. Assim, pôde-se concluir que o método é preciso, independentemente de qualquer uma dessas variáveis. Através do método de extração foi possível desenvolver outra equação para a tensão de limiar.

Na sequência, foi desenvolvido um modelo de corrente de dreno para os transistores em estudo, sendo utilizada a solução da equação de Poisson na modelagem. Também foi desenvolvido um cálculo como forma de se obter a tensão de saturação a partir da velocidade de saturação dos portadores. Foram 
utilizadas funções de suavização para se limitar a máxima tensão de dreno na tensão de saturação e para se obter uma transição contínua entre os regimes de condução pelo corpo e pela camada de acumulação ou apenas pelo corpo do dispositivo. Para a região de sublimiar, foi considerada uma variação exponencial da corrente de dreno com relação à tensão de porta, cuja inclinação depende do fator de corpo. O modelo foi validado através das curvas $I_{D} \times V_{G S}$ e $I_{D} \times V_{D S}$ obtidas por simulações numéricas e pelas suas derivadas com erro máximo inferior a $15 \%$. A curva da razão entre a transcondutância e a corrente de dreno, que é importante do ponto de vista das aplicações analógicas, também foi utilizada na validação. Por fim, o modelo foi comparado a resultados experimentais, sempre apresentando uma boa concordância. Foi também acrescentada ao modelo uma correção para os efeitos de canal curto, através da qual se pôde também determinar funções analíticas para o cálculo da dependência da inclinação de sublimiar com a redução do comprimento de canal bem como para o cálculo da redução de barreira induzida pelo dreno.

Também foi realizada a modelagem dos potenciais de superfície nos dispositivos MOS sem junções. A partir dessa modelagem, foram obtidas expressões analíticas para a carga de condução e para a corrente de dreno. Foram acrescentados ao potencial de superfície correções de efeito de canal curto e de efeito de quantização dos níveis energéticos. Novamente, o modelo foi comparado com simulações numéricas e com resultados experimentais. No caso da comparação com estes últimos, o erro médio foi menor que $12 \%$ para todas as curvas realizadas em diferentes polarizações. Deve-se ressaltar que nesta comparação com resultados experimentais, os dispositivos analisados possuíam comprimentos de canal de $30 \mathrm{~nm}$. A partir da carga de condução, pôde-se também obter a capacitância do dispositivo em função da polarização.

Terminada a etapa de modelagem, foi realizada uma análise da operação dos JNTs quanto ao ponto invariante com a temperatura. Através da caracterização elétrica dos dispositivos experimentais em função da temperatura, percebeu-se que os dispositivos sem junções podem ou não apresentar esse ponto em que a corrente é independente da temperatura. A resistência série desses dispositivos e sua dependência com a temperatura são determinantes na ocorrência do ponto invariante com a temperatura. Essa análise foi realizada baseada na influência de $T$ na tensão de limiar, na 
transcondutância máxima e na resistência série. Simulações numéricas também deram suporte às análises.

Os dispositivos também foram analisados quanto à sua aplicação em circuitos analógicos, operando como amplificador. Neste caso, os JNTs nMOS e pMOS foram analisados quanto ao ganho de tensão de malha aberta, condutância de saída, transcondutância e tensão Early. Os dispositivos com menores concentrações de dopantes apresentam um ganho de tensão de malha aberta ligeiramente maior que os dispositivos mais dopados para razões $\left|g_{m} / I_{D}\right|$ maiores. Já para razões menores, os dispositivos apresentam resultados similares independente da concentração de dopantes. Já a variação da temperatura não influenciou significativamente o ganho de tensão de malha aberta e a tensão Early, embora 0 aumento de $T$ tenha aumentado a transcondutância e a condutância de saída.

Como sugestões de trabalhos futuros, sugere-se analisar e modelar as características dinâmicas dos dispositivos sem junções, como transitório de corrente e capacitâncias intrínsecas. A partir das capacitâncias, pode-se desenvolver um modelo de pequenos sinais para esses dispositivos. Também se sugere a implementação do modelo de corrente proposto em um simulador de circuitos. Pode-se utilizar a linguagem Verilog-A para tal. A partir da implementação do modelo, pode-se analisar o comportamento dos dispositivos sem junções em circuitos simples, tais como espelhos de corrente. 


\section{REFERÊNCIAS BIBLIOGRAFICAS}

${ }^{1}$ COLINGE, J.-P.; Silicon-on-Insulator Technology: Materials to VLSI. 3a Edição Boston: Kluwer Academic Publishers, 2003.

2 HISAMOTO, D.; KAGA, T.; KAWAMOTO, Y.; TAKEDA, E.; A fully depleted lean-channel transistor (DELTA) - A novel vertical ultrathin SOI MOSFET, IEEE Electron Device Letters, vol. 11, n. 1, pp. 36-38, 1990.

${ }^{3}$ COLINGE, J. P.; FinFETs and Other Multi-Gate Transistors. $1 \stackrel{\text { a }}{\text { Edição }}$ Springer, 2008.

${ }^{4}$ COLINGE, J. P.; KRANTI, A.; YAN, R.; LEE, C.W. et al.; Junctionless Nanowire Transistor (JNT): Properties and design guidelines, Solid-State Electronics, vol. 65-66, n. 1, pp. 33-37, 2011.

${ }^{5}$ COLINGE, J. P.; LEE, C. W.; AFZALIAN, A.; AKHAVAN, N. D. et al.; SOI gated resistor: CMOS without junctions, IEEE International SOI Conference, $\underline{2009}$, pp. 1-2, 2009.

${ }^{6}$ COLINGE, J. P.; LEE, C. W.; AFZALIAN, A.; AKHAVAN, N. D. et al.; Nanowire transistors without junctions, Nature Nanotechnology, vol. 5, n. 3, pp. 225-229, 2010.

7 SORÉE, B.; MAGNUS, W.; POURTOIS, G.; Analytical and self-consistent quantum mechanical model for a surrounding gate MOS nanowire operated in JFET mode, Journal of Computational Electronics, vol. 7, pp. 380-383, 2008.

${ }^{8}$ LEE, C. W.; AFZALIAN, A.; AKHAVAN, N. D.; YAN, R. et al.; Junctionless multigate field-effect transistor, Applied Physics Letters, vol. 94, n. 5, pp. 053511, 2009.

${ }^{9}$ LEE, C. W.; FERAIN, I.; AFZALIAN, A.; YAN, R. et al.; Performance estimation of junctionless multigate transistors, Solid-State Electronics, vol. 54, n. 2, pp. 97-103, 2010. 
${ }^{10}$ LEE, C. W.; BORNE, A.; FERAIN, I.; AFZALIAN, A. et al.; High-Temperature Performance of Silicon Junctionless MOSFETs, IEEE Transactions on Electron Devices, vol. 57, n. 3, pp. 620-625, 2010.

${ }^{11}$ DORIA, R. T.; PAVANELLO, M. A.; TREVISOLI, R. D.; SOUZA, M. de et al.; Junctionless Multiple-Gate Transistors for Analog Applications, IEEE Transactions on Electron Devices, vol. 58, n. 8, pp. 2511-2519, 2011.

12 DORIA, R. T.; TREVISOLI, R. D.; SOUZA, M. de; COLINGE, J. P. et al.; Analysis of the Low-Frequency Noise of Junctionless Nanowire Transistors operating in saturation, IEEE International SOI Conference, 2011, pp. 1-2, 2011.

${ }^{13}$ DUARTE, J. P.; CHOI, S. J.; CHOI, Y. K.; A Full-Range Drain Current Model for Double-Gate Junctionless Transistors, IEEE Transactions on Electron Devices, vol. 58, n. 12, pp. 4219-4225, 2011.

${ }^{14}$ DUARTE, J. P.; CHOI, S. J.; MOON, D. I.; CHOI, Y. K.; Simple Analytical Bulk Current Model for Long-Channel Double-Gate Junctionless Transistors, IEEE Electron Device Letters, vol. 32, n. 6, pp. 704-706, 2011.

15 GNANI, E.; GNUDI, A.; REGGIANI, S.; BACCARANI, G.; Theory of the Junctionless Nanowire FET, IEEE Transactions on Electron Devices, vol. 58, n. 9, pp. 2903-2910, 2011.

${ }^{16}$ SALLESE, J. M.; CHEVILLON, N.; LALLEMENT, C.; INIGUEZ, B. et al.; Charge-Based Modeling of Junctionless Double-Gate Field-Effect Transistors, IEEE Transactions on Electron Devices, vol. 58, n. 8, pp. 2628-2637, 2011.

${ }^{17}$ GUTIERREZ, E. A.; DEEN, J.; CLAYES, C. L.; Low Temperature Electronics: Physics, Devices, Circuits and Applications. Academic Press, 1991.

${ }^{18}$ SZE, S. M.; Physics of Semiconductor Devices. 2a Edição New York: John Wiley and Sons, 1981.

${ }^{19}$ KRISHNAN, S.; FOSSUM, J. G.; Grasping SOI floating-body effects, IEEE Circuits and Devices Magazine, vol. 14, n. 4, pp. 32-37, 1998. 
20 KISTLER, N.; WOO, J.; Detailed characterization and analysis of the breakdown voltage in fully depleted SOI n-MOSFET's, IEEE Transactions on Electron Devices, vol. 41, n. 7, pp. 1217-1221, 1994.

${ }^{21}$ YOSHIMI, M.; HAZAMA, H.; TAKAHASHI, M.; KAMBAYASHI, S. et al.; Twodimensional simulation and measurement of high-performance MOSFETs made on a very thin SOI film, IEEE Transactions on Electron Devices, vol. 36, n. 3, pp. 493-503, 1989.

${ }^{22}$ YOUNG, K. K.; Short-channel effect in fully depleted SOI MOSFETs, IEEE Transactions on Electron Devices, vol. 36, n. 2, pp. 399-402, 1989.

${ }^{23}$ GRoeseneKen, G.; Colinge, J. P.; MAES, H. E.; ALDERMAN, J. C. et al.; Temperature dependence of threshold voltage in thin-film SOI MOSFETs, IEEE Electron Device Letters, vol. 11, n. 8, pp. 329-331, 1990.

${ }^{24}$ COLINGE, J. P.; Thin-film SOI technology: the solution to many submicron CMOS problems, International Electron Devices Meeting, 1989. IEDM '89. Technical Digest., pp. 817-820, 1989.

${ }^{25}$ COLINGE, J. P.; Subthreshold slope of thin-film SOI MOSFET's, IEEE Electron Device Letters, vol. 7, n. 4, pp. 244-246, 1986.

${ }^{26}$ LIM, H. K.; FOSSUM, J. G.; Threshold voltage of thin-film Silicon-on-insulator (SOI) MOSFET's, IEEE Transactions on Electron Devices, vol. 30, n. 10, pp. 1244-1251, 1983.

${ }^{27}$ COLINGE, J. P.; Conduction mechanisms in thin-film accumulation-mode SOI p-channel MOSFETs, IEEE Transactions on Electron Devices, vol. 37, n. 3, pp. 718-723, 1990.

${ }^{28} \mathrm{SU}, \mathrm{K} . \mathrm{W}$.; KUO, J. B.; Analysis of current conduction in short-channel accumulation-mode SOI PMOS devices, IEEE Transactions on Electron Devices, vol. 44, n. 5, pp. 832-840, 1997. 
${ }^{29}$ SEKIGAWA, T.; HAYASHI, Y.; Calculated threshold-voltage characteristics of an XMOS transistor having an additional bottom gate, Solid-State Electronics, vol. 27, n. 8-9, pp. 827-828, 1984.

${ }^{30}$ HUANG, X. Lee, W. C.; KUO, C.; HISAMOTO, D.; CHANG, L. et al.; Sub 50nm FinFET: PMOS, International Electron Devices Meeting, 1999. IEDM Technical Digest., pp. 67-70, 1999.

${ }^{31}$ HISAMOTO, D.; LEE, W. C.; KEDZIERSKI, J.; TAKEUCHI, H. et al.; FinFET A self-aligned double-gate MOSFET scalable to $20 \mathrm{~nm}$, IEEE Transactions on Electron Devices, vol. 47, n. 12, pp. 2320-2325, 2000.

${ }^{32}$ COLINGE, J. P.; GAO, M. H.; ROMANO-RODRIGUEZ, A.; MAES, H. et al.; Silicon-on-insulator 'gate-all-around device', International Electron Devices Meeting, 1990. IEDM '90. Technical Digest., pp. 595-598, 1990.

${ }^{33}$ PARK, J. T.; COLINGE, J. P.; DIAZ, C. H.; Pi-Gate SOI MOSFET, IEEE Electron Device Letters, vol. 22, n. 8, pp. 405-406, 2001.

${ }^{34}$ YANG, F. L.; CHEN, H. Y.; CHEN, F. C.; HUANG, C. C. et al.; 25 nm CMOS Omega FETs, International Electron Devices Meeting, 2002. IEDM '02. Technical Digest., pp. 255-258, 2002.

${ }^{35}$ MIYANO, S.; HIROSE, M.; MASUOKA, F.; Numerical analysis of a cylindrical thin-pillar transistor (CYNTHIA), IEEE Transactions on Electron Devices, vol. 39, n. 8, pp. 1876-1881, 1992.

${ }^{36}$ LANDGRAF, E.; RÖSNER, W.; STÄDELE, M.; DREESKORNFELD, L. et al.; Influence of crystal orientation and body doping on trigate transistor performance, Solid-State Electronics, vol. 50, n. 1, pp. 38-43, 2006.

${ }^{37}$ SUBRAMANIAN, V.; MERCHA, A.; PARVAIS, B.; LOO, J. et al.; Impact of fin width on digital and analog performances of $\mathrm{n}$-FinFETs, Solid-State Electronics, vol. 51, n. 4, pp. 551-559, 2007.

${ }^{38}$ XIONG, W.; PARK, J. W.; COLINGE, J. P.; Corner effect in multiple-gate SOI MOSFETs, IEEE International SOI Conference, 2003., pp. 111-113, 2003. 
${ }^{39}$ FOSSUM, J. G.; YANG, J. W.; TRIVEDI, V. P.; Suppression of corner effects in triple-gate MOSFETs, IEEE Electron Device Letters, vol. 24, n. 12, pp. 745747, 2003.

${ }^{40}$ BALESTRA, F.; CRISTOLOVEANU, S.; BENACHIR, M.; BRINI, J. et al.; Double-gate silicon-on-insulator transistor with volume inversion: $A$ new device with greatly enhanced performance, IEEE Electron Device Letters, vol. 8, n. 9, pp. 410-412, 1987.

${ }^{41}$ OUISSE, T.; Self-consistent quantum-mechanical calculations in ultrathin silicon-on-insulator structures, Journal of Applied Physics, vol. 76, n. 10, pp. 5989-5995, 1994.

${ }^{42}$ COLLAERT, N.; DEMAND, M.; FERAIN, I.; LISONI, J. et al.; Tall triple-gate devices with TiN/HfO2 gate stack, Symposium on VLSI Technology, 2005. Digest of Technical Papers. 2005, pp. 108-109, 2005.

43 DORIA, R. T.; TREVISOLI, R. D.; SOUZA, M. de; PAVANELLO, M. A.; Impact of the Series Resistance in the I-V Characteristics of Junctionless Nanowire Transistor and its Dependence on the Temperature, Journal of Integrated Circuits and Systems, vol. 7, n. 1, pp. 121-129, 2012.

${ }^{44}$ KRANTI, A.; YAN, R.; LEE, C. W.; FERAIN, I. et al.; Junctionless nanowire transistor (JNT): Properties and design guidelines, Proceedings of the European Solid-State Device Research Conference (ESSDERC), 2010, pp. 357-360, 2010.

${ }^{45}$ NICOLLIAN, E. H.; BREWS, J. R. ; MOS (Metal Oxide Semiconductor) Physics and Technology. Wiley-Interscience, 2002.

${ }^{46}$ DORIA, R. T.; TREVISOLI, R. D.; PAVANELLO, M. A.; Impact of the Series Resistance in the I-V Characteristics of nMOS Junctionless Nanowire Transistors, ECS Transactions, vol. 39, n. 1, pp. 231-238, 2011.

${ }^{47}$ COLINGE, J. P.; COLINGE, C. A.; Physics of Semiconductor Devices. $1^{\text {a }}$ Edição Massachusetts: Kluwer Academic Publishers, 2002. 
48 GARCÍA-SÁNCHEZ, F. J.; ORTIZ-CONDE, A.; MUCI, J.; Understanding threshold voltage in undoped-body MOSFETs: An appraisal of various criteria, Microelectronics and Reliability, vol. 46, n. 5-6, pp. 731-742, 2006.

49 CUNHA, A. I. A.; PAVANello, M. A.; TREVISOLI, R. D.; GALUPMONTORO, C. et al.; Direct determination of threshold condition in DGMOSFETs from the gm/ID curve, Solid-State Electronics, vol. 56, n. 1, pp. 8994, 2011.

$50 \mathrm{SHIH}$, C. H.; WANG, J. S.; Threshold Voltage of Ultrathin Gate-Insulator MOSFETs, IEEE Electron Device Letters, vol. 30, n. 3, pp. 278-281, 2009.

51 POIROUX, T.; VINET, M.; FAYNOT, O.; WIDIEZ, J. et al.; Multiple gate devices: advantages and challenges, Microelectronic Engineering, vol. 80, pp. 378-385, 2005.

52 DORIA, R. T.; TREVISOLI, R. D.; SOUZA, M. de; PAVANELLO, M. A.; Application of Junctionless Nanowire Transistor in the Self-Cascode Configuration to Improve the Analog Performance, ECS Transactions, vol. 49, n. 1, pp. 215-222, 2012.

${ }^{53}$ SELBERHERR, S.; MOS device modeling at $77 \mathrm{~K}$, IEEE Transactions on Electron Devices, vol. 36, n. 8, pp. 1464-1474, 1989.

${ }^{54}$ BLUDAU, W.; ONTON, A.; HEINKE, W.; Temperature dependence of the band gap of silicon, Journal of Applied Physics, vol. 45, n. 4, pp. 1846-1848, 1974.

${ }^{55}$ MCKELVEY, J. P.; Solid State and Semiconductor Physics. Krieger Pub Co, 1982.

${ }^{56}$ SCHENK, A.; ALTERMATT, P. P.; SCHMITHUSEN, B.; Physical Model of Incomplete Ionization for Silicon Device Simulation, International Conference on Simulation of Semiconductor Processes and Devices, 2006, pp. 51-54, 2006.

${ }^{57}$ MOTT, N. F.; On the transition to metallic conduction in semiconductors, Canadian Journal of Physics, vol. 34, n. 12A, pp. 1356-1368, 1956. 
58 ALTERMATT, P. P.; SCHENK, A.; HEISER, G.; A simulation model for the density of states and for incomplete ionization in crystalline silicon. I. Establishing the model in Si:P, Journal of Applied Physics, vol. 100, n. 11, pp. $113714,2006$.

59 ALTERMATT, P. P.; SCHENK, A.; SCHMITHUSEN, B.; HEISER, G.; A simulation model for the density of states and for incomplete ionization in crystalline silicon. II. Investigation of Si:As and Si:B and usage in device simulation, Journal of Applied Physics, vol. 100, n. 11, pp. 113715, 2006.

60 AKTURK, A.; ALLNUTT, J.; DILLI, Z.; GOLDSMAN, N. et al.; Device Modeling at Cryogenic Temperatures: Effects of Incomplete Ionization, IEEE Transactions on Electron Devices, vol. 54, n. 11, pp. 2984-2990, 2007.

61 TREVISOLI, R. D.; PAVANELLO, M. A.; Low Temperature and Silicon Thickness Influences on the Threshold Voltage of Double-Gate MOSFETs Considering a Charge Based Extraction Procedure, ECS Transactions, vol. 23, n. 1, pp. 605-612, 2009.

62 AKARVARDAR, K.; MERCHA, A.; SIMOEN, E.; SUBRAMANIAN, V. et al.; High-temperature performance of state-of-the-art triple-gate transistors, Microelectronics Reliability, vol. 47, n. 12, pp. 2065-2069, 2007.

63 SOUZA, M. de; PAVANELLO, M. A.; TREVISOLI, R. D.; DORIA, R. T. et al.; Cryogenic Operation of Junctionless Nanowire Transistors, IEEE Electron Device Letters, vol. 32, n. 10, pp. 1322-1324, 2011.

$64 \mathrm{SAH}$, C. T.; HO, P. C.; WANG, C. K.; SAH, R. L. Y. et al.; Effect of zinc impurity on silicon solar-cell efficiency, IEEE Transactions on Electron Devices, vol. 28, n. 3, pp. 304-313, 1981.

65 CAUGHEY, D.M.; THOMAS, R.E.; Carrier mobilities in silicon empirically related to doping and field, Proceedings of the IEEE, vol. 55, n. 12, pp. 21922193, 1967. 
LI, S. S.; THURDER, W. R.; The dopant density and temperature dependence of electron mobility and resistivity in n-type silicon, Solid-State Electronics, vol. 20, n. 7, pp. 609-616, 1977.

${ }^{67}$ DORKEL, J. M.; LETURCQ, Ph.; Carrier mobilities in silicon semi-empirically related to temperature, doping and injection level, Solid-State Electronics, vol. 24, n. 9, pp. 821-825, 1981.

${ }^{68}$ VEERARAGHAVAN, S.; FOSSUM, J. G.; A physical short-channel model for the thin-film SOI MOSFET applicable to device and circuit CAD, IEEE Transactions on Electron Devices, vol. 35, n. 11, pp. 1866-1875, 1988.

${ }^{69}$ COLINGE, J. P.; LEE, C. W.; FERAIN, I.; AKHAVAN, N. D. et al.; Reduced electric field in junctionless transistors, Applied Physics Letters, vol. 96, n. 7, pp. 073510, 2010.

${ }^{70}$ BREWS, J.R.; Subthreshold behavior of uniformly and nonuniformly doped long-channel MOSFET, IEEE Transactions on Electron Devices, vol. 26, n. 9, pp. 1282-1291, 1979.

${ }^{71}$ AKARVARDAR, K.; MERCHA, A.; CRISTOLOVEANU, S.; GENTIL, P. et al.; A Two-Dimensional Model for Interface Coupling in Triple-Gate Transistors, IEEE Transactions on Electron Devices, vol. 54, n. 4, pp. 767-775, 2007.

72 VEeRARAGHAVAN, S.; FOSSUM, J. G.; Short-channel effects in SOI MOSFETs, IEEE Transactions on Electron Devices, vol. 36, n. 3, pp. 522-528, 1989.

${ }^{73}$ WOO, J. C. S.; PLUMMER, J. D.; Short-channel effects in MOSFET's at liquid-Nitrogen temperature, IEEE Transactions on Electron Devices, vol. 33, n. 7, pp. 1012-1019, 1986.

74 SHAO, X.; YU, Z.; Nanoscale FinFET simulation: A quasi-3D quantum mechanical model using NEGF, Solid-State Electronics, vol. 49, n. 8, pp. 14351445, 2005. 
75 GNANI, E.; MARCHI, A.; REGGIANI, S.; RUDAN, M. et al.; Quantummechanical analysis of the electrostatics in silicon-nanowire and carbonnanotube FETs, Solid-State Electronics, vol. 50, n. 4, pp. 709-715, 2006.

${ }^{76}$ MARCHI, A.; GNANI, E.; REGGIANI, S.; RUDAN, M. et al.; Investigating the performance limits of silicon-nanowire and carbon-nanotube FETs, Solid-State Electronics, vol. 50, n. 1, pp. 78-85, 2006.

77 ANDO, T.; FOWLER, A. B.; STERN, F.; Electronic properties of twodimensional systems, Reviews of Modern Physics, vol. 54, n. 2, pp. 437-672, 1982.

78 JIMÉNEZ, D.; SÁENZ, J. J.; IÑÍQUEZ, B.; SUÑÉ, J. et al.; Unified compact model for the ballistic quantum wire and quantum well metal-oxidesemiconductor field-effect-transistor, Journal of Applied Physics, vol. 94, n. 2, pp. 1061-1068, 2003.

${ }^{79}$ KING, Y. C.; HU, C.; FUJIOKA, H.; KAMOHARA, S.; Small signal electron charge centroid model for quantization of inversion layer in a metal-on-insulator field-effect transistor, Applied Physics Letters, vol. 72, n. 26, pp. 3476-3478, 1998.

${ }^{80}$ DORT, M. J. van; WOERLEE, P. H.; WALKER, A. J.; A simple model for quantization effects in heavily-doped silicon MOSFETs at inversion conditions, Solid-State Electronics, vol. 37, n. 3, pp. 411-414, 1994.

${ }^{81}$ GE, L.; FOSSUM, J. G.; GAMIZ, F.; Mobility enhancement via volume inversion in double-gate MOSFETs, IEEE International SOI Conference, 2003, pp. 153-154, 2003.

82 TSUTSUI, G.; SAITOH, M.; SARAYA, T.; NAGUMO, T. et al.; Mobility enhancement due to volume inversion in [110]-oriented ultra-thin body doublegate nMOSFETs with body thickness less than $5 \mathrm{~nm}$, IEEE International Electron Devices Meeting, 2005. IEDM Technical Digest., pp. 729-732, 2005.

${ }^{83}$ HARELAND, S.; MANASSIAN, M.; SHIH, W.-K.; JALLEPALLI, S. et al.; Computationally efficient models for quantization effects in MOS electron and 
hole accumulation layers, IEEE Transactions on Electron Devices, vol. 45, n. 7, pp. 1487-1493, 1998.

${ }^{84}$ MULLER, R.S.; KAMINS, T.I.; CHAN, M.; Device electronics for integrated circuits. Wiley, 2002.

85 KRANTI, A.; CHUNG, T. M.; FLANDRE, D.; RASKIN, J. P.; Laterally asymmetric channel engineering in fully depleted double gate SOI MOSFETs for high performance analog applications, Solid-State Electronics, vol. 48, n. 6 , pp. 947-959, 2004.

${ }^{86}$ RASKIN, J. P.; CHUNG, T. M.; KILCHYTSKA, V.; LEDERER, D. et al.; Analog/RF performance of multiple gate SOI devices: wideband simulations and characterization, IEEE Transactions on Electron Devices, vol. 53, n. 5, pp. 1088-1095, 2006.

${ }^{87}$ DORIA, R. T.; PAVANELLO, M. A.; TREVISOLI, R. D.; SOUZA, M. de et al.; The Roles of the Electric Field and the Density of Carriers in the Improved Output Conductance of Junctionless Nanowire Transistors, ECS Transactions, vol. 35, n. 5, pp. 283-288, 2011.

${ }^{88}$ PAVANELLO, M. A.; MARTINO, J. A.; SIMOEN, E.; CLAEYS, C.; Cryogenic

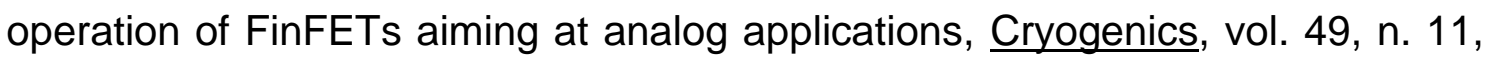
pp. 590-594, 2009.

${ }^{89}$ DORIA, R. T.; PAVANELLO, M. A.; TREVISOLI, R. D.; SOUZA, M. de et al.; Analog operation of junctionless transistors at cryogenic temperatures, IEEE International SOI Conference, 2010, pp. 1-2, 2010.

90 SILVEIRA, F.; FLANDRE, D.; JESPERS, P. G. A.; A gm/ID based methodology for the design of CMOS analog circuits and its application to the synthesis of a silicon-on-insulator micropower OTA, IEEE Journal of Solid-State Circuits, vol. 31, n. 9, pp. 1314-1319, 1996.

91 VITTOZ, E. A.; Low-power design: ways to approach the limits, IEEE International Solid-State Circuits Conference, 1994. Digest of Technical Papers. 41st ISSCC., 1994., pp. 14-18, 1994. 
${ }^{92}$ FLANDRE, D.; FERREIRA, L. F.; A., P. G.; COLINGE, J. P.; Modelling and application of fully depleted SOI MOSFETs for low voltage, low power analogue CMOS circuits, Solid-State Electronics, vol. 39, n. 4, pp. 455-460, 1996.

${ }^{93}$ DORIA, R. T.; PAVANELLO, M. A.; TREVISOLI, R. D.; SOUZA, M. de et al.; Analog Operation Temperature Dependence of nMOS Junctionless Transistors Focusing on Harmonic Distortion, Journal of Integrated Circuits and Systems, vol. 6, n. 2, pp. 114-121, 2011.

${ }^{94}$ Sentaurus Structure Editor User's Manual, SYNOPSYS, 2010.

${ }^{95}$ Sentaurus Device User's Manual, SYNOPSYS, 2010.

${ }^{96}$ KLAASSEN, D. B. M.; A unified mobility model for device simulation--I. Model equations and concentration dependence, Solid-State Electronics, vol. 35, n. 7, pp. 953-959, 1992.

97 KLAASSEN, D. B. M.; A unified mobility model for device simulation--II. Temperature dependence of carrier mobility and lifetime, Solid-State Electronics, vol. 35, n. 7, pp. 961-967, 1992.

${ }^{98}$ LOMBARDI, C.; MANZINI, S.; SAPORITO, A.; VANZI, M.; A physically based mobility model for numerical simulation of nonplanar devices, IEEE Transactions on Computer-Aided Design of Integrated Circuits and Systems, vol. 7, n. 11, pp. 1164-1171, 1988.

${ }^{99}$ CANALI, C.; MAJNI, G.; MINDER, R.; OTTAVIANI, G.; Electron and hole drift velocity measurements in silicon and their empirical relation to electric field and temperature, IEEE Transactions on Electron Devices, vol. 22, n. 11, pp. 10451047, 1975.

100 SHOCKLEY, W.; READ, W. T.; Statistics of the Recombinations of Holes and Electrons, Physical Review, vol. 87, n. 5, pp. 835-842, 1952.

${ }^{101}$ HALL, R. N.; Electron-Hole Recombination in Germanium, Physical Review, vol. 87, n. 2, pp. 387, 1952. 
102 KLAASSEN, D. B. M.; SLOTBOOM, J. W.; GRAAFF, H. C. de; Unified apparent bandgap narrowing in $\mathrm{n}$ - and $\mathrm{p}$-type silicon, Solid-State Electronics, vol. 35, n. 2, pp. 125-129, 1992.

103 SLOTBOOM, J. W.; GRAAFF, H. C. de; Measurements of bandgap narrowing in Si bipolar transistors, Solid-State Electronics, vol. 19, n. 10, pp. 857-862, 1976.

104 ANCONA, M. G.; IAFRATE, G. J.; Quantum correction to the equation of state of an electron gas in a semiconductor, Physical Review B, vol. 39, n. 13, pp. 9536-9540, 1989.

105 ANCONA, M. G.; TIERSTEN, H. F.; Macroscopic physics of the silicon inversion layer, Physical Review B, vol. 35, n. 15, pp. 7959-7965, 1987.

106 TREVISOLI, R. D.; PAVANELLO, M. A.; DORIA, R. T.; SOUZA, M. de et al.; Analytical Model for the Threshold Voltage of Junctionless Nanowire Transistors, EuroSOI 2011 - Seventh Workshop of the Thematic Network on Silicon on Insulator, Technology, Devices and Circuits - Conference Proceedings, pp. 67-68, 2011.

107 TREVISOLI, R. D.; DORIA, R. T.; PAVANELLO, M. A.; Analytical Model for the Threshold Voltage in Junctionless Nanowire Transistors of Different Geometries, ECS Transactions, vol. 39, n. 1, pp. 147-154, 2011.

108 TREVISOLI, R. D.; DORIA, R. T.; SOUZA, M. de; PAVANELLO, M. A.; Threshold voltage in junctionless nanowire transistors, Semiconductor Science and Technology, vol. 26, n. 10, pp. 105009, 2011.

109 READ, F. H.; Improved Extrapolation Technique in the Boundary Element Method to Find the Capacitances of the Unit Square and Cube, Journal of Computational Physics, vol. 133, n. 1, pp. 1-5, 1997.

${ }^{110}$ WONG, H. S.; WHITE, M. H.; KRUTSICK, T. J.; BOOTH, R. V.; Modeling of transconductance degradation and extraction of threshold voltage in thin oxide MOSFET's, Solid-State Electronics, vol. 30, n. 9, pp. 953-968, 1987. 
111 TERAO, A.; FLANDRE, D.; LORA-TAMAYO, E.; VAN DE WIELE, F.; Measurement of threshold voltages of thin-film accumulation-mode PMOS/SOI transistors, IEEE Electron Device Letters, vol. 12, n. 12, pp. 682-684, 1991.

112 ROTONDARO, A. L. P.; MAGNUSSON, U. K.; CLAEYS, C.; FLANDRE, D. et al.; Evidence of different conduction mechanisms in accumulation-mode $p$ channel SOI MOSFET's at room and liquid-helium temperatures, IEEE Transactions on Electron Devices, vol. 40, n. 4, pp. 727-732, 1993.

113 KRANTI, Abhinav; HALDAR, S.; GUPTA, R. S.; Analytical model for threshold voltage and I-V characteristics of fully depleted short channel cylindrical/surrounding gate MOSFET, Microelectronic Engineering, vol. 56, n. 3-4, pp. 241-259, 2001.

114 DAVIES, J. H.; The Physics of Low-Dimensional Semiconductors. Cambridge University Press, 1998.

115 TREVISOLI, R. D.; DORIA, R. T.; SOUZA, M. de; COLINGE, J. P. et al.; A Physically-Based Threshold Voltage Definition and Extraction for Junctionless Nanowire Transistors, EUROSOI 2012 - VIII Workshop of the Thematic Network on Silicon on Insulator Technology, Devices and Circuits, pp. 69-70, 2012.

116 TREVISOLI, R. D.; DORIA, R. T.; SOUZA, M. de; PAVANELLO, M. A.; A physically-based threshold voltage definition, extraction and analytical model for junctionless nanowire transistors, aceito para publicação na Solid-State Electronics, pp. , 2013.

117 PAO, H. C.; SAH, C. T.; Effects of diffusion current on characteristics of metal-oxide (insulator)-semiconductor transistors, Solid-State Electronics, vol. 9, n. 10, pp. 927-937, 1966.

118 ORTIZ-CONDE, A.; GARCÍA, F. J.; LIOU, J. J.; CERDEIRA, A. et al.; A review of recent MOSFET threshold voltage extraction methods, Microelectronics Reliability, vol. 42, n. 4-5, pp. 583-596, 2002.

119 FOTY, D. P.; MOSFET Modeling with SPICE: Principles and Practice. Prentice Hall, 1997. 
120 INIGUEZ, B.; DESSARD, V.; FLANDRE, D.; GENTINNE, B.; A physicallybased $C$ infin;-continuous model for accumulation-mode SOI pMOSFETs, IEEE Transactions on Electron Devices, vol. 46, n. 12, pp. 2295-2303, 1999.

121 BAUM, G.; BENEKING, H. ; Drift velocity saturation in MOS transistors, IEEE Transactions on Electron Devices, vol. 17, n. 6, pp. 481-482, 1970.

122 TREVISOLI, R.; DORIA, R.; DE SOUZA, M.; DAS, S. et al.; SurfacePotential-Based Drain Current Analytical Model for Triple-Gate Junctionless Nanowire Transistors, IEEE Transactions on Electron Devices, vol. 59, n. 12, pp. 3510-3518, 2012.

123 LAKHDAR, N.; DJEFFAL, F. ; A two-dimensional analytical model of subthreshold behavior to study the scaling capability of deep submicron doublegate GaN-MESFETs, Journal of Computational Electronics, vol. 10, pp. 382387, 2011.

${ }^{124}$ LUNDSTROM, M. ; Elementary scattering theory of the Si MOSFET, IEEE Electron Device Letters, vol. 18, n. 7, pp. 361-363, 1997.

${ }^{125}$ KUO, J.; CHANG, Y.; LAI, C. ; A velocity-overshoot capacitance model for $0.1 \mu \mathrm{m}$ MOS transistors, Solid-State Electronics, vol. 39, n. 8, pp. 1173-1178, 1996.

${ }^{126}$ ORTIZ-CONDE, A.; GARCÍA-SÁNCHEZ, F. J.; MUCI, J.; MUÑOZ, D. C. L. et al.; Indirect fitting procedure to separate the effects of mobility degradation and source-and-drain resistance in MOSFET parameter extraction, Microelectronics Reliability, vol. 49, n. 7, pp. 689-692, 2009.

${ }^{127}$ MUCI, J.; LATORRE-REY, A. D.; SANCHEZ, F. G.; LUGO-MUNOZ, D. et al.; Extraction of Mobility Degradation and Source-and-Drain Resistance in MOSFETs, Journal of Integrated Circuits and Systems, vol. 5, n. 2, pp. 103-109, 2010.

MARQUARDT, D. W. ; An Algorithm for Least-Squares Estimation of Nonlinear Parameters, Journal of the Society for Industrial and Applied Mathematics, vol. 11, n. 2, pp. 431-441, 1963. 
129 JEON, D.-Y.; PARK, S.J.; MOUIS, M.; BARRAUD, S. et al.; Electrical characterization and Revisited Parameter Extraction Methodology in Junctionless Transistors, EUROSOI 2012 - VIII Workshop of the Thematic Network on Silicon on Insulator Technology, Devices and Circuits, pp. 109-110, 2012.

130 TREVISOLI, R. D.; DORIA, R. T.; SOUZA, M. de; DAS, S. et al.; The zero temperature coefficient in junctionless nanowire transistors, Applied Physics Letters, vol. 101, n. 6, pp. 062101, 2012.

${ }^{131}$ TREVISOLI, R.D.; DORIA, R.T.; SOUZA, M. de; FERAIN, I. et al.; The Role of the Incomplete Ionization on the Operation of Junctionless Nanowire Transistors, IEEE International SOI Conference (SOI), 2012, pp. 1-2, 2012.

132 DIXIT, A.; KOTTANTHARAYIL, A.; COLLAERT, N.; GOODWIN, M. et al.; Analysis of the parasitic S/D resistance in multiple-gate FETs, IEEE Transactions on Electron Devices, vol. 52, n. 6, pp. 1132-1140, 2005. 


\section{APÊNDICE A}

Artigos publicados ao longo do trabalho:

- Periódicos

- R. D. Trevisoli, R. T. Doria, M. de Souza, M. A. Pavanello, "Threshold voltage in junctionless nanowire transistors", Semiconductor Science and Technology, vol. 26, n. 10, p. 105009, 2011.

- R. D. Trevisoli, J. A. Martino, E. Simoen, C. Claeys, M. A. Pavanello, "An analytic method to compute the stress dependence on the dimensions and its influence in the characteristics of triple gate devices", Microelectronics Reliability, vol. 52, no. 3, p. 519-524, 2012.

- R. D. Trevisoli, R. T. Doria, M. de Souza, S. Das, I. Ferian and M. A. Pavanello, "The Zero Temperature Coefficient in Junctionless Nanowire Transistors", Applied Physics Letters, vol. 101, no. 8, p. 062101, 2012.

- R. D. Trevisoli, R. T. Doria, M. de Souza, S. Das, I. Ferian and M. A. Pavanello, "Surface Potential-Based Drain Current Analytical Model for TripleGate Junctionless Nanowire Transistors", IEEE Transactions on Electron Devices, vol. 59, no. 12, p. 3510-3518, 2012.

- R. D. Trevisoli, R. T. Doria, M. de Souza, M. A. Pavanello, "A Physically-Based Threshold Voltage Definition, Extraction and Analytical Model for Junctionless Nanowire Transistors", aceito para publicação na Solid-State Electronics.

- J. Muci, A. D. Latorre-Rey, F. G. Sanchez, D. Lugo-Munoz, A. O. Conde, C. S. Ho, J. J. Liou, M. A. Pavanello, R. D. Trevisoli, "Extraction of Mobility Degradation and Source-and-Drain Resistance in MOSFETs", JICS Journal of Integrated Circuits and Systems, v. 5, p. 103-109, 2010.

- A. I. A. Cunha, M. A. Pavanello, R. D. Trevisoli, C. Galup-Montoro, M. C. Schneider, "Direct Determination of Threshold Condition in DG-MOSFETs from the $g_{m} / l_{D}$ Curve", Solid-State Electronics, v. 56, n. 1, p. 89-94, 2011. 
- R. T. Doria, M. A. Pavanello, R. D. Trevisoli, M. de Souza, C. W. Lee, I. Ferain, N. Dehdashti-Akhavan, R. Yan, P. Razavi, R. Yu, A. Kranti, J. P. Colinge, "Junctionless multiple gate transistors for analog applications", IEEE Transactions on Electron Devices, vol. 58, no. 8, p. 2511-2519, 2011.

- M. de Souza, M. A. Pavanello, R. D. Trevisoli, R. T. Doria, J. P. Colinge, "Cryogenic operation of junctionless nanowire transistors", IEEE Electron Device Letters, vol. 32, no. 10, p. 1322-1324, 2011.

- R. T. Doria, M. A. Pavanello, R. D. Trevisoli, M. de Souza, C. W. Lee, I. Ferain, N. Dehdashti-Akhavan, R. Yan, P. Razavi, R. Yu, A. Kranti, J. P. Colinge, "Analog operation temperature dependence of nMOS junctionless transistors focusing on harmonic distortion", Journal of Integrated Circuits and Systems, vol. 6, p. 114-121, 2011.

- R. T. Doria, R. D. Trevisoli, M. de Souza, M. A. Pavanello, "Impact of the series resistance in the I-V characteristics of nMOS junctionless nanowire transistors", Journal of Integrated Circuits and Systems, vol. 7, p. 121-129, 2012.

- A. Cerdeira, M. Estrada, B. Iniguez, R. D. Trevisoli, R. T. Doria, M. de Souza, M. A. Pavanello, "Charge-Based Continuous Model for Double-Gate Junctionless Transistors", aceito para publicação na Solid-State Electronics.

- R. T. Doria, R. D. Trevisoli, M. de Souza, M. A. Pavanello, "Trap density characterization through low-frequency noise in junctionless transistors", aceito para publicação na Microelectronics Engineering.

- R. D. Trevisoli, R. T. Doria, M. de Souza, M. A. Pavanello, "Drain Current and Short Channel Effects Modeling in Junctionless Nanowire Transistors", submetido para avaliação no Journal of Integrated Circuits and Systems.

- Anais de congresso

- R. D. Trevisoli, M. A. Pavanello, "Channel Length Influence on Threshold Voltage Variation with the Temperature in Strained and Unstrained nFinFETs", Em: Ninth International Workshop on Low Temperature Electronics 
(WOLTE9), Proceedings of the Ninth International Workshop on Low Temperature Electronics, p. 105-107, 2010.

- R. D. Trevisoli, M. A. Pavanello, "Three-Dimensional Simulation of Biaxially Strained Triple-Gate FinFETs: A Method to Compute the Fin Width and Channel Length Dependences on Device Electrical Characteristics", Em: 25th Symposium on Microelectronics Technology and Devices - SBMicro2010, ECS Transactions - Microelectronics Technology and Devices - SBMicro 2010, v. 31 , no. 1, p. 377-384, 2010.

- R. D. Trevisoli, M. A. Pavanello, R. T. Doria, M. de Souza, C. W. Lee, I. Ferain, N. D. Akhavan, R. Yan, P. Razavi, R. Yu, A. Kranti, J. P. Colinge, "Analytical Model for the Threshold Voltage of Junctionless Nanowire Transistors", Em: EuroSOI 2011 - Seventh Workshop of the Thematic Network on Silicon-on-Insulator Technology, Devices and Circuits, Conference Proceedings, p. 67-68,2011.

- R. D. Trevisoli, R. T. Doria, M. A. Pavanello, "Analytical model for the threshold voltage in junctionless nanowire transistors of different geometries", Em: 26th Symposium on Microelectronics Technology and Devices SBMicro2011, ECS Transactions - Microelectronics Technology and Devices SBMicro 2011, v. 39, no. 1, p. 147-154, 2011.

- R. D. Trevisoli, J. A. Martino, E. Simoen, C. Claeys, M. A. Pavanello, "Stress Relaxation Empirical Model for Biaxially Strained Triple-Gate Devices", Em: $219^{\text {th }}$ ECS Meeting - Advanced Semiconductor-on-Insulator Technology and Related Physics, ECS Transactions, vol. 35, no. 5, p. 289-294, 2011.

- R. D. Trevisoli, R. T. Doria, M. de Souza and M. A. Pavanello, "A Physically-Based Threshold Voltage Definition and Extraction for Junctionless Nanowire Transistors", Em: EuroSOI 2012 - Eighth Workshop of the Thematic Network on Silicon-on-Insulator Technology, Devices and Circuits, p. 69-70, 2011.

- R. D. Trevisoli, R. T. Doria, M. de Souza and M. A. Pavanello, "Drain current model for junctionless nanowire transistors", Em: ICCDCS 2012 Eighth International Caribbean Conference on Devices, Circuits and Systems, Conference Proceedings, vol. 1, p. 1-4, 2012.

- R. D. Trevisoli, R. T. Doria, M. de Souza, M. A. Pavanello, "Accounting for Short-Channel Effects in Drain Current Modeling of Junctionless Nanowire 
Transistors", Em: 27th Symposium on Microelectronics Technology and Devices - SBMicro2012, ECS Transactions - Microelectronics Technology and Devices - SBMicro 2012, v. 49, no. 1, p. 207-214, 2012.

- R. D. Trevisoli, R. T. Doria, M. de Souza, I. Ferain, S. Das, M. A. Pavanello, "The Role of Incomplete Ionization on the Operation of Junctionless Nanowire Transistors", Em: IEEE International SOI Conference, IEEE International SOI Conference Proceedings, v. 1, p. 1-2, 2012.

- R. D. Trevisoli, R. T. Doria, M. de Souza, M. A. Pavanello, "Experimental Evaluation of the Analog Performance of Short-Channel Junctionless Nanowire Transistors", Em: EuroSOI 2013 - Ninth Workshop of the Thematic Network on Silicon-on-Insulator Technology, Devices and Circuits, 2013.

- R. T. Doria, M. A. Pavanello, R. D. Trevisoli, M. de Souza, C. W. Lee, I. Ferain, N. Dehdashti-Akhavan, R. Yan, P. Razavi, R. Yu, A. Kranti, J. P. Colinge, "Analog Operation of Junctionless Transistors at Cryogenic Temperatures", Em: IEEE International SOI Conference, IEEE International SOI Conference Proceedings, v. 1, p. 1-2, 2010.

- R. T. Doria, R. D. Trevisoli, M. A. Pavanello, "Impact of the series resistance in the I-V characteristics of nMOS junctionless nanowire transistors", Em: 26th Symposium on Microelectronics Technology and Devices SBMicro2011, ECS Transactions - Microelectronics Technology and Devices SBMicro 2011, v. 39, p. 231-238, 2011.

- R. T. Doria, M. A. Pavanello, R. D. Trevisoli, M. de Souza, C. W. Lee, I. Ferain, N. Dehdashti Akhavan, R. Yan, P. Razavi, R. Yu, A. Kranti, J. P. Colinge, "The Roles of the Electric Field and the Density of Carriers in the Improved Output Conductance of Junctionless Nanowire Transistors", Em: $219^{\text {th }}$ ECS Meeting - Advanced Semiconductor-on-Insulator Technology and Related Physics, ECS Transactions, vol. 35, no. 5, p. 283-288, 2011.

- R. T. Doria, R. D. Trevisoli, M. de Souza, J. P. Colinge, M. A. Pavanello, "Analysis of the low-frequency noise of junctionless nanowire transistors operating in saturation", Em: IEEE International SOI Conference, IEEE International SOI Conference Proceedings, v. 1, p. 1-2, 2011.

- G. Mariniello, R. D. Trevisoli, R. T. Doria, M. de Souza and M. A. Pavanello, "Analysis of the gate capacitance of $n$-type junctionless nanowire 
transistors using a three-dimensional device simulation", Em: ICCDCS 2012 Eighth International Caribbean Conference on Devices, Circuits and Systems, Conference Proceedings, vol. 1, p. 1-4, 2012.

- R. T. Doria, R. D. Trevisoli, M. de Souza, M. A. Pavanello, "Application of Junctionless Nanowire Transistors in the Self-Cascode Configuration to Improve the Analog Performance", Em: 27th Symposium on Microelectronics Technology and Devices - SBMicro2012, ECS Transactions - Microelectronics Technology and Devices - SBMicro 2012, v. 49, no. 1, p. 215-222, 2012.

- G. Mariniello, R. T. Doria, R. D. Trevisoli, M. de Souza, M. A. Pavanello, "Intrinsic Gate Capacitances of n-type Junctionless Nanowire Transistors Using a Three-Dimensional Device Simulation and Experimental Measurements", Em: 27th Symposium on Microelectronics Technology and Devices - SBMicro2012, ECS Transactions - Microelectronics Technology and Devices - SBMicro 2012, v. 49, no. 1, p. 231-239, 2012.

- R. T. Doria, R. D. Trevisoli, M. de Souza, I. Ferain, S. Das, M. A. Pavanello, "Low Frequency Noise of Short Channel n-type and p-type Junctionless Nanowire Transistors", Em: IEEE International SOI Conference, IEEE International SOI Conference Proceedings, v. 1, p. 1-2, 2012.

- M. de Souza, R. D. Trevisoli, R. T. Doria, M. A. Pavanello, "Nanowire Width, Doping Concentration and Temperature Influence on Junctionless MOS Diodes", Em: EuroSOI 2013 - Ninth Workshop of the Thematic Network on Silicon-on-Insulator Technology, Devices and Circuits, 2013.

- M. de Souza, R. T. Doria, R. D. Trevisoli, A. Cerdeira, M. Estrada, M. A. Pavanello, "Performance of Junctionless Nanowire MOSFET as a Quasi-linear Resistor", Aceito para publicação no: $223^{\text {rd }}$ ECS Meeting - Advanced Semiconductor-on-Insulator Technology and Related Physics.

- R. T. Doria, R. D. Trevisoli, M. de Souza, M. A. Pavanello, "Trap density characterization through low-frequency noise in junctionless transistors", Aceito para publicação no: INFOS 2013 - 18th Conference of "Insulating Films on Semiconductors". 


\section{APÊNDICE B}

\section{Exemplo de arquivo para gerar um dispositivo com $\mathrm{W}_{\text {Fin }}=10 \mathrm{~nm}, \mathrm{H}_{\text {Fin }}=$ $10 \mathrm{~nm}, \mathrm{t}_{\mathrm{ox}}=2 \mathrm{~nm}$ e $\mathrm{L}=1 \mu \mathrm{m}$ no Sentaurus Structure Editor:}

; Definicoes
(define Wfin
(define Lfin
(define Hfin
(define Lfonte
(define tox
(define tbox
(define Wbox
(define Na
(define RefinoDrenoDist
(define RefinoDrenoCanalDist
(define nome
; Definição refino
;; Canal
(sdedr:define-refinement-size
(sdedr:define-refinement-size
;; Substrato
(sdedr:define-refinement-size
(sdedr:define-refinement-size
;:Oxido
(sdedr:define-refinement-size
(sdedr:define-refinement-size
(sdedr:define-refinement-size

\begin{tabular}{ll}
$0.010)$ & \\
$1.000)$ & \\
$0.010)$ & \\
$0.150)$ & \\
$0.002)$ & \\
$0.100)$ & \\
$0.120)$ & \\
$0.020)$ & $1 \mathrm{e}+19)$ \\
& \\
\hline$t$ & $0.020)$
\end{tabular}

"L1000-W10-H10-tox02-Na1e19")

;; REGIOES ;;

; Define o canal 2D

(define r1 (sdegeo:create-cuboid (position (- (/ Wfin 2)) (- (+ (/ Lfin 2) Lfonte)) (- (/ Hfin 2)))

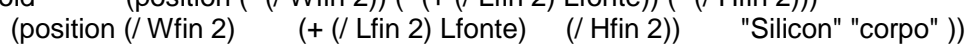

; Define o oxido de porta 2D

(define r3 (sdegeo:create-polygon (list

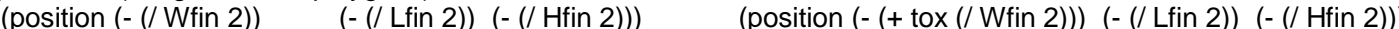

(position (- (+ tox (/ Wfin 2))) $\quad(-(/$ Lfin 2)) $\quad(+\operatorname{tox}(/$ Hfin 2)) $)($ position (+ tox (/ Wfin 2)) $(-(/$ Lfin 2)) (+ tox (/ Hfin 2))

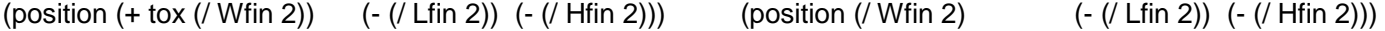

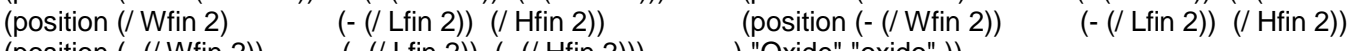

(position (- (/ Wfin 2) $\quad(-(/$ Lfin 2) $)(-(/$ Hfin 2) $)) \quad$ ) "Oxide" "oxido" )

; Alonga o oxido de porta no eixo z

(sdegeo:extrude (list (car (find-body-id (position (- (+ (/ Wfin 2) (/ tox 2))) (- (/ Lfin 2)) (- (/ Hfin 2)))))) (- Lfin))

; Define o substrato 3D

(define 4 (sdegeo:create-cuboid (position (- (/ Wbox 2)) (- (+ (/ Lfin 2) Lfonte)) (- (/ Hfin 2)))

"box" ))

(position (/ Wbox 2$) \quad(+(/$ Lfin 2$)$ Lfonte $) \quad(-(+(/$ Hfin 2$)$ tbox $)))$

"Oxide"

;: CONTATOS ;;

; Contato de porta

(sdegeo:define-contact-set "porta" 0.001 (color:rgb 10 0) "\#\#")

(sdegeo:set-current-contact-set "porta")

(car (find-face-id (position (- (+ tox (/ Wfin 2))) $0.000 \quad 0.000$

$\left.\left.\left.\int\right)\right)\right)$ "porta")

(sdegeo:define-3d-contact (list (car (find-face-id (position 0.000

$0.000(+\operatorname{tox}(/$ Hfin 2)) $))))$

"porta")

(sdegeo:define-3d-contact (list

(car (find-face-id (position (+ tox (/ Wfin 2))

$0.000 \quad 0.000$

$\left.\left.\left.\int\right)\right)\right)$ "porta")

; Contato de dreno

(sdegeo:define-contact-set "dreno" 0.001 (color:rgb 10 0) "\#\#")

(sdegeo:set-current-contact-set "dreno")

(sdegeo:define-3d-contact (list

(car (find-face-id (position 0.000 (+ (/ Lfin 2) Lfonte) 0.000 )))) "dreno")

; Contato de fonte

(sdegeo:define-contact-set "fonte" -0.001 (color:rgb 10 0) "\#\#") 
(sdegeo:set-current-contact-set "fonte")

(sdegeo:define-3d-contact (list

(car (find-face-id (position $0.000 \quad$ (- (+ (/ Lfin 2) Lfonte)) $\quad 0.000)))$ ) "fonte")

; Contato do substrato

(sdegeo:define-contact-set "substrato" -0.001 (color:rgb 10 0) "\#\#")

(sdegeo:set-current-contact-set "substrato")

(sdegeo:define-3d-contact (list (car (find-face-id (position 0.0000 .000 (- (+ (/ Hfin 2) tbox)) )))) "substrato")

;; DOPAGEM ;

; Canal

(sdedr:define-constant-profile "definicao perfil constante canal" "ArsenicActiveConcentration" $\mathrm{Na}$ )

(sdedr:define-constant-profile-region "placement_perfil_constante_canal" "definicao_perfil_constante_canal" "corpo")

$\because$ GRADE :.

; Definição de janelas

$\because$ :Canal

(sdedr:define-refeval-window "Refino0"

2))) (position (/ Wfin 2) (+ (/ Lfin 2) Lfonte)

(sdedr:define-refeval-window "RefinoDreno"
2))) (position (/ Wfin 2) (+ (/ Lfin 2) RefinoDreno

"Cuboid" (position (- (/ Wfin 2)) (- (+ (/ Lfin 2) Lfonte))

(- (/ Hfin (/ Hfin 2)))

2))) (position (/ Wfin 2) (+ (/ Lfin 2) RefinoDrenoCanalDist) (/ Hfin 2)))

(sdedr:define-refeval-window "RefinoFonte" "Cuboid" (position (- (/ Wfin 2)) (- RefinoDrenoDist (/ Lfin 2)) (- (/ Hfin

2))) (position (/ Wfin 2) (- (+ (/ Lfin 2) RefinoDrenoCanalDist)) (/ Hfin 2)))

\title{
;;Substrato
}

(sdedr:define-refeval-window "Refino1" "Cuboid" (position (- (/ Wbox 2)) (- (+ (/ Lfin 2) Lfonte)) (- (/ Hfin 2)))

(position (/ Wbox 2) (+ (/ Lfin 2) Lfonte) $\quad(-(+(/$ Hfin 2) tbox $))))$

(sdedr:define-refeval-window "Refino10" "Cuboid" (position (- (+ (/ Wfin 2) tox)) (- (+ (/ Lfin 2) RefinoDrenoCanalDist))

(- (+ (/ Hfin 2) 0.001))) (position (+ (/ Wfin 2) tox) (+ (/ Lfin 2) RefinoDrenoCanalDist) (- (/ Hfin 2))))

;Oxido

(sdedr:define-refeval-window "Refino2" "Cuboid" (position (- (+ (/ Wfin 2) tox)) (- (/ Lfin 2)) (- (/ Hfin 2))) (position (- (/

Wfin 2)) (/ Lfin 2) (/ Hfin 2)))

(sdedr:define-refeval-window "Refino20" "Cuboid" (position (+ (/ Wfin 2) tox) (- (/ Lfin 2)) (- (/ Hfin 2))) (position (/ Wfin 2) (/ Lfin 2) (/ Hfin 2)))

(sdedr:define-refeval-window "Refino21" "Cuboid" (position (- (/ Wfin 2)) $\quad$ (- (/ Lfin 2)) (/ Hfin 2)) $\quad$ (position (/ Wfin 2) (/ Lfin 2) (+ (/ Hfin 2) tox)))

(sdedr:define-refeval-window "Refino22" "Cuboid" (position (- (+ (/ Wfin 2) tox)) (- (/ Lfin 2)) (/ Hfin 2)) (position (- (/ Wfin 2)) (/ Lfin 2) (+ (/ Hfin 2) tox)))

(sdedr:define-refeval-window "Refino23" "Cuboid" (position (+ (/ Wfin 2) tox) $\quad$ (- (/ Lfin 2)) (/ Hfin 2)) $\quad$ (position (/ Wfin 2) (/ Lfin 2) (+ (/ Hfin 2) tox $)))$

\begin{abstract}
; Aplicação refino
(sdedr:define-refinement-placement "Ref1" "DefRef0" "Refino0" )

(sdedr:define-refinement-placement "RefDreno" "DefRefDreno" "RefinoDreno" )

(sdedr:define-refinement-placement "RefFonte" "DefRefDreno" "RefinoFonte" )

(sdedr:define-refinement-region "Ref2" "DefRef1" "box" )

(sdedr:define-refinement-placement "Ref3" "DefRef10" "Refino10" )

(sdedr:define-refinement-placement "Ref4" "DefRef2" "Refino23")

(sdedr:define-refinement-placement "Ref5" "DefRef2" "Refino22")

(sdedr:define-refinement-placement "Ref6" "DefRef20" "Refino2" )

(sdedr:define-refinement-placement "Ref7" "DefRef20" "Refino20")

(sdedr:define-refinement-placement "Ref8" "DefRef21" "Refino21")
\end{abstract}

;; CONSTRUCAO DA GRADE ;;

(sde:build-mesh "mesh" "-P -R -F tdr" nome) 


\section{APÊNDICE C}

Arquivo utilizado para a implementação do modelo de ionização incompleta descrito no item 2.4.1 no simulador Sentaurus Device:

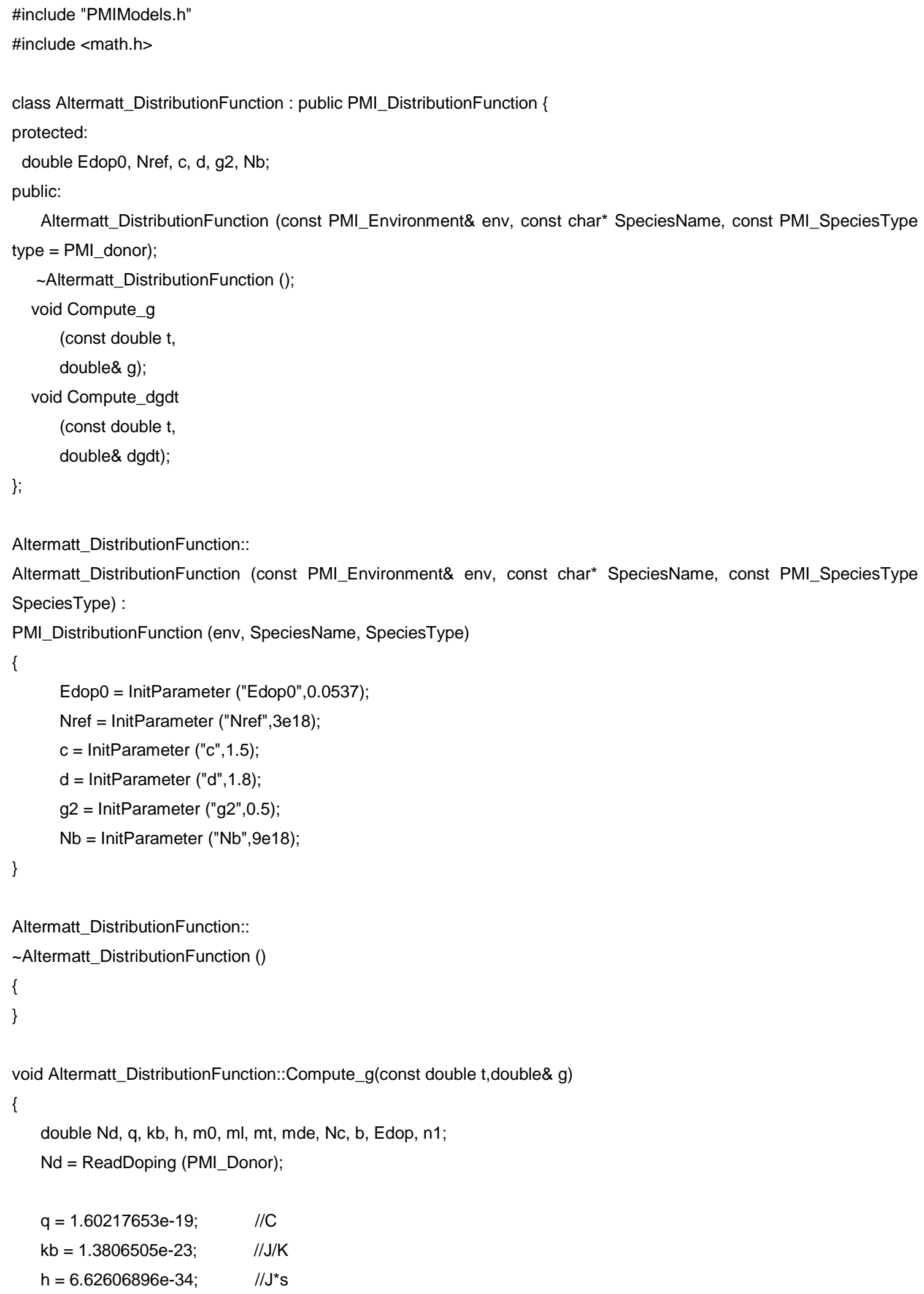




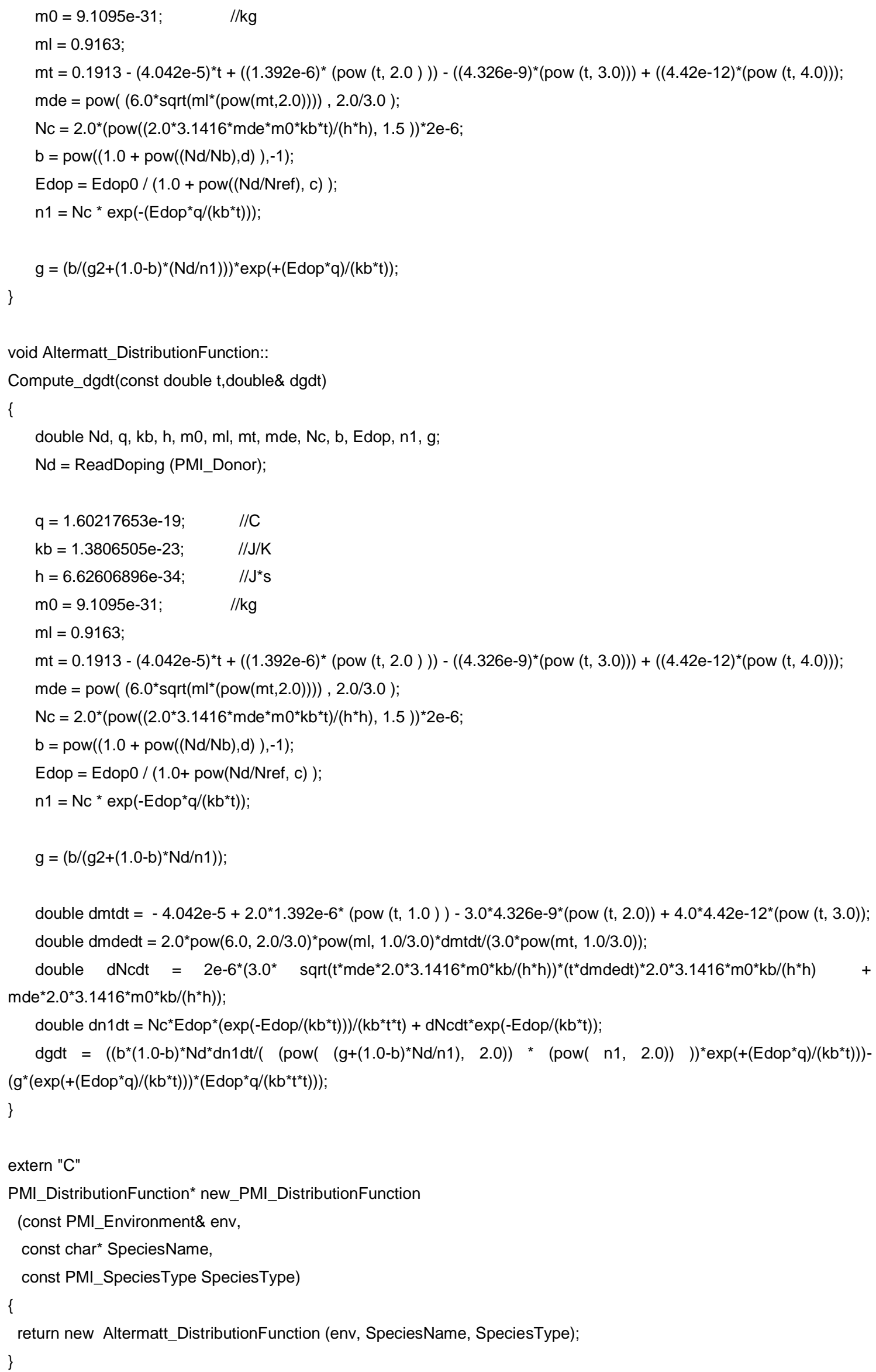




\section{APÊNDICE D}

Exemplo de um arquivo de simulação no Sentaurus Device utilizado para se obter a curva $I_{D}$ versus $V_{G S}$ com $V_{D S}=50 \mathrm{mV}$ em temperatura ambiente para o JNT gerado a partir do arquivo do Apêndica B:

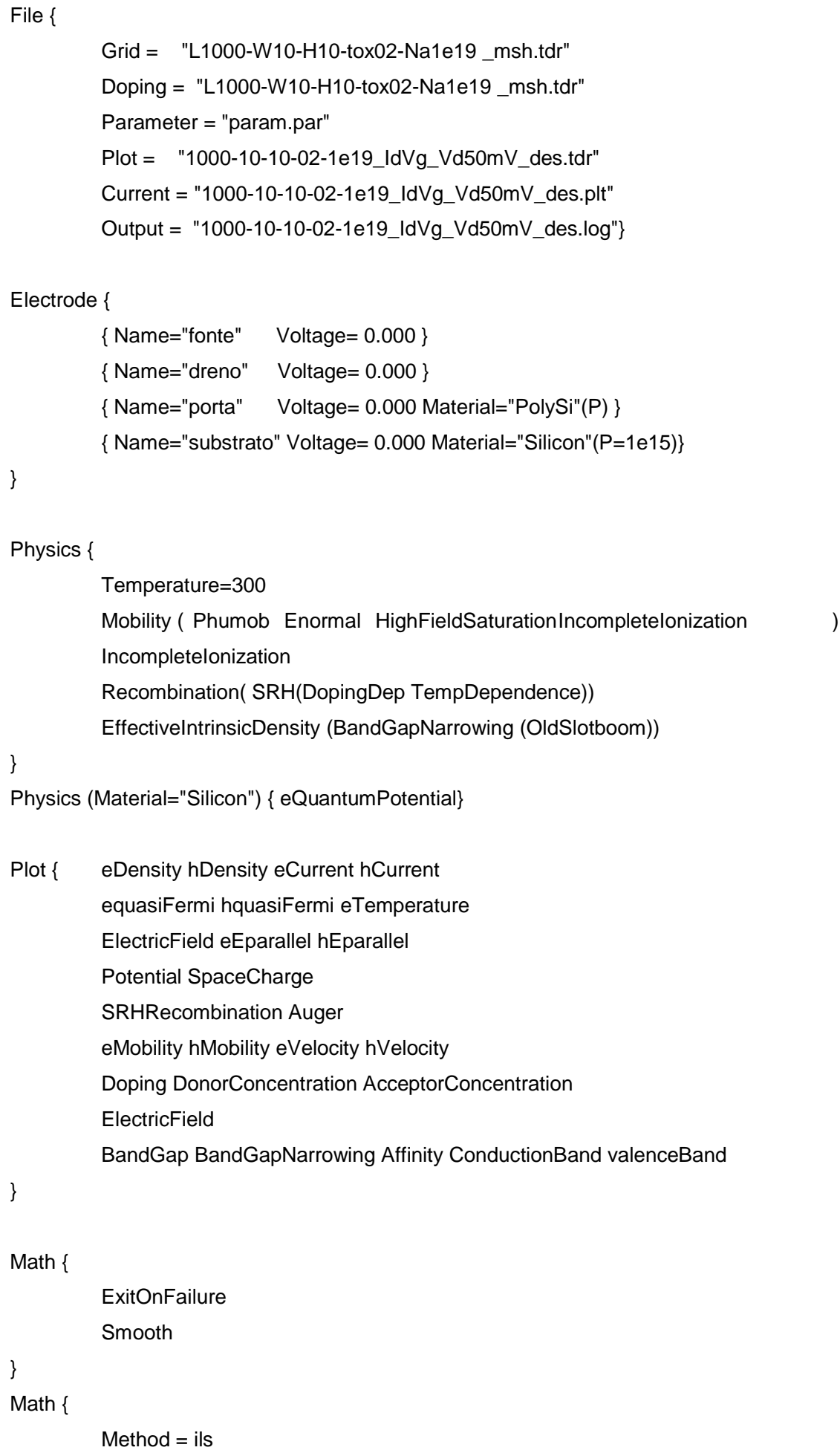


number_of threads $=2$

\}

Solve \{

\#-solucao inicial:

Quasistationary ( Goal $\{$ name="porta" voltage $=0.000\}$ )

\{Coupled $\{$ Poisson $\}$ CurrentPlot $($ Time $=(-1))\}$

Quasistationary (Goal $\{$ name $="$ porta" voltage $=0.000\}$ )

\{Coupled $\{$ Poisson eQuantumPotential\} CurrentPlot $($ Time $=(-1))\}$

Quasistationary (Goal $\{$ name $=$ "porta" voltage $=0.000\}$ )

\{Coupled $\{$ Poisson Electron Hole eQuantumPotential\} CurrentPlot $($ Time $=(-1))\}$

Quasistationary ( Goal $\{$ name="dreno" voltage $=0.05\}$ )

\{Coupled $\{$ Poisson Electron Hole eQuantumPotential $\}$ CurrentPlot $($ Time $=(-1))\}$

\#- Rampa:

Quasistationary

( Minstep=1e-5

Goal $\{$ name="porta" voltage $=1.5\}$ )

$\left\{\right.$ Coupled $\left\{\right.$ Poisson Electron Hole eQuantumPotential\} CurrentPlot $\left(\right.$ Time $=\left(\right.$ range $=\left(\begin{array}{ll}0 & 1\end{array}\right)$ intervals $\left.\left.\left.=150\right)\right)\right\}$ 